\title{
Median and ulnar nerve injuries: prognosis and predictors for clinical outcome
}


ISBN 90-9018600-X

(c) 2004 J.B. Jaquet

Median and ulnar nerve injuries: prognosis and predictors for clinical outcome Jean-Bart Jaquet - Proefschrift Erasmus Universiteit Rotterdam.

- Met samenvatting in het Nederlands

Cover design and illustrations by G. F. Jaquet

Printed by Optima Grafische Communicatie, Rotterdam, The Netherlands 


\section{Median and ulnar nerve injuries: prognosis and predictors for clinical outcome}

Medianus en ulnaris zenuwletsels:

prognose en voorspellende waarden voor de klinische uitkomst

\section{Proefschrift}

ter verkrijging van de graad van doctor aan de Erasmus Universiteit Rotterdam op gezag van de rector magnificus

Prof. dr. S.W.J. Lamberts

en volgens het besluit van het College voor Promoties

De openbare verdediging zal plaatsvinden op

24 november 2004 om 11:45 uur

door

\section{Jean-Bart Jaquet}

geboren te Rotterdam 


\section{Promotiecommissie}

Promotor:

Overige leden:

Co-promotor:
Prof. dr. S.E. R. Hovius

Prof. dr. H.J. Stam

Prof. dr. A. Hofman

Prof. dr. J. Passchier

Prof. dr. C.I. de Zeeuw

Dr. S. Kalmijn

The studies in this thesis were performed at the Department of Plastic and Reconstructive Surgery, Erasmus Medical Center Rotterdam.

The study was financially supported by:

A grant of the Esser Foundation Rotterdam and Foundation 'Vereniging Trustfonds Erasmus Universiteit Rotterdam'.

For the production of this thesis, financial support has be given by:

Pieksma Medical Supplies, Bioprof/Dermaprof, Stryker Leibinger, Valeant, J.E. Jurriaanse Stichting, Biomet Nederland BV, ABN AMRO district Delft, Ethicon products, AB Medical prs bv, B. Braun Medical B.V. 
To Sabine, Olivier and my parents 



\section{CONTENTS}

Chapter 1 General introduction and aim

Chapter 2 Median, ulnar and combined median-ulnar nerve injuries:

functional outcome and return to productivity

Journal of Trauma: 51(4): 687-692

Chapter 3 "Spaghetti wrist" trauma: functional recovery, return to work and

psychological impact

Accepted Plastic and Reconstructive Surgery

Chapter 4 Content validity of the DASH and a long-term functional outcome of median and ulnar nerve injuries

Accepted Journal of Hand Surgery, American Volume

Chapter 5 Predictors for return to work in patients with median and ulnar nerve injuries

Journal of Hand Surgery: $28 A(1): 28-34$

Chapter 6 Early psychological stress following forearm nerve injuries: a predictor for long-term functional outcome and return to productivity

Annals of Plastic Surgery: 49(1):82-90

Chapter 7 Cognitive functioning and level of intelligence are predictors for final sensory recovery of median and ulnar nerve injuries

Submitted Plastic and Reconstructive Surgery

Chapter 8 Median and ulnar nerve injuries: a meta-analysis of predictors of motor and sensory recovery after modern microsurgical nerve repair

Accepted Plastic and Reconstructive Surgery

Chapter 9 General discussion and conclusions

Future perspectives

Chapter 10 Summary

Samenvatting 
Chapter 11 Acknowledgements

List of publications

Curriculum Vitae 


\section{THE STORY}

A 32 year old man was brought to the first aid department of a university hospital with an upper extremity injury to his dominant hand. He informed the plastic surgeon on call that he had fallen through a pane of glass in the course of his work as a glazier. He was in a state of some confusion and said that the wound was pouring with blood, the total length of the wound was about 3 centimetres and it looked to him like "spaghetti bolognaise". The surgeon performed his physical examination of the arm, hand and wound. During this examination some of the fingers could not be flexed, the blood supply appeared diminished and sensibility in all fingers was impaired, especially when compared to the other side. When the surgeon had finished his examination, the patient asked the following questions:

Do I need an operation or can it be stitched here right now?

What will be the functional consequences?

What will the final outcome be and how long will this take?

How long will it take before I can start work again?

The surgeon on call tried to answer his patient's questions. On his way to the operating theatre, he asked himself the following questions:

Do we need to operate this evening or can we delay the operation?

Does this man need psychological assistance?

Epineural or fascicular repair of the nerves?

Do I need a nerve graft or can I perform an "end to end" repair of both nerve ends?

How should we assess functional recovery?

What are the prognostic factors?

The patient visited the outpatient clinic frequently and the following questions raised:

How long do I need to participate in the rehabilitation program?

When will my 'end-point' of functional recovery be reached?

l experience pain during exposure to cold will this diminish? 



\section{CHAPTER 1}

\section{GENERAL INTRODUCTION AND AIM}

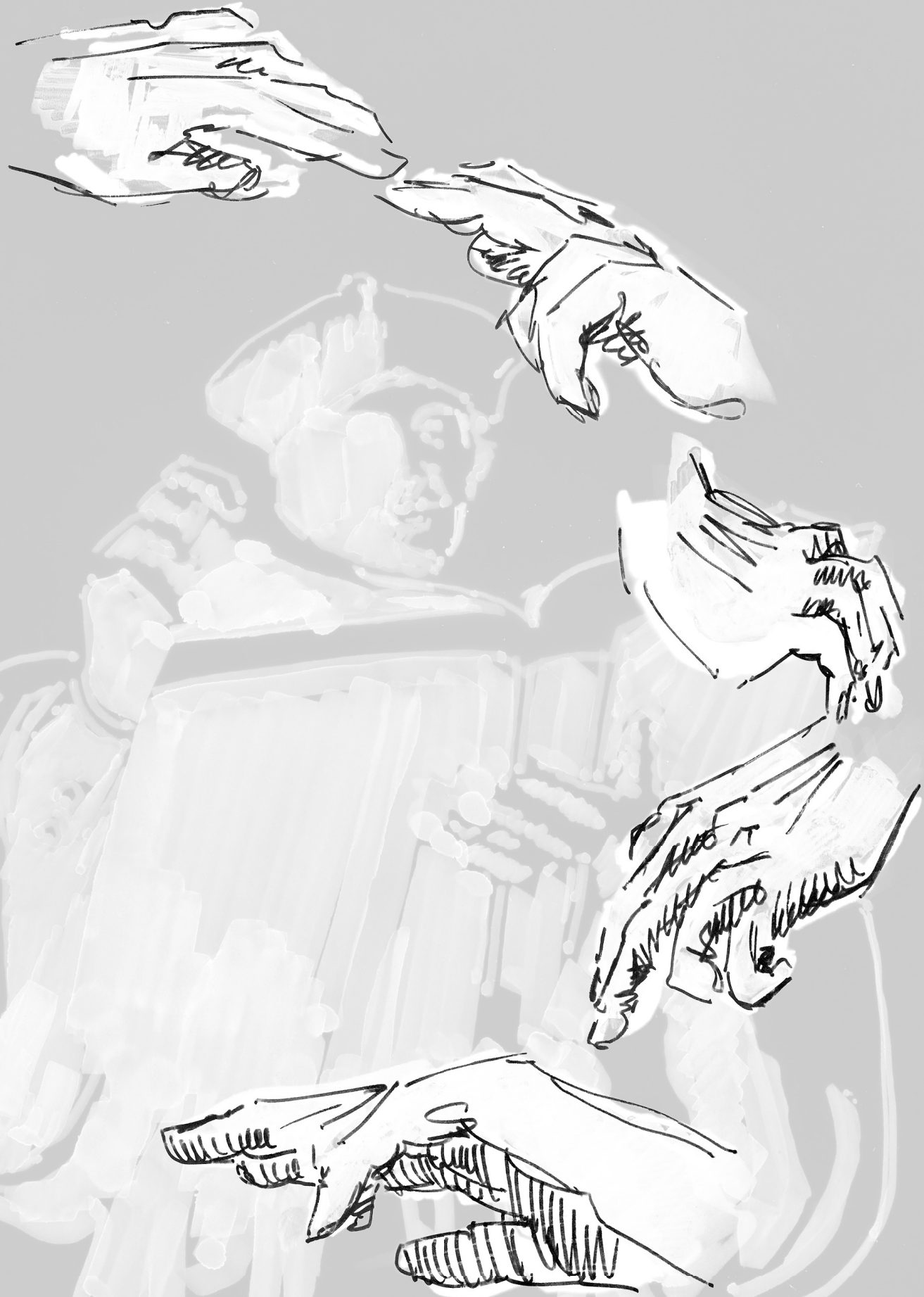





\title{
INTRODUCTION
}

\author{
History of nerve repair
}

Peripheral nerve injuries were first described by Hippocrates (460-370 BC). Based on his descriptions, it was believed for centuries that there was a relationship between nerve injuries and convulsions. ${ }^{1}$ Conservative therapy of these injuries was considered the appropriate method of treatment. The first report of nerve suture is variously attributed to Paulus of Aegineta (625-690 AD), Rhazes (850-932) and Avicenna, Ali Abu Ibn Sina (980-1037 AD) in Persia or Ferrara in Italy $1608 .{ }^{2}$ Guglielmo da Salicento $(1210-1280)$ is seen as one of the great pioneers of surgical treatment of nerve injuries. ${ }^{1}$ He stitched the surrounding tissue to approximate the nerve ends. Despite this early record of physicians attempting to classify and treat nerve injuries, the common belief prior to the 19th century was that nerves did not regenerate. As a result, any kind of major nerve injury was treated non surgically or with amputation. ${ }^{3}$ Peripheral upper extremity nerve surgery was introduced in the 19th century. The first epineural repair of the nerve, with fine sutures, was published by Hueter in 1871. However, the results following repair were disappointing. The introduction in the mid 1960s of an operating microscope, new suture techniques and suture materials led to significantly better outcomes.

How often does it occur?

"Many persons from business and industry, as well as government and private life, remain unaware of the overall significance of hand injuries".4

Injuries and diseases of the upper extremity have a large impact on the population because of their high frequency, associated disability and economic cost. About $31 \%$ of all injuries affect the upper extremity and are the most common cause of injury in the United States (National Center of Health Statistics, National Health Interview Survey, Public Use Tapes). ${ }^{4}$ Each year in the United States around 18.000.000 acute upper extremity injuries occur that are of sufficient severity to bring about restriction of activity or a visit to a physician. ${ }^{5}$ About two thirds of upper extremity injuries occur to individuals in their most productive years of their life: $65 \%$ of the nerve injury patients were between 16 and 40 years of age. ${ }^{6}$ The total costs of upper extremity disorders in the United states in 1995 are estimated to be almost $\$ 19.000 .000 .000$ per year. ${ }^{5}$

In $73 \%$ of the cases the accident had a domestic cause and three times more males than females were injured. As a protective instinct the forearm and hand are often outstretched to absorb the impact of the trauma, with a slight preference for the dominant hand. ${ }^{7}$ In the Netherlands, between 1988 and 1997, on average 839 upper extremity nerve lesions were operated on annually, with an increase in recent years (SIG Zorgregistratie, 1997). The median nerve is involved in $19 \%$ of upper extremity nerve injuries and the ulnar nerve in $15.9 \% .{ }^{6}$ About 
78\% of these nerve injuries were repaired by plastic surgeons. Twice as many patients were operated on in 'peripheral' hospitals compared to the university hospitals (SIG Zorgregistratie, 1997). In modern practice most upper extremity nerve injuries, approximately $90 \%$ were treated by primary repair or elective delayed repair (within two weeks). ${ }^{6,8,9}$

What are the functional consequences?

"The hand is a unique tool, which provides us the ability to feel, perform tasks and communicate".

The hand is the primary interface between the human individual and the environment. Peripheral nerves transport very specific information to the brain. The somatotopic representation of the human body surface is nicely demonstrated by the 'homunculus' or 'little man'. The arm and hand are responsible for a large part of the homunculus (figure 1). In upper extremity nerve injuries, morbidity is often not determined by the wound size but by the type of nerve that is injured. ${ }^{4}$ Injury to a sensory nerve will give loss of touch perception, temperature perception and sweating and often result in pain syndromes. Without sensation the hand is blind. ${ }^{10}$ Absence of sensation of digits disables the patient from using the hand as a functional tool. The primary interface between the human individual and the environment has been disrupted. Injury to a motor nerve will give muscle weakness or paralysis. Interruption of motor control makes the hand ineffective to perform and control necessary daily small and rapid finger movements and

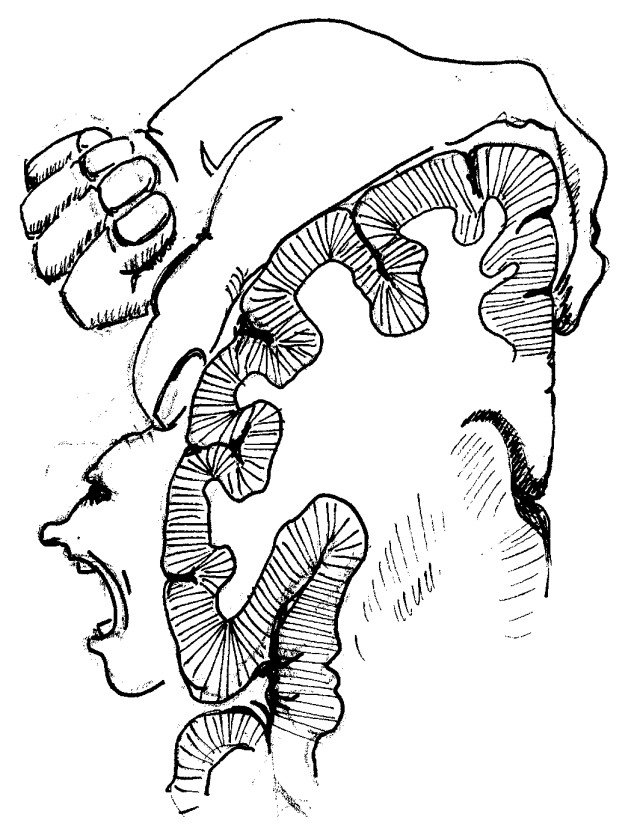

Figure 1. Homunculus. 
will usually result in loss of different grip strengths. Both the median and ulnar nerve carry sensory and motor functions.

Anatomically, at wrist level the median nerve is centrally and slightly more superficially located, compared to the ulnar nerve, and is therefore more vulnerable to injury. ${ }^{11}$ The median nerve innervates anterior forearm and thenar intrinsic muscles. Muscles innervated by the median nerve and their function are displayed in table 1. Injury to the median nerve at wrist level produces inability to abduct and pronate the thumb, paralysis of thenar muscles and a sensible deficit of the radial three and a half digits (figure 2). Grip and pinch strength are mainly diminished. The hand shows an externally rotated thumb into the plane of the palm and a wasted thenar eminence. The median nerve lies directly volar of the superficial flexor tendons and close to the radial artery. Associated flexor tendon and vascular injury is common.

A traumatized ulnar nerve is characterized by an awkward hand with profound weakness and significant sensory loss. ${ }^{12}$ Sensibility is lost over the volar side of the little finger and ulnar half of the ring finger (figure 3). In proximal lesions there is also sensory loss in the dorso-ulnar aspect of the palm. Furthermore, ulnar nerve paralysis results in a severe muscle imbalance destroying the exquisite mechanical system of the hand and profoundly affecting the grip function. Muscles innervated by the ulnar nerve and their function are shown in table 2. Profound deficiencies

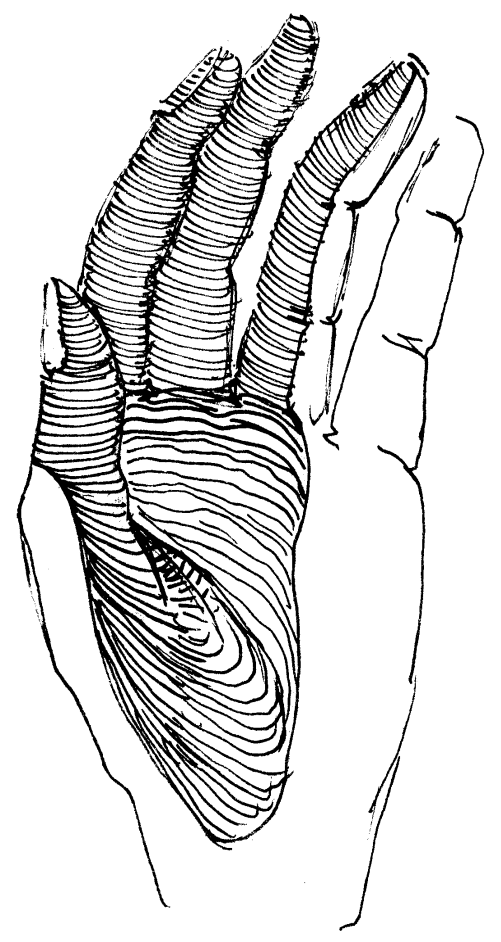

Figure 2. Sensory innervation by median nerve.

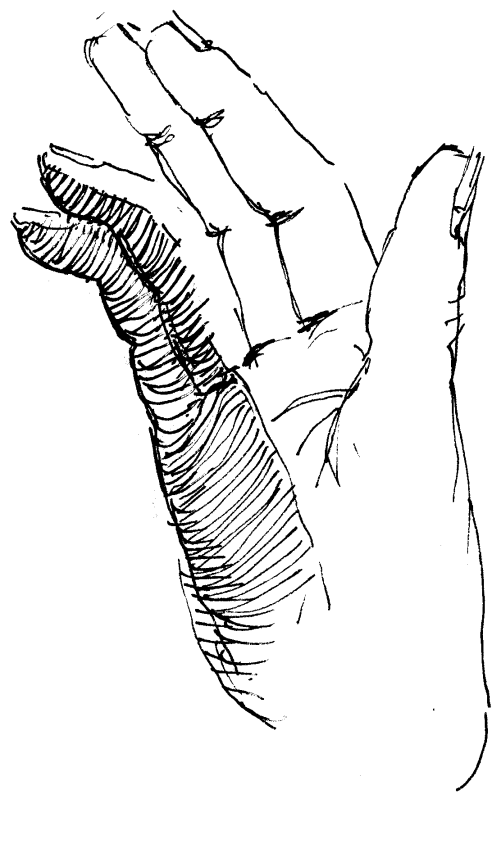

Figure 3. Sensory innervation by ulnar nerve. 
Table 1. Muscles innervated by the median nerve and their function, from proximal to distal

\begin{tabular}{ll}
\hline Muscle & Function \\
\hline Pronator Teres & Pronation \\
Flexor Carpi Radialis & Palmar flexion and radial abduction of the hand; pronation \\
Palmaris Longus & Palmar flexion and tensioning of the palmar aponeurosis \\
Flexor Digitorum Superficialis & Palmar flexion of the wrist, flexion of the MCP and PIP joints \\
Flexor Pollicis Longus & Palmar flexion, flexion and adduction of the MCP joint of the \\
& thumb and flexion of the IP joint of the thumb \\
Flexor Digitorum Profundus (2-3) & Palmar flexion, flexion MCP, PIP and DIP joints of digits 2 and 3 \\
Pronator Quadratus & Pronation \\
Abductor Pollicis Brevis & Abduction thumb \\
Flexor Pollicis Brevis & Flexion thumb \\
Opponens Pollicis & Opposition thumb \\
Lumbrical (1-2) & Flexion MCP joints and extension IP joints \\
\hline
\end{tabular}

Table 2. Muscles innervated by the ulnar nerve and their function, from proximal to distal

\begin{tabular}{ll}
\hline Muscle & Function \\
\hline Flexor Carpi Ulnaris & Flexion and ulnar abduction of the hand \\
Flexor Digitorum Profundus (4-5) & Palmar flexion, flexion MCP, PIP and DIP joints of digits 4 and 5 \\
Lumbrical muscles (3-4) & Flexion MCP joints and extension IP joints \\
Abductor Digiti Minimi & Abduction digit 5 \\
Flexor Digiti Minimi & Flexion digit 5 \\
Opponens Digiti Minimi & Opposition digit 5 \\
Flexor Pollicis Brevis & Flexion of the thumb \\
Interossei (four dorsal and three volar) & Spreading of digits 2, 3, and 4 (dorsal) \\
& Closure of all fingers (palmar) \\
Adductor Pollicis & Adduction of thumb \\
\hline
\end{tabular}

occur in the 'intrinsic minus' hand with loss of the interossei, thenar, hypothenar, and adductor pollicis muscles. ${ }^{13}$ The appearance of the hand is indicative of the muscles involved. The fourth and fifth fingers are hyperextended at the metacarpophalangeal (MCP) joint but flexed at the distal phalangeal (DIP) joint. The thumb is abducted and the second and third fingers are extended with a slight flexion of the DIP joint. Based on their close relationship with the nerve, concomitant injury to the ulnar artery and the flexor carpi ulnaris (FCU) tendon are common.

Because of the close approximation of both nerves at wrist level, frequent concomitant injury of median and ulnar nerves at this area is seen. Combined median and ulnar nerve injuries have devastating prospects. Sensibility loss is more profound with loss of position sense and feedback mechanisms. ${ }^{14}$ With the exception of extension of the wrist and fingers of the hand is totally paralyzed. The skeleton may be unstable with loss of normal joint stability and motion. ${ }^{14}$ Especially the proximal level injuries can result in a 'main en griffe', which is characterized by a non-functional severely clawed hand. ${ }^{15}$

Compared to median and ulnar nerve injuries, the incidence of injury to the dorsal located radial nerve is lower. The radial nerve is involved in only $2 \%$ of all upper extremity nerve injuries. 
Outcome following injury to the radial nerve is not analyzed in this thesis. The radial nerve is also a combined sensory and motor nerve. Depending on the level of the injury, patients are unable to extend the elbow joint, the wrist joint (dropping hand) and the fingers. This is also a disabling injury, since a person cannot flex the fingers sufficiently strong to grip an object due to muscle imbalance. Sensory loss is mainly found on the dorsum of the hand and fingers.

What is the final outcome and when will it be reached?

"Like it or not, outcome studies are here to stay, at least for the near future. Hand surgery patients have been minimally analyzed but are an important subpopulation. We must become more aggressive in providing appropriate outcomes, not only to the patient but also to those payers and corporations that need to have the data to substantiate the procedures and reconstructions that we are undertaking". ${ }^{16}$

In the past two decades outcome has become a fashionable term. The growing emphasis on cost-effectiveness in the health care industry has highlighted the need for comprehensive outcomes research in a variety of medical specialties. ${ }^{17}$ Current interest in outcomes of all kinds of pathological processes is generating rapid growth in the number of individuals and organizations involved in outcome research. ${ }^{17-20}$ Outcomes of medical care include many dimensions: physical, social, and emotional functioning; symptoms and satisfaction. ${ }^{21}$

Upper extremity nerve injury patients need information about their functional prospects and are interested in their ability to return to work and their time off work. After World War II, many clinical peripheral nerve injury outcome studies were performed. Most of these studies were retrospective, based on microsurgical repair of the nerve and focused on the classic outcome markers sensory and motor recovery. ${ }^{22-75}$ Some outcome studies were case reports on iatrogenic injuries, partial nerve injuries, war or gunshot injuries, non-microsurgical repair or repair with experimental techniques. ${ }^{15,76-106}$ Psychological stress, ability to perform normal everyday activities, return to work, pain, discomfort and cost effectiveness were underexposed in all of these publications. Furthermore, there is a shortage of studies on long-term outcomes. ${ }^{107}$

Determination of an 'end-point' of functional recovery will provide essential information for the patient, doctor and social authorities. Unfortunately, few studies have examined this issue and therefore no consensus exists on this subject. Function has been found to improve from one to up to six years..$^{70,71,108}$ To examine this subject in detail, data are needed from a large prospective national or international multi-center outcome study. 
How should we assess functional recovery?

"Without assessment, we cannot treat, we cannot communicate and we cannot progress". 109

Assessment of clinical outcome following nerve injuries is complex and has many dimensions. The World Health Organization determined that assessment methods need to support clinical diagnosis, evaluate treatment and describe impairment, disability and handicap. ${ }^{10}$ Different assessment methods of outcome are available to evaluate recovery from nerve injuries. It is essential to standardize these tests to create the ability to compare the results of multiple studies. ${ }^{2}$ Unfortunately, only a select number of methods meet the criteria for quality of an assessment method and there is no international consensus on the appropriate set of tests that should be used to evaluate nerve recovery after injury and repair. ${ }^{2}$ Rosen and co-authors published rationale for evaluation of recovery of sensory and motor functions following nerve repair."11

The primary outcome markers for nerve injuries are motor and sensory recovery. To evaluate functional recovery after nerve repair adequately, sensory and motor functions need to be defined and quantified, both separately and integratedly. ${ }^{12}$ Five key factors for recovery of hand function can be defined: 1) the structural and functional status of peripheral and sensory components, the basis for perceiving tactile stimuli; 2) tactile gnosis, the ability to interpret the new sensory input to the brain, based on tactile stimuli; 3 ) integrated sensory and motor functions, "what the hand can do"; 4) muscle strength and 5) the degree of pain and/or discomfort in terms of hyperesthesia and cold intolerance. ${ }^{11}$

After introduction of Von Frey hairs in $1896^{113}$, to evaluate sensory recovery, there has been an ongoing development of new assessment methods. Tinel and Hoffmann who treated nerve injuries during World War I, introduced in 1915 the tingling sensation of the regenerating nerve, still known as the 'Tinel sign'.114 In chronological order the following frequently used tests were introduced to evaluate nerve regeneration. 1948, electromyography ${ }^{115}$; 1954, Grip strength by Jamar dynamometer'16; 1954, Medical Research Council (MRC) scale ${ }^{117} ; 1958$, Mobergs pick up test ${ }^{118} ; 1960$, Semmes-Weinstein monofilaments ${ }^{19} ; 1969$, Jebsen-Taylor hand function test' ${ }^{120}$; 1960, static two point discrimination (s2PD) ${ }^{118}$; 1975, McGill pain questionnaire ${ }^{121}$; 1978, moving two point discrimination (m2PD) ${ }^{122} ; 1980$, Sollerman hand function test ${ }^{123,124}$; 1984, Pinch strength by Jamar dynamometer ${ }^{125} ; 1989$, Visual analog scale(VAS) ${ }^{126 ;}$ 1991, Cold Sensitivity Severity questionnaire ${ }^{127}$; 1996, the Disability of Arm Shoulder and Hand (DASH) questionnaire ${ }^{128 ;}$ 1997, Cold Intolerance Severity Score (CISS) ${ }^{129} ; 1998$, Shape Identification Test $(\mathrm{STI})^{130}$ and 2004, Rotterdam Intrinsic Hand Meter (RIHM) ${ }^{131}$. The available assessment methods for evaluation of different outcome parameters following nerve repair are displayed in table 3.

All available assessment methods only give information about the current status of reinnervation. Unfortunately, there is still no adequate quantitative test that has a predictive value for final clinical functional outcome. ${ }^{132}$ Only Semmes Weinstein monofilaments (sensory recovery) and the Jamar dynamometer (motor recovery) fulfil all the requirements of 
Table 3. The available assessment methods for evaluation of different outcome parameters following nerve repair

\begin{tabular}{|c|c|}
\hline Outcome parameter & Assessment methods \\
\hline \multirow[t]{5}{*}{ Sensory recovery } & Von Frey hairs \\
\hline & Medical Research Council (MRC) scale (S0-S4) \\
\hline & Semmes-Weinstein monofilaments \\
\hline & Perception of touch and vibration \\
\hline & Electroneurography (ENG) \\
\hline \multirow[t]{6}{*}{ Motor recovery } & Electromyography (EMG) \\
\hline & Jamar dynamometer (Grip) \\
\hline & Medical Research Council (MRC) scale (M0-M5) \\
\hline & Jamar dynamometer (Tip-pinch) \\
\hline & Manual Muscle Testing (ex- \& intrinsic) \\
\hline & Rotterdam Hand Intrinsic Muscle (RHIM) meter \\
\hline \multirow[t]{2}{*}{ Motor \& sensory recovery } & Jebsen-Taylor hand function test \\
\hline & Sollerman hand function test \\
\hline \multirow[t]{4}{*}{ Tactile gnosis } & Moberg pick-up test \\
\hline & 2 point discrimination (static \& dynamic) \\
\hline & STI (shape-texture identification) test \\
\hline & Other shape and object identification tests \\
\hline \multirow[t]{6}{*}{ Discomfort and disability } & McGill pain questionnaire \\
\hline & Visual analog scale (VAS) \\
\hline & Cold Sensitivity Severity questionnaire \\
\hline & Disability of Arm Shoulder and Hand (DASH) questionnaire \\
\hline & Cold Intolerance Severity Score (CISS) \\
\hline & Other activities of daily living ( $\mathrm{ADL}$ ) questionnaire \\
\hline
\end{tabular}

standardization and have all specific clinical utility features considered important. ${ }^{111}$ Based on these results we used these tests to assess motor and sensory recovery for our study.

What are the prognostic factors?

"From the point of view of the ultimate utility of the limb, a nerve injury overshadows in importance of any other damage that may have occurred. A badly united fracture or a clumsy scar are mere trifles compared with an unhealed nerve". ${ }^{133}$

Since the introduction of peripheral nerve surgery, many improvements have been achieved in treatment of traumatic nerve lesions. Nevertheless, recovery following these injuries is often disappointing. One of the major problems is that the final outcome is unpredictable. ${ }^{134}$ For both patient and doctor it is necessary to predict the chances of recovery, so that treatment expectations can be realistic and appropriate rehabilitation measures can be taken.

Several predicting factors have been described to influence outcome of nerve injuries. Many of these publications were based on small numbers of patients. Chronically the following predicting variables have been described: age ${ }^{135}$; level of the injury ${ }^{15}$; skill of the surgeon ${ }^{15}$; sensory reeducation ${ }^{10,136}$; specialized hand therapy ${ }^{39}$; delay ${ }^{52,63,67,137}$; severity and type of 
injury ${ }^{63,83,138}$; repair of the ulnar artery ${ }^{63}$; diabetes ${ }^{139}$; cooperation and motivation of the patient ${ }^{31}$; alcoholism ${ }^{60}$, cognitive capacity ${ }^{140}$ and different neurotrophic factors ${ }^{141}$.

Despite numerous studies on the outcome of nerve repair there is no conclusive agreement on which variables are independent predictors for functional outcome of median and ulnar nerve injuries. Most factors of importance such as age, level of injury, psychological stress, cognitive capacity, delay and plasticity of the brain have never been quantified regarding their independent contribution.

Aim of the thesis

"In spite of an enormous amount of new experimental laboratory data based on evolving neuroscientific concepts during the last 25 years, peripheral nerve injuries still belong to the most challenging and difficult surgical reconstructive problems". ${ }^{142}$

The primary aim of this thesis was to investigate the overall long-term functional outcome of median and ulnar nerve injuries, in terms of restoration of normal everyday activities, return to work, time off work, psychological morbidity, cold intolerance, sensory recovery and motor recovery. Furthermore, we aimed to identify the major independent prognostic factors for functional outcome and to determine an 'end point' for progression of functional recovery. With these research objectives, we hope to find answers to the questions that will be asked by the patient with a median or ulnar nerve injury and raised by the surgeon treating this patient.

\section{Outline of the thesis}

Chapter $\mathbf{2}$ comprises an investigation into the overall functional outcome of median and ulnar nerve injuries. In addition, an analysis is made of the association between sensory and motor recovery. Furthermore, this study was used to define further aims for the thesis.

Chapter 3. The main objective of this chapter was to assess long-term outcome following 'spaghetti wrist' injury in terms of functional recovery, return to work potential and psychological distress for a large group of patients. Furthermore, this part of the thesis aimed to compare the two most commonly used definitions for 'spaghetti wrist' injury, by means of statistical analysis of long-term outcome when applying these two different definitions.

In chapter 4 content validity of the DASH (Disabilities of Arm Shoulder and Hand) questionnaire was examined. This study was additionally designed to investigate the ability to resume various everyday tasks and provide long-term DASH scores for forearm nerve injury patients.

Chapter $\mathbf{5}$ analyzes absence from work and the ability to return to work after surgical repair of median, ulnar and combined median-ulnar nerve injuries. In this chapter, factors were also investigated for their contribution to the ability to return to work within one year after injury. 
Psychological stress following median and ulnar nerve injuries has never been investigated in detail. Chapter $\mathbf{6}$ discusses the psychological impact of forearm nerve injuries and assesses the incidence of post-traumatic psychological stress. This chapter also examines to what extent psychological stress has an effect on functional outcome and return to work. We additionally aimed to identify risk factors for early psychological stress.

The level of cognitive capacity plays a role in the remodelling process of the somatosensory cortex and therefore may have a substantial effect on the prognosis of sensory recovery. The study described in chapter $\mathbf{7}$ was designed to quantify the association between cognitive capacity and long-term sensory recovery.

In chapter $\mathbf{8}$ the results of a meta-analysis based on individual patient data on motor and sensory recovery after microsurgical nerve repair are reported. The predicting variables that influence outcome after median and ulnar nerve injuries were quantified.

Chapter $\mathbf{9}$ includes the general discussion and conclusions and chapter $\mathbf{1 0}$ the summary of this thesis. 


\section{REFERENCES}

1. Rijnders WE. De microchirurgische behandeling van patienten met scherpe letsels van de nervus medianus en de nervus ulnaris ter hoogte van de pols: Rijksuniversiteit Utrecht, 1979.

2. Allan C. Functional results of primary nerve repair. Hand Clinics 2000;16(1):67-71.

3. Gupta S, Littman T. Nerve injury repair. In: Sudekum A, Talavera F, Chang D, Slenkovich N, Downey S, eds. Hand: eMedicine, 2003.

4. Gaul JS J. Identifiable costs and tangible benefits resulting from the treatment of acute injuries of the hand. J Hand Surg [Am] 1987;12:966-70.

5. Kelsey J, Praemer A, Nelson L, Felberg A, Rice D. Upper extremity disorders: Frequency impact and cost. New York: Churchill Livingstone, 1997.

6. McAllister R, Gilbert S, Calder J, Smith P. The epidemiology and management of upper limb peripheral nerve injuries in modern practice. J Hand Surg [Br] 1996;21(1):4-13.

7. Carter GT, Robinson LR, Chang VH, Kraft GH. Electrodiagnostic evaluation of traumatic nerve injuries. Hand Clinics 2000;16(1):1 - 12.

8. Kim Y, Park J. The epidemiologic analysis of the upper extremity peripheral nerve injuries in korea. IFSSH 1998, Vancouver.

9. de Medinaceli L, Prayon M, Merle M. Percentage of nerve injuries in which primary repair can be achieved by end-to-end approximation: review of 2,181 nerve lesions. Microsurgery 1993;14(4): 244-6.

10. Dellon AL, Curtis RM, Edgerton MT. Re-education of the sensation in the hand after nerve injury and repair. Plastic and Reconstructive Surgery 1974;53:297-305.

11. McAllister RMR, Gilbert SEA, Calder JS, Smith PJ. The epidemiology and management of upper limb peripheral nerve injuries in modern practise. J Hand Surg 1996;21B(1):4-13.

12. Omer GE J. Ulnar nerve palsy. In: Green DP, ed. Operative Hand Surgery. San Antonio, Texas: Churchill Livingstone, 1988: 1535 - 1554.

13. Kozin SH, Porter S, Clark P, Thoder JJ. The contribution of the intrinsic muscles to grip and pinch strength. 1999;24(1):64-72.

14. Omer GE J. Combined nerve palsy. In: Green DP, ed. Operative Hand Surgery. San Antonio, Texas: Churchill Livingstone, 1988: 1555 - 1567.

15. Sakellarides $\mathrm{H}$. A follow-up study of 172 peripheral nerve injuries in the upper extrenity in civilians. J Bone Joint Surg 1962;44-A(1):141 - 8.

16. Smith Jr DJ. Year Book Plastic, Reconstructive and Aesthetic Surgery: Mosby-Year Book, Inc., 1997.

17. Wilkins E, Lowery J, Smith DJ J. Outcomes research: a primer for plastic surgeons. Ann Plast Surg 1996;37(1):1 - 11 .

18. Guadagnoli E, McNeil BJ. Outcomes research: hope for the future or the latest rage? Inquiry 1994;31(1):14-24.

19. McAuliffe J. Outcome research: definitions and directions. Journal of Hand Therapy 1998:164-170.

20. Sage WM. Outcomes research. NEngl J Med 1994;330(6):434-5.

21. Amadio P. Outcomes assessment in hand surgery. What's new? Clin Plast Surg 1997;24(1):191-4.

22. Amillo S, Mora G. Surgical management of neural injuries associated with elbow fractures in children. J Ped Orthop 1999;19(5):573-7.

23. Barrios C, Amillo S, de Pablos J, Canadell J. Secondary repair of ulnar nerve injury. 44 cases followed for 2 years. Acta Orthopaedica Scandinavica 1990;61(1):46-9.

24. Barrios $C$, de Pablos J. Surgical management of nerve injuries of the upper extremity in children: a 15-year survey. J Pediatr Orthop 1991;11(5):641-5.

25. Daoutisn, Gerostathopoulos N, Efstathopoulos D, Misitizis D, Bouchlis G, Anagnostou S. Microsurgical reconstruction of large nerve defects using autologous nerve grafts. Microsurgery 1994;15:502 - 5 .

26. Finseth F, Constable J, Cannon B. Interfascicular nerve grafting. Plast Reconstr Surg 1975;56(5): 492-5.

27. Frykman GK, Cally D. Interfascicular nerve grafting. Orthop Clin NA 1988;19(1):71 -80.

28. Hakistan RW. Funicular orientation by direct stimulation. J Bone Joint Surg 1968;50-A(6):1178-86.

29. Ito T, Hirotani H, Yamamoto K. Peripheral nerve repairs by the funicular suture technique. Acta Orthop Scand 1976;47(3):283-9. 
30. Jerosch Herold C. Should sensory function after median nerve injury and repair be quantified using two-point discrimination as the critical measure? Scandinavian Journal of Plastic and Reconstructive Surgery and Hand Surgery 2000;34(4):339-43.

31. Jongen $S$, Van Twisk R. Results of primary repair of ulnar and median nerve injuries at the wrist: an evaluation of sensibility and motor recovery. Neth J Surg 1988;40(3):86-9.

32. Kato H, Minami A, Kobayashi M, Takahara M, Ogino T. Functional results of low median and ulnar nerve repair with intraneural fascicular dissection and electrical fascicular orientation. 1998;23(3):471-82.

33. Millesi H, Meissl G, Berger A. The interfascicular nerve-grafting of the median and ulnar nerves. Journal of Bone and Joint Surgery 1972;54A(4):727-50.

34. Millesi $\mathrm{H}$, Meissl G, Berger A. Further experience with interfascicular grafting of the median, ulnar, and radial nerves. J Bone Joint Surg 1976;58-A(2):209-18.

35. Moneim MS. Interfascicular nerve grafting. Clin Orthop Rel Res 1982;163:65 - 74.

36. Puckett $\mathrm{CL}$, Meyer VH. Results of treatment of extensive volar wrist lacerations: the spaghetti wrist. Plast Reconstr Surg 1985;75(5):714-21.

37. Rogers $G$, Henshall A, Sach R, Wallis K. Simultaneous laceration of the median and ulnar nerves with flexor tendons at the wrist. J Hand Surg [Am] 1990;15(6):990-5.

38. Selma P, Emre O, Oguz P, Ersin N, Oya B. Evaluation of the improvement of sensibility after primary median nerve repair at the wrist. Microsurg 1998;18:192-6.

39. Stellini L. Interfascicular autologous grafts in the repair of peripheral nerves: eight years experience. Br J Plast Surg 1982;35:478-82.

40. Stevenson JH, Zuker RM. Upper limb motor and sensory recovery after multiple proximal nerve injury in children: a long term review in five patients. Br J Plast Surg 1986;39:109-13.

41. Tackmann W, Brennwald J, Nigst H. Sensory electroneurographic parameters and clinical recovery of sensibility in sutured human nerves. Journal of Neurology 1983;229(3):195-206.

42. Trumble TE, Kahn U, Vanderhooft E, Bach AW. A technique to quantitate motor recovery following nerve grafting. J Hand Surg. American Volume 1995;20(3):367-72.

43. Walton R, Finseth F. Nerve grafting in the repair of complicated peripheral nerve trauma. J Trauma 1977;17(10):793-6.

44. Widgerow A. Full-house/spaghetti wrist injuries. Analysis of results. S Afr J Surg 1990;28(1):6-10.

45. Deutinger $M$, Girsch W, Burggasser $G$, et al. Peripheral nerve repair in the hand with and without motor sensory differentiation. J Hand Surg [Am] 1993;18(3):426-32.

46. Imai $\mathrm{H}$, Tajima $\mathrm{T}$, Natsumi Y. Successful reeducation of functional sensibility after median nerve repair at the wrist [see comments]. J Hand Surg [Am] 1991;16(1):60-5.

47. Jerosch-Herold C. Measuring outcome in median nerve injuries. J Hand Surg [Br] 1993;18(5):624-8.

48. Rosen B, Lundborg G, Dahlin L, Holmberg J, Karlson B. Nerve repair: correlation of restitution of functional sensibility with specific cognitive capacities. J Hand Surg [Br] 1994;19(4):452-8.

49. Tajima T, Imai H. Results of median nerve repair in children. Microsurgery 1989;10(2):145-6.

50. Trevett MC, Tuson C, de Jager LT, Juon JM. The functional results of ulnar nerve repair. Defining the indications for tendon transfer. J Hand Surg [Br] 1995;20(4):444-6.

51. Berger A, Mailander P. Advances in peripheral nerve repair in emergency surgery of the hand. World J Surg 1991;15(4):493-500.

52. Birch R, Raji A. Repair of median and ulnar nerves. Primary suture is best. J Bone Joint Surg [Br] 1991;73(1):154- 7.

53. Birch R, Achan P. Peripheral nerve repairs and their results in children. Hand Clinics 2000;16(4): 579-95.

54. Chin G, Weinzweig N, Mead M, Gonzalez M. "Spaghetti wrist": management and results. Plast Reconstr Surg 1998;102(1):96-102.

55. Duteille F, Petry D, Poure L, Dautel G, Merle M. A comparative clinical and electromyographic study of median and ulnar nerve injuries at the wrist in children and aldults. $J$ Hand Surg [Br] 2001;26(1): 58-60.

56. Haase J, Bjerre $P$, Simesen K. Median and ulnar nerve transections treated with microsurgical interfascicular cable grafting with autogenous sural nerve. J Neurosurg 1980;53:73-84.

57. Hudson $D$, de Jager $L$. The spaghetti wrist. Simultaneous laceration of the median and ulnar nerves with flexor tendons at the wrist. J Hand Surg [Br] 1993;18(2):171 - 3. 
58. Hudson DA, Bolitho DG, Hodgetts K. Primary epineural repair of the median nerve in children. $J$ Hand Surg 1997;22B(1):54-6.

59. Iconomou T, Zuker R, Michelow B. Management of major penetrating glass injuries to the upper extremities in children and adolescents. Microsurg 1993;14:91-6.

60. Kalomiri DE, Soucacos PN, Beris AE. Nerve grafting in peripheral nerve microsurgery of the upper extremity. Microsurgery 1994;15(7):506-11.

61. Kalomiri DE, Soucacos PN, Beriis AE. Management of ulnar nerve injuries. Acta Orthop Scand $1995 ; 264: 41-4$.

62. Kim DH, Kam AC, Chandika P, Tiel RL, Kline DG. Surgical management and outcomes in patients with median nerve lesions. J Neurosurg 2001;95:584-94.

63. Leclercq DC, Carlier AJ, Khuc T, Depierreux L, Lejeune GN. Improvement in the results in sixty-four ulnar nerve sections associated with arterial repair. J Hand Surg 1985;10A(6):997-9.

64. Lijftogt HJ, Dijkstra R, Storm van Leeuwen JB. Results of microsurgical treatment of nerve injuries of the wrist. Netherlands Journal of Surgery 1987;39(6):170-4.

65. Marsh D, Barton N. Does the use of the operating microscope improve the results of peripheral nerve suture? J Bone Joint Surg [Br] 1987;69(4):625-30.

66. Mailander P, Berger A, Schaller E, Ruhe K. Results of primary nerve repair in the upper extremity. Microsurgery 1989;10(2):147-50.

67. Merle M, Amend P, Cour C, Foucher G, Michon J. Microsurgical repair of peripheral nerve lesions: A study of 150 injuries of the median and ulnar nerves. Peripheral Nerve Repair 1986;2:17-26.

68. Pluchino F, Laccarelli G. Interfascicular suture with nerve autografts for median, ulnar and radial nerve lesions. Ital J Neurol Sci 1981;2:139-46.

69. Posch J, Cruz-Saddul Fdl. Nerve repair in trauma surgery: A ten-year study of 231 peripheral injuries. Orthopaedic Review 1980;9(3):35-45.

70. Rosen B, Dahlin LB, Lundborg G. Assessment of functional outcome after nerve repair in a longitudinal cohort. Scandinavian Journal of Plastic and Reconstructive Surgery and Hand Surgery 2000;34(1):71 - 8.

71. Rosen $B$, Lundborg $G$. The long term recovery curve in adults after median or ulnar nerve repair: a reference interval. J Hand Surg 2001;26B(3):196-200.

72. Tallis R, Staniforth P, Fisher R. Neurophysiological studies of autogenous sural nerve grafts. J Neur Neurosurg Psych 1978;41:677-83.

73. Vastamaki $M$, Kallio $P$, Solonen $K$. The results of secondary microsurgical repair of ulnar nerve injury. J Hand Surg [Br] 1993;18(3):323-6.

74. Young VL, Wray RC, Weeks PM. The results of nerve grafting in the wrist and hand. Ann Plast Surg 1979;5(3):212-5.

75. Kim DH, Han K, Tiel RL, Murovic JA, Kline DG. Surgical outcomes of 654 ulnar nerve lesions. Journal of Neurosurgery 2003;98(5):993-1004.

76. Chakrabarti AJ, Kunzru KMN. Complete ulnar nerve division in a displaced supracondylar fracture: a case report. J Bone Joint Surg 1995;77-B(6):977-8.

77. Garg M, Kumar S. Entrapment and transection of the median nerve associated with minimally displaced fractures of the forearm: case report and review of the literature. Arch Orthop Trauma Surg 2001;121:544-5.

78. Huang K, Pun WK, Coleman S. Entrapment and transection of the median nerve associated with greenstick fractures of the forearm. J Trauma 1998;44(6):1101-2.

79. Sud V, Chang J, Lineaweaver W. Acute nerve grafting in traumatic injuries: two case studies. Ann Plast Surg 2001;47:555-61.

80. Trail I. Delayed repair of the ulnar nerve. Br J Hand Surg 1985;10B(3):345-5.

81. Yamano Y. Electrophysiological study of nerve grafting. J Hand Surg 1982;7(6):588-92.

82. Hurst LC, Dowd A, Sampson SP, Badalamente MA. Partial lacerations of median and ulnar nerves. $J$ Hand Surg 1991;16A(2):207-10.

83. Kallio $\mathrm{P}$, Vastamaki M. An analysis of the results of late reconstruction of 132 median nerves. J Hand Surg [Br] 1993;18(1):97-105.

84. Barisic N, Perovic D, Mitrovic Z, Jurenic D, Zagar M. Assessment of war and accidental nerve injuries in children. Pediatr Neurol 1999;21(1):450-5.

85. Omer GE. Injuries to nerves of the upper extremity. J Bone Joint Surg 1974;56-A(8):1615-24. 
86. Taha A, Taha J. Results of suture of the radial, median, and ulnar nerves after missile injury below the axilla. Journal Of Trauma 1998;45(2):335-9.

87. Almquist $\mathrm{E}$, Eeg-Olofsson $\mathrm{O}$. Sensory-nerve-conduction velocity and two-point discrimmination in sutured nerves. J Bone Joint Surg [Am] 1970;52(4):791-6.

88. Gaul JSJ. Intrinsic motor recovery - a long-term study of ulnar nerve repair. J Hand Surg 1982;7A(5):502-8.

89. Lindsay W, Walker F, Farmer A. Traumatic peripheral nerve injuries in children. Results of repair. Plast Reconstr Surg 1962;30(4):462-8.

90. Nicholson O, Seddon H. Nerve repair in civil practice. Br Med J 1957;2:1065- 71.

91. Strzyzewski H. Multiple injuries to flexor tendons and nerves above the wrist. Hand 1972;4(2): 178-83.

92. McEwan L. Median and ulnar nerve injuries. Austr NZJ Surg 1962;32(2):89-104.

93. Rana NA, Kenwright J, Taylor RG, Rushworth G. Complete lesion of the median nerve associated with dislocation of the elbow joint. Acta Orthop Scand 1974;45(3):365 - 9.

94. Match RM. Laceration of the median nerve from skiing. Am J Sports Med 1978;6(1):22-5.

95. Vahvanen V, Gripenberg L, Nuutinen P. Peripheral nerve injuries of the hand in children. A follow-up study of 38 patients. Scand J Plast Reconstr Surg 1979;15:49-51.

96. Braga-Silva J. The use of silicone tubing in the late repair of the median and ulnar nerves in the forearm. J Hand Surg 1999;24B(6):703-6.

97. Calder J, McAllister R. Interpreting the results of unilateral digital nerve repair. J Hand Surg [Br] 1993;18(6):797-9.

98. Dahlin LB, Anagnostaki L, Lundborg G. Tissue response to silicone tubes used to repair human median and ulnar nerves. Scand J Plast Reconstr Hand Surg 2001;35:29-34.

99. Lundborg G, Rosen B, Dahlin L, Danielsen N, Holmberg J. Tubular versus conventional repair of median and ulnar nerves in the human forearm: early results from a prospective, randomized, clinical study. J Hand Surg [Am] 1997;22(1):99-106.

100. Matsunaga T, Saitoh S, Tanikawa H, Hayashi M, Ohira M, Kimura T. Deep cutting injury from the edges of a snowboard. British Journal of Sports Medicine 2004;38(1):80-3.

101. del Pinal F, Cruz Camara A, Jado E. Total ulnar nerve transection during endoscopic carpal tunnel release. Arthroscopy: the Journal of Arthroscopic \& Related Surgery 1997;13(2):235 - 7.

102. Swenson JD, Bull DA. Postoperative ulnar neuropathy associated with prolonged ischemia in the upper extremity during coronary artery bypass surgery. Anesthesia and Analgesia 1997;85(6): 1275 - 7.

103. Martens PR, Driessen JJ, Lanckriet W, Lust P. Bilateral ulnar nerve injury after high abdominal surgery. Acta Anaesthesiologica Belgica 1988;39(2):113-5.

104. Perreault L, Drolet P, Farny J. Ulnar nerve palsy at the elbow after general anaesthesia. Canadian Journal of Anaesthesia 1992;39:499-503.

105. Scott TF, Yager JG, Gross JA. Handcuff neuropathy revisited. Muscle \& Nerve 1989;12(3):219-20.

106. Kankaanpaa U, Bakalim G. Peripheral nerve injuries of the upper extremity. Sensory return of 137 neurorrhaphies. Acta Orthopaedica Scandinavica 1976;47(1):41 - 5.

107. Cano SJ, Browne JP, Lamping DL. Patient-based measures of outcome in plastic surgery: current approaches and future directions. British Journal Of Plastic Surgery 2004;57(1):1 - 11.

108. Ghandi A, Jaquet JB, Kalmijn S, Hovius S. Motor recovery following median and ulnar nerve injuries. 2003;28 Suppl 1:16.

109. Fess EE. Rehabilitation of the patient with peripheral nerve injury. Hand Clin 1986;2(1):207-15.

110. Worldhealthorganization. International Classification of Impairmants, Disabilities and Handicaps. Geneva:WHO, 1980.

111. Rosen B. Recovery of sensory and motor function after nerve repair. A rationale for evaluation. $J$ Hand Ther 1996;9(4):315-27.

112. Lundborg G. Nerve Injury and Repair. Edinburgh: Churchill Livingstone, 1988.

113. von Frey M. Untersuchungen uber die sinnesfunktionen der menschlichen haut. Abh Sachs Ges (Akad) Wiss 1896;40:175-226.

114. Hoffmann P, Buck-Gramcko D, Lubahn JD. The Hoffmann-Tinel sign. 1915 [classical article]. J Hand Surg [Br] 1993;18(6):800-5.

115. Hodes R, Larrabee M, German W. The human electromyogram in response to nerve stimulation and the conduction velocity of motor axons: studies on normal and injured peripheral nerves. Arch. Neurol. Psychiat. 1948;60:340-365. 
116. Bechtol CO. Grip test: The use of a dynamometer with adjustable handle spacings. Journal of Bone and Joint Surgery 1954;36A:820-824.

117. Medical Research Council. Results of nerve suture. London: Her Majesty's Stationer Office, 1954.

118. Moberg E. Objective methods for determining the functional value of sensibility in the hand. Journal of Bone and Joint Surgery 1958;40B(3):454-476.

119. Semmes J, Weinstein S, Ghent L, Teuberg HL. Somato-sensory changes after penetrating brain wounds in man. Cambridge: Harvard University Press, 1960.

120. Jebsen RH, Taylor N, Trieschmann RB, Trotter MJ, Howard LA. An objective and standardized test of hand function. Archives Of Physical Medicine And Rehabilitation 1969;50(6):311 - 9.

121. Melzack R. The McGill Pain Questionnaire: major properties and scoring methods. Pain 1975;1(3): 277-299.

122. Dellon AL. The moving two-point discrimination test: clinical evaluation of the quickly adapting fiber/receptor system. American J Hand Surg 1978;3:474-481.

123. Sollerman C. Grip Function of the Hand. Analysis, Evaluation and a New Test Method: Sahlgren Hospital, 1980.

124. Sollerman C, Ejeskar A. Sollerman hand function test. A standardised method and its use in tetraplegic patients. Scand J Plast Reconstr Surg Hand Surg 1995;29(2):167-76.

125. Mathiowetz V, Weber K, Volland G, Kashman N. Reliability and validity of grip and pinch strength evaluations. J Hand Surg [Am] 1984;9(2):222-6.

126. Gift AG. Visual analog scale: measurement of subjective phenomena. Nursing Research 1989;38: 286-288.

127. McCabe S, Mizgala C, Glickman L. The measurement of cold sensitivity of the hand. J Hand Surg 1991;16A:1037-1040.

128. Hudak P, Amadio P, Bombardier C. Development of an upper extremity outcome measure: the DASH (disabilities of the arm, shoulder and hand [correction of head]). The Upper Extremity Collaborative Group (UECG). Am J Ind Med 1996;29(6):602-8.

129. Irwin M, Gilbert S, Terenghi G, Smith R, Green C. Cold intolerance following peripheral nerve injury. Natural history and factors predicting severity of symptoms. J Hand Surg [Br] 1997;22(3):308 - 16.

130. Rosen B, Lundborg G. A new tactile gnosis instrument in sensibility testing. Journal of Hand Therapy 1998; 11:251- 257.

131. Schreuders TA, Roebroeck ME, Jaquet JB, Hovius SE, Stam HJ. Measuring the strength of the intrinsic muscles of the hand in patients with ulnar and median nerve injuries: reliability of the Rotterdam Intrinsic Hand Myometer (RIHM). 2004;29(2):318-24.

132. Shen N, Zhu J. Functional assessment of peripheral nerve injury and repair. J Reconstr Microsurg 1996;12(3):153-7.

133. Souttar S, Onon MC. Some points arising in nerve injuries. British Medical Journal 1917;8:817-820.

134. Fahmy W, Fahmy M. Prediction of early outcome of nerve reconstruction: a statistic and mathematic approach. 6th IFFSH 1995, Helsinki, Finland: 457-461.

135. Onne L. Recovery of sensibility and sudomotor activity after nerve suture. Acta Chir Scand 1962;300: $1-70$.

136. Parry CW. Rehabilitation of the hand. 1 ed. London: Butterwoods, 1966.

137. Merle M, Foucher G, Genechten van F, Michon J. The repair of peripheral nerve injuries in emergency. Bull Hosp Jt Dis Orthop Inst 1984;44(2):338-46.

138. Noble J, Munro CA, Prasad VS, Midha R. Analysis of upper and lower extremity peripheral nerve injuries in a population of patients with multiple injuries. Journal Of Trauma 1998;45(1):116-22.

139. Mackinnon S, Dellon A. Results of nerve repair and grafting. In: Mackinnon S, Dellon A, eds. Surgery of the peripheral nerve. 1 ed. New York: Thieme Medical Publishers, Inc, 1988: 115-129.

140. Lundborg G, Rosen B, Dahlin LB, Holmberg J, Karlson B. Functional sensibility of the hand after nerve repair. Lancet 1993;342:1300.

141. Levi-Montalcini R, Hamburger V. A diffusable agent of mouse sarcoma producing hyperplasia of sympathetic ganglia and hypernemotization of viscera in the chick embryo. J Exp Zool 1953;123: $233-278$.

142. Lundborg G. A 25-year perspective of peripheral nerve surgery: evolving neuroscientific concepts and clinical significance. J Hand Surg. American Volume 2000;25(3):391 - 414. 


\section{CHAPTER 2}

\section{MEDIAN, ULNAR AND COMBINED MEDIAN-ULNAR}

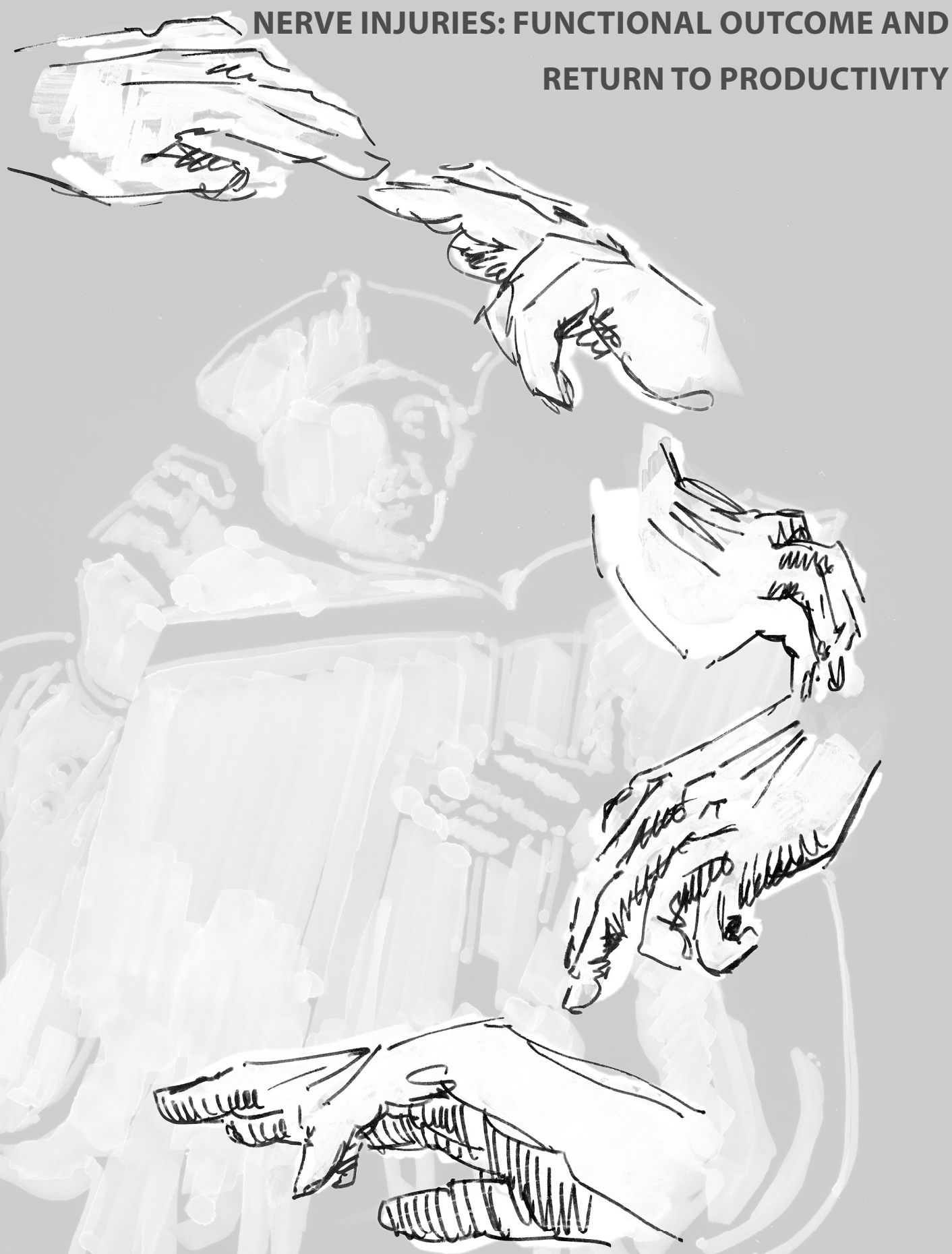

Jaquet J. B., Luijsterburg A.J.M., Kalmijn S., Kuypers P.D. L., Hofman A. and Hovius S. E. R. Journal of Trauma: 51(4): 687-692. 



\section{ABSTRACT}

Background - Forearm and wrist injuries are a common cause of morbidity and are often associated with sub-optimal recovery of hand function. This study describes and compares outcome following median, ulnar or combined median-ulnar nerve injuries.

Methods - 313 wrist and forearm nerve injuries operated upon between 1980 and 1997 in a large university hospital were reviewed in relation to complications, return to work, sensor and motor recovery. Of these 313 patients, 220 (5-73 years) met the inclusion criteria.

Results - Motor recovery, progress of sensory reinnervation and number of severed structures were related to the type of injury $(\mathrm{p}<.05)$. Multiple linear regression analysis revealed a relation between the appearance of sensory reinnervation and motor recovery $(\beta=.02,95 \% \mathrm{Cl}$ : $.01-.04$ and $\mathrm{p}=.01$ ). A probability of a $24 \%$ of work loss, after a mean follow-up of 17.7 months, was found. Poor sensory and motor recovery were associated with work disability $(O R=2.9, p=.002$ and $O R=2.9, p=.007$ respectively). No relationship was found between type of injury and return to work $(p=.47)$. Level of injury $(O R=2.6, p=.01)$, type of work $(O R=3.1, p=.002)$, number of complications $(p<.001)$ and hand-therapy $(O R=.24, p=.001)$ were found to influence return to work.

Conclusion - It may be concluded that peripheral nerve injuries at forearm level can result in substantial functional loss and have major social consequences. This study identified factors influencing return to work that can be used to optimize postoperative treatment strategy. 


\section{INTRODUCTION}

In the United States approximately one third of all injuries affect the upper extremities (National Center of Health Statistics, National health Interview Survey, Public Use Tapes). These injuries, especially at the forearm and wrist level, are a common cause of severe tendon, muscle and neurovascular damage. Due to the superficial location of these structures at forearm level, a relatively minor trauma can have a devastating impact. Particularly in cases where a nerve is involved, both sensory and motor function may be impaired, resulting in a non-functional hand. Upper extremity injuries have been an important cause of morbidity and disability in both the working and non-working population. The true impact of hand and forearm injuries may be greatly underestimated. 'In the United States, 18 million acute upper extremity injuries resulted in 32 million days of restricted activity and 10 million lost working-days over a period of one year. ${ }^{2}$

Attention was recently drawn to a deficit in comprehensive studies concerning the epidemiology and pattern of upper limb nerve injuries was emphasized. ${ }^{3,4}$ After World War II, extensive series of war victims suffering from peripheral nerve injury were analyzed. ${ }^{5,6}$ More recently, several upper extremity outcome studies were performed.-10 Most of these studies focussed on sensory and motor recovery, but less emphasis was placed on the ability to return to work and the impact of these injuries on the activities of daily life. For economic reasons, returning workers to employment is becoming an issue of national concern. ${ }^{11}$ Furthermore, return to economic productivity plays an important role with regard to a patient's quality of life. To our knowledge, none of the outcome studies compared return to work of median, ulnar and combined median-ulnar nerve injuries. Taha and Taha focussed on differences in outcome between radial, median and ulnar nerve lacerations after missile injuries, which can be expected to have a worse prognosis, compared to the most commonly seen sharp cut nerve injuries. ${ }^{12,13}$ It is evident that combined median-ulnar nerve injuries have a poorer functional prognosis in comparison with single nerve injuries. However, despite the functional impairment, ${ }^{14}$ not many data are available on the extent to which combined median-ulnar nerve injuries have a different prognosis.

The main objective of this study was to compare a large population of median, ulnar and combined median-ulnar nerve injuries, according to functional recovery and return to work. Furthermore, we aimed to identify factors influencing the outcome. Early identification of patients at risk of non-return to productivity would be of importance to vocational rehabilitation programs. 


\title{
PATIENTS \& METHODS
}

\author{
Study population
}

We retrospectively collected medical record data of all median and ulnar nerve injury patients (0955.0 according to the International Classification of Diseases, ICD 9) who were operated upon at the University Hospital Rotterdam "Dijkzigt" from January 1980 to December 1997. All forearm nerve injuries were repaired by plastic surgeons specialized in hand surgery. A peripheral nerve injury chart was designed to collect data on demographic information, etiology, diagnosis, treatment, complications, outcome and work status. Over this period, 313 patients were primarily treated for complete or partial median and/ or ulnar nerve injury at a forearm level. In order to participate in this study the forearm nerve injuries were required to meet four entrance criteria. 1) A trauma of at least a single ulnar or median nerve located within the area between the flexor elbow crease (proximal border) and the wrist crease (distal border). 2) Patients had to have been followed for a minimum of three months or have been discharged from our outpatient department within a period of three months with total recovery of the hand function (e.g. neuropraxia). 3) Subjects needed to be functionally tested following valid standard hand assessment methods and 4) had to be evaluated and treated according to our departmental protocol. We excluded any person diagnosed with a non-traumatic compression neuropathy (e.g. carpal tunnel syndrome) or replantation of the forearm or wrist. 220 (70\%) were patients were ultimately included.

\section{Outcome measures}

In order to test whether median, ulnar and combined median-ulnar nerve injuries have different prognosis, we examined return of sensibility, motor recovery, complications and return to work as outcome measures. The reports were reviewed by one person who did not operate on any of the patients in this study and was not involved in the post-operative treatment.

A modified classification of the British Medical Research Council (MRC scale) was used to evaluate and classify sensory and motor recovery. ${ }^{15}$ The final status of motor function and sensory recovery was classified as good, satisfactory, moderate and bad. Sensory recovery was 'good' if grade S3+ or S4 was achieved, 'satisfactory' for grade S3, 'moderate' for grade S2 and 'bad' if grades S0 or $\mathrm{S} 1$ were reached. With regard to evaluation of motor recovery, we considered M4 and M5 as 'good', M3 as 'satisfactory', M2 as 'moderate' and M1 and M0 as 'bad'. Functional recovery was considered as 'useful' when 'good' or 'satisfactory' scores were reached. Tinel sign, electrodiagnostic testing, Semmes Weinstein monofilaments and two-point discrimination were used to evaluate progress of nerve regeneration. The first sign of sensory reinnervation was defined as the time between the date of nerve repair and any improvement of sensibility. Ability to return to the pre-injury employer was classified as Return To Work (RTW). Retraining was not taken in consideration. 
Statistical methods

Complete information on motor recovery, sensory recovery and return to work (RTW) was available for 220 patients. Student $t$-tests were used to compare continuous variables and chi-square tests to compare categorical data. Sensory recovery and motor recovery were categorized as "good, satisfactory, moderate and bad" and RTW as "yes or no". Thirteen patients were excluded from the analysis on return to work: these patients were either below the age of 16 years or above the age of 65 years on the day of injury. Differences in motor and sensory recovery between median, ulnar and combined median-ulnar nerve injuries were obtained with analysis of covariance (ANCOVA), controlling for age. Differences in RTW according to the type of injury and possible prognostic factors were examined with logistic regression analysis with RTW as dependent variable and type of injury and prognostic factors as independent variables. The obtained odds ratios (OR) can be regarded as an estimation of the relative risk (RR). Sex, age and severity of the trauma were added to the model as potential confounding factors. All tests were two sided and a p-value of less than .05 was considered statistically significant. Data analyses were performed using SPSS statistical software.

\section{RESULTS}

Patient characteristics for the included and excluded study groups are displayed in table 1. Age and male-female ratio did not differ significantly and severity of the injury and the distribution of injured nerve were comparable between both groups. The study population, 174 men and 46 women (ratio 3.8:1), were aged between 5 and 73 years with an average age of 31.4 years (SD 13.7). A single median nerve injury was diagnosed in 105 patients, a single ulnar nerve injury in 72 and a combined median-ulnar nerve injury in 43 patients. In 125 cases (57\%) the dominant hand was affected and three patients had both arms injured. One hundred and four (64\%) patients received surgery within 24 hours of the trauma (median 5.0 hours) and 64 (29\%) patients had a delay of over 24 hours (median 1.0 day). Exact delay could not be calculated for $7 \%$ of the subjects because time of injury occurrence was not noted. The study population was followed for an average of 17.7 months (SD 22.5 and range between 1.2 months - 14.4 years).

Activity in and around the home environment was the major cause of injury (41\%), followed by work related (21\%) and night-live (14\%) activities. Another frequently observed injury cause was attempted suicide (10\%). The most frequent mechanisms of injury were accidental glass laceration (62\%), knife wounds (16\%) and mechanical cause (10\%).

Functional outcome

In 199 subjects (90\%) tendon, bone or vascular damage complicated the upper extremity nerve injury. A difference was seen in the distribution of the associated injured structures (figure 1). There were on average 5.5 separate $(S D=3.3)$ anatomical structures involved in cases where 
Table 1. Characteristics of included $(n=220)$ and excluded subjects $(n=93)$.

\begin{tabular}{|c|c|c|}
\hline Characteristic & $\begin{array}{l}\text { Included } \\
(\mathrm{n}=\mathbf{2 2 0})\end{array}$ & $\begin{array}{l}\text { Excluded } \\
(n=93)\end{array}$ \\
\hline \multicolumn{3}{|l|}{ Age } \\
\hline Mean \pm SD & $31.4 \pm 13,7$ & $29.7 \pm 13.4$ \\
\hline Range & $5-73$ & $5-70$ \\
\hline \multicolumn{3}{|l|}{$\operatorname{Sex}(\%)$} \\
\hline Male & $174(79)$ & $76(82)$ \\
\hline Female & $46(21)$ & $17(18)$ \\
\hline \multicolumn{3}{|l|}{ Type of injury (\%) } \\
\hline Median & $105(48)$ & $49(53)$ \\
\hline Ulnar & $72(33)$ & $30(32)$ \\
\hline Combined & $43(20)$ & $11(12)$ \\
\hline Unknown & $0(0)$ & 3 (3) \\
\hline \multicolumn{3}{|c|}{ Dominant hand affected } \\
\hline Yes (\%) & $125(57)$ & $27(29)$ \\
\hline Unknown (\%) & $0(0)$ & $46(49)$ \\
\hline \multicolumn{3}{|l|}{ Causation (\%) } \\
\hline Glass & $137(62)$ & $46(49)$ \\
\hline Knife & $35(16)$ & $25(27)$ \\
\hline Mechanical & $21(10)$ & 8 (9) \\
\hline Other & $22(10)$ & $9(10)$ \\
\hline Unknown & $5(2)$ & $5(5)$ \\
\hline \multicolumn{3}{|c|}{ Follow-up (months) } \\
\hline Mean \pm SD & $17.7 \pm 22.5$ & $1.7 \pm 2.2$ \\
\hline Range & $1.2-172.4$ & $0-13.2$ \\
\hline \multicolumn{3}{|c|}{ Structures affected } \\
\hline Mean \pm SD & $5.9 \pm 3.7$ & $5.2 \pm 3.9$ \\
\hline Range & $1-16$ & $1-18$ \\
\hline \multicolumn{3}{|l|}{ Lesion (\%) } \\
\hline Sharp & $181(82)$ & $79(85)$ \\
\hline Crush & $21(10)$ & $8(9)$ \\
\hline Avulsion & $15(7)$ & 4 (4) \\
\hline Unknown & $3(1)$ & $2(2)$ \\
\hline
\end{tabular}

$\mathrm{SD}=$ Standard deviation.

the median nerve was injured, $5.0(S D=3.3)$ in the case of the ulnar and $8.4(S D=4.1)$ in the combined median-ulnar cases $(p<.0001$ compared with single median and single ulnar nerve injuries).

Sensory and motor recovery scores of the patient group are presented in table 2. Good sensory and motor recovery was achieved in $20.9 \%$ and $49.1 \%$, respectively. Sensory recovery in these series of forearm nerve injuries was useful in $62 \%$ of the median cases and $59 \%$ of the ulnar cases $(p=.71)$. The combined median-ulnar nerve injuries tended to achieve worse sensory outcome, $55 \%$ of the combined injuries reached useful sensory recovery ( $p=.39$ vs. median and $p=.61$ vs. ulnar). The first sign of sensory reinnervation was seen on average at 4.0 months ( $S D=2.6)$ in case the median nerve was injured and 3.2 months $(S D=2.3)$ for ulnar nerve injuries $(p=.09)$. 
Figure 1. Distribution of associated injured anatomical structures.

A. Median nerve injury $(\mathrm{n}=105)$

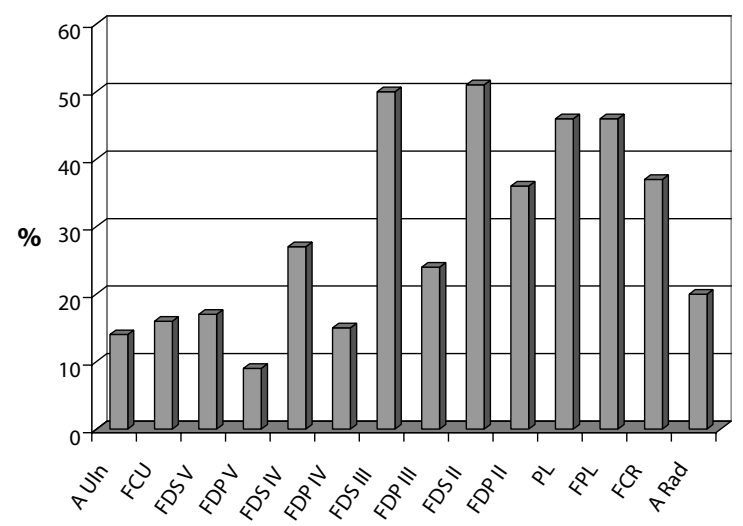

B. Ulnar nerve injury $(n=72)$

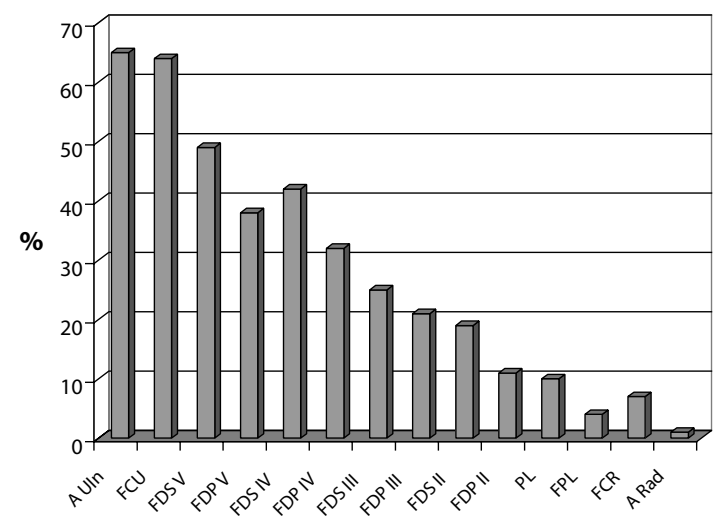

C. Combined nerve injury $(n=43)$

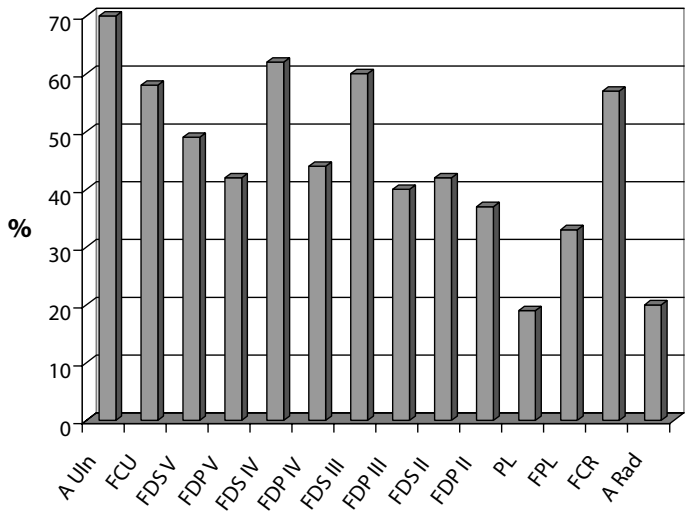

Abbreviations

A. Uln = Ulnar artery; FCU = Flexor Carpi Ulnaris; FDS = Flexor Digitorum Superficialis; FDP = Flexor Digitorum Profundus; FPL = Flexor Policis Longus; $\mathrm{PL}=$ Palmaris Longus; $\mathrm{A}$. Rad $=$ Radial artery 
Table 2. Functional outcome, adjusted for age, according the affected nerve.

\begin{tabular}{|c|c|c|c|}
\hline & $\begin{array}{l}\text { Median } \\
(n=105)\end{array}$ & $\begin{array}{l}\text { Ulnar } \\
(n=72)\end{array}$ & $\begin{array}{l}\text { Combined } \\
(n=43)\end{array}$ \\
\hline \multicolumn{4}{|c|}{ Sensory recovery (\%) } \\
\hline Good & $25.7 \%$ & $21.7 \%$ & $11.9 \%$ \\
\hline Satisfactory & $36.6 \%$ & $37.7 \%$ & $42.9 \%$ \\
\hline Moderate & $24.8 \%$ & $26.1 \%$ & $40.5 \%$ \\
\hline Bad & $12.9 \%$ & $14.5 \%$ & $4.8 \%$ \\
\hline Useful $^{\dagger}$ & $62.3 \%$ & $59.4 \%$ & $54.8 \%$ \\
\hline \multicolumn{4}{|c|}{ Sensory reinnervation } \\
\hline In months $\pm S D$ & $4.0 \pm 2.6$ & $3.2 \pm 2.3$ & $5.5 \pm 7.3^{*}$ \\
\hline \multicolumn{4}{|c|}{ Motor recovery (\%) } \\
\hline Good & $61.5 \%$ & $39.4 \%$ & $38.1 \%$ \\
\hline Satisfactory & $22.1 \%$ & $45.1 \%$ & $31.0 \%$ \\
\hline Moderate & $13.5 \%$ & $14.1 \%$ & $28.6 \%$ \\
\hline Bad & $2.9 \%$ & $1.4 \%$ & $2.4 \%$ \\
\hline Useful $^{\dagger}$ & $83.6 \%$ & $84.5 \%$ & $69.1 \% *$ \\
\hline
\end{tabular}

${ }^{*} \mathrm{p}<.05$ for difference with single median or single ulnar nerve injury. Differences between the combined and single nerve injuries were only calculated for useful recovery.

${ }^{+}$Useful includes good + satisfactory recovery.

Sensory reinnervation of a combined median-ulnar nerve injury appeared later (mean 5.5 months, $S D=7.3)$ compared to single ulnar nerve injury $(p=.03)$ and the median nerve injury $(p=.08)$. All three types of nerve injury showed better final outcome scores for motor recovery in comparison with sensory recovery $(p=.015)$. Useful motor recovery was reached in $84 \%$ for lacerated median nerves and in $85 \%$ for ulnar nerve lacerations $(p=.885)$. When comparing the group of good median motor recovery with the good ulnar recovery, ulnar motor function was poorer $(p=.004)$. The combined median-ulnar nerve injuries ended in poorer motor recovery (69\% useful) compared to the single nerve injuries (median $p=.044$ and ulnar $p=.044$ ).

Multiple linear regression analysis, after adjusting for age, sex, and severity of the trauma, revealed a relation between appearance of sensory reinnervation and motor recovery (Beta coefficient $=.24,95 \% \mathrm{Cl}$ : .008- .04 and $\mathrm{p}=.02$ ). No relation was found between appearance of sensory reinnervation and sensory recovery (Beta coefficient $=.06,95 \% \mathrm{Cl}:-.016-.035$ and $p=.45)$.

\section{Social consequences}

Fifty-two (24\%) subjects were unable to return to their former employer at the end of the followup (mean: 17,7 months). Analysis indicated a possible difference between type of nerve injury and return to work (RTW) potential, suggesting that combined median-ulnar nerve injuries (71\% RTW) have poorer prospects (75\% median and $81 \%$ ulnar). However, after adjustment for age, sex and number of severed structures, the association between type of injury and RTW was not statistical significant $(p=.47)$. 
Table 3. Age and sex adjusted odds ratios (95\% confidence intervals) for inability to return to work (RTW).

\begin{tabular}{llll}
\hline Prognostic Factors & OR & $\mathbf{9 5 \%} \mathbf{C l}$ & p-value \\
\hline Combined vs. single & 1.27 & $0.56-2.87$ & .56 \\
Poor sensory recovery & 2.94 & $1.50-5.76$ & .002 \\
Poor motor recovery & 2.85 & $1.33-6.08$ & .007 \\
Proximal vs. distal & 2.55 & $1.25-5.21$ & .011 \\
Dominant hand & 1.12 & $0.46-2.72$ & .80 \\
Structure nr. (1-16) & 1.05 & $0.95-1.13$ & .47 \\
Manual labors vs. others & 3.06 & $1.50-6.22$ & .002 \\
Nr. Sensory complications & 1.75 & $1.28-2.38$ & $<.001$ \\
(0-9) & & & $<.001$ \\
Nr. Motor complications & 1.49 & $1.18-1.88$ & .001 \\
(0-8) & & & \\
Handtherapy & 0.24 & $0.10-0.56$ & \\
\hline OR= odds ratio & & & \\
(I= confidence interval & & &
\end{tabular}

Table 3 shows the risk of inability to return to work according to a number of prognostic factors. Poor sensory recovery and poor motor recovery increased the risk of incapacity for work $(\mathrm{OR}=2.94,95 \% \mathrm{Cl}: 1.50-5.76$ and $\mathrm{OR}=2.85,95 \% \mathrm{Cl}: 1.33-6.08$, respectively). Subjects with a more proximally located nerve laceration had less chance of returning to their former employer $(p=.01)$. Surprisingly, dominance of the hand showed not to be associated with the return to work potential $(p=.80)$. On the other hand, type of work was significantly associated with loss of employment $(p<0.001)$. Manual labors appeared to be at higher risk of being unable to return to their former employer (OR=3.1,95\%Cl: $1.5-6.2)$.

In 178 subjects ( $81 \%)$ at least one forearm nerve injury related complication was noted. No association was found between type of injury and number of complications $(p=.52)$. However, the number of sensory and motor complications, related to a nerve injury, was associated with work disability $(<.001$ and $<.001$, respectively). The following complications were significant predictors of work disability: Atrophy of thenar muscles $(p=.04)$, diminished gripforce of abductor pollicis brevis $(p=.002)$, clawing $(p<.001)$, cold intolerance $(p=.001)$ and paresthesia $(p=.04)$. Postoperative hand therapy, focussed on sensory relearning, muscle strength and coordination, reduced the risk of work disability $(\mathrm{OR}=.24,95 \% \mathrm{Cl}: 0.10-0.56)$.

\section{DISCUSSION}

This study indicates that nerve injuries at forearm or wrist level can cause functional loss and have major social consequences. Twenty-one percent of the study-population achieved good sensory recovery. Good motor recovery occurred in forty-nine percent. In comparison with the single nerve injuries, combined median-ulnar nerve injuries had worse prospects. Combined median-ulnar nerve injuries resulted in worse motor recovery. Time between laceration of 
the nerve and the first sign of sensory reinnervation seemed to be a good predictor for final motor recovery. Twenty-four percent could not return to their former employer after an average follow-up of one and a half years. No difference in return to work (RTW) potential was found for the three types of nerve injury. Poor motor and sensory recovery were associated with lower chances of employment. Furthermore, return to work was related to type of work, level of the injury, a number of complications and post-operative hand therapy.

It is known that upper extremity injury is the most common type of work trauma and therefore of major importance from a public health point of view. ${ }^{2}$ One of the principal clinical problems following a nerve injury, is the uncertainty concerning functional recovery. Reinnervation following nerve injuries at wrist and forearm level is often incomplete and causes a long period of suspense. In most of the forearm nerve injuries two years may not be sufficient for adequate motor recovery and sensory reinnervation. ${ }^{16,17}$ Based on our results, the time until first sign of sensory reinnervation was noticed, seemed to be a good predictor for final motor recovery. Therefore, patients at risk of poor motor recovery can be distinguished by regular assessment of sensory reinnervation within the first five months. Additionally, early identification of poor recovery is essential to achieve best benefit of secondary procedures, i.e. tendon transfers and nerve grafts.

Many different reporting methods, scoring systems and evaluation techniques are being used to quantify sensory and motor recovery following upper extremity nerve injuries. ${ }^{18}$ Comparison with earlier contributions dealing with functional outcome $e^{4,7,9,13,19,20}$, is therefore difficult. Although it is generally accepted that ulnar nerve injuries result in poorer motor function and less sensory recovery, ${ }^{21}$ this study revealed no statistical differences between median and ulnar nerve injuries. With respect to the proportion of subjects with good recovery, patients with ulnar nerve injuries achieved good recovery less often. Combined median-ulnar nerve injuries can end in a much worse functional condition, clawing of all the fingers and a totally paralyzed hand. ${ }^{22}$ Chin and co-authors suggested that trauma of median, ulnar, or a combination determines overall functional outcome. ${ }^{8}$ Our study showed a difference in motor recovery between the combined nerve injuries and single nerve injuries.

Seventy-six percent of the study-population was able to restart work after a mean follow-up of 18 months. Depending on the length of follow-up and severity of the injury, reemployment of trauma patients ranges from low $57 \% \%^{12,23}$ to high $82 \%{ }^{24,25}$. After one year, $58 \%$ were employed full-time following injury to one or more extremities. ${ }^{26}$ The ability to restart work was found to be associated with motor and sensory recovery. Surprisingly, despite differences in motor recovery, the ability to restart work did not differ between single and combined nerve injuries. Studies that focussed on factors associated with delayed return to work concluded that correlation between physical impairment and the rate of RTW is weak. ${ }^{27,28}$ Furthermore, it has been stated that severity of the injury does not predict return to productivity. ${ }^{29}$ On the other hand, the relationship between motor recovery and regeneration time suggests that time off work will vary between the different groups. Prospective extension is needed to obtain more 
precise information about socio-economic losses in terms of lost work-days and restricted work activity.

Outcome studies on functional recovery have shown that occupational therapy plays a major role in the recovery and rehabilitation of forearm nerve injury patients. ${ }^{10,26}$ Re-education of sensory function was found to have a positive influence on functional results. ${ }^{30}$ It may be concluded from this study that retraining programs also have a positive effect on successful return to work. Since motivation could not be measured from our data, we could not exclude this factor to be responsible for the association.

Although this study was based on retrospective medical record data, the results provide comparative information for three different types of forearm nerve injury. Our results confirm and extend the findings that volar nerve injuries at wrist and forearm level have dramatic prospects and can be placed among the severe disabling injuries. ${ }^{12,29,31,32}$ With regard to the upper extremity, only traumatic amputations tend to be associated with longer times off work and a lower percentage of successful return to work. ${ }^{33}$ The majority of upper extremity trauma affects young people and will make long-term claims on social services. Knowledge of contributing factors for adverse return to work potential could therefore be of significant health care importance. These factors can be taken in consideration for rehabilitation programs to prevent continued work disability and to improve the efficacy of vocational rehabilitation services. 


\section{REFERENCES}

1. O'Sullivan ME, Colville J. The economic impact of hand injuries. J Hand Surg [Br]. 1993; 18:395-398.

2. Kelsey J, Praemer A, Nelson L, Felberg A, Rice D. Upper extremity disorders: Frequency impact and cost. In: Kelsey J, Praemer A, Nelson L, Felberg A, Rice D, eds. New York: Churchill Livingstone, 1997.

3. McAllister R, Gilbert S, Calder J, Smith P. The epidemiology and management of upper limb peripheral nerve injuries in modern practice. J Hand Surg [Br]. 1996; 21:4-13.

4. Noble J, Munro CA, Prasad VS, Midha R. Analysis of upper and lower extremity peripheral nerve injuries in a population of patients with multiple injuries. Journal Of Trauma. 1998; 45:116-122.

5. Bristow W. Injuries of peripheral nerves in two World Wars. British Journal of Surgery. 1947; 34: $333-348$.

6. Woodhall B, Beebe G. Peripheral nerve regeneration: A follow-up study of 3,656 world war II injuries. Veterans administration medical monograph. Washington DC, US GPO; 1956.

7. Posch J, Cruz-Saddul Fdl. Nerve repair in trauma surgery: A ten-year study of 231 peripheral injuries. Orthopaedic Review. 1980; 9:35-45.

8. Chin G, Weinzweig N, Mead M, Gonzalez M. "Spaghetti wrist": management and results. Plast Reconstr Surg. 1998; 102:96-102.

9. Merle M, Amend P, Cour C, Foucher G, Michon J. Microsurgical repair of peripheral nerve lesions: A study of 150 injuries of the median and ulnar nerves. Peripheral Nerve Repair. 1986; 2:17-26.

10. Puckett $\mathrm{CL}$, Meyer $\mathrm{VH}$. Results of treatment of extensive volar wrist lacerations: the spaghetti wrist. Plast Reconstr Surg. 1985; 75:714-721.

11. Tate DG. Workers' disability and return to work. American Journal Of Physical Medicine And Rehabilitation. 1992; 71:92-96.

12. Taha A, Taha J. Results of suture of the radial, median, and ulnar nerves after missile injury below the axilla. Journal Of Trauma. 1998; 45:335-339.

13. Mackinnon S, Dellon A. Results of nerve repair and grafting. In: Mackinnon S, Dellon A, eds. Surgery of the peripheral nerve. New York: Thieme Medical Publishers, Inc; 1988:115-129.

14. Rogers G, Henshall A, Sach R, Wallis K. Simultaneous laceration of the median and ulnar nerves with flexor tendons at the wrist. J Hand Surg [Am]. 1990; 15:990-995.

15. (MRC) MRC. Results of nerve suture. In: Seddon H, ed. Peripheral nerve injuries. London: Her Majesty's Stationer Office, 1954.

16. Birch R, Raji A. Repair of median and ulnar nerves. Primary suture is best. J Bone Joint Surg [Br]. 1991; 73:154- 157.

17. Trevett MC, Tuson C, de Jager LT, Juon JM. The functional results of ulnar nerve repair. Defining the indications for tendon transfer. J Hand Surg [Br]. 1995; 20:444-446.

18. Rosen B. Recovery of sensory and motor function after nerve repair. A rationale for evaluation. $J$ Hand Ther. 1996; 9:315-327.

19. Kallio P, Vastamaki M. An analysis of the results of late reconstruction of 132 median nerves. $J$ Hand Surg [Br]. 1993; 18:97-105.

20. Vastamaki M, Kallio $\mathrm{P}$, Solonen $\mathrm{K}$. The results of secondary microsurgical repair of ulnar nerve injury. J Hand Surg [Br]. 1993; 18:323-326.

21. Kline D, Hudson A. Nerve Injuries: Operative Results from Major Nerve Injuries, Entrapments and Tumors. In: Kline D, Hudson A, eds. Philadelphia: WB Saunders Company, 1995.

22. Widgerow A. Full-house/spaghetti wrist injuries. Analysis of results. S Afr J Surg. 1990; 28:6-10.

23. MacKenzie EJ, Siegel JH, Shapiro S, Moody M, Smith RT. Functional recovery and medical costs of trauma: an analysis by type and severity of injury. Journal Of Trauma. 1988; 28:281 - 297.

24. Kivioja AH, Myllynen PJ, Rokkanen PU. Is the treatment of the most severe multiply injured patients worth the effort? A follow-up examination 5 to 20 years after severe multiple injury. Journal Of Trauma. 1990; 30:480-483.

25. Glinz W, Affentranger T. The fate of patients with severe multiple injuries, 5 years after intensive care. Bulletin De La Societe Internationale De Chirurgie. 1975; 34:545-548.

26. MacKenzie EJ, Shapiro S, Smith RT, Siegel JH, Moody M, Pitt A. Factors influencing return to work following hospitalization for traumatic injury. American Journal Of Public Health. 1987; 77:329-334. 
27. Crook J, Moldofsky H, Shannon H. Determinants of disability after a work related musculetal injury [see comments]. Journal Of Rheumatology. 1998; 25:1570-1577.

28. MacKenzie EJ, Morris JA Jr, Jurkovich GJ, et al. Return to work following injury: the role of economic, social, and job-related factors. American Journal Of Public Health. 1998; 88:1630 - 1637.

29. Morris JA Jr, Sanchez AA, Bass SM, MacKenzie EJ. Trauma patients return to productivity. Journal Of Trauma. 1991; 31:827-833.

30. Parry CB, Salter M. Sensory re-education after median nerve lesions. Hand. 1976; 8:250-257.

31. Stefanich RJ, Putnam MD, Peimer CA, Sherwin FS. Flexor tendon lacerations in zone V. J Hand Surg [Am]. 1992; 17:284-291.

32. Brenneman FD, Redelmeier DA, Boulanger BR, McLellan BA, Culhane JP. Long-term outcomes in blunt trauma: who goes back to work? Journal Of Trauma. 1997; 42:778-781.

33. Johns A. Time off work after hand injury. Injury. 1981; 12:417-424. 


\section{CHAPTER 3}

\section{"SPAGHETTI WRIST" TRAUMA: FUNCTIONAL RECOVERY,}

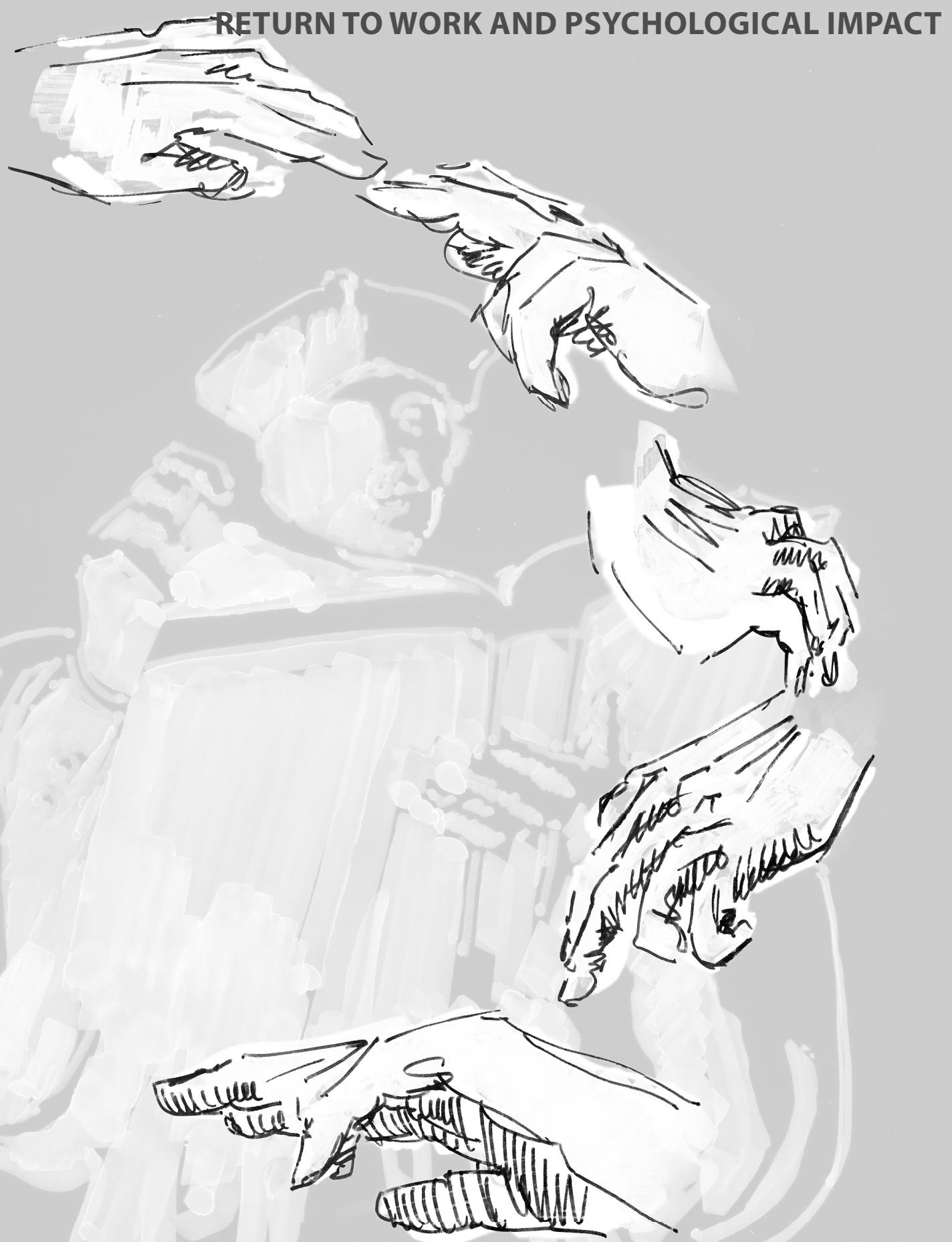

Jaquet J. B., van der Jagt, I., Kuypers P.D. L., Schreuders, T. A. R., Kalmijn S. and Hovius S. E. R. Accepted Plastic and Reconstructive Surgery. 



\section{ABSTRACT}

Introduction - Few studies on spaghetti wrist trauma have been published. The study populations all consisted of small numbers of patients and most studies focused on functional recovery. In addition, different definitions of this injury were used.

Objective - To assess outcome for a larger group of patients in terms of functional recovery, return to work potential and psychological distress, and to compare outcome between the two most commonly used definitions for spaghetti wrist injury.

Methods - The initial study-population consisted of 67 patients. Fifty patients completed a questionnaire-package consisting of the DASH (Disabilities of Arm, Shoulder and Hand, including the Functional Symptom Score (FSS, range 0-100)), a questionnaire to evaluate Return To Work (RTW) and Time Off Work (TOW, range 0-52) and the Impact of Event Scale (IES, range 0 - 75). Motor and sensory recovery were assessed in an outpatient setting, on average 10 years (range 2 - 18 ) following surgery $(n=43)$.

Results - Mean Functional Symptom Score was 15.1 (SD 16.1; range 0-74) after a mean followup of 10.0 years (SD 4.4; range 2-18). Mean TOW was 34.7 weeks (SD 17.9; range 4-52) and $45.2 \%$ of the patients could not return to work within one year following the injury. Mean score on the IES was 26.2 (SD 19.7; range 2-69). Compared to the unaffected hand, grip and tip pinch strength were decreased with means of $23.5 \%$ (SD 22.4; range 0 - 93) and 33.9\% (SD 23.7; range $0-83$ ), respectively. Regarding sensory recovery, 12 patients (27.9\%) had no protective sensation. No statistical differences were found between the two different definitions.

Conclusions - This study demonstrated that spaghetti wrist injury can be placed among the severe disabling injuries. Comparison of the two definitions did not reveal any differences in outcome. To complete the evaluation of long-term outcome, a patient-derived assessment of function can be added to the clinical examination, and attention should be paid to psychological distress following the injury. 


\section{INTRODUCTION}

At the volar side of the wrist, 16 structures including 12 tendons, 2 nerves and 2 arteries are located just beneath the skin, and are therefore vulnerable to injury. The 'Spaghetti wrist' or'fullhouse' injury describes an extensive volar wrist laceration, in which several of these structures are injured.

Besides amputation, combined injury of nerves, flexor tendons and arteries at wrist level, may be the most traumatizing injury to the forearm. Nerve injury causes loss of motor and sensory functions of the hand. Diminished grip strength, imbalance of hand movements due to loss of intrinsic muscle functions and loss of sensation in some or all fingers, leaves the hand as a non-functional tool. Laceration of several flexor tendons can lead to extensive scar tissue formation, resulting in elimination of differential gliding of the tendons. ${ }^{1}$

Despite the devastating nature of spaghetti wrist injury, little attention has been paid to this extensive wrist trauma. ${ }^{2-6}$ Various definitions have been used ranging from a relatively minor injury of three lacerated structures, including injuries without nerve-laceration, to a major trauma with laceration of at least ten structures including the median and/or ulnar nerve. Therefore, comparison of these studies is difficult. In addition, numbers of patients reported are small and all studies focused on functional outcome, e.g. motor and sensory recovery. Little attention was paid to the impact of a spaghetti wrist trauma on employment and to posttraumatic psychological stress.

The main objective of this study was to assess long-term outcome following spaghetti wrist injury for a large group of patients. Apart from evaluation of motor and sensory recovery, attention was paid to performance of activities of daily living, ability to return to work, and the psychological impact of a spaghetti wrist trauma. Furthermore this study aimed to compare the two most commonly used definitions for spaghetti wrist injury, by means of statistical analysis of long-term outcome applying these two different definitions.

\section{PATIENTS AND METHODS}

Study population

Records of patients with peripheral nerve injury of the upper extremity, operated on between January 1980 and December 1998 at the Erasmus MC, University Medical Center Rotterdam, were reviewed $(n=313)$. The inclusion criterion for spaghetti wrist injury was defined as: an injury at wrist level, located between the distal wrist crease and the flexor musculotendineous junctions (zone 5), which met one or both of the following definitions. Definition 1: Simultaneous laceration of both the median and ulnar nerves with flexor tendons at the wrist., ${ }^{3,4}$ Definition 2: At least 10 divided structures including the median and/or ulnar nerve., ${ }^{5,7}$ 
Table 1. Summary of the injuries $(n=67)$

\begin{tabular}{lccc}
\hline & Median & Ulnar & Combined \\
\hline Total of severed structures & $11.7 \pm 1.4$ & $10.7 \pm 0.8$ & $10.6 \pm 3.7$ \\
Total of severed tendons & $9.9 \pm 1.1$ & $8.7 \pm 0.8$ & $8.3 \pm 3.0$ \\
Artery & & & \\
$\quad$ ulnar & $3(17.6 \%)$ & $7(100 \%)$ & $31(68.9 \%)$ \\
radial & $4(23.5 \%)$ & $0(0 \%)$ & $0(0 \%)$ \\
$\quad$ radial-ulnar & $3(17.6 \%)$ & $0(0 \%)$ & $6(13.3 \%)$ \\
Definition & & & \\
1 & 0 & 0 & 16 \\
2 & 17 & 7 & 0 \\
$1 \& 2$ & 0 & 0 & 29 \\
\hline
\end{tabular}

definition $1=$ combined median and ulnar nerve injury

definition $2=$ minimum of 10 lacerated structures including at least one major nerve

Patients with associated hand fractures or amputation of hand or fingers were excluded. Finally, according to these criteria 67 patients were included in the study (69 cases, two patients injured both arms. A summary of injuries is listed in table 1.

To trace these patients hospital medical records, general practitioners and municipal archives were consulted. A questionnaire package was sent to patients of whom the address could be retrieved $(n=60)$. Three follow-up mailings were sent to non-responders in two-month intervals. Fifty (50) patients returned the questionnaires. Ten patients rejected participation. The remaining seven patients were untraceable (four had moved abroad, one had died without any relation to the surgery and two were not known by municipal records). All responders were invited to our hospital for a visit in an outpatient setting to assess motor and sensory recovery. Patients unable to come to our hospital, were visited at home. Seven patients rejected this invitation.

The investigators had not been involved in the patients surgery or treatment following the injury. The protocol of the study was approved by the Medical Ethics Committee of the Erasmus MC, University Medical Center Rotterdam and informed consent was provided by all participants.

\section{Questionnaires}

The questionnaire package consisted of three questionnaires. To assess functioning in daily living, the DASH-questionnaire version 2.0 (May 1997) was used. ${ }^{8,9}$ It was translated according the criteria of the Institute for Work \& Health (IWH) and the American Academy of Orthopedic Surgeons (AAOS). Five translations and two "back translations" by two native speakers were compared, aiming for semantic, idiomatic and conceptual equivalence. Using a self-report system, patients attribute scores of 1 to 5 (Likert scale) on 30 items related to functional activities (such as preparing a meal and writing) and symptoms (such as pain and weakness). The raw Functional Symptom Score (FSS) is then transformed to a 0-100 scale, whereby 0 reflects minimum and 100 maximum disability. 
A questionnaire concerning profession and return to work had been developed by the authors and was applied to examine return to work and time until resumption of work. No distinction was made between returning to the pre-injury job and finding new employment.

The Impact of Event Scale (IES) ${ }^{10}$ was selected to establish psychological impact and posttraumatic psychological stress. Since its introduction in 1979, by Horowitz and co-authors, it is widely used. The Impact of Event Scale, is a 15-item self-report questionnaire that assesses stress-related symptomatology and records patient's subjective responses to the traumatic event. Patients were asked to think of the period until a month following the accident and rate questions such as: "I had trouble falling asleep or staying asleep, because of pictures or thoughts about it that came into my mind", "I tried not to think about it" and "Any reminder brought back feelings about it". Each item has a scoring range of $0-5$ on a 4-point scale $(0=$ not at all, $1=$ rarely, $3=$ sometimes and $5=$ often), with seven items covering intrusive symptoms and eight items avoidance symptoms. Total IES scores range from 0 to 75 (worst score). Following their visit at our outpatient clinic patients were requested to complete the IES again for the current psychological status.

\section{Follow-up review}

During a one-hour session in an outpatient setting, motor and sensory recovery was examined. To assess motor recovery, grip and tip pinch strength were measured using a JAMAR Hydraulic Hand Dynamometer and Hydraulic Pinch Gauge meter (kilograms force, DeRoyal Industries, TN, USA) as described by Mathiowetz. ${ }^{11,12}$ Both the injured and uninjured hand were tested three times. In case the third measurement was the highest, a fourth measurement was performed. All results were noted and the mean was calculated. Results were mapped as percentage loss compared to the unaffected hand with a scoring range of $-100 \%$ to $100 \%$. Corrections for hand dominance were made according to Petersen. ${ }^{13}$

Manual Muscle Strength Tests (MMST) were performed, as described by Brandsma et al. ${ }^{14}$, to evaluate recovery of the intrinsic muscles of the hand. Scores were noted using the Modified Medical Research Council Scale (table 2). ${ }^{14}$ Muscles tested with the MMST were the abductor digiti minimi, the first dorsal interosseous, the abductor pollicis brevis, the opponens pollicis and the dorsal lumbricals/interossei II-IV. In one of the responders nerves of both the left and right arm were injured. No valid reference for motor recovery could be obtained. Therefore, this patient was excluded from analysis concerning motor recovery.

Sensory recovery was tested with Semmes-Weinstein monofilaments (North Coast Medical Inc, CA, USA). The monofilaments (2.83, 3.61, 4.31, 4.56 and 6.10, ranked 1-5) were used according to the procedure described by Bell-Krotosky. ${ }^{15}$ Ten zones in the hand were tested, 6 in the area of the median nerve and 4 in the area of the ulnar nerve. The scores were interpreted as suggested by Imai. ${ }^{16}$ Score 6.10 was interpreted as anesthetic. 
Table 2. Recovery of the intrinsic muscles scored according the Modified Medical Research Council Scale

\begin{tabular}{llll}
\hline Intrinsic muscle recovery & Grade & Range of Movement & Resistance \\
\hline Excellent & 5 & Normal & Normal \\
Good & 4 & Normal & Reduced \\
Fair & 3 & Normal & None \\
Fair & 2 & Reduced & None \\
Poor & 1 & None & Palpable contraction only \\
Failure & 0 & None & No palpable contraction \\
\hline
\end{tabular}

\section{Statistical analysis}

Participants and non-participants were compared, using chi-square analysis for categorical data and $t$-tests for continuous variables, to detect if selection bias had occurred (table 3). In case the expected count of the cells was less than 5 the Fisher's exact test was used. Subjects who attempted suicide $(n=6,12 \%)$ were excluded from analysis concerning the Impact of Event Scale, because they are more likely to have extensive psychological problems pre-existing to injury. To investigate psychological stress following a spaghetti wrist trauma a homogenous population was needed. Most nerve injuries have an accidental cause. Inclusion of the patients who attempted suicide might lead to misinterpretation of the results. In order to compare the two definitions, patients who matched both definitions $(n=29)$ were randomly divided between the two definitions. To check if randomly dividing the patients who met both definitions did not change the results we redid the analysis after exclusion of the patients who fulfilled both definitions. Differences in outcome between the two definitions were examined by the non parametric Mann-Whitney $U$ test for continuous data. Categorical data were analyzed using the chi-square test and if the expected values in one of the cells was less than 5, the Fisher's exact test was used. All tests were performed two-sided and a $p$-value of $<.05$ was considered statistically significant. Data analysis was performed using SPSS statistical software (version 9.0, Real Stats, SPSS Inc., IL, USA).

\section{RESULTS}

\section{Study population}

The study population consisted of 67 patients. A total of 50 patients returned the questionnaires. Table 3 lists patient characteristics for responders and non-responders. No statistical difference was found between the responders and non-responders for gender $(p=1.0)$, age $(p=0.55)$, type of injury $(p=0.36)$, injury of the dominant hand $(p=1.0)$ and time between injury and follow-up $(p=0.21)$. 
Table 3. Patient characteristics of responders and non-responders $(n=67)$

\begin{tabular}{lcc}
\hline & Responders & Non-responders \\
\hline $\begin{array}{l}\text { No. of patients } \\
\text { Gender }\end{array}$ & 50 & 17 \\
male & $42(84.0 \%)$ & $15(88.2 \%)$ \\
female & $8(16.0 \%)$ & $2(11.8 \%)$ \\
Age (years) & & \\
mean \pm SD & $29.1 \pm 12.4$ & $31.2 \pm 13.5$ \\
range & $8-58$ & $18-71$ \\
Type of injury & & \\
glass & $32(64.0 \%)$ & $8(47.1 \%)$ \\
knife & $7(14.0 \%)$ & $6(35.3 \%)$ \\
other & $11(22.0 \%)$ & $3(17.6 \%)$ \\
Environment & & \\
home & $20(40.0 \%)$ & $4(23.5 \%)$ \\
work & $12(24.0 \%)$ & $2(11.8 \%)$ \\
suicide attempt & $6(12.0 \%)$ & $6(35.3 \%)$ \\
other & $12(24.0 \%)$ & $5(29.4 \%)$ \\
dominant hand affected & & \\
yes & $27(54.0 \%)$ & $4(23.5 \%)$ \\
no & $19(38.0 \%)$ & $2(11.8 \%)$ \\
unknown & $4(8.0 \%)$ & $11(64.7 \%)$ \\
Definition & & \\
1 & 34 & 10 \\
2 & 36 & 16 \\
1\&2 & 20 & 9 \\
Time since injury (years) & & $12.7 \pm 5.4$ \\
mean \pm SD & $11.0 \pm 4.4$ & \\
range & $3-19$ & \\
\hline
\end{tabular}

Questionnaires

Mean Functional Symptom Score (FSS) was 15.1 (SD 16.1; range 0 -74), after a mean follow-up of 10 years (range 2-18). Thirty-one patients were employed at the day of injury. Twenty-nine of the subjects (93.5\%) took sick leave, with a mean of 34.7 weeks (SD 17.9; range 4-52) and 14 patients (45.2\%) did not return to work within one year. One month postoperatively, mean score on the Impact of Event Scale (IES) was 26.2 (SD 19.7; range 2-69). Mean IES during followup, on average 10 years after the trauma, was 7.3 (SD 11.2; $p<.001$ ).

\section{Follow-up review}

Forty-three patients were available for follow-up review. One of these patients sustained spaghetti wrist injury to both his left and right arm, therefore the number of injuries is 44 . Regarding grip and tip pinch strength mean losses of $23.5 \%$ (SD 22.4; range -15-93) and 33.9\% (SD 23.7; range -25-83) were found respectively. Results for Manual Muscle Strength Testing (MMST) are listed in table 4. For results of the Semmes Weinstein monofilament testing for sensory recovery see table 5 . 
Table 4. Results for Manual Muscle Strength Testing $(n=43)$

\begin{tabular}{lll}
\hline Muscle & Mean \pm SD & No. of patients recovering grade $\mathbf{4}$ or $\mathbf{5}$ \\
\hline Abductor digiti minimi & $2.8 \pm 1.4$ & $11(30.6 \%)$ \\
First dorsal interosseous & $2.7 \pm 1.5$ & $12(33.3 \%)$ \\
Lumbricals/Interossei & $3.6 \pm 1.2$ & $24(66.6 \%)$ \\
Abductor pollicis brevis & $3.5 \pm 1.6$ & $25(65.8 \%)$ \\
Opponens pollicis & $3.8 \pm 1.3$ & $28(73.7 \%)$ \\
\hline
\end{tabular}

$\mathrm{SD}=$ Standard deviation

Table 5. Results for Semmes Weinstein Testing $(n=43)$

\begin{tabular}{llc}
\hline Quality of sensation & Filament & No. of Patients \\
\hline Normal & 2.83 & 0 \\
Diminished light touch & 3.61 & $5(7.4 \%)$ \\
Diminished protective sensation & 4.31 & $17(25.0 \%)$ \\
Loss of protective sensation & 4.56 & $15(22.1 \%)$ \\
Anesthetic & 6.10 & $7(10.3 \%)$ \\
\hline
\end{tabular}

Comparing two definitions

In tables 6-8 the two definitions are compared for Functional Symptom Score (table 6), Return To Work (table 6), psychological distress (table 6), motor recovery (table 7) and sensory recovery (table 8). Statistical analysis on these results showed no significant differences in outcome between the two definitions. Difference for sensory recovery showed to be borderline statistical significant. Mean grade of sensory recovery for definition 1 and 2 was respectively 3,8 (SD 1.0) and 3.2 (SD 0.9) ( $p=0.07)$. After exclusion of the patients who fulfilled both definitions patients who met definition 2 (median 3.5) had a statistical better outcome for sensory recovery compared to the patients who met definition 1 (median 3.9) $(p=0.03)$. No statistical difference was found between both definitions for the FSS, weeks of sick leave, RTW within one year, the IES, grip strength, tip pinch strength and MMST, after exclusion of the patients who fulfilled both definitions.

\section{DISCUSSION}

This study demonstrated that, despite a mean follow-up of 10 years, spaghetti wrist patients were still functionally impaired in performing certain tasks of daily living. The impact of spaghetti wrist injury on employment is not to be underestimated. Almost half of the studypopulation, employed at the day of injury, could not return to work within one year following the accident. Moderate to severe psychological symptoms (IES > 17) during the first month following the injury, were present in 28 patients (64\%).

Previous studies on spaghetti wrist injury mainly assessed sensory recovery, motor recovery and range of motion in order to evaluate long-term functional outcome. ${ }^{2-6}$ Although these three 
Table 6. Comparing two definitions; questionnaires $(n=50)$

\begin{tabular}{|c|c|c|c|}
\hline & Definition 1 & Definition 2 & Statistics \\
\hline \multicolumn{4}{|l|}{ No. of questionnaires } \\
\hline returned & 24 & 26 & \\
\hline \multicolumn{4}{|l|}{ FSS } \\
\hline mean $\pm S D$ & $16.9 \pm 17.7$ & $13.5 \pm 14.5$ & $p=0.39$ \\
\hline range & $1-74$ & $0-53$ & \\
\hline \multicolumn{4}{|l|}{ Employment } \\
\hline no. of workers & $17(70.8 \%)$ & $14(53.8 \%)$ & \\
\hline \multicolumn{4}{|l|}{ weeks of sick leave: } \\
\hline mean $\pm S D$ & $36.4 \pm 18.8$ & $32.8 \pm 17.5$ & $p=0.54$ \\
\hline range(min. 0; max. 52) & $4-52$ & $10-52$ & \\
\hline RTW within one year & $8(47.1 \%)$ & $9(64.3 \%)$ & \\
\hline No RTW within one year & $9(52.9 \%)$ & $5(35.7 \%)$ & $p=0.34$ \\
\hline \multicolumn{4}{|l|}{ Impact of Event Scale } \\
\hline mean $\pm S D$ a & $26.5 \pm 20.7$ & $28.9 \pm 21.6$ & $p=0.69$ \\
\hline range $^{a}$ & 4-71 & $2-75$ & \\
\hline
\end{tabular}

Table 7. Comparing two definitions; motor recovery $(n=43)$

\begin{tabular}{llcc}
\hline & Definition 1 & Definition 2 & Statistics \\
\hline $\begin{array}{l}\text { No. of patients } \\
\text { Grip strength a }\end{array}$ & 22 & 21 & \\
$\quad$ mean \pm SD & $26.0 \pm 26.1$ & $20.7 \pm 17.5$ & $\mathrm{p}=0.56$ \\
$\quad$ range & $-15-93$ & $-2-59$ & \\
Tip pinch strength a & & & \\
$\quad$ mean \pm SD & $36.9 \pm 27.2$ & $30.5 \pm 19.0$ & $\mathrm{p}=0.23$ \\
range & $-25-83$ & $0-75$ & \\
MMST (mean \pm SD) & & & \\
$\quad$ Abductor digiti minimi & $3.0 \pm 1.5$ & $2.6 \pm 1.3$ & $\mathrm{p}=0.22$ \\
$\quad$ First dorsal interosseous & $2.9 \pm 1.6$ & $2.5 \pm 1.3$ & $\mathrm{p}=0.46$ \\
$\quad$ Lumbricals/introssei & $3.5 \pm 1.3$ & $3.9 \pm 1.0$ & $\mathrm{p}=0.92$ \\
$\quad$ Abductor pollicis brevis & $3.3 \pm 1.8$ & $3.8 \pm 1.3$ & $\mathrm{p}=0.41$ \\
$\quad$ Opponens pollicis & $3.5 \pm 1.5$ & $4.1 \pm 1.0$ & $\mathrm{p}=0.21$ \\
\hline
\end{tabular}

a percentage loss compared to the non-affected hand

factors can all limit a patient in the performance of certain activities of daily living, none of these studies collected data about the patient's daily functioning. The DASH-questionnaire provides an easy and valid method to evaluate functional impairment in daily living. ${ }^{17}$ The DASH can detect and differentiate small and large changes of disability over time after surgery. ${ }^{18}$ Recently population-based norms for the DASH have been collected and an significant association between the severity of the injury and the FSS was described. ${ }^{19,20}$ Quality of motor and sensory recovery following upper extremity nerve injuries are related to the FSS. ${ }^{21}$ Findings in this study indicated that spaghetti wrist injury has a long-lasting high impact on performance of daily 
Table 8. Comparing two definitions; sensory recovery $(n=43)$

\begin{tabular}{llll}
\hline & Grade & Definition 1 & Definition 2 \\
\hline Semmes-Weinstein & & & \\
$\quad$ Normal (2.83) & 1 & $0(0.0 \%)$ & $0(0.0 \%)$ \\
Diminished light touch (3.61) & 2 & $2(9.1 \%)$ & $3(13.6 \%)$ \\
Diminished protective sensation (4.31) & 3 & $8(36.4 \%)$ & $9(40.9 \%)$ \\
Loss of protective sensation (4.56) & 4 & $8(36.4 \%)$ & $7(31.8 \%)$ \\
Anesthetic (6.10) & 5 & $4(18.2 \%)$ & $3(13.6 \%)$ \\
\hline
\end{tabular}

$p=0.07$

living activities. Only two patients (4.0\%) were not disabled in daily living functioning (FSS =0), after a mean follow-up of ten years. For example one of our patients with a FSS of 15 complained of moderate difficulties with writing, mild difficulties preparing a meal, severe problems with recreational activities in which the arm is moved freely and having moderate stiffness, tingling and/or weakness in arm shoulder or hand. Since the introduction of the DASH-questionnaire in 1996, an increasing amount of studies used the FSS to evaluate functional disability. Functional symptom scores varied between 2 for proximal phalanx fractures and 52 for distal biceps rupture. ${ }^{22,23}$ Variation of the FSS is caused by difference in severity of injury and length of follow-up. On average 5.5 years following the operation combined median-ulnar nerve injuries reported a mean FSS of $24 .{ }^{21}$ Comparative FSS for other hand injuries are: a ray amputation: 29 (follow-up 32 months) ${ }^{24}$ and for a scaphoid fracture: 13 (follow-up 66 months) ${ }^{25}$ Besides evaluation of motor and sensory recovery by a physician, the inclusion of a patient-completed questionnaire concerning daily living functioning can be an easy method to optimize the evaluation of short- and long-term functional recovery following nerve injury. In addition, this could facilitate comparison of results between studies. ${ }^{26}$

Return to productivity is becoming an issue of growing national concern for economic reasons. ${ }^{27}$ Many studies reported on return to work following trauma or illness., ${ }^{47-31}$ Despite the suggestion that extremity injuries disproportionately contribute to long-term disability ${ }^{27-31}$, return to productivity has been underexposed in the previous studies on spaghetti wrist injuries. Rogers et al. ${ }^{4}$ reported an $87.5 \%$ return to work-ratio among patients with combined median and ulnar nerve injuries. Taha and Taha ${ }^{29}$ reported a $0 \%$ return to work ratio among patients with combined median and ulnar nerve injury following missile injuries. Both studies reported small numbers of patients ( 8 and 7 patients, respectively). The present study showed that $45.2 \%$ of the employed patients did not return to work within one year following the injury. Furthermore, spaghetti wrist patients took sick leave with a mean of 35 weeks.

Throughout history, the hand has been identified as an important component of human anatomy, unique in structure and function..$^{32}$ Because the hand is frequently used as a non-verbal medium of communication, a disfigured hand results in negative changes in self-image. ${ }^{33}$ Earlier studies reported on psychological problems following severe hand trauma. ${ }^{32,33}$ Grunert et al. ${ }^{33}$ and found that $94 \%$ of patients with severe hand injury experienced psychological symptoms at some point early in rehabilitation. Richmond et al. ${ }^{34}$ reported a mean IES score of 30.6 
among patients three months after a non-central nervous system trauma. To our knowledge, no reports have been published on psychological distress following spaghetti wrist injury. In our study population, psychological impact was considerable; $64 \%$ of the patients experienced a moderate (IES 18-39) to severe (IES >40) psychological response within the first month following the injury. This study reported an average IES score of 26 , one month post operatively, which is comparable to the amount of psychological stress found among the survivors of the cruise-ship Estonia. ${ }^{35}$ Patients with scores greater than 30 , have sufficient symptoms to be in the need for psychological treatment and patients whose initial scores are over 19 have a 12.4 times higher risk of developing a Post-Traumatic Stress Disorder (PTSD), than patients whose scores were 19 or less. ${ }^{36}$ Predictors for the amount of post-traumatic psychological stress, following median and ulnar nerve injuries, are number of severed structures, combined versus single nerve injuries and gender. Education was found a protecting variable. ${ }^{37}$ There were limitations to this part of the study. Retrospective data collection will tend to underestimate the amount of psychological stress. Patients may have failed to recall their reaction to their traumatic nerve injury. On the other hand, patients with worse functional outcome and reduced capacity for work, may tend to exaggerate the amount of psychological stress. Despite these limitations in can be concluded that the early psychological consequences of spaghetti wrist injury are not to be underestimated. During follow-up, on average 10 years postoperatively, spaghetti wrist patients reported a statistical decrease of the IES. Early recognition and treatment of patients who are at great risk to develop a post-traumatic stress disorder may influence the functional outcome. Results on the clinical utility of the IES, showed that the Impact of Event Scale has sufficient reliability and validity to warrant its use as a clinical screening method for traumatic stress. ${ }^{38,39}$

Nerve injury causes motor and sensory loss of the hand. Several previous studies reported on motor recovery following nerve injury. ${ }^{2-6,40-43}$ Our results are comparable to findings in these studies, although reports on grip and tip pinch strength recovery vary. We found overall recovery of intrinsic muscles to be better than reported by others. ${ }^{2-6,40-43}$

Reports on sensory recovery vary, but are overall unsatisfying with most patients recovering only gross protective sensation. ${ }^{2-6}$ Our findings on sensible recovery were disappointing with 12 patients loosing protective sensation and 7 patients recovering no sensation.

Three different definitions are used to define spaghetti wrist injury. In this study, we tried to reach consensus which definition can be used best, by means of statistical analysis of differences between two definitions (1. combined median and ulnar nerve injury and 2. laceration of ten or more structures including at least the median and/or ulnar nerve). The third definition used in literature, a laceration of at least three structures ${ }^{2,6}$, can be applied to most minor injuries to the wrist, including injuries without nerve laceration. In our opinion, this describes an injury with less severe functional consequences compared to injuries described by the other two definitions. Therefore, we did not use this third definition in our study. Statistical analysis showed no significant differences in outcome between the two definitions (table 6-8). Only 
a statistical difference was found for sensory recovery after excluding the patients who met both definitions. So it seemed that the combined median and ulnar nerve injuries have worse prospects concerning sensory recovery compared to the single nerve injuries. May be the larger area in the somatosensory cortex, which needs to be reorganized, can explain this finding. Focusing on the descriptive character of the name spaghetti wrist, we agreed with $\mathrm{Katz}^{7}$ and considered the second definition'a minimum of ten completely injured structures, including at least one major nerve' the most appropriate to describe spaghetti wrist trauma.

Spaghetti wrist injuries can be placed among the severe disabling injuries. Assessment of functional recovery involves more than evaluation of motor and sensory recovery by a physician. Besides a clinical examination, assessment of long-term outcome following nerve injury should include a patient-derived assessment of function, evaluation of the return to work-ratio and assessment of psychological distress. Furthermore, we recommend that in future studies spaghetti wrist injury is defined as a laceration of the volar wrist with a minimum of ten structures involved including at least the median and/or ulnar nerve. 


\section{REFERENCES}

1. Yii, N.W., Urban, M., Elliot, D. A prospective study of flexor tendon repair in zone 5. J Hand Surg [Br]. 23: 642, 1998.

2. Chin, G., Weinzweig, N., Mead, M., Gonzalez, M. "Spaghetti wrist": management and results. Plast Reconstr Surg. 102: 96, 1998.

3. Hudson, D., de Jager, L. The spaghetti wrist. Simultaneous laceration of the median and ulnar nerves with flexor tendons at the wrist. J Hand Surg [Br]. 18: 171, 1993.

4. Rogers, G., Henshall, A., Sach, R., Wallis, K. Simultaneous laceration of the median and ulnar nerves with flexor tendons at the wrist. J Hand Surg [Am]. 15: 990, 1990.

5. Widgerow, A. Full-house/spaghetti wrist injuries. Analysis of results. S Afr J Surg. 28: 6, 1990.

6. Puckett, C.L., Meyer, V.H. Results of treatment of extensive volar wrist lacerations: the spaghetti wrist. Plast Reconstr Surg. 75: 714, 1985.

7. Katz, R. Results of treatment of extensive volar wrist lacerations: The spaghetti wrist (discussion). Plast Reconstr Surg. 75: 720, 1985.

8. McConnel, S., Beaton, D., Bombardier, C. The DASH Outcome Measure User's Manual. $1^{\text {st }}$ Ed. Toronto: Institute for Work \& Health, 1999. Pp. 95.

9. Hudak, P., Amadio, P., Bombardier, C. Development of an upper extremity outcome measure: the DASH (disabilities of the arm, shoulder and hand). The Upper Extremity Collaborative Group (UECG). Am J Ind Med. 29: 602, 1996.

10. Horowitz, M., Wilner, N., Alvarez, W. Impact of Event Scale: a measure of subjective stress. Psychosom Med. 41: 209, 1979.

11. Mathiowetz, V., Weber, K., Volland, G., Kashman, N. Reliability and validity of grip and pinch strength evaluations. J Hand Surg [Am]. 9: 222, 1984.

12. Hamilton, A., Balnave, R., Adams, R. Grip strength testing reliability. J Hand Ther. 7: 163, 1994.

13. Petersen, P., Petrick, M., Connor, H., Conklin, D. Grip strength and hand dominance: challenging the 10\% rule. Am J Occup Ther. 43: 444, 1989.

14. Brandsma, W. Manual Muscle Strength Testing: Intraobserver and interobserver reliabilities for intrinsic muscles of the hand. J Hand Ther. 8: 185, 1995.

15. Bell-Krotoski, J., Weinstein, S., Weinstein, C. Testing sensibility, including touch-pressure, two-point discrimination, point localization, and vibration. J Hand Ther. 6: 114, 1993.

16. Imai, H., Tajima, T., Natsuma, Y. Interpretation of cutaneous pressure threshold (Semmes-Weinstein monofilament measurement) following median nerve repair and sensory reeducation in the adult. Microsurgery. 10: 142, 1989.

17. Beaton, D. E., Katz, J. N., Fossel, A.H., Wright, J.G., Tarasuk, V., Bombardier, C. Measuring the whole or the parts? Validity, reliability, and responsiveness of the disabilities of the arm, shoulder and hand outcome measure in different regions of the upper extremity. J Hand Ther. 14: 128, 2001.

18. Gummesson, C., Atroshi, I., Ekdahl, C. The disabilities of the arm, shoulder and hand (DASH) outcome questionnaire: longitudinal construct validity and measuring self-rated health change after surgery. BMC Musculoskelet Disord. 4: 11, 2003.

19. Saxena, P., Cutler, L., Feldberg, L. Assessment of the severity of hand injuries using 'hand injury severity score', and its correlation with the functional outcome. Injury. 35: 511, 2004.

20. Amadio, P.C. Outcome assessment in hand surgery and hand therapy: an update. J Hand Ther. 14: 63, 2001.

21. Jaquet, J. B., Kuypers, P.D. L., Kalmijn, S., Hovius, S.E. R. The DASH: A useful assessment method to evaluate functional recovery following median and ulnar nerve injuries. $J$ Hand Surg [Br]. 28: 16, 2003.

22. Kuhn, K.M., Dao, K.D., Shin, A.Y. Volar A1 pulley approach for fixation of avulsion fractures of the base of the proximal phalanx. J Hand Surg [Am]. 26: 762, 2001.

23. Karunakar, M. A., Cha, P., Stern, P.J. Distal biceps ruptures. A follow-up of Boyd and Anderson repair. Clin Orthop. 100, 1999.

24. Melikyan, E.Y., Beg, M. S., Woodbridge, S., Burke, F.D. The functional results of ray amputation. J Hand Surg [Am] 8: 47, 2003. 
25. Sauerbier, M., Gunther, C., Bickert, B., Pelzer, M., Germann, G. [Long-term outcome of reconstruction of proximal scaphoid pseudarthroses with Matti-Russe-plasty]. Handchir, Mikrochir, Plast Chir. 31 : $182,1999$.

26. Turchin, D., Beaton, D., Richards, R. Validity of observer-based aggregate scoring systems as descriptors of elbow pain, function, and disability. J Bone Joint Surg Am. 80: 154, 1998.

27. Tate, D.G. Workers' disability and return to work. Am J Phys Med Rehab. 71: 92, 1992.

28. Morris, J.A. Jr, Sanchez, A. A., Bass, S. M., MacKenzie, E. J. Trauma patients return to productivity. J Trauma. 31: 827, 1991.

29. Taha, A., Taha, J. Results of suture of the radial, median, and ulnar nerves after missile injury below the axilla. J Trauma. 45: 335, 1998.

30. Smith, M. E., Auchincloss, J. M., Ali, M. S. Causes and consequences of hand injury. J Hand Surg [Br].10: 288, 1985.

31. Brenneman, F. D., Redelmeier, D. A., Boulanger, B. R., McLellan, B. A., Culhane, J. P. Long-term outcomes in blunt trauma: who goes back to work? J Trauma. 42: 778, 1997.

32. Haese, J.B. Psychological aspects of hand injuries. Their treatment and rehabilitation. J Hand Surg [Br]. 10: 283, 1985.

33. Grunert, B.K., Smith, C.J., Devine, C.A., et al. Early psychological aspects of severe hand injury. $J$ Hand Surg [Br]. 13: 177, 1988.

34. Richmond, T.S., Kauder, D., Schwab, C.W. A prospective study of predictors of disability at 3 months after non-central nervous system trauma. J Trauma. 44: 635, 1998.

35. Eriksson, N.G., Lundin, T. Early traumatic stress reactions among Swedish survivors of the $\mathrm{m} / \mathrm{s}$ Estonia disaster. Br J Psychiatry. 169: 713, 1996.

36. Shalev, A.Y., Peri, T., Canetti, L., Schreiber, S. Predictors of PTSD in injured trauma survivors: a prospective study. Am J Psychiatry. 153: 219, 1996.

37. Jaquet, J. B., Kalmijn, S., Kuypers, P.D. L., Hofman, A., Passchier, J., Hovius, S. E. R. Early psychological stress after forearm nerve injuries: a predictor for long-term functional outcome and return to productivity. Ann Plast Surg. 49: 82, 2002.

38. Briere, J., Elliott, D.M. Clinical utility of the impact of event scale: psychometrics in the general population. Assessment. 5: 171, 1998.

39. Zilberg, N.J., Weiss, D.S., Horowitz, M.J. Impact of Event Scale: a cross-validation study and some empirical evidence supporting a conceptual model of stress response syndromes. J Consult Clin Psych. 50: 407, 1982.

40. Vastamaki, M., Kallio, P., Solonen, K. The results of secondary microsurgical repair of ulnar nerve injury. J Hand Surg [Br]. 18: 323, 1993.

41. Stefanich, R. J., Putnam, M.D., Peimer, C. A., Sherwin, F. S. Flexor tendon lacerations in zone V. J Hand Surg [Am]. 17: 284, 1992.

42. Posch, J., Cruz-Saddul, F. Nerve repair in trauma surgery: A ten-year study of 231 peripheral injuries. Orth Rev. 9: 35, 1980.

43. Kallio, P., Vastamaki, M. An analysis of the results of late reconstruction of 132 median nerves. J Hand Surg [Br]. 18: 97, 1993. 



\section{CHAPTER 4}

CONTENT VALIDITY OF THE DASH AND A LONGTERM

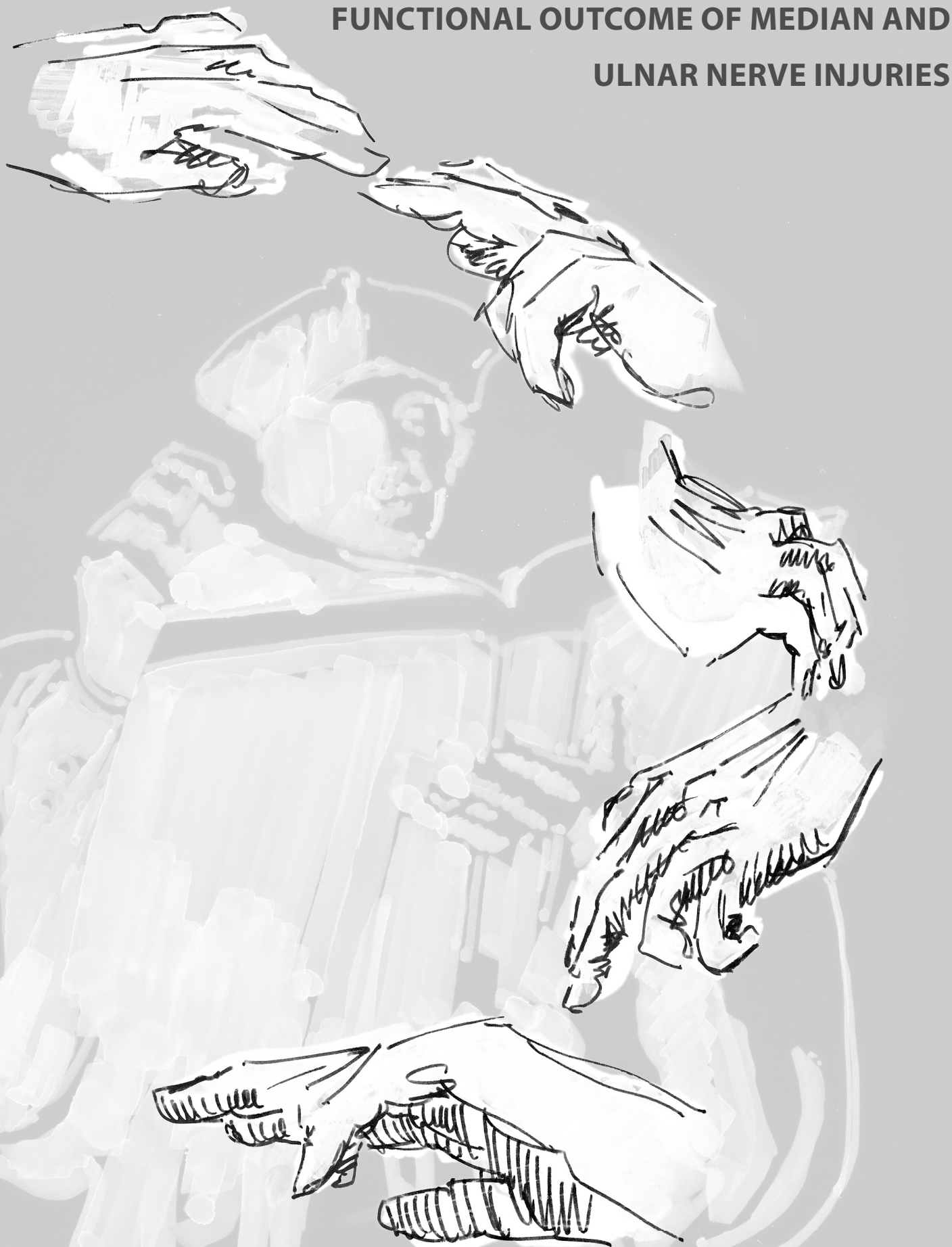

Jaquet, J. B., Schreuders, T. A. R., Ghandi, A., Kalmijn S. Stam, H. J. and Hovius S. E. R. 



\section{ABSTRACT}

Purpose - Nerve injury outcome studies have generally focused on the recovery of motor and sensory function, less attention has been paid to possibilities related to the patient's activities of daily living. This study was designed to establish content validity of the DASH and to provide long-term DASH scores for forearm nerve injury patients.

Methods - This was a retrospective study of 107 patients diagnosed with a median, ulnar or combined median-ulnar nerve injury (79\% response rate), who completed a questionnaire package consisting of the DASH (Disabilities of Arm, Shoulder and Hand) and a questionnaire concerning Return To Work (RTW). In an outpatient setting, motor (Jamar) and sensory (Semmes Weinstein monofilaments) recovery were examined.

Results - Mean DASH score was 18.7 (SD 19.7) after a mean follow-up of 5.5 years (range 110). Combined median-ulnar nerve injuries (adjusted mean DASH score= 23.8: SE 3.9) were not accompanied by significantly higher functional disabilities compared to the single nerve injuries (median: adjusted mean DASH score $=16.4$ : SE 2.7 and ulnar: adjusted mean DASH score $=18.6$ : $S E 2.7$, respectively $p=0.13$ and $p=0.28$ ). Multiple linear regression adjusted to age, sex, hand dominance and severity of the trauma revealed an association between the DASH score and sensory recovery ( $\beta=5.6,95 \% \mathrm{Cl}: 1.0-10.2, p=0.02)$ and motor recovery (Grip: $\beta=0.33$, 95\%Cl: 0.19-0.47, $\mathrm{p}<0.001$; Tip-pinch: $\beta=0.22,95 \% \mathrm{Cl}$ : 0.09-0.36, $\mathrm{p}=0.001)$. Patients capable of returning to productivity showed lower DASH scores (adjusted mean=12.5; SE 2.2) compared to the non-return to work population (adjusted mean=26.6; SE 2.6) $(p<.001)$.

Conclusions - It can be concluded that median and ulnar nerve injuries cause long-lasting functional loss affecting various activities of daily living. The strength of correlation between the DASH score and motor and sensory recovery gave evidence of good content validity. The DASH is therefore a useful additional instrument to evaluate functional recovery following median and ulnar nerve injuries. 


\section{INTRODUCTION}

Loss of motor and sensory function following nerve injuries to the upper extremity may result in a less functional hand, with major consequences for a patient's activities of daily living (ADL). ${ }^{1}$ Most outcome studies concerning recovery following peripheral nerve injuries have focused on the return of the classic impairment markers sensory and motor recovery. ${ }^{2-5}$ The use of the Semmes-Weinstein monofilaments ${ }^{6}$ and the Jamar dynamometer ${ }^{7}$ has proven to be valuable and reliable in evaluating sensory and motor recovery of the upper extremity after injury to the median and ulnar nerve. ${ }^{8}$ However, performance of various tasks of daily living may not rely on these markers.

Recently there has been increased emphasis on the reliability and validity of testing instruments and procedures to quantify functional outcome. ${ }^{8,9}$ Many methods are currently being used to quantify functional outcome of nerve repair. The activities of daily living (ADL) are severely limited for a patient with a non-functional hand. Evaluation of the activities of daily living therefore needs to be performed during the progress of nerve regeneration. Assessment of these activities will provide additional information concerning the patient's disability and may influence therapy.

Quality of life and performance of activities of daily living are important parts of assessment and treatment of patients with upper extremity dysfunction. This has led to the development of a number of objective and subjective upper extremity functional outcome measurement tools. For example, the Musculoskeletal Function Assessment ${ }^{10}$, the Michigan Hand Outcomes Questionnaire (Chung, 1998), the Hand Outcome Survey Sheet ${ }^{12}$ and the Self-administered questionnaire for the assessment of carpal tunnel syndrome ${ }^{13}$ are designed to evaluate disability. Recently a questionnaire for evaluating disability of an upper extremity injury or disease, called the DASH (Disabilities of Arm, Shoulder and Hand), has been introduced by the American Academy of Orthopedic Surgeons (AAOS), the Council of Musculoskeletal Specialty Societies (COMSS), and the Institute for Work and Health (Toronto, Ontario). ${ }^{14}$ During recent years the DASH questionnaire has been increasingly used, reflecting a growing interest in this outcome assessment tool. ${ }^{15-35}$ It has already been translated into German ${ }^{36}$, French ${ }^{37}$, Japanese, Swedish $^{38}$, Spanish and Dutch ${ }^{39}$.

Since the introduction of functional tests by Moberg ${ }^{40}$ in 1958, the relationship between clinical examinations and function has been debated. ${ }^{41-44}$ The strength of relationship between the DASH and motor and sensory recovery has never been investigated. Comparison between the DASH score and the standardized methods to assess sensory and motor recovery is essential to test "content validity" of the DASH. The main objective of this study was to determine the content validity of the DASH. Furthermore this study was designed to provide long-term DASH scores for forearm nerve injury patients. 


\section{PATIENTS AND METHODS}

\section{Study population}

The study cohort was defined as all subjects who entered the Rotterdam University Hospital for surgical treatment of a median, ulnar or combined median-ulnar traumatic nerve injury during the period between January 1990 and December 1998. We reviewed all medical records of patients who suffered an upper extremity nerve injury. A peripheral nerve injury chart was designed to score baseline data on: etiology, diagnosis, treatment, complications and work status. In order to be included in this study, patients were required to meet three entrance criteria. 1) A trauma of at least a single ulnar or median nerve. 2) The location of the laceration was restricted to within the area between the wrist crease (distal border) and the flexor elbow crease (proximal border). 3) Patients had to be 12 years or older at the day of their injury. Excluded were subjects diagnosed with complete amputation of the hand followed by a replantation, patients with associated hand and or forearm fractures, patients with amputation of hand or one or more digits and excluded were nerve contusions and avulsions. On the basis of these entrance criteria, a total of 136 patients were included over the study period.

Follow-up data were collected in two ways: a questionnaire package and a follow-up examination at our outpatient clinic. Hospital medical records, general practitioners and municipal archives were consulted in order to trace the initially selected patient population. A questionnaire package was mailed to the selected individuals with a cover letter requesting participation in a retrospective follow-up study on functional outcome following a trauma of the forearm. Patients were asked to complete the questionnaires. The questionnaire package consisted of the DASH (Disabilities of Arm, Shoulder, and Hand) and a questionnaire concerning profession and return to work potential. Three follow-up mailings were sent to non-responders at a two-month interval. This resulted in a study population of 107 patients (response rate $79 \%$ ). Thirteen subjects rejected participation. Of the remaining non-responders, 13 were untraceable (moved abroad or were not known in municipal records), 1 patient was detained in a foreign prison and 2 patients died without any relation to the surgery.

The protocol of the study was approved by the Medical Ethics Committee of Erasmus MC, University Medical Center Rotterdam and informed consent was provided by all participants.

\section{Outcome measures}

We considered the following outcomes of interest in our study: functional recovery, Return To Work (RTW), sensory and motor recovery. The DASH (Disabilities of Arm, Shoulder, and Hand), version 2.0 (May 1997) ${ }^{14,45}$, was selected to assess functional recovery. It was translated according to the criteria of the Institute for Work \& Health (IWH) and the American Academy of Orthopedic Surgeons (AAOS). Five translations and two "back-translations" by two native speakers were compared, aiming for semantic, idiomatic and conceptual equivalence. Reliability and validity were tested for the American version (test-retest reliability; ICC, 0.92 and internal consistency; 
Crohnbach's alpha, 0.96). ${ }^{45}$ Using a self-report system, patients allocated scores 1- 5 (Likert scale), on thirty items relating to functional activities (such as preparing a meal and writing) and symptoms (such as pain and weakness). The raw functional symptom score (FSS) was converted into a 0-100 scale, whereby 0 reflects minimum and 100 maximum disability. A questionnaire concerning profession and return to work was developed by the authors and was applied to examine return to work and time until work resumption (in months).

Patients who returned the questionnaires were invited to our hospital for a physical examination in an outpatient setting. Subjects who were unable to come to our hospital were visited at home. During a one-hour session, motor and sensory recovery were examined. One person who did not operate on any of the patients and was not involved in the post-operative treatment carried out the assessments. In addition, the follow-up session was used to check the accuracy of the self-reported outcome data and to complete the questionnaires in the case of incompleteness.

In order to assess motor recovery, grip strength and tip-pinch grip strength were measured using JAMAR Hydraulic Hand Dynamometer and JAMAR Hydrolic Pinch Gauge Meter in (kilograms force) (DeRoyal Industries, Powell, TN, USA) respectively. ${ }^{7}$ For grip strength the second handle position was used. For the pinch strength measurements the "tip-to-tip" pinch was performed between the tip of the index finger and thumb, with the other fingers extended. The positioning of the patient, verbal commands, etc. were carried out according to the recommendations of the American Society of Hand Therapists (ASHT). Both the injured and uninjured hands were tested three times. In cases where the third measurement was highest, a fourth measurement was performed. All results were noted and the mean was calculated. Results were mapped as percentage loss compared to the unaffected hand with a scoring range of $-100 \%$ to $100 \%$. Corrections for hand dominance were made. ${ }^{46}$ In cases where the right hand was the dominant hand, the left hand was considered to have $10 \%$ less grip- and tip pinch -strength than the right hand, in cases where the left hand was the dominant hand, the right hand and left hand were considered to be equally strong. For statistical analysis, cases were considered as $0 \%$ grip or tip-pinch strength loss if the affected hand was slightly stronger (>-10\%) than the unaffected hand (grip $n=10$ and tip-pinch $n=6$ ).

Sensory recovery was tested with Semmes-Weinstein monofilaments (North Coast Medical Inc, CA, USA). The monofilaments (2.83, 3.61, 4.31, 4.56 and 6.10; ranked 1-5) were used according to the procedure described by Bell-Krotosky. ${ }^{47}$ Ten zones in the hand were tested: 6 in the median nerve area and 4 in the ulnar nerve area. The scores were interpreted as suggested by Imai et al. ${ }^{48} \mathrm{~A}$ score of 6.10 was interpreted as anesthetic.

In two patients, nerves in both the left and right arm were injured. No valid reference for sensory and motor recovery could be obtained. These patients were therefore excluded from the analysis concerning sensory and motor recovery. 
Statistical methods

Respondents and non-respondents were compared in order to identify whether selection bias had occurred. Differences were tested, using chi-square analysis for categorical data and $t$-tests for continuous variables. Differences in functional symptom scores between median, ulnar and combined median-ulnar nerve injuries were obtained with analysis of covariance (ANCOVA), controlling for age and gender. Multiple linear regression analysis was applied to identify the association between the FSS and the dependent variables sensory recovery and motor recovery. Age, gender and severity of the trauma were included as confounding factors. Differences in functional symptom scores for the return to work (RTW) and non-return to work (non-RTW) population were obtained with analysis of covariance (ANCOVA) adjusted for age, gender, severity of the injury and type of job (white and blue collar). All tests were performed two-sided and a p-value of <.05 was considered as statistically significant. Data analyses were performed using SPSS statistical software, version 9.0.

\section{RESULTS}

\section{Study population}

Characteristics of responders and non-responders are presented in table 1. The responders and non-responders had similar age and gender distributions and no statistical difference was found for severity of the injury.

Data are reported for the 107 patients who were prepared to participate. The study population consisted of 85 male and 22 female ( $\mathrm{m}: \mathrm{f}=3.9: 1$ ), with a mean age of 30.7 years (SD:12.0 and range 14-67) on the day of repair. Accidental injuries at work were the primary cause of trauma (30.8\%), followed by activities at home (29.9\%), nightlife (12.1\%), victim of some kind of violence (8.4\%), suicide attempt (6.5\%) and others (e.g. sport accidents, 6.5\%).

Outcome

The mean value of the functional symptom score (FSS), after a mean follow-up of 5.5 years, was 18.7 (SD 19.7; range 0-80). Combined median-ulnar nerve injuries reported higher FSS than the single nerve injuries. However, analysis of covariance adjusted for gender and age, revealed that combined median-ulnar nerve injuries (mean $23.8:$ SE 2.7) were not significantly associated with higher FSS compared to the single nerve injuries (median: mean=16.4: SE 2.7 and ulnar: mean $=18.6$ : SE $2.7, p=.126$ and $p=.282$ respectively). Mean FSS for the quality of sensory recovery can be seen in table 2 .

Multiple linear regression adjusting for age, sex, hand dominance and severity of the injury revealed an association between the FSS and sensory recovery $(\beta=5.6,95 \% \mathrm{Cl}: 1.0-10.2, p=0.02)$ and motor recovery (Grip: $=0.33,95 \% \mathrm{Cl}: 0.19-0.47, \mathrm{p}<0.001$; Tip-pinch: $\beta=0.22,95 \% \mathrm{Cl}$ : 0.09 $0.36, p=0.001$ ) (Table 3 ). Analysis of covariance, controlling for age gender severity of the injury 
Table 1. Characteristics of responders $(n=107)$ and non-responders $(n=29)$.

\begin{tabular}{|c|c|c|}
\hline Characteristics & $\begin{array}{l}\text { Responders } \\
(n=107)\end{array}$ & $\begin{array}{l}\text { Non-responders } \\
(\mathrm{n}=29)\end{array}$ \\
\hline \multicolumn{3}{|l|}{ Age (years) } \\
\hline Mean \pm SD & $30.7 \pm 12.0$ & $28.9 \pm 12.0$ \\
\hline Range & $14-67$ & $15-61$ \\
\hline \multicolumn{3}{|l|}{ Sex (\%) } \\
\hline Male & $85(79)$ & $20(69)$ \\
\hline Female & $22(21)$ & $9(31)$ \\
\hline \multicolumn{3}{|l|}{ Type of injury (\%) } \\
\hline Median & $44(41)$ & $15(52)$ \\
\hline Ulnar & $41(38)$ & $11(38)$ \\
\hline Combined & $22(21)$ & $3(10)$ \\
\hline \multicolumn{3}{|c|}{ Dominant hand affected (\%) } \\
\hline Yes & $64(59)$ & $13(45)$ \\
\hline Unknown & $7(6)$ & $6(21)$ \\
\hline \multicolumn{3}{|c|}{ Number of structures affected } \\
\hline Mean \pm SD & $5.8 \pm 4.1$ & $5.5 \pm 4.1$ \\
\hline Range & $1-15$ & $1-15$ \\
\hline \multicolumn{3}{|l|}{ Lesion (\%) } \\
\hline Sharp & $73(68)$ & $23(79)$ \\
\hline Crush & $16(15)$ & $3(10)$ \\
\hline Avulsion & $13(12)$ & $2(7)$ \\
\hline Unknown & $5(5)$ & 1 (3) \\
\hline
\end{tabular}

$\mathrm{SD}=$ Standard deviation.

Table 2. Mean Functional Symptom Scores (FSS) for quality* of sensory recovery

\begin{tabular}{llc}
\hline Quality of sensation & Filament & Mean FSS ( \pm SD) \\
\hline Normal & 2.83 & $7.9 \pm 5.3$ \\
Diminished light touch & 3.61 & $16.4 \pm 20.5$ \\
Diminished protective sensation & 4.31 & $17.3 \pm 19.5$ \\
Loss of protective sensation & 4.56 & $23.7 \pm 17.1$ \\
Anesthetic & 6.10 & $49.4 \pm 21.9$ \\
\hline
\end{tabular}

p-trend $=0.02$

* classification according Imai (1989)

Table 3. Adjusted* $\beta$ 's for the association between objective functional outcome variables and the Functional Symptom Scores (FSS), assessed by multiple linear regression analyses

\begin{tabular}{lllll}
\hline Objective outcome variables & Range & Beta & $\mathbf{9 5 \%} \mathbf{C l}$ & p-value \\
\hline Sensory recovery & $1-5$ & 5.6 & $1.0-10.2$ & 0.02 \\
Grip strength & $0-100$ & 0.33 & $0.19-0.47$ & $<0.001$ \\
Tip-pinch strength & $0-100$ & 0.22 & $0.09-0.36$ & 0.001 \\
\hline
\end{tabular}

* adjusted for sex, age, handdominance and severity of the injury

and type of job, showed that patients capable of returning to work (RTW) reported lower mean FSS values (adjusted mean: 12.5 ; SE: $2.2,95 \% \mathrm{Cl}$ : 8.1-16.9) compared to the non-RTW population (adjusted mean: 26.6; SE:2.9, 95\%Cl: 20.8-32.5) $(p<0.001)$. Additionally, we investigated the association between several well-known predicting variables for the outcome following nerve 
Table 4. Adjusted* ${ }^{\prime}$ 's for association between predicting variables and the Functional Symptom Scores (FSS), assessed by multiple linear regression analyses

\begin{tabular}{lllll}
\hline Predictors & Range & Beta & $\mathbf{9 5 \% ~ C l}$ & p-value \\
\hline Nr injured structures & $1-15$ & 0.47 & $-0.47-1.41$ & .33 \\
Level of injury & $1-3$ & 1.65 & $-4.31-7.60$ & .59 \\
Age & $14-67$ & 0.17 & $-0.11-0.45$ & .33 \\
\hline
\end{tabular}

* adjusted for sex

injuries and the functional symptom score. Multiple linear regression analysis, adjusted for sex, showed that the number of severed anatomical structures $(p=.33)$, level of injury $(p=.59)$ and age $(p=.33)$ was not statistically significantly associated with the FSS on average 5.5 years after surgery (Table 4).

\section{DISCUSSION}

Outcome of medical care includes many dimensions: physical, social and emotional functioning, symptoms and satisfaction. ${ }^{49}$ Surgical interventions are increasingly evaluated on the basis of the patient's long-term physical functioning, well-being and quality of life..$^{50}$ Most studies regarding outcome following median and ulnar nerve injuries focused on sensory and motor recovery, but less emphasis was placed on the impact of these injuries on activities of daily living. There has been an increase in interest in the use of generic health questionnaires to provide broad measures of health, which can be used to provide normative population data. ${ }^{51}$ According to the designers of the DASH, the main purpose of the DASH is to describe different groups of people and provide the ability to compare the impact of different upper-limb disorders. ${ }^{45}$ The mean FSS values provided by this study can be used to compare the functional impairment of different upper extremity diseases and conditions. The population-based norms for the DASH have recently been collected..$^{52}$ These data will make it possible to compare our mean FSS values with age and gender adjusted normal values.

The true impact of hand and forearm injuries may be greatly underestimated..$^{53}$ DASH functional symptom scores, published between 1999 and 2001, varied between 2 and 52. ${ }^{15-35}$ This large variation is due to differences in type of injury or disease and the length of follow-up between trauma and assessment. A mean FSS of nearly nineteen on a scale ranging from 0-100 could be interpreted as "minor" disability. The maximum score of our study population was 80 . For example: one of our patients with a FSS of 18 complained of mild difficulties preparing a meal, having mild difficulties with writing, having severe problems with recreational activities in which the arm is moved freely, having mild pain when performing any specific activity and having moderate stiffness, tingling and/or weakness in arm, shoulder or hand. Comparative FSS values, of recent published studies on upper extremity injuries or diseases, are depicted in table 5. Our study population completed the DASH questionnaire after a mean follow-up of 
Table 5. Mean functional symptom scores (=FSS), of recently published studies on upper extremity injuries or diseases

\begin{tabular}{llcc}
\hline Study & Injury/disease & Mean FSS & Follow-up* \\
\hline Karanukar et al. (1999) & 1 Distal biceps rupture & 52.4 & 44 \\
Krimmer et al. (1999) & 1 Proximal scaphoid pseudoarthrosis & 10 & 29 \\
Navsarkar et al. (1999) & 1 Psoriatic arthritis & 27.5 & - \\
Ring et al. (1999) & Fractures of humeral diphysis & 24 & 37 \\
Sauerbier et al. (1999) & Fracture of proximal scaphoid & 12.7 & 66 \\
Sauerbier et al. (2000) & Kienböcks disease & 24.8 & 35 \\
Sauerbier et al. (2000) & Scaphoid fractures & 39 & 15 \\
Sauerbier et al. (2000) & Carpal collaps & 28 & 25 \\
Bartellmann et al. (2000) & Fracture of first metacarpal bone & 7 & 33 \\
Beyermann et al. (2000) & Distal radius fractures & 11.2 & 33 \\
MacDermid et al. (2000) & Distal radius fractures & $\#$ & 6 \\
Trankle et al. (2000) & Semilunar bone necrosis & 24.8 & 35 \\
McKee et al. (2000) & Supracondylar fracture humerus & 23.7 & 51 \\
McKee et al. (2000) & Intra-articular distal humeral fracture & 20 & 37 \\
Trumble et al. (2000) & Thumb basal joint arthritis & $\#$ & 42 \\
Eichhorn et al. (2001) & Carpo-metacarpal dislocation & 24 & 36 \\
Kalb et al. (2001) & STT arthrosis \& Scapholunate necrosis & 29 & 36 \\
Kuhn et al. (2001) & Proximal phalanx fractures & 1.8 & 19 \\
Kuntscher et al. (2001) & Scaphoid fractures & 15 & $\#$ \\
Shin et al. (2001) & Lunotriquetral ligament injuries & $\#$ & 34 \\
\hline
\end{tabular}

* Follow-up: mean time between injury or diagnosis of the disease and assessment by the DASH questionnaire (in months).

"No mean FSS values provided. These studies used different calculation methods.

5.5 years (66 months). In our opinion it may be concluded that median and ulnar nerve injuries cause long-lasting disabilities. Besides diminished sensibility and muscle strength, activities of daily living are impaired on a long-term basis. It is therefore important to include assessment of activities of daily living in the post-operative evaluation following treatment of any physical upper extremity injury.

The results of this study tended to confirm that combined median-ulnar nerve injuries gave less functional recovery than single nerve injuries, although this was not statistically significant. The differences can be expected to be greater if assessment is performed at an earlier stage. A longitudinal follow-up study is needed to confirm this idea and to examine the responsiveness (clinical change over time) of the DASH. On the other hand, it was stated that the DASH should be able to discriminate between different groups.$^{45}$ This study showed lower mean FSS values for the return to work population than the non-return to work population, a greater capacity to function normally in daily life. These data may be of interest to hand surgeons, hand therapists, insurance companies and employers. Additionally, these FSS values can be used to inform patients about their prognosis.

No association was found between the FSS and several well-known predicting variables for the outcome following nerve injuries, such as number of severed structures, level of the injury and age. FSS values are calculated regardless of which hand or arm is used to perform the 
activities. Patients will compensate for their dysfunction, for example by using their uninjured hand to perform tasks. This may lead to a lower FSS value and may therefore be responsible for the lack of association. Furthermore, the time interval between surgery and assessment may be an additional explanation for this finding. Functional status of the hand is a combination of both sensory and motor recovery. Most predictors are associated with either sensory or motor recovery. Amadio ${ }^{52}$ reported that anatomy and function are only loosely correlated, which may be an explanation for the absence of association between the number of severed structures and the FSS values.

It was observed by Smith ${ }^{54}$ that we must become more aggressive in providing appropriate upper extremity outcomes. Consistency in the reporting of these upper extremity outcomes is essential to standardize data collection..$^{52,55}$ The general measuring methods used to evaluate the functional outcome following peripheral nerve injury to the upper extremity have proven to be reliable and valid. ${ }^{8}$ Semmes-Weinstein monofilaments and Jamar dynamometer are standardized methods and frequently used to evaluate sensory recovery and grip strength respectively. ${ }^{8,56-59}$ Comparison between these standardized methods and the FSS is essential to test content validity of the DASH. Mean FSS values were associated with the Semmes-Weinstein monofilaments and Jamar dynamometer grip and tip-pinch values. These data provide evidence that the DASH can be used to evaluate the outcome of median and ulnar nerve injuries. Testretest reliability (reproducibility) of the DASH was reported to be excellent, which makes it possible to complete the DASH by mail or telephone. ${ }^{60}$

There were limitations to the present study. This was a retrospective cohort study, which is susceptible to selection bias. Responders and non-responders had similar age and gender distributions and no statistical difference was found for severity of the injury. To reduce recall bias, patients did not complete the DASH questionnaire at the same time as motor and sensory recovery were tested. Furthermore patients were asked to complete the DASH questionnaire at home to exclude the "white jacket or doctors" phenomenon. About 25 minutes are required to complete the entire DASH questionnaire. The fact that the FSS section is one of the latest parts of the DASH may contribute to less accurate answers on the questions related to the FSS. It was suggested that the DASH might be a little unwieldy for use in a community setting. ${ }^{55}$ In addition to the number of questions, the questions were considered to be complex. In our opinion, the recently developed "Quick DASH" may solve this problem. Another option would be to ask the patients to complete only the 30 simple questions related to the FSS.

In conclusion, in addition to physical examinations, attention must be paid to health-related quality of life following upper extremity injuries or diseases. The DASH is a useful and valid instrument to supply this information. Based on our results and Levine's criteria for assessing a good instrument, ${ }^{13}$ this study proved that the DASH can be suitably used to evaluate upper extremity physical (dys-)functioning, following median and ulnar nerve injuries. Furthermore, the DASH questionnaire provides the opportunity to assess impairment and functional recovery from the patient's point of view. The data of the present study can be applied to modern 
treatment and evaluation criteria. In the near future more studies using the DASH are needed to provide a wider range of comparative FSS values. 


\section{REFERENCES}

1. Jaquet JB, Luijstenburg AJM, Kalmijn S, et al. Median, ulnar, and combined median-ulnar nerve injuries: functional outcome and return to productivity. Journal of Trauma 2001;51:687-692

2. Posch J, Cruz-Saddul Fdl. Nerve repair in trauma surgery: A ten-year study of 231 peripheral injuries. Orthopaedic Review 1980;9:35-45

3. Chin G, Weinzweig N, Mead M, et al. "Spaghetti wrist": management and results. Plast Reconstr Surg 1998;102:96-102

4. Merle M, Amend $\mathrm{P}$, Cour $C$, et al. Microsurgical repair of peripheral nerve lesions: $A$ study of 150 injuries of the median and ulnar nerves. Peripheral Nerve Repair 1986;2:17-26

5. Puckett $\mathrm{CL}$, Meyer VH. Results of treatment of extensive volar wrist lacerations: the spaghetti wrist. Plast Reconstr Surg 1985;75:714-721

6. Bell-Krotoski J. Light touch-deep pressure testing using Semmes-Weinstein monofilaments. In: Hunter J, Schneider L, Mackin E, Calahan A, eds. Rehabilitation of the Hand. St Louis: Mosby; 1990:585-593

7. Mathiowetz V, Weber K, Volland G, et al. Reliability and validity of grip and pinch strength evaluations. J Hand Surg [Am] 1984;9:222-226

8. Rosen B. Recovery of sensory and motor function after nerve repair. A rationale for evaluation. $J$ Hand Ther 1996;9:315-327

9. Wilkins E, Lowery J, Smith DJ J. Outcomes research: a primer for plastic surgeons. Ann Plast Surg 1996;37:1-11

10. Martin DP, Engelberg R, Agel J, et al. Comparison of the Musculoskeletal Function Assessment questionnaire with the Short Form-36, the Western Ontario and McMaster Universities Osteoarthritis Index, and the Sickness Impact Profile health-status measures. Journal of Bone and Joint Surgery. American Volume 1997;79:1323-1335

11. Chung K, Pillsbury M, Hayward M. Reliability and validity testing of the Michigan Hand Outcomes Questionnaire. Paper presented at the 52nd Annual Meeting of the American Society for Surgery of the Hand, September 13, 19971997

12. Sharma R, Dias JJ. Validity and reliability of three generic outcome measures for hand disorders. $2000 ; 25: 593-600$

13. Levine DW, Simmons BP, Koris MJ, et al. A self-administered questionnaire for the assessment of severity of symptoms and functional status in carpal tunnel syndrome. Journal of Bone and Joint Surgery. American Volume 1993;75:1585-1592

14. Hudak P, Amadio P, Bombardier C. Development of an upper extremity outcome measure: the DASH (disabilities of the arm, shoulder and hand [correction of head]). The Upper Extremity Collaborative Group (UECG). Am J Ind Med 1996;29:602-608

15. Bartelmann U, Dietsch V, Landsleitner B. Fractures near the base of the first metacarpal bone: clinical outcome of 21 patients. Handchirurgie, Mikrochirurgie, Plastische Chirurgie 2000;32:93-101

16. Karunakar MA, Cha P, Stern PJ. Distal biceps ruptures. A follow-up of Boyd and Anderson repair. Clinical Orthopaedics and Related Research 1999:100-107

17. Krimmer H, Kremling E, van Schoonhoven J, et al. Proximal scaphoid pseudarthrosis: reconstruction by dorsal bone screw and spongiosa transplantation. Handchirurgie, Mikrochirurgie, Plastische Chirurgie 1999;31:174-177

18. MacDermid JC, Richards RS, Donner A, et al. Responsiveness of the short form-36, disability of the arm, shoulder, and hand questionnaire, patient-rated wrist evaluation, and physical impairment measurements in evaluating recovery after a distal radius fracture. Journal of Hand Surgery. American Volume 2000;25:330-340

19. McKee MD, Kim J, Kebaish K, et al. Functional outcome after open supracondylar fractures of the humerus. The effect of the surgical approach. Journal of Bone and Joint Surgery. British Volume 2000;82:646-651

20. Navsarikar A, Gladman DD, Husted JA, et al. Validity assessment of the disabilities of arm, shoulder, and hand questionnaire (DASH) for patients with psoriatic arthritis. Journal of Rheumatology 1999;26:2191-2194 
21. Ring D, Perey BH, Jupiter JB. The functional outcome of operative treatment of ununited fractures of the humeral diaphysis in older patients. Journal of Bone and Joint Surgery. American Volume 1999;81:177-190

22. Sauerbier M, Gunther C, Bickert B, et al. Long-term outcome of reconstruction of proximal scaphoid pseudarthroses with Matti-Russe-plasty. Handchirurgie, Mikrochirurgie, Plastische Chirurgie 1999;31:182-186

23. TrumbleTE, Rafijah G, Gilbert M, et al. Thumb trapeziometacarpal joint arthritis: partial trapeziectomy with ligament reconstruction and interposition costochondral allograft. Journal of Hand Surgery. American Volume 2000;25:61-76

24. Sauerbier M, Bickert B, Trankle M, et al. Surgical treatment possibilities of advanced carpal collapse (SNAC/SLAC wrist). Unfallchirurg 2000;103:564-571

25. Sauerbier M, Trankle M, Linsner G, et al. Midcarpal arthrodesis with complete scaphoid excision and interposition bone graft in the treatment of advanced carpal collapse (SNAC/SLAC wrist): operative technique and outcome assessment. 2000;25:341-345

26. Sauerbier M, Trankle M, Erdmann D, et al. Functional outcome with scaphotrapeziotrapezoid arthrodesis in the treatment of Kienbock's disease stage III. Annals of Plastic Surgery 2000;44:618625

27. Beyermann K, Prommersberger KJ. Simultaneous management of multi-fragment distal radius fractures with palmar and dorsal approach. Handchirurgie, Mikrochirurgie, Plastische Chirurgie 2000;32:404-410

28. Trankle M, Sauerbier M, Linsner G, et al. STT arthrodesis for treatment of stage III semilunar bone necrosis: functional outcome. Handchirurgie, Mikrochirurgie, Plastische Chirurgie 2000;32:419-423

29. McKee MD, Wilson TL, Winston $L$, et al. Functional outcome following surgical treatment of intraarticular distal humeral fractures through a posterior approach. Journal of Bone and Joint Surgery. American Volume 2000;82-A:1701-1707

30. Eichhorn_Sens J, Katzer A, Meenen NM, et al. Carpo-metacarpal dislocation injuries. Handchirurgie, Mikrochirurgie, Plastische Chirurgie 2001;33:189

31. Kalb K, Ludwig A, Tauscher A, et al. Treatment outcome after surgical arthrodesis. Handchirurgie, Mikrochirurgie, Plastische Chirurgie 1999;31:253-259

32. KalbK, FuchsV, Bartelmann U, et al. Experiences with the STT (scapho-trapezio-trapezoid) arthrodesis. A retrospective evaluation. Handchirurgie, Mikrochirurgie, Plastische Chirurgie 2001;33:181-188

33. Kuhn KM, Dao KD, Shin AY. Volar A1 pulley approach for fixation of avulsion fractures of the base of the proximal phalanx. 2001;26:762-771

34. Kuntscher M, Trankle M, Sauerbier M, et al.. Unfallchirurg 2001;104:813-819

35. Shin A, Weinstein L, Berger $R$, et al. Treatment of isolated injuries of the lunotriquetral ligament. A comparison of arthrodesis, ligament reconstruction and ligament repair. J Bone Joint Surg $(\mathrm{Br})$ 2001;83:1023-1028

36. Germann G, Wind G, Harth A. The DASH (Disability of Arm-Shoulder-Hand) Questionnaire: a new instrument for evaluating upper extremity treatment outcome. Handchirurgie, Mikrochirurgie, Plastische Chirurgie 1999;31:149-152

37. Dubert $T$, Voche $P$, Dumontier $C$, et al. The DASH questionnaire. French translation of a trans-cultural adaptation. Chir Main 2001;20:294-302

38. Atroshi I, Gummesson C, Andersson B, et al. The disabilities of the arm, shoulder and hand (DASH) outcome questionnaire: reliability and validity of the Swedish version evaluated in 176 patients. Acta Orthopaedica Scandinavica 2000;71:613-618

39. Jaquet JB, Mink van der Molen AB, Hovius SER. BASH (Beperkingen van de Arm Schouder en Hand), Dutch translation of the DASH questionnaire. Rotterdam, 1999

40. Moberg E. Objective methods for determining the functional value of sensibility in the hand. Journal of Bone and Joint Surgery 1958;40B:454-476

41. Brink EE, Mackel R. Sensorimotor performance of the hand during peripheral nerve regeneration. Journal of the Neurological Sciences 1987;77:249-266

42. Marsh D. The validation of measures of outcome following suture of divided peripheral nerves supplying the hand. J Hand Surg [Br] 1990;15:25-34

43. Chassard $M$, Pham E, Comtet JJ. Two-point discrimination tests versus functional sensory recovery in both median and ulnar nerve complete transections. J Hand Surg [Br] 1993;18:790-796 
44. Dellon AL, Kallman CH. Evaluation of functional sensation in the hand. J Hand Surg [Am] 1983;8:865870

45. McConnell S, Beaton D, Bombardier C. The DASH outcome measure user's manual. Toronto: Institute for Work \& Health, 1999

46. Petersen $\mathrm{P}$, Petrick $\mathrm{M}$, Connor $\mathrm{H}$, et al. Grip strength and hand dominance: challenging the $10 \%$ rule. American Journal Of Occupational Therapy 1989;43:444-447

47. Bell-Krotoski J, Weinstein S, Weinstein C. Testing sensibility, including touch-pressure, two-point discrimination, point localization, and vibration. J Hand Ther 1993;6:114-123

48. Imai H, Tajima T, Natsuma Y. Interpretation of cutaneous pressure threshold (Semmes-Weinstein monofilament measurement) following median nerve repair and sensory reeducation in the adult. Microsurgery 1989;10:142-144

49. Amadio P. Outcomes assessment in hand surgery. What's new? Clin Plast Surg 1997;24:191-194

50. Greenfield S, Nelson EC. Recent developments and future issues in the use of health status assessement measures in clinical settings. Medical Care 1992;30:23-41

51. Jenkinson C, Coulter A, Wright L. Short form 36 (SF36) health survey questionnaire: normative data for adults of working age. Bmj (Clinical Research Ed.) 1993;306:1437-1440

52. Amadio PC. Outcome assessment in hand surgery and hand therapy: an update. Journal of Hand Therapy 2001;14:63-67

53. O'Sullivan ME, Colville J. The economic impact of hand injuries. J Hand Surg [Br] 1993;18:395-398

54. Smith Jr DJ. Year Book Plastic, Reconstructive and Aesthetic Surgery. Vol. 1: Mosby-Year Book, Inc., 1997

55. McAuliffe J. Outcome research: definitions and directions. Journal of Hand Therapy 1998:164-170

56. Bell-Krotoski J, Tomancik E. The repeatability of testing with Semmes-Weinstein monofilaments. J Hand Surg [Am] 1987;12:155-161

57. Bellace JV, Healy D, Besser MP, et al. Validity of the Dexter Evaluation System's Jamar dynamometer attachment for assessment of hand grip strength in a normal population. Journal of Hand Therapy 2000;13:46-51

58. Peolsson A, Hedlund R, Oberg B. Intra- and inter-tester reliability and reference values for hand strength. J Rehabil Med 2001;33:36-41

59. Lehman JB, Abreau B. Evaluating the hand: Issues in reliability and validity. Physical Therapy 1989;69:1025-1033

60. Turchin D, Beaton D, Richards R. Validity of observer-based aggregate scoring systems as descriptors of elbow pain, function, and disability. J Bone Joint Surg Am 1998;80:154-162 



\section{CHAPTER 5}

\section{PREDICTORS FOR RETURN TO WORK IN PATIENTS WITH}

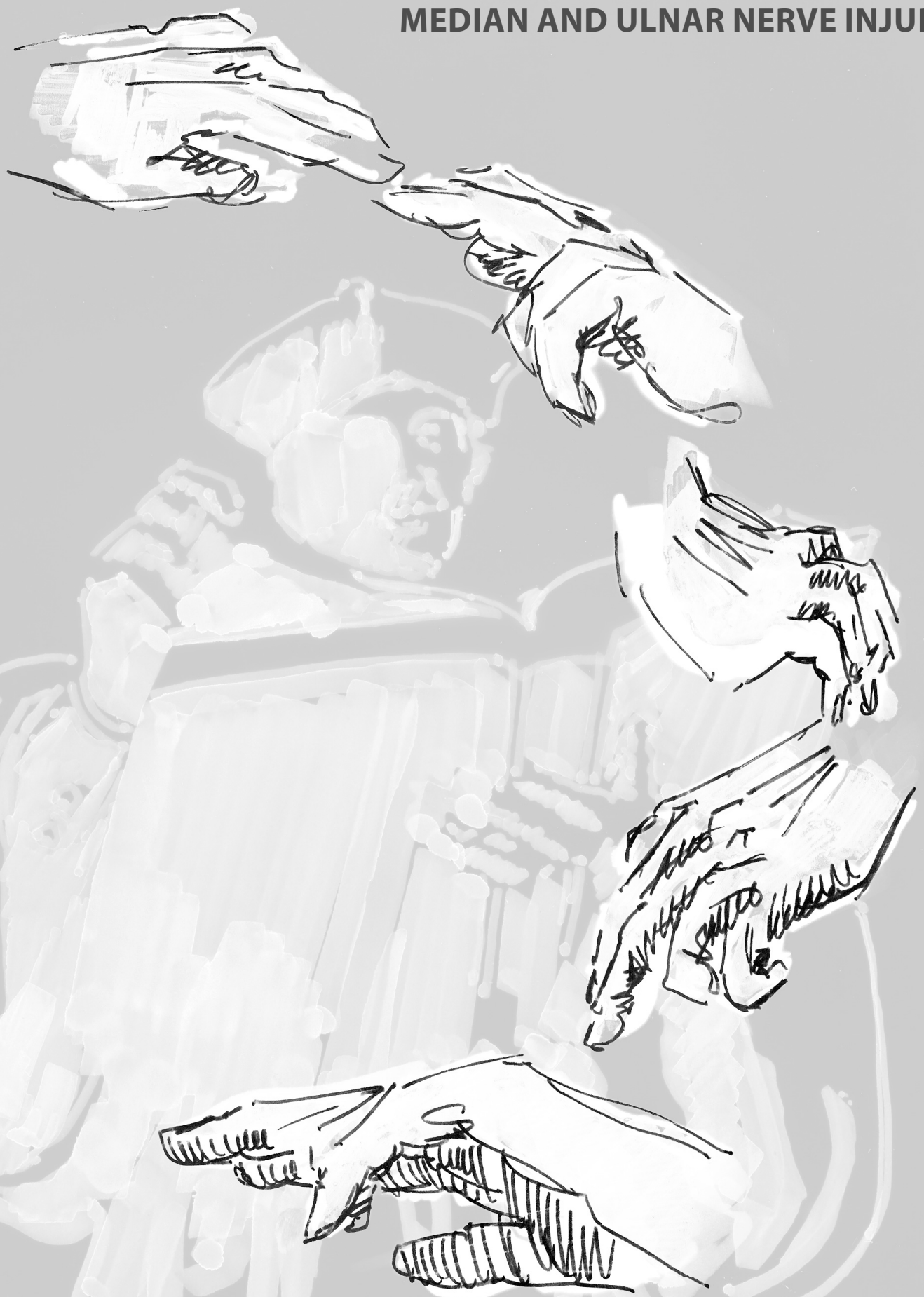

Bruyns C.N.P., Jaquet, J. B., Schreuders, T. A. R., Kalmijn S., Kuypers, P.D. L. and Hovius S. E. R. Journal Hand Surgery: 28A(1): 28-34 



\section{ABSTRACT}

Purpose - One of the consequences of median and ulnar nerve trauma is delayed return to work. The aim of this study was to determine Return To Work (RTW) and risk factors for delayed RTW. Differences between median, ulnar and combined median-ulnar nerve injuries were examined.

Method - In this study 96 patients who were employed at the time of injury and who had undergone surgery for median, ulnar or combined nerve injuries between 1990 and 1998 were evaluated. The response rate was $84 \%(n=81)$.

Results - Within 1 year after injury, 59\% $(n=48)$ returned to work. Mean TOW was 31.3 weeks. RTW after combined nerve injuries was $24 \%$ versus after isolated median (80\%) and ulnar $(59 \%)$ nerve injuries $(p<.001$ and $p=.032)$. Level of education, type of job and compliance to hand therapy were found predictors for RTW. Grip strength loss $(p<.001)$, tip pinch strength loss $(p=.002)$ and sensory recovery $(p=.001)$ differed strongly between the RTW and No RTW population.

Conclusions - The predictors found in this study increase our understanding of delayed RTW after median and ulnar nerve injuries and may be used to optimize postinjury rehabilitation. 


\section{INTRODUCTION}

Upper extremity nerve injuries have drawn increasing attention in recent literature. Most studies assessed motor and sensory recovery. ${ }^{1-7}$ Costs to society, human toll and morbidity also have been described. ${ }^{8-10}$ Estimates of the percent return to work (RTW) following traumatic upper extremity nerve injury have been scarcely reported ${ }^{1}$. Time off work, to our knowledge, has not been described; therefore, the true impact of forearm nerve injuries is unknown.

The ability to return to work is influenced not only by physical health, but also by several other factors. ${ }^{11-13}$ Return to productivity following upper extremity injury is facilitated by early intervention and rehabilitation that addresses these factors in recovery. ${ }^{8}$ Studies have suggested a direct relationship between successful return to productivity and demographic and disabilityrelated characteristics, early referral to rehabilitation. ${ }^{14-15}$ Their relative importance in explaining delayed return to work has not been characterized in detail. This clarifies why little is known about the profile of a worker who is at a high risk for continued work disability. ${ }^{13} \mathrm{~A}$ better understanding of this profile may contribute to a decrease in the costs of lost work days by optimizing rehabilitation programs and by changing jobs early, if necessary.

This large outcome study was primarily designed to describe return to work within 1 year after surgical repair of median, ulnar and combined median-ulnar nerve injuries. Factors investigated in this study were type of injury, educational level, type of job, compliance to hand therapy and location of lesion. Furthermore, motor recovery, sensory recovery and pain in the hand were examined. By means of these factors, the authors aimed to determine the profile of a worker suffering from traumatic upper extremity nerve injury who is at risk not returning to productivity within 1 year.

\section{MATERIALS AND METHODS}

Study population

We retrospectively collected medical record data of patients who had suffered a traumatic median, ulnar or combined median-ulnar nerve injury (0955.1 and 0955.2 according to the International Classification of Diseases) between January 1990 and December 1998. All nerve injuries were repaired by plastic surgeons specialized in hand surgery at the Department of Plastic and Reconstructive Surgery of the Academic Hospital Rotterdam, The Netherlands. All lesions were primarily repaired.

To identify the study population, the following inclusion criteria were used: 1) a traumatic laceration of at least an isolated median or ulnar nerve, 2) the location of the laceration was restricted between the wrist and the flexor elbow crease, 3 ) patients had to be at least 18 years of age at the moment of injury, 4) patients had to be employed at the time of injury, 5) patient data had to be complete. Amputations, nerve contusions and nerve avulsions were 
Table 1. Characteristics of study population

\begin{tabular}{ll}
\hline Characteristic & Patients $(\mathbf{n}=\mathbf{8 1})$ \\
\hline Age (yr) & $30.5(10.4)$ \\
Mean (SD) & $18-58$ \\
Range & $72(89)$ \\
Sex (\%) & $9(11)$ \\
Male & \\
Female & $30(37)$ \\
Type of injury (\%) & $34(42)$ \\
Median & $17(21)$ \\
Ulnar & \\
Combined & $52(64)$ \\
Dominant hand affected (\%) & \\
Yes & $5.5(4.1)$ \\
Number of structures injured & \\
Mean (SD) & $59(73)$ \\
Lesion (\%) & $17(21)$ \\
Sharp & $5(6)$ \\
Crush & \\
Avulsion &
\end{tabular}

$S D=$ Standard deviation

excluded. The inclusion criteria were met by 96 patients. A postal questionnaire package was sent to all patients whose address could be retrieved. Six patients (7\%) were lost to follow-up and two patients (2\%) had died. Two patients (2\%) were not contacted for they moved abroad. In total, five patients (5\%) refused to respond, leaving a final group of 81 participants. This was a response rate of $84 \%$, acquired after 4 mailings.

Patient characteristics of the study population $(n=81)$ are shown in table 1 . Transections were mainly caused by glass (54\%) and knives (19\%). Injuries occurred at the workplace in $37 \%$ of the cases $(n=30)$. Analysis of the preinjury work status showed that 56 patients $(69 \%)$ were blue-collar workers and 25 patients (31\%) were white-collar workers.

\section{Methods}

The main outcome of the study was return to work (RTW). Return to work was defined as the resumption of employment within 1 year (a "yes" or "no" response). Time off work (TOW) was defined as the length of time between the injury and return to work, expressed in weeks (0 - 52). In this period, sick pay was received from the employer during work absence by all injured workers according to the Dutch Health Law. In case work absence exceeds 52 weeks, sick pay is replaced by permanent disability compensation from the government.

Factors influencing RTW investigated in this study were type of injury (median, ulnar or combined), educational level which ranged from 1 ('did not finish primairy school') to 7 ('university degree') and type of job, divided into blue-collar and white-collar workers, depending on the physical characteristics of the job held before injury. Blue collar jobs were 
defined as hard manual labor, whereas white collar jobs were defined as office employment. Furthermore, compliance to hand therapy, defined as being compliant to the standard hand therapy program for a minimum of 3 months (a "yes" or "no" response), location of lesion (distal, midforearm or proximal) and pain in the hand were investigated. In addition, grip strength loss, tip pinch strength loss and sensory recovery were factors, examined for their predictive value on return to work. Severity of the trauma, reflected by the number of volar structures severed (12 tendons (flexor digitorum superficialis II/IV, flexor digitorum profundus II/IV, flexor carpi ulnaris, flexor carpi radialis, flexor pollicis longus), 2 nerves (median and ulnar), 2 arteries (ulnar and radial), range 1-15), was put in the model as an additional confounding factor for grip strength loss and tip-pinch strength loss.

Medical records were reviewed to extract information on diagnosis at entry into treatment. $A$ peripheral nerve injury chart was designed to gather data about demographic characteristics, diagnosis, etiology, treatment, follow up and complications. The postal questionnaire included questions on status of employment, physical characteristics of work, level of education, RTW and TOW.

In an outpatient setting, motor recovery was assessed by measuring grip strength and tip pinch grip strength, using the JAMAR Hydraulic Hand Dynamometer and JAMAR Hydraulic Pinch Gauge meter (kilograms force) (DeRoyal Industries, Powell, TN, USA), respectively ${ }^{16}$. Both the injured and uninjured hand was tested 3 times. In case the third measurement was the highest, a fourth measurement was performed. All results were noted and the mean was calculated. Results were mapped as percentage loss compared to the unaffected hand with a scoring range of 0 to $100 \%$. Corrections for hand dominance were made ${ }^{17}$. In case the right hand was the dominant hand, the left hand was considered to have $10 \%$ less grip and tip pinch strength than the right hand, in case the left hand was the dominant hand, the right hand and left hand were considered to be equally strong. For statistical analysis these cases were considered as $0 \%$ grip or tip pinch strength loss, if the affected hand was slightly stronger $(>-10 \%)$ than the unaffected hand.

Sensory recovery was tested with Semmes-Weinstein monofilaments (North Coast Medical Inc, Morgan Hill, CA, USA). The monofilaments (2.83, 3.61, 4.31, 4.56 and 6.10, ranked 1-5) were used according to the procedure described by Bell-Krotosky ${ }^{18}$. Ten zones in the hand were tested, 6 in the area of the median nerve and 4 in the area of the ulnar nerve. The scores were interpreted as suggested by Imai $^{19}$. Score 6.10 was interpreted as anesthetic. Pain in the hand was evaluated using the Visual Analogue Scale: patients were asked to mark the point on a $10 \mathrm{~cm}$ bar (scoring range $0-10$ ) that corresponded to their experience of pain in the hand in particular daily situations.

Statistical analysis

Complete information, including functional testing was available for all 81 patients. Descriptive statistics were summarized with means, standard deviations and ranges. Factors were examined 
for their influence on return to work using logistic regression analysis for categorical data and linear regression analysis for continuous data. Odds ratios were calculated for all categorical predictors examined. Differences in motor and sensory recovery between the RTW and No RTW population were determined by analysis of covariance (ANCOVA) after adjusting for sex, age and hand dominance. Severity of the trauma was put in the model as an additional confounding factor for grip strength loss and tip-pinch strength loss. Significance was accepted for $p$-values less than .05. All p-values were two-tailed. The SPSS statistical package (version 9.0; Real Stats, SPSS Inc., Chicago, IL, USA) was used for all statistical analyses.

\section{RESULTS}

The RTW rate within one year was 59\% $(n=48)$. The cumulative proportion of return to work at 3, 6 and 9 months postinjury was 19\%, 43\% and 53\%, respectively. The majority of patients, 41 $(85 \%)$, who successfully returned to work indicated that they were doing the same kind of work as they had done prior to the injury. Five workers (10\%) switched from a blue to a white collar job; two patients switched from white to blue collar employment (5\%).

The average time off work (TOW) was 31.3 weeks (range $3-52$ weeks, SD 19.4). No significant difference in time off work was found between median nerve injuries ( 24.2 weeks, SD 3.2) and ulnar nerve injuries (30.7 weeks, SD 3.5), $\mathrm{p}=.246$. Combined median-ulnar nerve injury took significantly more time off work, 44.8 weeks (SD 3.5), than both isolated median nerve injury $(p<.001)$ and isolated ulnar nerve injury $(p=.024)$. There was a difference in time off work between blue and white collar workers; blue collar workers averaged 34.4 weeks (range 3-52 weeks, SD 2.6) whereas white collar workers averaged 24.2 weeks (range 3-52, SD 3.6).

The difference in return to work within the year between combined median-ulnar nerve trauma ( $24 \%$ RTW) and an isolated median nerve injury ( $80 \%$ RTW) was $p<.001$. Return to work was also significantly different for combined nerve trauma and an isolated ulnar nerve injury (59\% RTW), $p=.032$. After adjusting for age and sex, no significant difference in return to work potential was found between a median and an ulnar nerve injury $(p=.116)$. After adjusting for age, sex and severity of the trauma, means for grip strength loss, tip pinch strength loss and sensory recovery were lower for people who could return to work within the year compared to those of who could not (table 2). The level of education was positively associated with return to work $(p=.002)$. Higher rates of RTW were found for patients in white collar employment compared to those in blue collar employment $(p=.014)$. Compliance to hand therapy significantly increased return to work $(p=.045)$. Injuries at wrist crease level tended to provide better perspectives than proximal injuries at midforearm level and the region of the flexor elbow crease. Pain in the hand did not influence RTW $(p=.113)$. Odds ratios for the predicting variables for RTW within 1 year are summarized in table 3 . 
Table 2. Adjusted* means for the functional outcome variables of the Return To Work population and No-Return to Work population

\begin{tabular}{llll}
\hline Adjusted means for: & No RTW & RTW & p-value \\
\hline Grip strength loss (0-100) & 40.4 (SE 4.6) & 16.9 (SE 3.3) & $<.001$ \\
Tip pinch strength loss (0-100) & $48.8($ SE 6.3) & 22.4 (SE 4.6) & .002 \\
Sensory recovery (1-5) & 3.5 (SE 0.2) & 2.9 (SE 0.1) & .001 \\
\hline
\end{tabular}

$\mathrm{SE}=$ Standard Error, RTW $=$ Return To Work

* Adjusted for sex, age and hand dominance. For grip strength loss and tip pinch strength loss, severity of the trauma was put in the model as an additional confounding factor

Table 3. Adjusted* odds ratios for ability to Return To Work

\begin{tabular}{llll}
\hline Prognostic Factors & p-value & odds & $\mathbf{9 5 \% ~ C l ~}$ \\
\hline Type of injury (isolated vs combined) & .002 & 7.0 & $2.0-24.3$ \\
Educational level (7-1) & .014 & 1.6 & $1.2-2.4$ \\
Type of job (white vs blue collar) & .014 & 4.3 & $1.3-13.7$ \\
Compliance to hand therapy (yes vs no) & .045 & 3.5 & $1.0-11.6$ \\
Location of lesion (distal, midforearm, proximal) & .154 & 0.6 & $0.3-1.2$ \\
Pain in the hand (0-10) & .113 & 0.7 & $0.3-1.6$ \\
\hline
\end{tabular}

* Adjusted for sex and age. For educational level, type of job was put in the model as an additional confounding factor

\section{DISCUSSION}

One year after suffering from a nerve injury to the upper extremity, $59 \%$ of the patients had returned to work. The ability to return to work after combined nerve injuries was considerably lower than the ability to return to work after isolated nerve injuries. Levels of motor and sensory recovery differed significantly between the RTW and no-RTW workers.

Almost one third of all injuries involve the upper extremities. ${ }^{20}$ The total cost of upper extremity disorders in the United States in 1995 is estimated to be almost $\$ 19$ billion. ${ }^{20}$ Studies have shown that the indirect costs of lost productivity were nearly twice the direct health care costs. ${ }^{14,21,22}$ Returning to employment quickly after upper extremity injury is therefore becoming an issue of growing interest. 23,24

It is well established that patients recovering from upper extremity nerve injury usually do not return to their previous level of functioning. ${ }^{25,26}$ Little investigation has been performed on the probability of return to work after median and ulnar nerve injuries. Published results were mostly based on small study populations. Return to work after upper extremity trauma has been reported to be as low as $0 \%(n=7)$ for combined nerve injuries ${ }^{1}$ or as high as $90 \%(n=54)$ after trauma to the hand. ${ }^{27}$ In our study, 59\% of the workers suffering from upper extremity nerve injury were able to return to work within one year. Patients with isolated median nerve injuries returned to work in a greater percentage than patients with isolated ulnar nerve injuries ( $80 \%$ vs $59 \%$, respectively). The authors believe that the explanation is 2 -fold. First the authors believe that decreased grip-strength (resulting from loss of ulnar intrinsic nerve function) does influence the ability to return to work more strongly because one's grip strength is a more 
valuable factor in performing (hard) labor than one's level of functional sense, which depends on the median nerve. Second, the authors assume the regeneration time of the injured ulnar nerve to be considerably longer than that of the median nerve.

Our results were in agreement with those published by Taha and Taha, who found a 57\% return to work ratio after sustaining a missile injury to the ulnar nerve $(n=14) .{ }^{1}$ Return to work after median nerve injury $(n=11)$ in the study by Taha and Taha was worse $(55 \%)$. Compared with non-nerve trauma to the upper arm and hand, the potential to return to work after forearm nerve injury is considerably lower., ${ }^{9,27}$ It is reasonable to expect a low ability to return to work for combined median-ulnar nerve injuries, in accordance with earlier reports on outcomes following this kind of severe trauma. ${ }^{1,29}$ Prospects of a successful return to work after combined median-ulnar nerve injuries seem to be as bleak as those after upper extremity amputation. $22,30,31$

We found an average TOW of 31 weeks after injury. Results presented by this study should be regarded as primarily descriptive because the Dutch setting of workers compensation insurance does not allow objective TOW measurement beyond 52 weeks after the injury. Sick pay then is being replaced by permanent disability. The automatically enrolled disability regulations enable workers to return to work only after agreement on recovery between the patient and his physician. Therefore, work absence in this study is limited to 52 weeks. Consequently, the average TOW is underestimated as the provided mean TOW is used as a reference for the first year only. At the moment we are performing a large prospective multicenter study to investigate work absence beyond 52 weeks.

Information on risk factors for return to work resulting from upper extremity trauma has been scarce. ${ }^{32-36}$ Therefore, predicting the ability to return to work after forearm nerve injury has been very difficult. Several factors contributing to the profile of a worker at high risk not to return to work within one year were found. Isolated nerve injuries result in higher rates of return to work than combined nerve injuries. Functional recovery was comparable with other outcome studies on upper extremity nerve injury. ${ }^{26,37-39}$ The importance of grip strength loss, tip pinch strength loss and sensory recovery as a predictive value for RTW was comparable with earlier results. This supports opinion in literature that grip and tip pinch strength measurements are important and reliable factors for capability to work. ${ }^{40,41} \mathrm{~A}$ high level of education has been described as a protective factor for work absence after injury. ${ }^{11,14,42}$ Blue collar employment proved to hinder return to work in the first year after injury: expectations to return to work of white collar employees were times 4.3 higher than that of manual laborers (table 3). Compliance to the standard hand therapy program offered, was found to correlate strongly with successful return to work. ${ }^{42-44}$ The program focussed on mobility, muscle strength and sensory reeducation. The procedure did not include work hardening. Nevertheless, after completing the program chances to return to work within the year were times 3.5 higher. No important influence in our study was exerted by the location of the injury; however the more proximal the injury was 
located, the more difficult it was to return to work within the year. Pain in the hand was not a predictor for RTW in this study.

The precarious increase of costs due to injury is a serious problem that societies have been facing for years. Therefore therapists have been requested to help minimize costs by returning a worker as rapidly as possible to the workplace. ${ }^{8,45}$ Efforts to get workers suffering from upper extremity nerve trauma back to employment are usually done through special rehabilitation programs. These programs have significantly reduced time off work. ${ }^{44,46,47}$ Effective rehabilitation programs should be based on the profile drawn up by the risk factors that delay return to work after upper extremity nerve injury. ${ }^{8,45}$ The profile of a patient with a nerve injury who quickly returns to work comprises both demographic- and injury-related characteristics. The worker is highly educated, holds a white collar job and is compliant with hand therapy. The injury is preferably isolated. The level of functional recovery was higher for the RTW population. By evaluating the grip strength loss, tip pinch strength loss and sensory recovery, it is possible to reason whether a patient is functionally capable of returning to work. Insight into these factors also provides an economic advantage because a quick return to work offers an optimal form of rehabilitation. ${ }^{46}$ In addition, an early and more accurate prognosis of perspectives to return to work can be provided to the patient.

After analysis of a large number of patients, this study found several factors that have an influence on return to work after median and ulnar nerve injury. By means of these factors, we provided a framework of understanding recovery and rehabilitation after upper extremity nerve trauma. In planning rehabilitation services, careful consideration ought to be given to these factors in order to limit work absence and related costs. In case the profile of a worker who does not return to work consists of factors that are not under control of the physician, the patient should be retrained or directed at different employment as early as possible. 


\section{REFERENCES}

1. Taha A, Taha J. Results of suture of the radial, median, and ulnar nerves after missile injury below the axilla. J Trauma 1998;45:335-339.

2. Eggers IM, Mennen U. The EFFUL (Evaluation of Function in the Flail Upper Limb) system. A ranking score system to measure improvement achieved by surgical reconstruction and rehabilitation. $J$ Hand Surg 1997;22B:388-394.

3. Frykman GK. The quest for better recovery from peripheral nerve injury: current status of nerve regeneration research. J Hand Ther 1993;6:83-88.

4. Pransky G, Feuerstein M, Himmelstein J, Katz J, Vickers-lahti M. Measuring functional outcomes in work-related upper extremity disorders. Development and validation of the Upper Extremity Function Scale. J Occup Environ Med 1997;39:1195-1202.

5. Rosen B. Recovery of sensory and motor function after nerve repair. A rationale for evaluation. $J$ Hand Ther 1996;9:315-327.

6. Lithell M, Backman C, Nyström A. Pattern recognition in post-traumatic cold intolerance. J Hand Surg 1997;22B:783-787.

7. Irwin M, Gilbert S, Terenghi G, Smith RT, Green C. Cold intolerance following peripheral nerve injury. Natural history and factors predicting severity of symptoms. J Hand Surg 1997;22B:308-316.

8. Schultz-Johnson K. Assessment of upper extremity-injured persons' return to work potential. J Hand Surg 1987;12A:950-957.

9. Skov O, Jeune B, Lauritsen JM, Barfred T. Time off work after occupational hand injuries. J Hand Surg 1999;24B:187- 189.

10. Noble J, Munro CA, Prasad VS, Midha R. Analysis of upper and lower extremity peripheral nerve injuries in a population of patients with multiple injuries. J Trauma 1998;45:116-122.

11. MacKenzie EJ, Shapiro S, Smith RT, Siegel JH, Moody M, Pitt A. Factors influencing return to work following hospitalization for traumatic injury. Am J Of Public Health 1987;77:329-334.

12. Burnham RS, Warren SA, Saboe LA, Davis LA, Russell GG, Reid DC. Factors predicting employment 1 year after traumatic spine fracture. Spine 1996;21:1066-1071.

13. Crook J, Moldofsky H, Shannon H. Determinants of disability after a work related musculetal injury. J Rheumatol 1998;25:1570-1577.

14. Tate DG. Workers' disability and return to work. Am J Of Phys Med Rehabil 1992;71:92-96.

15. Morris JAJ, Sanchez AA, Bass SM, MacKenzie EJ. Trauma patients return to productivity. J Trauma 1991;31:827-834.

16. Mathiowetz V, Weber K, Volland G, Kashman N. Reliability and validity of grip and pinch strength evaluations. J Hand Surg 1984;9A:222-226.

17. Petersen $\mathrm{P}$, Petrick $\mathrm{M}$, Connor $\mathrm{H}$, Conklin D. Grip strength and hand dominance: challenging the $10 \%$ rule. Am J Occup Ther 1989;43:444-447.

18. Bell-Krotoski J, Weinstein S, Weinstein C. Testing sensibility, including touch-pressure, two-point discrimination, point localization, and vibration. J Hand Ther 1993;6:114-1123.

19. Imai H, Tajima T, Natsuma Y. Interpretation of cutaneous pressure threshold (Semmes-Weinstein monofilament measurement) following median nerve repair and sensory reeducation in the adult. Microsurgery 1989;10:142-144.

20. Kelsey J, Praemer A, Nelson L, Felberg A, Rice D. Upper extremity disorders: Frequency impact and cost. New York: Churchill Livingstone, 1997.

21. MacKenzie, E.J., et al., Return to work following injury: the role of economic, social, and job-related factors. Am J Of Public Health 1998;88:1630-1637.

22. O'Sullivan ME, Colville J. The economic impact of hand injuries. J Hand Surg 1993;18B:395-398.

23. van Beeck EF, van Roijen L, Mackenbach JP. Medical costs and economic production losses due to injuries in the Netherlands. J Trauma 1997;42:1116-1123.

24. Hashemi L, Webster BS, Clancy EA, Courtny TK. Length of disability and cost of work-related musculoskeletal disorders of the upper extremity. J of Occup and Environ Med 1998;40:261 -269.

25. Chin G, Weinzweig N, Mead M, Gonzalez M. "Spaghetti wrist": management and results. Plast Reconstr Surg 1998;102:96-102. 
26. Trevett MC, Tuson S, de Jager LT, Juon JM. The functional results of ulnar nerve repair. Defining the indications for tendon transfer. J Hand Surg 1995;20B:444-446.

27. Watts A, Greenstock M, Cole R. Outcome following the rehabilitation of hand trauma patients: The importance of a sujective functional assessment. J Hand Surg 1998;23B:485-489.

28. Smith ME, Auchincloss JM, Ali MS. Causes and consequences of hand injury. J Hand Surg 1985;10B:288-292.

29. Rogers G, Henshall A, Sach R, Wallis K. Simultaneous laceration of the median and ulnar nerves with flexor tendons at the wrist. J Hand Surg 1990;15A:990-995.

30. Livingston DH, Keenan D, Kim D, Elcavage J, Malangoni MA. Extent of disability following traumatic extremity amputation. J Trauma 1994;37:495-499.

31. Pinzur MS, Angelas J, Light TR, Izuierdo R, Pluth T. Functional outcome following traumatic upper limb amputation and prosthetic limb fitting. J Hand Surg 1994;19A:836-839.

32. Burdorf A, Naaktgeboren B, Post W. Prognostic factors for musculoskeletal sickness absence and return to work among welders and metal workers. Occup Environ Med 1998;55:490-495.

33. Blair SJ, McCormick E, Bear-Lehman J, Fess EE, Rader E. Evaluation of impairment of the upper extremity. Clin Orthop 1987;221:42-58.

34. Bonzani PJ, Millender L, Keelan B, Mangieri MG. Factors prolonging disability in work-related cumulative trauma disorders. J Hand Surg 1997;22A:30-34.

35. Frykman GK, Waylett J. Rehabilitation of peripheral nerve injuries. Orthop Clin North Am 1981;12:361-379.

36. Jaquet JB, Luijsterburg AJM, Kalmijn S, Kuypers PDL, Hofman A, Hovius SER. Median, Ulnar, and Combined Median-Ulnar Nerve Injuries: Functional Outcome and Return to Productivity. J Trauma 2001;51:687-692.

37. Chassard M, Pham E, Comtet J. Two-point discrimination tests versus functional sensory recovery in both median and ulnar nerve complete transections. J Hand Surg 1993;18B:790 - 796.

38. Kallio $\mathrm{P}$, Vastamaki $\mathrm{M}$, Solonen $\mathrm{K}$. The results of secondary microsurgical repair of radial nerve in 33 patients. J Hand Surg 1993;18B:320-322.

39. Kallio P, Vastamaki M. An analysis of the results of late reconstruction of 132 median nerves. J Hand Surg 1993;18B:97-105.

40. Hamilton A, Balnave R, Adams R. Grip strength testing reliability. J Hand Ther 1994;7:163 - 170 .

41. Marx RG, Bombardier C, Wright JG. What do we know about the reliability and validity of physical examination tests used to examine the upper extremity? J Hand Surg 1999;24A:185 - 193.

42. MacKenzie EJ, Siegel JH, Shapiro S, Moody M, Smith RT. Functional recovery and medical costs of trauma: an analysis by type and severity of injury. J Trauma 1988;28:281-297.

43. Brenneman FD, Redelmeier DA, Boulanger BR, McLellan BA, Culhane JP. Long-term outcomes in blunt trauma: who goes back to work? J Trauma 1997;42:778-781.

44. Blackmore S, Wright P, Petralia PB. Analysis of treatment effectiveness and patient satisfaction. J Hand Ther 1990;3:111-116.

45. Richmond TS, Kauder D, Schwab CW. A prospective study of predictors of disability at 3 months after non-central nervous system trauma. J Trauma 1998;44:635-643.

46. Kasdan ML, June LA. Returning to work after a unilateral hand fracture. J Occup Med 1993;35:132-135.

47. Ballard $M$, Baxter $\mathrm{P}$, Bruening L, Fried S. Work therapy and return to work. Hand Clinics 1986;2:247-258. 


\section{CHAPTER 6}

\section{EARLY PSYCHOLOGICAL STRESS FOLLOWING FOREARM}

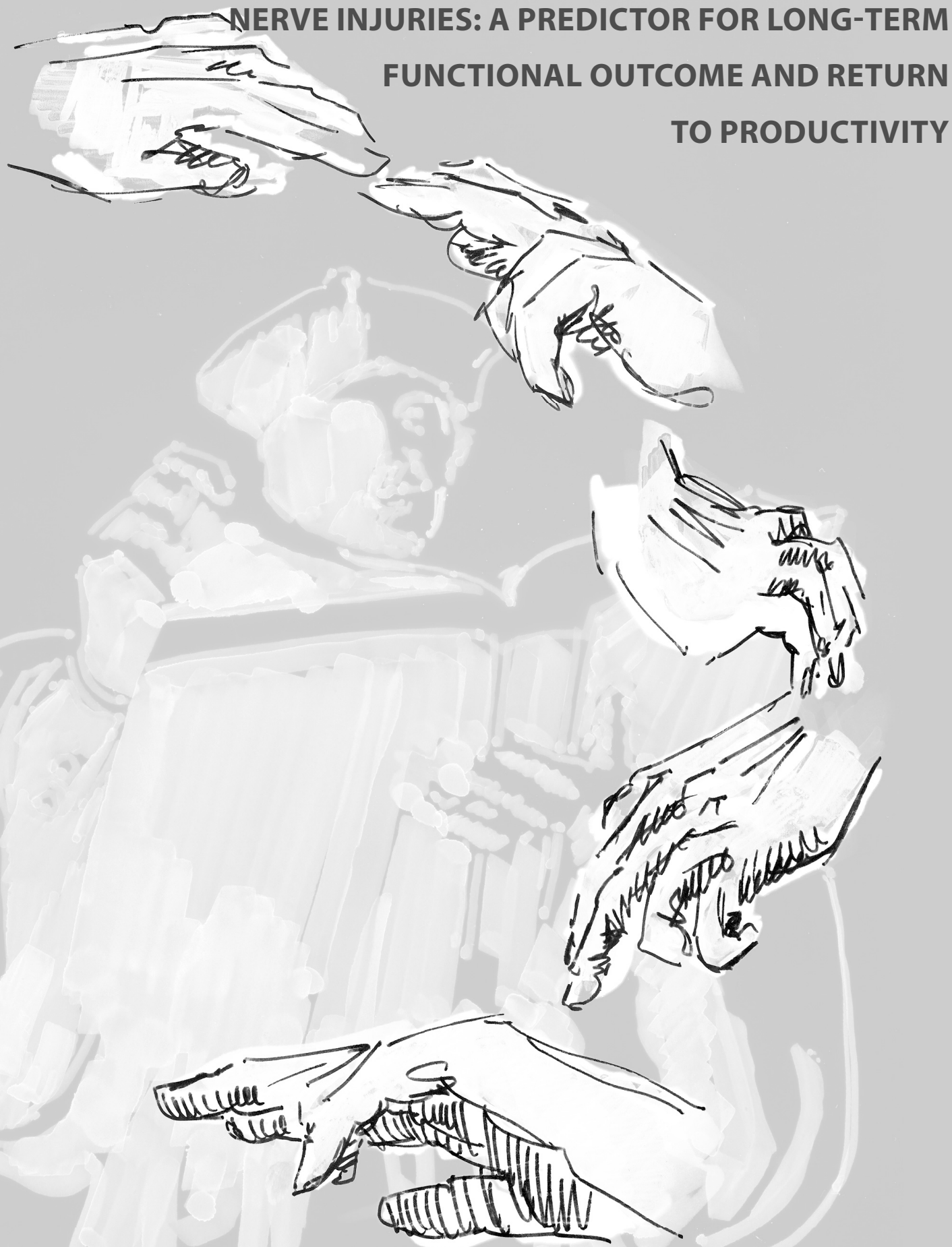

Jaquet, J. B., Kalmijn S., Kuypers, P.D. L., Hofman, A., Passchier, J. and Hovius S.E. R.

Annals of Plastic Surgery: 49(1): $82-90$ 



\section{ABSTRACT}

Introduction - Forearm and wrist injuries can result in a non-functional hand caused by loss of motor and sensory functions. Psychological stress is known to accompany traumatic hand injuries and may therefore affect functional outcome.

Methods - This was a retrospective study of 107 patients diagnosed with a median, ulnar or combined median-ulnar nerve injury (79\% response rate), who completed a questionnairepackage consisting of Impact of Event Scale (IES), DASH (Disabilities of Arm Shoulder and Hand) and a questionnaire concerning Return To Work (RTW) and Time Off Work (TOW). In an outpatient setting motor and sensory recovery were examined.

Results - Ninety-four percent experienced early psychological stress. Thirty-six (36\%) percent of subjects reported sufficient symptoms at one month post-operatively to be classified as, in need for psychological treatment (IES > 30). Combined median-ulnar nerve injuries (mean 35.0 \pm SD 20.3) were accompanied with a higher psychological stress compared to the single nerve injuries (median: mean $=24.2 \pm 20.6$ and ulnar: mean $=22.6 \pm 19.5$ : respectively $p=.049$ and $p=.021$ ). Multiple linear regression adjusting for age, sex and severity of the trauma revealed an association between the IES-score and functional symptom score (FSS) (Beta $=0.51,95 \% \mathrm{Cl}$ : $0.35-0.65$ ), mean TOW (Beta $=0.44,95 \% \mathrm{Cl}: 0.25-0.75$ ) and motor recovery (Grip: Beta $=0.37$, 95\%Cl: 0.09-0.65; Tip-pinch: Beta $=0.46,95 \% \mathrm{Cl}: 0.13-0.80$ ). Patients with higher scores on the IES were found to be at increased risk for incapacity for work (OR 3.32, 95\%Cl: 1.60-6.91). High education was found to be a protecting variable for post traumatic psychopathology (Beta $=-0.23,95 \% \mathrm{Cl}:-6.05--.246)$.

Conclusions - This study demonstrated a high level of early posttraumatic psychological stress following forearm and wrist nerve injuries. These data provide evidence that functional outcome and work resumption are negatively influenced by early psychological stress, independent from severity of the somatic trauma. This indicates that outcome following upper extremity nerve injuries may be positively influenced by psychological intervention. 


\section{INTRODUCTION}

Inability to use the hand, no matter the "causation" will have major consequences. Traumatic upper extremity nerve injuries are leading causes of severe functional disability and prolonged incapacity for work. ${ }^{1}$ Post injury rehabilitation is often seen in physical terms, on the other hand it has been suggested that the psychological state of the patient may affect outcome. ${ }^{2}$ Injuries of the hand attack the personality itself and therefore psychological factors could play an important role in the final functional outcome of the therapy. ${ }^{2-6}$

In literature growing attention can be perceived on patients' quality of life.? It has been suggested that psychological morbidity is an important part of patients perceived general health. ${ }^{8}$ Posttraumatic stress (PTS) among trauma patients is a well-recognized phenomenon and disabling consequence of trauma. ${ }^{9}$ Although, functional disabilities are extensively examined, few investigations have focused on psychological stress following upper extremity traumas. Former contributions dealing with psychological stress indicated that peripheral nerve injury patients are at risk to develop psychological problems. ${ }^{10,11}$ Ninety-four percent of severe hand injuries experience psychological symptoms early in rehabilitation. ${ }^{12}$

Disability prevention has stimulated efforts to recognize contributing factors for functional outcome. Several studies have identified risk factors for disappointing functional recovery following upper extremity nerve injuries. ${ }^{13-17}$ However to our knowledge, the long-term effect of early post-traumatic psychological stress on functional outcome has not been previous investigated. Outcome following a peripheral nerve injury is related with the severity of the trauma. ${ }^{18}$ In addition, severity of the trauma is associated with the development and the amount of post-traumatic psychological stress. ${ }^{19}$ This indicates that psychological stress may thus be associated with outcome, by an indirect pathway (severity of the trauma). But its relationship might also be a more directly character, i.c. by the impact of distress on the outcome.

The present investigation was designed to evaluate the psychological impact of forearm nerve injuries and to assess the incidence of post-traumatic psychological stress. The main objective was, to examine to what extent psychological stress has an effect on functional outcome and return to work. Furthermore, we aimed to identify risk factors for early psychological stress.

\section{PATIENTS AND METHODS}

Study cohort

The study cohort was defined as all subjects who entered the Academic Hospital Rotterdam for operative treatment of a median, ulnar or combined median-ulnar traumatic nerve injury during the period between January 1990 and December 1998. We reviewed all medical records of patients who suffered an upper extremity nerve injury. A peripheral nerve injury chart was designed to score baseline data about: etiology, diagnosis, treatment, complications 
and work status. To participate in this study the forearm nerve injuries were required to meet three entrance criteria. 1) A trauma of at least a single ulnar or median nerve located within the area between the wrist crease (distal border) and the flexor elbow crease (proximal border). 2) Patients had to be 12 years or older at the day of their injury and 3) Excluded were subjects diagnosed with complete amputation of the hand followed by a replantation, patients with associated hand and or forearm fractures and excluded were patients with amputation of hand or digits. Concerning the entrance criteria 136 patients were included.

Follow-up data were collected in two ways: a questionnaire package and a follow-up session at our outpatient clinic. Hospital medical records, general practitioner and municipal archives were consulted to trace the primarily selected patient sample. A questionnaire package was mailed to the included individuals with a cover letter requesting participation in a retrospective follow-up study on psychological consequences following a trauma of the forearm. Patients were asked to complete the questionnaires. The questionnaire package consisted the Impact of Event Scale (IES), DASH (Disabilities of Arm, Shoulder, and Hand) and a questionnaire concerning profession and return to work potential. For the Impact of Event Scale the study population had to answer the IES, for the first month post-operatively. Three follow-up mailings were sent to non-responders at a two-month interval. This resulted in a study sample of 107 patients (response rate 79\%). Thirteen (13) subjects rejected participation. Of the remaining non-responders, 13 were untraceable (moved to foreign countries or were not known by municipal records), 1 patient was kept in a foreign prison and 2 patients died without any relation to the surgery.

The protocol of the study was approved by the Medical Ethics Committee of Academic Hospital Rotterdam 'Dijkzigt' and informed consent was provided by all participants.

Psychological assessment

The Impact of Event Scale (IES) ${ }^{20}$ was selected to establish psychological impact and posttraumatic psychological stress, as contributing risk factors for functional outcome and return to work potential. Since its introduction in 1979, by Horowitz and co-authors, it is widely used. The Impact of Event Scale, is a 15-item self-report questionnaire that assesses stress-related symptomatology and records patient's subjective responses to the traumatic event. Patients were asked to rate questions such as: "I had trouble falling asleep or staying asleep, because of pictures or thoughts about it that came into my mind", "I tried not to think about it" and "Any reminder brought back feelings about it". Each item has a scoring range of 0 -5 on a 4-point scale $(0=$ not at all, $1=$ rarely, $3=$ sometimes and $5=$ often $)$, with seven items covering intrusive symptoms and eight items avoidance symptoms. Total IES scores range from 0 to 75 (worst score). The results on the clinical utility of the IES, showed that the Impact of Event Scale has sufficient reliability and validity to warrant its use as a clinical screening method for traumatic stress. $^{21,22}$ 


\section{Outcome measures}

Outcome could be studied with respect to functional recovery, Return To Work, Time Off Work (range 0-52 weeks), sensory and motor recovery. To assess functioning in daily living, the DASH-questionnaire (baseline assessment) was used according to version 2.0 (may 1997). ${ }^{23,24}$ Using a self-report system, patients attribute scores $1-5$, on thirty items relating to functional activities and symptoms. The raw functional symptom score (FSS) is transformed to a 0-100 scale, whereby 0 reflects minimum and 100 maximum disability. A questionnaire concerning profession and return to work had been developed by the authors and was applied to examine return to pre injury work and time till work resumption (in months).

Patients who returned the questionnaires were invited to our hospital for a visit in an outpatient setting. Subjects who were unable to come to our hospital were visited at home. During a one-hour session motor and sensory recovery were examined. Furthermore patients were requested to complete the IES again for the current psychological status. A research fellow who did not operate on any of the patients and was not involved in the post-operative treatment performed the assessment. In addition, the follow-up session was used to check accuracy of the self-reported outcome data and to complete the questionnaires in case of incompleteness.

To assess motor recovery, grip strength and tip-pinch grip strength were measured using respectively, Jamar hand dynamometer and pinch gauge meter (kilograms force) (DeRoyal, TN, USA). ${ }^{25}$ Both the injured and uninjured hand were tested three times. In case the third measurement was highest, a fourth measurement was performed. All results were noted and the mean was calculated. Results were mapped as percentage loss compared to the unaffected hand with a scoring range of $-100 \%$ to $100 \%$. Corrections for hand dominance were made. ${ }^{26}$ In case the right hand was the dominant hand, the left hand was considered to have $10 \%$ less grip- and tip pinch-strength than the right hand, in case the left hand was the dominant hand, the right hand and left hand were considered to be equally strong. In five cases the affected hand was slightly stronger $(>-10)$ than the unaffected hand after a mean of 5.5 years of followup. For statistical analysis these cases were considered as $0 \%$ grip- or tip pinch-strength loss.

Sensory recovery was tested with Semmes-Weinstein monofilaments (North Coast Medical Inc, CA, USA). The monofilaments $(2.83,3.61,4.31,4.56$ and 6.10$)$ were used according to the procedure described by Bell-Krotosky. ${ }^{27}$ Ten zones in the hand were tested, 6 in the area of the median nerve and 4 in the area of the ulnar nerve. The scores were interpreted as suggested by Imai, ${ }^{28}$ and are listed in table 1 . Patients who did not respond on the ' $6.10^{\prime}$-filament were considered as untestable.

In two patients nerves of both the left and right arm were injured. No valid reference for sensory and motor recovery could be obtained. Therefore these patients were excluded from analysis concerning sensory and motor recovery. 
Table 1. Interpretation of Semmes Weinstein monofilaments

\begin{tabular}{ll}
\hline Quality of sensation (range 1-5) & Filament marking \\
\hline Normal (=1) & $1.65-2.83$ \\
Diminished light touch (=2) & $3.22-3.61$ \\
Diminished protective sensation (=3) & $3.84-4.31$ \\
Loss of protective sensation (=4) & $4.56-6.65$ \\
Untestable, no sensation (=5) & $>6.65$ \\
\hline
\end{tabular}

\section{Statistical methods}

Responders and non-responders were compared to identify if selection bias had occurred. The subjects were compared, using chi-square analysis for categorical data and $t$-tests for continuous variables. Differences in early psychological stress between median, ulnar and combined median-ulnar nerve injuries were obtained with analysis of covariance (ANCOVA), controlling for age and gender. Subjects who attempted suicide $(n=7,6.5 \%)$ were excluded from the analysis concerning the Impact on Event Scale. To investigate the association between psychological stress and functional outcome, a homogenous population was needed. Most nerve injuries have an accidental cause. Inclusion of the patients who attempted suicide might lead to misinterpretation of the results.

We performed logistic regression analysis to estimate odds ratio (OR) and 95\% confidence interval $(\mathrm{Cl})$ for the association between post operative psychological stress and return to work within one year, adjusting for age, sex and severity of the trauma. Multiple linear regression analysis was used to describe the relation with continuous outcomes. The Beta coefficient indicates the predicted increase of the outcome variable for each unit increase in the predicting variable. Multiple linear regression analysis was applied to identify early psychological stress as a predictor of sensory recovery, motor recovery, functional symptom score and time off work. Age, gender and severity of the trauma (=number of severed structures, range 1-15) were always included as confounding factors. Means for the outcome variables according minor, moderate and severe psychological stress were obtained with analysis of covariance (ANCOVA), controlling for age, gender and severity of the trauma. All test were performed two-sided and a p-value of $<.05$ was considered as statistically significant. Data analyses were performed using SPSS statistical software, version 9.0.

\section{RESULTS}

\section{Study sample}

Characteristics of responders and non-responders are presented in table 2 . The responders and non-responders had similar age and gender distributions and no statistical difference was found for severity of the injury. 
Table 2. Characteristics of responders $(n=107)$ and non-responders $(n=29)$

\begin{tabular}{lcc}
\hline Characteristic & $\begin{array}{l}\text { Responders } \\
(\mathbf{n = 1 0 7 )}\end{array}$ & $\begin{array}{l}\text { Non-responders } \\
(\mathbf{n}=\mathbf{2 9 )}\end{array}$ \\
\hline Age & $30.7 \pm 12.0$ & $28.9 \pm 12.0$ \\
Mean \pm SD & $14-67$ & $15-61$ \\
$\quad$ Range & & \\
Sex (\%) & $85(79)$ & $20(69)$ \\
$\quad$ Male & $22(21)$ & $9(31)$ \\
Female & & \\
Type of injury (\%) & $44(41)$ & $15(52)$ \\
Median & $41(38)$ & $11(38)$ \\
Ulnar & $22(21)$ & $3(10)$ \\
Combined & & \\
Dominant hand affected & $64(59)$ & $13(45)$ \\
Yes (\%) & $7(6)$ & $6(21)$ \\
Unknown (\%) & & \\
Structures affected & $5.8 \pm 4.1$ & $1-15$ \\
Mean \pm SD & $1-15$ & \\
Range & & $23(79)$ \\
Lesion (\%) & $73(68)$ & $3(10)$ \\
Sharp & $16(15)$ & $2(7)$ \\
Crush & $13(12)$ & $1(3)$ \\
Avulsion & $5(5)$ & \\
Unknown & & \\
\hline
\end{tabular}

$S D=$ Standard deviation.

Data are reported for the 107 patients who were willing to participate. The study sample consisted of 85 male and 22 female $(m: f=3.9: 1)$, with a mean age of 30.7 years (SD:12.0 and range 14-67) at the day of repair. Accidental injuries at work was the primary cause of trauma (31.8\%), followed by activities at home (29.0\%), nightlife (13.1\%), victim of some sort of violence (8.4\%), suicide attempt (4.7\%) and others (e.g. sport accidents, $7.5 \%)$. Mean follow-up time was 5.5 years (range 1 - 10 years).

Psychological impact

The results from the Impact of Event Scale (IES) revealed that $94 \%$ of the study sample experienced psychological stress within the first month post-operatively (mean score $25.8 \pm 20.5$ ). Thirty-six (36.1\%) percent of subjects reported sufficient symptoms to be in need for psychological treatment, on basis of scores greater than 30 . The average scores on the Impact of Event intrusion and avoidance subscales were respectively, 14.2 (SD:10.8) and 11.5 (SD: 10.8). Twenty-eight percent (28\%) of the subjects reported above the threshold for severe psychological stress, that is a score of 40 on the IES. A minor response $(<18)$ was reported by $41 \%$ and a moderate response $(18-39)$ by $31 \%$ of the study sample. Combined median-ulnar nerve injuries reported higher psychological stress (mean $=35.0 \pm 20.3$ ) within the first month postoperatively, than the single nerve injuries (median: mean $=24.2 \pm 20.6$ and 
Table 3. Multiple linear regression analysis: Adjusted* betas ( $95 \%$ confidence intervals) for association between predicting variables and early psychological stress

\begin{tabular}{llll}
\hline Predicting variables & Beta & $\mathbf{9 5 \%} \mathbf{C l}$ & $\mathbf{p}$-value \\
\hline N. of severed structures (1-15) & .99 & $0.05-1.92$ & .038 \\
Single vs combined & 12.2 & $2.73-21.6$ & .012 \\
Gender (male vs female) & 12.9 & $3.5-22.7$ & .008 \\
Arterial bleeding & .98 & $-6.91-8.86$ & .807 \\
Education (1-7) & -.23 & $-6.05--0.25$ & .034 \\
Dominant hand affected & 2.6 & $-5.91-11.0$ & .550 \\
\hline
\end{tabular}

Beta = beta coefficient; $\mathrm{Cl}=$ confidence interval

${ }^{*}$ Adjusted for age

${ }^{\dagger}$ As defined by the IES, score ranging from 0 (no psychological stress) to 75 .

Table 4. Multiple linear regression analysis: Adjusted* betas (95\% confidence intervals) for association between early psychological stresst and several outcome variables

\begin{tabular}{lllll}
\hline Outcome variables & Range & Beta & $\mathbf{9 5 \% ~ C l}$ & p-value \\
\hline Functional recovery (FSS) & $0-100$ & .51 & $0.35-0.65$ & $<.001$ \\
Grip strength loss & $0-100$ & .37 & $0.09-0.65$ & .01 \\
Tip-pinch strength loss & $0-100$ & .46 & $0.13-0.80$ & .007 \\
Sensory recovery & $1-5$ & .01 & $-0.01-0.02$ & .409 \\
Time off Work (TOW) & $0-52$ & .44 & $0.25-0.75$ & $<.001$ \\
\hline
\end{tabular}

Beta = beta coefficient; $\mathrm{Cl}=$ confidence interval

* Adjusted for sex, age and severity of the injury (= number of severed structures)

${ }^{\dagger}$ Assessed by the IES, continuously (range 0 - 75)

ulnar: mean $=22.6 \pm 19.5$ : respectively $p=.049$ and $p=.021$ ). No difference was found between median and ulnar nerve injuries $(p=.707)$. In the multiple linear regression model adjusted for age (table 3), the significant independent predictors of post-traumatic psychological stress were number of severed structures (Beta $=0.99, \mathrm{p}=.038$ ), combined median ulnar nerve injuries (Beta $=12.2, \mathrm{p}=.012$ ) and gender (Beta $=12.9, \mathrm{p}=.008$ ). Education ( $1=$ did not finish primary school $-7=$ universal degree) was found a protecting variable for psychological stress (Beta $=-0.23, p=.034)$. Concomitant arterial bleeding and injury of the dominant hand, were not significantly associated with the amount of psychological stress, after adjustment for confounding factors. Patients who attempted suicide $(n=7)$ reported higher psychological stress (mean $34.7 \pm 35.8$ ), however this was not statistical significant $(p=.234)$. Mean IES score on average 5.5 years after the trauma, assessed during follow-up, was 6.5 (SD: 12.4) and 4 percent of the patients reported an IES $>30$.

The results of multiple linear regression analysis on early psychological stress as a predictor of several outcome variables are shown in table 4 . The early psychological stress, within the first month, measured with the Impact of Event Scale (IES), was associated with functional outcome. Multiple linear regression adjusting for age, sex and severity of the trauma (= number of severed structures) revealed a positive relation between the IES-score and Functional Symptom Score (FSS) (Beta coefficient $=0.51,95 \% \mathrm{Cl}: 0.35-0.65, \mathrm{p}<.001$ ). Motor recovery, as assessed by grip- 
Table 5. Adjusted* means for the outcome variables according minor, moderate and severe psychological stress $\dagger$

\begin{tabular}{lcccc}
\hline Adjusted means for: & Minor & Moderate & Severe & p-value \\
\hline Functional recovery (FSS) (0-100) & 8.3 & 19.8 & 34.9 & $<.001$ \\
Grip strength loss (0-100) & 16.8 & 21.8 & 31.1 & .09 \\
Tip-pinch strength loss (0-100) & 23.2 & 32.0 & 44.1 & .06 \\
Sensory recovery (1-5) & 2.7 & 3.6 & 3.2 & .06 \\
Time off Work (0-52) & 23.5 & 33.5 & 45.3 & .001 \\
\hline
\end{tabular}

${ }^{*}$ Adjusted for sex, age and severity of the injury

${ }^{\dagger}$ Assessed by the IES: minor IES $<18$, moderate IES 18 - 39 and severe IES 40 - 75

strength and tip-pinch grip strength, was significantly associated with IES-score (respectively, $\mathrm{p}=.010$ and $\mathrm{p}=.007$ ). Sensory recovery was not affected by early psychological stress (Beta coefficient $=.01,95 \% \mathrm{Cl}:-0.01-0.02, \mathrm{p}=.409$ ). Adjusted means for the outcome variables according minor, moderate and severe psychological stress are presented in table 5.

Subjects who were able to restart working within one year, had lower IES scores than those who were not reemployed within one year $(18.5 \pm 16.2$ vs $34.3 \pm 18.3, p<.001)$. After adjustment for age, sex and severity of the injury, logistic regression analysis showed that patients with higher (classified as minor, moderate and severe) psychological stress, according the IES morbidity scale, were found to be at increased risk for incapacity for work $(O R=3.32$, $95 \% \mathrm{Cl}: 1.6-6.91, \mathrm{p}=.001)$. This can be interpreted, that patients who suffered severe early posttraumatic psychological stress are six times more likely not to return to work within one year, compared to the group which reported a minor psychological stress. Mean Time Off Work (TOW) was 32.7 weeks (SD: 21.1). In multiple linear regression analysis, adjusted for age, sex and severity of the injury, early psychological stress showed to be a predictor of time off work (Beta coefficient $=0.44,95 \% \mathrm{Cl}: 0.25-0.75, \mathrm{p}<.001$ ).

\section{DISCUSSION}

In this study the association between posttraumatic psychological stress and different outcome variables following trauma of upper extremity nerves was investigated. Our results showed that psychological stress following traumatic upper extremity injuries is considerable. Combined median-ulnar nerve injuries are at greater risk of early psychological stress than single nerve injuries. Furthermore, this study identified early psychological stress after injury (high scores on the impact of event scale) as a prognostic indicator for functional recovery, motor recovery, capacity for work and time till work resumption. High educational level was associated with lower levels of post-traumatic psychological stress.

Upper extremity nerve injuries are a major cause of morbidity and can cause long lasting and in some cases, permanent disability. In addition, it was not surprising to discover the presence of posttraumatic psychological stress following median and ulnar nerve injuries. Even for a patient with a good psychological status, it is hard to live with a partly paralyzed hand. According to 
the DSM IV, Posttraumatic Stress Disorder is characterized by persistent reexperiencing of the traumatic event, avoidance of stimuli associated with the trauma and numbing of general responsiveness and persistent symptoms of increased arousal. ${ }^{29}$ Comparing psychological stress of forearm nerve injuries with previously reported impact scores of other stressful events, it can be concluded that disability of hand-function is a stressful event. This study observed an average IES-score of 26, which is comparable to the psychological distress found among survivors of the disaster with the cruise-ship Estonia. ${ }^{30}$ Grunert and colleagues demonstrated high incidences of psychological stress following hand injuries, mainly in the first two months. ${ }^{4}$ Previous studies have reported a decrease of psychological stress during the first two years after the accidental injury, which was comparable to our results. ${ }^{31,32}$ However, psychological symptoms following work-related hand injuries were still persistent 18 months post-injury and continued to be debilitating. ${ }^{11}$ In most forearm nerve injuries two years may not be enough for adequate motor and sensory recovery. ${ }^{16} \mathrm{Hand}$ and forearm injury patients are concerned about their ability to reuse their disabled hands for activities of daily living and work. ${ }^{6}$ To our opinion daily confrontation with a disabled functional hand will cause considerable psychological stress and may even exist after two years. Prospective extension is needed to examine this hypothesis.

Our results confirm and extend the findings of earlier studies that psychological stress is related to the intensity of the traumatic event. ${ }^{19,31}$ Acute psychological stress varied according the type and severity of the trauma. No major differences in psychological stress could be found between single median and single ulnar nerve injuries. Combined median-ulnar nerve injuries end in a much worse condition and might even total paralyze the hand. ${ }^{33}$ It was therefore not surprising to find a higher psychological stress for the combined nerve injuries. On the other hand, concomitant injury of radial or ulnar artery seemed not to be associated with the posttraumatic psychological stress.

Functional status of the hand is a combination of both sensory and motor recovery. Functional recovery following nerve injuries is determined by a number of factors. The present study revealed a relation between early posttraumatic stress (PTS) and long-term functional outcome. These findings are in line with the results that general health outcome is compromised by post-traumatic stress disorders. ${ }^{8}$. Richmond and co-authors found high levels of intrusive thoughts to be predictive of severe disability at three months after discharge. ${ }^{10}$ Surprisingly, no association was found between the amount of posttraumatic stress and long term sensory recovery. Sensory recovery of the hand and fingers depends on a reorganization of the somatosensory cortex. ${ }^{34}$ Sensory perception and the process of reorganization will start when target skin areas have been reinnervated. Depending on the level of the injury, this may take at least several months. It can be expected that the amount of psychological stress is then diminished and may less influence long-term sensory outcome.

In comparison with earlier studies dealing with RTW potential and morbidity it can be concluded, that median-ulnar nerve injuries can be placed among the severe disabling injuries. ${ }^{35}$ 
While functional impairment is a significant determinant of return to work, many non-medical factors influence vocational outcome. ${ }^{36}$ Studies that focussed on different kind of injuries, showed that psychological stress was associated with a lower rate of return to work. ${ }^{9,31,37,38}$ The results of the present study indicate that higher levels of early posttraumatic psychological stress, following upper extremity nerve injuries, were associated with prolonged time off work (TOW) and reduced ability to return to work. This study firstly showed that patients who suffered severe early posttraumatic psychological stress were six times more likely not to return to work within one year, compared to the group which reported a minor psychological response. Experience of flashbacks was found to be an important determinant for prolonged time until return to work. ${ }^{39}$ Recognition and treatment of psychological symptoms may therefore be critical to successful return to productivity and a decrease of being on sickness benefit.

There were a number of limitations to the present study, which have been taking into account when interpreting the results. Retrospective data collection will tend to underestimate the psychological impact of the nerve injury. After nearly five and a half-year between date of trauma and the assessment, patients may have failed to recall their reaction to the traumatic injury. Reported psychological impact and associations between the impact and outcome values may therefore even be higher. On the other hand, patients with worse functional outcome and reduced capacity for work, may tend to exaggerate the psychological stress of the trauma, thereby leading to an overestimation of the association between early psychological stress and outcome. Furthermore, Brown ${ }^{40}$ explored a relationship between motivation and functional disability following distal upper limb amputations. Since motivation could not be measured from our data, we could not exclude this factor to be responsible for a part of the association. In addition, we suppose both psychological stress and motivation will influence the outcome. A combination of severe posttraumatic psychological stress and diminished motivation may even result in worse functional recovery. Despite these limitations the data from the present study provide evidence for an adverse effect of psychological stress on both functional recovery and capacity for work.

Upper extremity nerve injury patients face long-term disabilities and difficulties in rehabilitation. Knowledge of the factors that influence rehabilitation is essential if we want to reduce the high social costs associated with upper extremity injuries. Early identification of those subjects who develop a post-traumatic stress disorder, according DSM IV, may be important if we want to increase the efficiency of disability prevention. To our opinion patients with a severe psychological response on the traumatic nerve injury may be less motivated for the post-operative functional rehabilitation program. Different pre- and post surgical screening methods can be used to select patients who are at increased risk for post-traumatic stress disorder (PTSD). ${ }^{8}$ Originally the Impact of Event Scale was not designed to diagnose a post-traumatic stress disorder. The original intent was to construct an instrument suitable for obtaining reports of characteristic experiences from persons with syndromes as PTSD. ${ }^{20}$ More recent investigations on the Impact of Event Scale showed that this questionnaire, which is 
easily available to clinicians, can be used to identify those people likely to develop PTSD. ${ }^{41-43}$ Despite low specificity, IES scores at one week after the trauma can be used to predict a PTSD at four months at a cut-off of 19 on the IES. ${ }^{44}$ These authors showed that patients whose initial scores on the Impact of Event Scale were over 19 have a 12.4 times higher risk of developing PTSD, than that of subjects whose scores were 19 or less. Where prediction of post-traumatic stress disorder is less certain on the basis of the IES a clinician-administered instrument as the CAPS (Clinician Administered PTSD Scale) is recommended. ${ }^{41,45}$ Rush and co-authors suggested a symptom checklist, which can be used by surgeons and physicians, during medical follow-up visits, to detect adjustment difficulties. ${ }^{46}$ In case psychological complications are diagnosed, a great number of psychological symptoms are potentially treatable. For example, learning patients already in an early phase to cope with their handicap. Beside the awareness of a nonfunctional hand, non-medical factors as return to work and social consequences were reported to be very stressful. ${ }^{47}$ Further intervention implications can therefore include vocational rehabilitation services, social work assistance and family counseling to cope with stress and increase support to the patient. ${ }^{47,48} \mathrm{~A}$ graded work exposure showed to be an effective treatment, to promote return to work for patients experiencing significant psychological symptomatology after severe hand injury. ${ }^{49}$

In conclusion, our findings showed that upper extremity nerve injuries are often accompanied by considerable early psychological stress. The amount of psychological stress played a role in long-term outcome. Since this study was retrospective, prospective studies are needed to confirm our findings. Post-operatively psychological assistance may thus be of great value trying to achieve better functional recovery and reemploy patients. To our opinion this aspect must be included in the process of treatment and attention must be paid to these problems during rehabilitation. The data of the present study can be applied to modern treatment criteria to adapt therapeutic strategy. Hospital caregivers involved in treatment of nerve injuries should pay attention to post-traumatic psychological stress. 


\section{REFERENCES}

1. Jaquet JB, Luijstenburg AJM, Kalmijn $\mathrm{S}$, et al. Median, ulnar, and combined median-ulnar nerve injuries: functional outcome and return to productivity. J Trauma 2001;51:687-692

2. Paterson M, Burke F. Psychosocial consequences of upper limb injury. J Hand Surg [Br] 1995;20: 776- 781

3. Parry CW. Rehabilitation of the hand. In: Parry CW, ed. London: Butterwoods, 1973

4. Grunert BK, Smith CJ, Devine CA, et al. Early psychological aspects of severe hand injury. J Hand Surg [Br] 1988;13:177-180

5. Grunert BK, Devine CA, Matloub HS, et al. Sexual dysfunction following traumatic hand injury. Ann Plast Surg 1988;21:46-48

6. Haese JB. Psychological aspects of hand injuries. Their treatment and rehabilitation. J Hand Surg [Br] 1985; 10:283-287

7. Ellwood PM. Shattuck lecture: outcomes management. A technology of patient experience. New Engl J Med 1988;318:1549-1556

8. Michaels AJ, Michaels $\mathrm{CE}$, Moon $\mathrm{CH}$, et al. Posttraumatic stress disorder after injury: impact on general health outcome and early risk assessment. J Trauma 1999;47:460-466

9. Michaels AJ, Michaels CE, Moon CH, et al. Psychosocial factors limit outcomes after trauma. J Trauma 1998;44:644-648

10. Richmond TS, Kauder D, Schwab CW. A prospective study of predictors of disability at 3 months after non-central nervous system trauma. J Trauma 1998;44:635-642

11. Grunert BK, Devine CA, Matloub HS, et al. Psychological adjustment following work-related hand injury: 18-month follow-up. Ann Plast Surg 1992;29:537-542

12. Grunert BK, Devine CA, Matloub HS, et al. Flashbacks after traumatic hand injuries: prognostic indicators. J Hand Surg [Am] 1988;13:125-127

13. Gaul JS J. Intrinsic motor recovery: a long-term study of ulnar nerve repair. J Hand Surg [Am] 1982;7:502-508

14. Sunderland SS. Nerve injuries and their repair: acritical appraisal. Factors influencing the quality of the recovery after nerve repair. Singapore: Churchill Livingstone, 1991

15. Mackinnon S, Dellon A. Results of nerve repair and grafting. In: Mackinnon S, Dellon A, eds. Surgery of the peripheral nerve. New York: Thieme Medical Publishers, Inc; 1988:115-129

16. Birch R, Raji A. Repair of median and ulnar nerves. Primary suture is best. J Bone Joint Surg [Br] 1991;73:154- 157

17. Kallio $P$, Vastamaki $M$, Solonen $K$. The results of secondary microsurgical repair of radial nerve in 33 patients. J Hand Surg [Br] 1993;18:320-322

18. Noble J, Munro CA, Prasad VS, et al. Analysis of upper and lower extremity peripheral nerve injuries in a population of patients with multiple injuries. J Trauma 1998;45:116-122

19. Green BL. Psychosocial research in traumatic stress: an update. J Traumatic Stress 1994;7:341-362

20. Horowitz M, Wilner N, Alvarez W. Impact of Event Scale: a measure of subjective stress. Psychosom Med 1979;41:209-218

21. Briere J, Elliott DM. Clinical utility of the impact of event scale: psychometrics in the general population. Assessment 1998;5:171-180

22. Zilberg NJ, Weiss DS, Horowitz MJ. Impact of Event Scale: a cross-validation study and some empirical evidence supporting a conceptual model of stress response syndromes. J Consult Clin Psychol 1982;50:407-414

23. Hudak P, Amadio P, Bombardier C. Development of an upper extremity outcome measure: the DASH (disabilities of the arm, shoulder and hand). The Upper Extremity Collaborative Group (UECG). Am J Ind Med 1996;29:602-608

24. McConnell S, Beaton D, Bombardier C. The DASH outcome measure user's manual. Toronto: Institute for Work \& Health, 1999

25. Mathiowetz V, Weber K, Volland G, et al. Reliability and validity of grip and pinch strength evaluations. J Hand Surg [Am] 1984;9:222-226

26. Petersen $\mathrm{P}$, Petrick $\mathrm{M}, \mathrm{Connor} \mathrm{H}$, et al. Grip strength and hand dominance: challenging the $10 \%$ rule. Am J Of Occup Ther 1989;43:444-447 
27. Bell-Krotoski J, Weinstein S, Weinstein C. Testing sensibility, including touch-pressure, two-point discrimination, point localization, and vibration. J Hand Ther 1993;6:114-123

28. Imai H, Tajima T, Natsuma Y. Interpretation of cutaneous pressure threshold (Semmes-Weinstein monofilament measurement) following median nerve repair and sensory reeducation in the adult. Microsurgery 1989;10:142-144

29. Diagnostic and statistical manual of mental disorders. Washington DC: American Psychiatric Association, 1994

30. Eriksson NG, Lundin T. Early traumatic stress reactions among Swedish survivors of the $\mathrm{m} / \mathrm{s}$ Estonia disaster. Br J Psychiatry 1996;169:713-716

31. Mayou R, Bryant B, Duthie R. Psychiatric consequences of road traffic accidents. BMJ 1993;307: 647-651

32. Malt U. The long-term psychiatric consequences of accidental injury. A longitudinal study of 107 adults. Br J Psychiatry 1988;153:810-818

33. Widgerow A. Full-house/spaghetti wrist injuries. Analysis of results. S Afr J Surg 1990;28:6-10

34. Lundborg G. Brain plasticity and hand surgery: an overview. J Hand Surg [Br] 2000;25:242-252

35. Brenneman FD, Redelmeier DA, Boulanger BR, et al. Long-term outcomes in blunt trauma: who goes back to work? J Trauma 1997;42:778-781

36. MacKenzie EJ, Morris JA Jr, Jurkovich GJ, et al. Return to work following injury: the role of economic, social, and job-related factors. Am J Public Health 1998;88:1630-1637

37. Crook J, Moldofsky H, Shannon H. Determinants of disability after a work related musculetal injury. J Rheumatol 1998;25:1570-1577

38. Brewin CR, Robson MJ, Shapiro DA. Social and psychological determinants of recovery from industrial injuries. Injury 1983;14:451-455

39. Skov O, Jeune B, Lauritsen JM, et al. Time off work after occupational hand injuries. J Hand Surg [Br] 1999;24:187- 189

40. Brown PW. Less than ten - surgeons with amputated fingers. J Hand Surg [Am] 1982;7:31 - 37

41. Shalev AY, Freedman S, Peri T, et al. Predicting PTSD in trauma survivors: prospective evaluation of self-report and clinician-administered instruments. Br J Psychiatry 1997;170:558-564

42. Feinstein A, Dolan R. Predictors of post-traumatic stress disorder following physical trauma: an examination of the stressor criterion. Psychol Med 1991;21:85-91

43. Koopman C, Classen C, Spiegel D. Predictors of posttraumatic stress symptoms among survivors of the Oakland/Berkeley, Calif., firestorm. Am J Psychiatry 1994;151:888-894

44. Shalev AY, Peri T, Canetti L, et al. Predictors of PTSD in injured trauma survivors: a prospective study. Am J Psychiatry 1996;153:219-225

45. Blake DD, Weathers FW, Nagy LM, et al. The development of a Clinician-Administered PTSD Scale. J Traumatic Stress 1995;8:75-90

46. Rusch MD, Grunert BK, Sanger JR, et al. Psychological adjustment in children after traumatic disfiguring injuries: a 12 month follow-up. Plast Reconstr Surg 2000;106:1451 - 1458

47. Landsman IS, Baum CG, Arnkoff DB, et al. The psychosocial consequences of traumatic injury. J Behav Med 1990;13:561-581

48. Grunert BK, Hargarten SW, Matloub HS, et al. Predictive value of psychological screening in acute hand injuries. J Hand Surg [Am] 1992;17:196-199

49. Grunert BK, Devine CA, Smith CJ, et al. Graded work exposure to promote work return after severe hand trauma: a replicated study. Ann Plast Surg 1992;29:532-536 



\section{COGNITIVE FUNCTIONING AND LEVEL OF INTELLIGENCE}

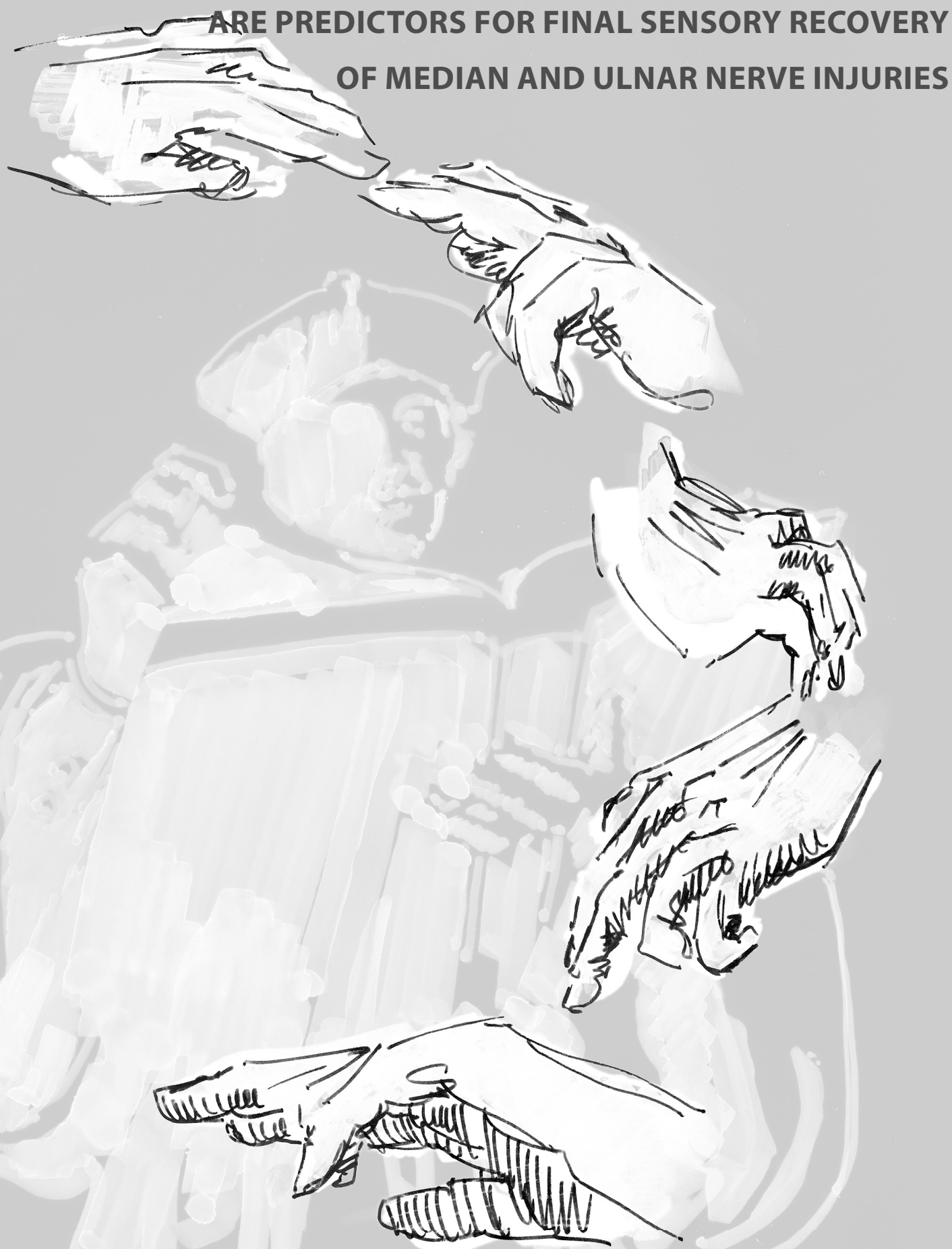

Jaquet, J. B., de Koning, I. Kalmijn S., Kuypers, P.D. L., Hofman, A., Passchier, J. and Hovius S. E. R. Submitted Plastic and Reconstructive Surgery 



\section{ABSTRACT}

Introduction - The denervated hand loses cortical representations. In order to establish pre-injury representations, remodelling of the somatosensory cortex is needed. The level of cognitive capacity may play a role in this process and may therefore have a substantial effect on the prognosis. This study was designed to quantify the association between cognitive capacity and long-term sensory recovery in terms of perception of touch and pressure.

Methods -88 patients diagnosed with a median, ulnar or combined median-ulnar nerve injury, operated on between 1990 and 1998, underwent a cognitive evaluation and were assessed for sensory recovery on average 5.5 years following surgery. The Stroop Colour Word Test (SCWT), the Dutch version of the National Adult Reading Test (NART) and the California Verbal Learning Test (CVLT) were used to assess the different components of cognition. Sensory recovery was tested with Semmes-Weinstein monofilaments and interpreted according the classification of Imai (range 1 - 5).

Results - Mean sensory recovery was 3.1 (SD: 0.9). Combined median-ulnar nerve injuries (mean $3.7 \pm 0.7$ ) were accompanied by less sensory recovery compared to the single nerve injuries (median: mean $=2.9 \pm 0.9$ and ulnar: mean $=3.1 \pm 0.8$, respectively $p=0.02$ and $p=0.02$ ). No statistical difference was found between the single nerve injuries $(p=0.19)$. Multiple linear regression adjusted according to age, sex and education revealed an association between longterm sensory recovery and SCWT (Beta $=0.30, p=0.01,95 \% \mathrm{Cl}: 0.01-0.02)$; NART (Beta $=-0.39$, $p=0.02,95 \% \mathrm{Cl}:-0.05--0.01$ ) and a number of scores of the CVLT (learning Beta $=0.28, p=0.04$, $95 \% \mathrm{Cl}: 0.02-0.64$ and perception Beta $=0.25, \mathrm{p}=0.05,95 \% \mathrm{Cl}: 0.01-1.29)$.

Discussion - The level of cognitive functioning is associated with long-term sensory recovery following median ulnar and combined median-ulnar nerve injuries. Sensory re-education and cognitive training programs are essential to improve sensory recovery. Functional MRI can be used to evaluate the remodelling process of somatosensory cortex and optimize our postoperative rehabilitation programs. 


\section{INTRODUCTION}

Sensibility is one of the most important functions of the hand. Absence of sensation reduces the ability to use the hand for daily necessary activities and disables use of the hand without eye-control.' For decades, most peripheral nerve research focused on the nerve lesion. During the last two decades, the effect of the central nervous system on the outcome of nerve injuries has received increasing interest.

Nerve injury outcome studies have shown that sensory recovery depends on a number of variables. ${ }^{2}$ The positive effect of sensory re-education was described in the mid 70 s, despite the fact that the exact mechanism was not understood. ${ }^{3}$ Additionally, age was shown to be one of the most important predicting factors on functional outcome following nerve injuries. ${ }^{4}$ Even without sensory re-education, children can achieve excellent functional recovery following forearm nerve injuries. ${ }^{5,6}$ The exact mechanism for this phenomenon was not understood, but Tajima and Imai concluded that capacity for peripheral neural regeneration and cerebral plasticity in children is such that excellent recovery of functional sensation in the hand can occur without the need for sensory re-education.

It is known that repair of a complete nerve transection will be accompanied by a certain degree of mismatch, which may result in incorrect end-organ innervation. It may therefore be reasonable that pre-injury topographical representations of skin areas in the somatosensory cortex alter. ${ }^{7}$ Based on an animal study, Merzenich described that after the median nerve was cut and tied, the cortex representing the skin of the median nerve was completely occupied by 'new' inputs from the ulnar and radial nerves. ${ }^{8,9}$ To re-establish pre-injury representations, extensive remodelling of the somatosensory cortex is needed. Patients with better capacity to reorganize the "new" sensory inputs of the somatosensory cortex may have better long-term sensory outcome.

The term cognition embraces the processes of perception, attention, learning, memory and communication. Cognitive capacity is the ability of the brain to observe and memorize, the ability of the brain to adjust to stimuli and the ability of the brain to reorganize, which is also called plasticity of the brain. Based on the ability of the central nervous system to adjust to incorrect end organ innervation, cognitive capacity may have a great effect on the prognosis of sensory recovery. Lundborg and Rosen were the first to report $(n=19)$ an association between cognitive capacity and sensory recovery. ${ }^{10,11}$ They focused on tactile gnosis as functional sensory recovery. The exact contribution of cognitive capacity to the recovery of perception of touch and pressure (Semmes Weinstein monofilaments), which is the potential for sensory function, was not established.

The present study was designed to carry out a large-scale study to determine the association between cognitive capacity and long-term recovery of perception of touch and pressure. Furthermore, we aimed to quantify the contribution of cognitive functioning to sensory recovery. 


\section{PATIENTS AND METHODS}

\section{Study population}

The study cohort was defined as all subjects who entered the Erasmus Medical Center Rotterdam Hospital for surgical treatment of a median, ulnar or combined median-ulnar traumatic nerve injury during the period between January 1990 and December 1998. Medical records were reviewed to extract information on diagnosis and symptoms at entry into treatment. A peripheral nerve injury chart was designed to gather data about diagnosis, etiology, treatment, complications and demographic characteristics. In order to participate in this study, the forearm nerve injuries were required to meet four entrance criteria. 1) A trauma of at least a single ulnar or median nerve located within the area between the wrist crease (distal border) and the flexor elbow crease (proximal border) 2). Patients had to be 12 years or older on the day of their injury and 3) knowledge of the Dutch language was required to meet the inclusion criteria. 4) Excluded were subjects diagnosed with complete amputation of the hand followed by a replantation, patients with associated hand and or forearm fractures and also patients with amputation of the hand or digits. On the basis of these entrance criteria, 136 patients were included over the study period. Hospital medical records, general practitioners and municipal archives were consulted in order to trace the initially selected patient population. A letter requesting participation was mailed to the selected individuals. Three follow-up mailings were sent to non-responders at a two-month interval. This resulted in a population of 88 patients who were prepared to undergo cognitive evaluation (response rate: $65 \%$ ). The protocol for the study was approved by the Research Ethics Committee of the Rotterdam University Hospital and informed consent was provided by all participants. Data were collected during a follow-up session at our out-patient clinic.

\section{Cognitive capacity}

Cognitive capacity was assessed at our out-patient clinic by an experienced clinical psychologist.

The Stroop Color and Word Test (SCWT) has long been a standard measure in neuropsychological assessment. ${ }^{12}$ The Stroop Color Word Test is based on differences between the speeds of reading color names, naming colors and naming colors of words that are printed in incongruous colors. It measures cognitive flexibility and provides information about a person's susceptibility to interference effects in various mental functions, especially learning and memory. ${ }^{13}$ Validity and reliability are good and its quick and easy administration make it a highly useful tool to measure cognitive capacity. ${ }^{13}$

The NART is a widely used test which was originally devised by Hazel Nelson in 1978.14 The NART requires people to try to pronounce words that do not follow the usual rules of pronunciation. The NART can provide an accurate estimate of premorbid intelligence levels and IQ. ${ }^{14,15}$ The Dutch version of the National Adult Reading Test (NART) was used. 
Table 1. Interpretation of Semmes Weinstein monofilaments

\begin{tabular}{ll}
\hline Quality of sensation (range 1-5) & Filament marking \\
\hline Normal (=1) & 2.83 \\
Diminished light touch (=2) & 3.61 \\
Diminished protective sensation (=3) & 4.31 \\
Loss of protective sensation (=4) & 4.56 \\
Anesthetic (=5) & 6.10 \\
\hline
\end{tabular}

Table 2. Characteristics of participants $(n=88)$ and non-participants $(n=48)$.

\begin{tabular}{lcc}
\hline Characteristic & $\begin{array}{l}\text { Participants } \\
\text { (n=88) }\end{array}$ & $\begin{array}{l}\text { Non-participants } \\
\text { (n=48) }\end{array}$ \\
\hline Age & $36.3 \pm 12.8$ & $33.7 \pm 11.4$ \\
Mean \pm SD & $17-74$ & $15-61$ \\
Range & & \\
Sex (\%) & $68(77)$ & $37(77)$ \\
Male & $20(23)$ & $11(23)$ \\
Female & & $16(33)$ \\
Type of injury (\%) & $42(48)$ & $22(46)$ \\
Median & $32(36)$ & $10(21)$ \\
Ulnar & $14(16)$ & $19(40)$ \\
Combined & & $13(27)$ \\
Dominant hand affected & $56(64)$ & \\
Yes (\%) & $0(0)$ & $6.3 \pm 4.5$ \\
Unknown (\%) & & $1-15$ \\
Structures affected & $10(11)$ & $2(15)$ \\
Mean \pm SD & $4(5)$ & $5(10)$ \\
Range & $5.3 \pm 3.8$ & $2(15)$ \\
Lesion (\%) & $1-15$ &
\end{tabular}

SD $=$ Standard deviation

California Verbal Learning Test (CVLT) ${ }^{16}$ is based on a list of words which contains sixteen common words, each of which belongs to one of four categories. It is a neuropsychological test which can be used to assess an individual's verbal learning and memory abilities. ${ }^{17}$ We used the official Dutch version of the California Verbal Learning Test. It scores different components of cognition: attention, learning, memory and perception.

\section{Sensory recovery}

Sensory recovery was tested with Semmes-Weinstein monofilaments (North Coast Medical Inc, Morgan Hill, CA). The monofilaments $(2.83,3.61,4.31,4.56$ and 6.10$)$ were used according to the procedure described by Bell-Krotosky. ${ }^{18}$ Ten zones in the hand were tested, 6 in the area of the 
median nerve and 4 in the area of the ulnar nerve. The scores were interpreted as suggested by Imai (table 1). ${ }^{19} \mathrm{~A}$ score of 6.10 was interpreted as anesthetic.

Statistical methods

Participants and non-participants were compared, using chi-square analysis for categorical data and $t$-tests for continuous variables, to detect if selection bias had occurred (table 2). The Fisher's exact test was used in cases where the expected count of the cells was less than 5 . Multiple linear regression analysis was applied to identify cognitive capacity as a predictor of sensory recovery. Age, gender and level of education were included as confounding factors. All tests were performed two-sided and a p-value of $<.05$ was considered statistically significant. Data analysis was performed using SPSS statistical software (version 10.1, Real Stats, SPSS Inc., IL, USA).

\section{RESULTS}

\section{Study population}

Eighty-eight patients (65\%) were prepared to undergo cognitive evaluation. 9 (7\%) subjects rejected assessment of cognitive functioning and $10(7 \%)$ had inadequate knowledge of the Dutch language. The characteristics of the participants and non-participants are presented in table 2. No statistical difference was found between the participants and non-participants for age $(p=0.40)$, gender $(p=1.0)$, type of injury $(p=0.27)$, injury of the dominant hand $(p=0.41)$, number of structures $(p=0.21)$ and lesion $(p=0.90)$.

\section{Sensory recovery}

Mean sensory recovery, on average 5.5 years following surgery, was 3.1 (SD: 0.9). Combined median-ulnar nerve injuries (mean $3.7 \pm 0.7$ ) were accompanied by less sensory recovery compared to the single nerve injuries (median: mean $=2.9 \pm 0.9$ and ulnar: mean $=3.1 \pm 0.8$, respectively $p=0.02$ and $p=0.02$ ). No statistical difference for sensory recovery was found between the single median and ulnar nerve injuries $(p=0.19)$. Frequency distribution for quality of sensation is given in table 3 .

Association between cognitive capacity and sensory recovery Association between cognitive capacity measured by different tests and sensory recovery is shown in table 4. 
Table 3. Frequency distribution for quality of sensory recovery

\begin{tabular}{llc}
\hline Quality of sensation & Filament & No. of Patients \\
\hline Normal & 2.83 & $2(2.3 \%)$ \\
Diminished light touch & 3.61 & $20(22.7 \%)$ \\
Diminished protective sensation & 4.31 & $38(43.2 \%)$ \\
Loss of protective sensation & 4.56 & $24(27.3 \%)$ \\
Anesthetic & 6.10 & $4(4.5 \%)$ \\
\hline
\end{tabular}

Table 4. Multiple linear regression analysis: Adjusted* betas ( $95 \%$ confidence intervals) for association between cognitive capacity and sensory recovery

\begin{tabular}{lccc}
\hline Cognitive capacity & Beta & $\mathbf{9 5 \% ~ C l}$ & p-value \\
\hline Stroop Colour Word Test (SCWT) & 0.30 & $0.01-0.02$ & $\mathrm{p}=0.01$ \\
National Adult Reading Test (NART) & -0.39 & $-0.05--0.01$ & $\mathrm{p}=0.02$ \\
California Verbal Learning Test (CVLT) & & & \\
Attention & 0.25 & $-0.01-0.59$ & $\mathrm{p}=0.06$ \\
Learning & 0.28 & $0.02-0.64$ & $\mathrm{p}=0.04$ \\
Memory & -0.64 & $-0.39-0.24$ & $\mathrm{p}=0.62$ \\
Perception & 0.25 & $0.01-1.29$ & $\mathrm{p}=0.05$ \\
\hline
\end{tabular}

Beta $=$ beta coefficient; $\mathrm{Cl}=$ confidence interval

${ }^{*}$ Adjusted for sex, age and education

\section{DISCUSSION}

Sensory recovery is one of the most important outcome markers following peripheral nerve surgery. The combination of sensory, motor recovery and discomfort are responsible for $73 \%$ of the final outcome. ${ }^{20}$ Without sensation the hand is blind. ${ }^{3}$

Clinical outcome of upper extremity nerve injuries is not much different from that of 25 years ago. ${ }^{21}$ Despite microsurgical repair and all the modern surgical techniques and suture materials, full sensory recovery following nerve injuries is scarcely ever achieved. In our study, 'good' sensory (normal and diminished light touch) was achieved in $24 \%$ of the study population. These results do not greatly differ from the results of previous outcome studies.22,23 It is well known from the literature that children achieve better functional recovery compared to adults. Back in 1962 , Onne ${ }^{24}$ already described better functional sensibility in younger patients. Many others confirmed his findings. ${ }^{25-32}$ It has been supposed that they achieve better sensory outcome due to their continual curious investigation of their environment ${ }^{3}$ Recently, a well-defined critical period for sensory relearning after nerve repair was described. ${ }^{33}$ The curve correlates with previously published data on critical periods for language acquisition among immigrants. ${ }^{33}$ The superior ability of children to adjust the central nervous system to the misdirected axons seemed to be of greater importance in relation to their better results.

The physical changes in the brain resulting from new memories, the addition of new neurons, changes in hormones and trauma all point to constant remodelling of the brain. ${ }^{34}$ Reprogramming the 'brain computer' to adjust to the new sensory stimuli is necessary to regain 
functional sensory recovery. Lundborg and Rosen were the first to find a relationship between specific cognitive capacities and functional sensory recovery. ${ }^{10,11}$ They focused on tactile gnosis as functional sensory recovery. We found an association between specific cognitive capacities and long-term recovery of perception of touch and pressure, which is the potential for sensory function. Based on a small number of patients $(n=19)$ Rosen and Lundborg only found verbal learning and visuo-spatial ability to be associated with functional sensibility. Our study showed that in addition to specific verbal learning capacities, cognitive flexibility and level of intelligence also appeared to affect the level of sensory recovery. We did not include tests to investigate visual spatiality. Higher visuo-spatial capacities might also be associated with sensory recovery. Further research is needed to confirm this hypothesis. Based on our results, specific cognitive training programs may improve sensory outcome following peripheral nerve injuries. Cognitive training and rehabilitation programs have already been shown to be effective for patients with focal seizures ${ }^{35}$, brain injuries ${ }^{36}$ and dementia ${ }^{37}$ Furthermore, cardiovascular fitness can affect improvements in the plasticity of the brain and results in increased functioning of key aspects of the attentional network of the brain. ${ }^{38-40}$

It is obvious that there must be other factors, besides cognitive capacity, to explain the difference in clinical sensory results. Since it is not possible to influence the factors regarding the injury, efforts should be made to intervene with the postoperative predicting variables. The results of the present study reconfirm the importance of sensory re-education. A positive effect of sensory re-education was described in the mid $70 \mathrm{~s}^{3,41} \mathrm{~A}$ program of sensory reeducation minimized discomfort and improved sensibility in the postoperative period. ${ }^{41,42}$ Furthermore, patients who followed a specialized hand therapy program, which focuses on early passive motion, muscle strength and sensory re-education, had a higher chance of getting back to work. ${ }^{43,44}$

Neuroimaging especially $\mathrm{fMRI}$, is an immensely powerful tool for cognitive research. It appears to make it possible to discover which brain circuits are responsible for specific cognitive processes ${ }^{34}$. Based on our results, the possibility of assessing, visualizing and influencing the reorganization process of the brain will be an important goal to improve sensory recovery and functional outcome of the hand. The different digits of the hand have already been visualised separately in the somatosensory cortex and quantified for their activation..$^{45-48}$ The ability to visualize the somatosensory cortex will help us to determine the exact time interval for the axons to reach their target organs. In addition, the amount of mismatch can be visualized. Our sensory re-education program can be adjusted to the type and amount of mismatch which has been visualised by the fMRI. A first pilot study has shown better sensory recovery when sensory re-education was adjusted to the results of the fMRI (www.hand.mas.lu.se) A large randomized clinical trial is needed to confirm this finding.

An increasing number of studies suggest that cortical reorganisation is one of the reasons for sensory dysfunction. ${ }^{49-52}$ Lundborg stated that outcome from nerve repair depends mainly on central nervous system factors including functional cortical reorganisational processes caused 
by misdirection in axonal outgrowth. ${ }^{51}$ This study contributes to the growing evidence that cognitive functioning is related to the sensory outcome of wrist and forearm nerve injuries. Knowledge of cognitive capacity may therefore be of importance to predict sensory recovery following forearm nerve injuries. 


\section{REFERENCES}

1. Foucher G. Prospects for hand transplantation. Lancet 1999;353(9161):1286-7.

2. Sunderland SS. Nerve injuries and their repair: a critical appraisal. Third ed. Singapore: Churchill Livingstone, 1991.

3. Dellon AL, Curtis RM, Edgerton MT. Re-education of the sensation in the hand after nerve injury and repair. Plastic and Reconstructive Surgery 1974;53:297-305.

4. Gaul JSJ. Intrinsic motor recovery - a long-term study of ulnar nerve repair. J Hand Surg. American Volume 1982;7(5):502-8.

5. Tajima T, Imai H. Results of median nerve repair in children. Microsurgery 1989;10(2):145-6.

6. Merle M, Amend P, Cour C, Foucher G, Michon J. Microsurgical repair of peripheral nerve lesions: A study of 150 injuries of the median and ulnar nerves. Peripheral Nerve Repair 1986;2:17-26.

7. Wall JT, Kaas JH, Sur M, Nelson RJ, Felleman DJ, Merzenich MM. Functional reorganization in somatosensory cortical areas $3 \mathrm{~b}$ and 1 of adult monkeys after median nerve repair: possible relationships to sensory recovery in humans. Journal Of Neuroscience 1986;6(1):218-33.

8. Merzenich MM, Kaas JH, Wall JT, Sur M, Nelson RJ, Felleman DJ. Progression of change following median nerve section in the cortical representation of the hand in areas $3 \mathrm{~b}$ and 1 in adult owl and squirrel monkeys. Neuroscience 1983;10(3):639-65.

9. Merzenich MM, Kaas JH, Wall J, Nelson RJ, Sur M, Felleman D. Topographic reorganization of somatosensory cortical areas $3 \mathrm{~b}$ and 1 in adult monkeys following restricted deafferentation. Neuroscience 1983;8(1):33-55.

10. Lundborg G, Rosen B, Dahlin LB, Holmberg J, Karlson B. Functional sensibility of the hand after nerve repair. Lancet 1993;342(8882):1300.

11. Rosen B, Lundborg G, Dahlin L, Holmberg J, Karlson B. Nerve repair: correlation of restitution of functional sensibility with specific cognitive capacities. J Hand Surg [Br] 1994;19(4):452 - 8.

12. Stroop J. Studies of interference in serial verbal reactions. Journal of Experimental Psychology $1935 ; 18: 643-662$.

13. Jensen A, Rohwer W. The Stroop color word test: a review. Acta Psychologica 1966;25:36-93.

14. Nelson $\mathrm{H}, \mathrm{O}^{\prime}$ Connell A. Dementia: the estimation of premorbid intelligence levels using the New Adult Reading Test. Cortex 1978;14(2):234-244.

15. McGurn B, Starr J, Topfer J, et al. Pronunciation of irregular words is preserved in dementia, validating premorbid IQ estimation. Neurology 2004;62(7):1184-1186.

16. Delis D, Freeland J, Kramer J, Kaplan E. Integrating clinical assessment with cognitive neuroscience: construct validation of the California Verbal Learning Test. J Consult Clin Psychol. 1988;56(1): 123-130.

17. Wiegner S, Donders J. Performance on the California Verbal Learning Test after traumatic brain injury. J Clin Exp Neuropsychol 1999;21(2):159-70.

18. Bell-Krotoski J, Weinstein S, Weinstein C. Testing sensibility, including touch-pressure, two-point discrimination, point localization, and vibration. J Hand Ther 1993;6(2):114-23.

19. Imai H, Tajima T, Natsuma Y. Interpretation of cutaneous pressure threshold (Semmes-Weinstein monofilament measurement) following median nerve repair and sensory reeducation in the adult. Microsurgery 1989;10(2):142-4.

20. Rosen B, Lundborg G. A model instrument for the documentation of outcome after nerve repair. $J$ Hand Surg. American Volume 2000;25(3):535-43.

21. Lundborg G. A 25-year perspective of peripheral nerve surgery: evolving neuroscientific concepts and clinical significance. J Hand Surg. American Volume 2000;25(3):391 - 414.

22. Dellon AL. Ulnar nerve. In: Kline DG, Hudson AR, eds. Nerve injuries. Philadelphia: W. B. Saunders, 1995: 256.

23. Dellon AL. Median nerve. In: Kline DG, Hudson AR, eds. Nerve injuries. Philadelphia: W. B. Saunders, 1995: 205.

24. Onne L. Recovery of sensibility and sudomotor activity after nerve suture. Acta Chir Scand 1962;300: $1-70$.

25. Kallio $\mathrm{P}$, Vastamaki M. An analysis of the results of late reconstruction of 132 median nerves. J Hand Surg [Br] 1993;18(1):97-105. 
26. Bolitho DG, Boustred M, Hudson DA, Hodgetts K. Primary epineural repair of the ulnar nerve in children. J Hand Surg 1999;24A(1):16-20.

27. Hudson DA, Bolitho DG, Hodgetts K. Primary epineural repair of the median nerve in children. $J$ Hand Surg 1997;22B(1):54-6.

28. Selma P, Emre O, Oguz P, Ersin N, Oya B. Evaluation of the improvement of sensibility after primary median nerve repair at the wrist. Microsurg 1998;18:192-6.

29. Holst H. Primary peripheral nerve repair in the hand and upper extremity. J Trauma 1975;15(10): 909-11.

30. Marsh D, Barton N. Does the use of the operating microscope improve the results of peripheral nerve suture? J Bone Joint Surg [Br] 1987;69(4):625-30.

31. Vastamaki $M$, Kallio $P$, Solonen $K$. The results of secondary microsurgical repair of ulnar nerve injury. J Hand Surg [Br] 1993;18(3):323-6.

32. Posch J, Cruz-Saddul Fdl. Nerve repair in trauma surgery: A ten-year study of 231 peripheral injuries. Orthopaedic Review 1980;9(3):35-45.

33. Lundborg G, Rosen B. Sensory relearning after nerve repair. Lancet 2001;358(9284):809-10.

34. NIMH. Cognitive research. Cognition. www.nimh.nih.gov ed, 2000: 1-4.

35. Engelberts N, Klein M, Ader H, Heimans J, Trenite D, van der Ploeg $\mathrm{H}$. The effectiveness of cognitive rehabilitation for attention deficits in focal seizures: a randomized controlled study. Epilepsia 2002;43(6):587-595.

36. Tam S, Man W. Evaluating computer-assisted memory retraining programmes for people with posthead injury amnesia. Brain Inj. 2004;18(5):461 - 470.

37. Ball $K$, Berch $D$, Helmers $K$, et al. Effects of cognitive training interventions with older adults: a randomized controlled trial. JAMA 2002;288(18):2271-2281.

38. Colcombe S, Kramer A, Erickson K, et al. Cardiovascular fitness, cortical plasticity, and aging. Proc Natl Acad Sci 2004;101(9):3316-3321.

39. McAuley E, Kramer A, Colcombe S. Cardiovascular fitness and neurocognitive function in older adults: a brief review. Brain Behav Immun 2004;18(3):214-220.

40. Kramer A, Colcombe S, McAuley E, et al. Enhancing brain and cognitive function of older adults through fitness training. J Mol Neurosci 2003;20(3):213-221.

41. Parry CB, Salter M. Sensory re-education after median nerve lesions. Hand 1976;8(3):250 - 7 .

42. Imai $H$, Tajima T, Natsumi Y. Successful re-education of functional sensibility after median nerve repair at the wrist. J Hand Surg [Am] 1991;16(1):60-5.

43. Jaquet JB, Luijsterburg AJ, Kalmijn S, Kuypers PD, Hofman A, Hovius SE. Median, ulnar, and combined median-ulnar nerve injuries: functional outcome and return to productivity. The Journal of Trauma 2001;51(4):687-92.

44. Bruyns CN, Jaquet JB, Schreuders TA, Kalmijn S, Kuypers PD, Hovius SE. Predictors for return to work in patients with median and ulnar nerve injuries. J Hand Surg 2003;28A(1):28-34.

45. Maldjian JA, Gottschalk A, Patel RS, Pincus D, Detre JA, Alsop DC. Mapping of secondary somatosensory cortex activation induced by vibrational stimulation: an fMRI study. Brain Research 1999;824(2):291 - 5.

46. Nakamura A, Yamada T, Goto A, et al. Somatosensory homunculus as drawn by MEG. Neuroimage 1998;7:377-86.

47. Gelnar PA, Krauss BR, Szeverenyi NM, Apkarian AV. Fingertip representation in the human somatosensory cortex: an fMRI study. Neuroimage 1998;7:261-83.

48. Baumgartner C, Doppelbauer A, Deecke L, et al. Neuromagnetic investigation of somatotopy of human hand somatosensory cortex. Experimental Brain Research 1991;87(3):641 - 8.

49. Anders B, Rosen B, Lundborg G. Acute improvement of contralateral after deafferentation. 9 th IFSSH 2004, Budapest, Hungary: $303-304$.

50. Jaquet J, Koning I, Kalmijn S, Kuypers P, Hofman A, Hovius S. Central nervous system plays a major role in sensory outcome following nerve injuries. J Hand Surg 2002;27B:11 - 12.

51. Lundborg G. Richard P. Bunge memorial lecture. Nerve injury and repair - a challenge to the plastic brain. Journal of the Peripheral Nervous System 2003;8(4):209-26.

52. Braune S, Schady W. Changes in sensation after nerve injury or amputation: the role of central factors. Journal Of Neurology, Neurosurgery And Psychiatry 1993;56(4):393 - 9. 


\section{CHAPTER 8}

\section{MEDIAN AND ULNAR NERVE INJURIES: A META-ANALYSIS}

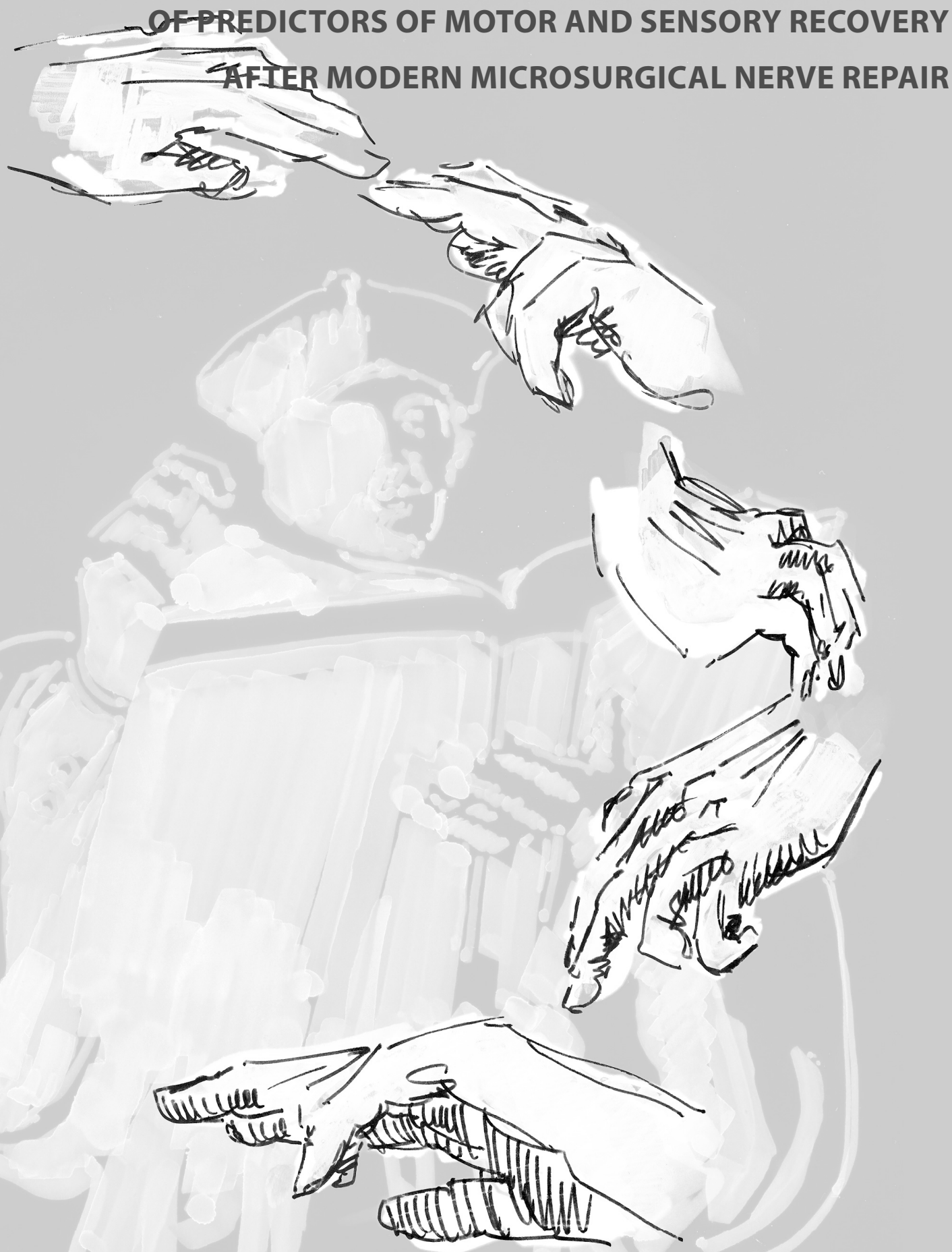

Ruys, A.C. J., Jaquet, J. B., Kalmijn, S., Giele, H. and Hovius S.E. R. 



\section{ABSTRACT}

Background - The aim of this study is to quantify variables that influence outcome after median and ulnar nerve transection injuries. We present a meta-analysis based on individual patient data on motor and sensory recovery after microsurgical nerve repair.

Methods - Twenty-three articles were ultimately included, giving individual data for 623 median or ulnar nerve injuries. The variables age, gender, nerve, site of injury, type of repair, use of grafts, delay between injury and repair, follow-up period and outcome were extracted. Satisfactory motor recovery was defined as MRC grade 4 and 5 , satisfactory sensory recovery as MRC grade 3+ and 4. For motor and sensory recovery, complete data were available for 281 and 380 nerve injuries respectively.

Results - Motor and sensory recovery were significantly associated (Spearman $r=0.62, p<0.001$ ). Multivariate logistic regression analysis showed that age $(<16$ years versus $>40$ years $\mathrm{OR}=4.3$, $95 \% \mathrm{Cl} 1.6-11.2$ ), site (proximal versus distal $\mathrm{OR}=0.46,95 \% \mathrm{Cl} 0.20-1.10$ ) and delay (per month $\mathrm{OR}=0.9495 \% \mathrm{Cl} 0.90-0.98$ ) were significant predictors of successful motor recovery. In ulnar nerve injuries the chance of motor recovery was $71 \%$ lower than in median nerve injuries $(\mathrm{OR}=0.29,95 \% \mathrm{Cl} 0.15-0.55)$. For sensory recovery age $(\mathrm{OR}=27.0,95 \% \mathrm{Cl} 9.4-77.6)$, and delay (per month $\mathrm{OR}=0.92,95 \% \mathrm{Cl} 0.87-0.98$ ) were found to be significant predictors.

Conclusions - In this individual patient data meta-analysis age, site, injured nerve and delay significantly influenced prognosis after microsurgical repair of median and ulnar nerve injuries. 


\section{INTRODUCTION}

Peripheral nerve injuries in general have a great impact on the patient's life. The amount of posttraumatic stress accompanying traumatic hand and forearm injuries is equal on the IES scale to the amount of stress experienced by survivors of the disaster with the cruise ship Estonia. ${ }^{1}$ When motor and sensory function in the hand are altered, return to work activity may be jeopardized. Despite improvements in treatment, recovery after peripheral nerve injuries is not only often disappointing, but also difficult to predict. For both patient and doctor it is necessary to prognosticate the chances of recovery, so that treatment expectations can be realistic and appropriate rehabilitation measures can be taken. In previous literature, a number of factors have been found to predict motor and sensory recovery after peripheral nerve injury. These include age, delay between injury and repair and surgical technique. However, despite numerous published reports on peripheral nerve repair there is no agreement on which variables are independent predictors of a successful prognosis and the effect of the predictors is not quantified. Although some excellent reviews have been published on nerve grafting ${ }^{2,3}$, only Frykman performed a meta-analysis. ${ }^{4}$ In 114 median nerve injuries and 98 ulnar nerve injuries it was found that type of nerve, age, gap length and level of injury affected outcome. He based his results on 10 studies published between 1972 and 1988.

At present, a larger number of studies with detailed individual data are available, which enabled us to do an individual patient data meta-analysis ${ }^{5}$ examining independent predictors of motor and sensory recovery. Predictors that could be investigated included age, gender, site of injury, median or ulnar nerve, combined median and ulnar nerve injuries, delay between injury and repair, the use of grafts, gap length and follow-up period. This is the largest metaanalysis with individual data on outcome after repair of median and ulnar nerve injuries undertaken so far.

\section{MATERIAL AND METHODS}

A literature review up to April 2004 was performed to collect publications on outcome of median or ulnar nerve repair after transection injury. Studies were found by using the following search strategy: (Median Nerve/surgery [MAJR] OR Ulnar Nerve/surgery [MAJR]) AND (nerve repair (text word) OR outcome (text word)) with the limits English and human in the Pubmed database. With this strategy 122 articles were found. Additionally, the text word "spaghetti wrist" was entered, which gave 8 hits. A reference check was performed and the Cochrane database was searched. No effort was made to find unpublished reports or fugitive literature. Abstracts were screened by AR to select qualifying studies according to the in- and exclusion criteria. Included are studies that use microsurgical techniques for median or ulnar nerve repair and give individual data on sensory and/or motor recovery outcome scores using the British 
Medical Research Committee scale. ${ }^{6-28}$ In a number of studies the assessment method was not the BMRC motor or sensory scale ${ }^{29-35}$, or the individual data were not given. ${ }^{36-61}$ Furthermore, case reports ${ }^{62-68}$, iatrogenic injuries ${ }^{69-73}$, partial nerve injuries ${ }^{74,75}$, war or gunshot injuries ${ }^{76-78}$, nonmicrosurgical repair ${ }^{79-89}$ and repair with the aid of experimental techniques. ${ }^{90-94}$ were excluded.

Ultimately, 23 studies were suitable for inclusion in this individual patient data meta-analysis. The following data were extracted from the studies: age at time of injury, gender, injured nerve, type and site of injury, adjacent injuries, delay between injury and repair, type of repair, use of grafts, length of gap, follow-up period and motor and sensory BMRC-scores. The British Medical Research Council introduced in 1954 scales for motor and sensory testing of peripheral nerve function. ${ }^{95}$ Part of the sensory scale consists of two-point discrimination measurement. This has been demonstrated to be a widespread, often used measurement of sensibility in the hand. ${ }^{96-100}$ Manual muscle testing is a widespread method for the testing of motor function and has adequate intra and interobserver reliability. ${ }^{98,101}$

Groups were classified as follows. Age: $<16$ years, $16-25$ years, $26-40$ years and $>40$ years. Injured nerve: median, ulnar or combined median and ulnar nerve injury. Delay between injury and repair was counted in months. Site of injury: low (wrist and distal two third of the forearm), intermediate (proximal one third of the forearm and the elbow) and high (upper arm). The use of autologous nerve grafts was also noted. The remaining gap after removal of injured nerve ends was grouped as $\leq 50 \mathrm{~mm}$ or $>50 \mathrm{~mm}$. Follow-up time was counted in years: $<1$ year, 1 to $\leq 2$ years, 2 to $\leq 3$ years and $>3$ years. Although various classifications have been made previously, we choose to classify satisfactory motor recovery as BMRC grade M4 or M5 and unsatisfactory as BMRC grades M0 to M3. Based on clinical experience, we classified satisfactory sensory recovery as BMRC grade $\mathrm{S} 3+$ and $\mathrm{S} 4$ and unsatisfactory as BMRC grades $\mathrm{S} 0$ to $\mathrm{S} 3$.

Data analysis

All data analyses were performed using SPSS for windows, release 10.1. Data analyses were separately performed for sensory recovery and motor recovery. In the final model, only subjects with complete data on all risk factors were included, resulting in 380 cases for sensory recovery and 281 cases for motor recovery. The association between each predictor and recovery was first assessed by univariate logistic regression analyses, with the odds ratio (OR) and 95\% confidence interval $(95 \% \mathrm{Cl})$ as measure of association. The above-described risk factors were all tested. Additionally, we adjusted for study, since heterogeneity of the studies may affect the relation between risk factors and outcome. Variables that were univariately associated with motor or sensory recovery $(p<0.10)$ were then included in a multivariate logistic regression model to evaluate the independent contribution in the prediction of recovery. Model reduction was performed by excluding variables that were not borderline significantly related with recovery $(O R$ with $\mathrm{p}<0.10)$ from the overall model. To assess the predictive or discriminative ability of the models we calculated the area under the receiver operating characteristics curve (ROC area) with $95 \% \mathrm{Cl}$. The ROC curve of a multivariate logistic model plots the sensitivity and 
1-specificity at each consecutive threshold in the range of predicted probabilities of the model. The area under this curve, i.e. the ROC area, can range from 0.5 (no discrimination between subjects with and without recovery) to 1.0 (perfect discrimination).

\section{RESULTS}

Of the collected studies, 23 gave appropriate individual data and were included in our meta-analysis (Table 1). Of the studies that could not be included in our meta-analysis due to lack of individual data, the ones with more than 100 nerve repairs $(n=5)$ are described in Table 2. ${ }^{37,46,47,54,60}$ All studies were retrospective observational studies. The number of nerve injuries included per study ranged from $6-88$, and a total of 623 nerve injuries were available. In the final model, only subjects with complete data on all risk factors were included, resulting in 380 cases for sensory recovery and 281 cases for motor recovery. A description of the study population is given in Table 3 .

A satisfactory sensory outcome was achieved in $42.6 \%$ of the patients and a satisfactory motor outcome in $51.6 \%$. Motor and sensory recovery outcome scores were significantly correlated

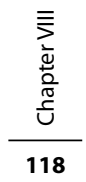

Table 1. Description of included studies

\begin{tabular}{|c|c|c|c|c|c|c|c|c|c|}
\hline \multirow{2}{*}{\multicolumn{2}{|c|}{ Author and year of publication }} & \multirow{3}{*}{$\begin{array}{l}\mathbf{n} \\
13\end{array}$} & \multirow{3}{*}{$\begin{array}{l}\text { Nerve } \\
M / U / C\end{array}$} & \multirow{2}{*}{\multicolumn{2}{|c|}{$\begin{array}{l}\text { Age (yrs) } \\
\text { Mean/ range }\end{array}$}} & \multirow{2}{*}{\multicolumn{2}{|c|}{$\begin{array}{l}\text { FU (months) } \\
\text { Mean/ range }\end{array}$}} & \multirow{2}{*}{\multicolumn{2}{|c|}{$\begin{array}{l}\text { Delay(months) } \\
\text { Mean/range }\end{array}$}} \\
\hline & & & & & & & & & \\
\hline Hakistan $^{12}$ & 1968 & & & - & - & - & - & 0 & $0-0$ \\
\hline Millesi ${ }^{17}$ & 1972 & 65 & $M / U$ & 33 & $7-67$ & 22 & $6-48$ & 9.2 & $0-56$ \\
\hline Walton \& Finseth ${ }^{10,27}$ & 1977 & 8 & $M / U$ & 27 & $16-51$ & 23 & $10-31$ & 17.6 & $3-84$ \\
\hline $\mid$ to $^{13}$ & 1976 & 20 & $M / U$ & 28 & $2-68$ & 48 & - & - & - \\
\hline Millesi ${ }^{18}$ & 1976 & 22 & $M / U$ & 30 & $11-69$ & 35 & $9-48$ & 12.4 & $1-49$ \\
\hline Moneim ${ }^{19}$ & 1982 & 20 & $M / U$ & 33 & $14-79$ & 25 & $10-36$ & 14.3 & $0.5-48$ \\
\hline Stellini $i^{22}$ & 1982 & 39 & $M / U$ & - & $15-65$ & 31 & $18-52$ & - & - \\
\hline Tackmann 25 & 1983 & 41 & $M / U$ & 34 & $7-72$ & 20 & $4-59$ & 0 & $0-0$ \\
\hline Puckett $^{20}$ & 1985 & 46 & $\mathrm{M} / \mathrm{U} / \mathrm{C}$ & 22 & $1-61$ & 40 & $12-84$ & 0 & $0-0$ \\
\hline Stevenson ${ }^{23}$ & 1986 & 10 & $C$ & 5 & $3-9$ & - & $>15$ & 0 & $0-0$ \\
\hline Jongen ${ }^{15}$ & 1987 & 22 & $M / U$ & 20 & $4-58$ & 24 & $12-60$ & 0 & $0-0$ \\
\hline Frykman ${ }^{11}$ & 1988 & 13 & $M / U$ & 27 & $3-51$ & 60 & $18-120$ & 6.1 & $1-30$ \\
\hline Barrios $^{7}$ & 1989 & 44 & U & 29 & $6-69$ & 24 & $>6$ & 5.2 & $0-23$ \\
\hline Rogers ${ }^{24}$ & 1990 & 8 & $C$ & 26 & $17-47$ & 74 & 24-132 & 0 & $0-0$ \\
\hline Widgerow ${ }^{28}$ & 1990 & 30 & $\mathrm{M} / \mathrm{U} / \mathrm{C}$ & 34 & $13-63$ & 36 & $20-60$ & 0 & $0-0$ \\
\hline Barrios $^{8}$ & 1991 & 31 & $M / U$ & 9.5 & 4-15 & 24 & $12-60$ & 8.2 & $0-70$ \\
\hline Daoutis ${ }^{9}$ & 1994 & 88 & $M / U$ & 31 & $8-52$ & 26 & $>24$ & 4.6 & $1-24$ \\
\hline Trumble 26 & 1995 & 13 & $M / U$ & 29 & $7-61$ & 33 & $23-66$ & 2.7 & $0.5-6$ \\
\hline Kato $^{16}$ & 1998 & 51 & $\mathrm{M} / \mathrm{U}$ & 28 & $12-61$ & 37 & $25-65$ & 1.7 & $0-9$ \\
\hline Selma ${ }^{21}$ & 1998 & 28 & $M$ & 26 & $4-45$ & 25 & $14-48$ & 0.1 & $0-1$ \\
\hline Amillo ${ }^{6}$ & 1999 & 6 & $M / U$ & 11 & $6-16$ & 24 & $18-60$ & 9.3 & $2.5-16$ \\
\hline Jerosch-Herold ${ }^{14}$ & 2000 & 41 & $M$ & 33 & $12-72$ & 34 & $9-90$ & 0.1 & $0-3$ \\
\hline
\end{tabular}


Table 2. Large studies not included in meta-analysis due to lack of individual patient data

\begin{tabular}{|c|c|c|c|c|c|}
\hline Study & Nerve Injuries & Follow-up methods & Remarks & Predictors & Not predictors \\
\hline Birch $^{37}$ & $\begin{array}{l}56 \mathrm{MN}+ \\
52 \mathrm{UN}\end{array}$ & $\begin{array}{l}\text { BMRC motor \& } \\
\text { sensory, questions }\end{array}$ & & $\begin{array}{l}\text { Age (child vs adult)* } \\
\text { Primary repair } \\
\text { Distal injury }\end{array}$ & \\
\hline Kalomiri' ${ }^{46}$ & $\begin{array}{l}73 \mathrm{MN}+ \\
85 \mathrm{UN}+27 \mathrm{C}\end{array}$ & $\begin{array}{l}\text { BMRC motor \& } \\
\text { sensory }\end{array}$ & Grafts & Age (child vs adult)* Delay & \\
\hline Kalomiri $^{47}$ & $118 \mathrm{UN}$ & $\begin{array}{l}\text { BMRC motor \& } \\
\text { sensory }\end{array}$ & Grafts & $\begin{array}{l}\text { Age } \\
\text { Delay }\end{array}$ & Length of graft \\
\hline Merle $^{54}$ & $150 M N+U N$ & Chanson's method & $\begin{array}{l}\text { Partial } \\
\text { lesions } \\
\text { included }\end{array}$ & $\begin{array}{l}\text { Age } \\
\text { Type of accident }{ }^{* *} \\
\text { Type of trauma*** } \\
\text { Level of injury } \\
\text { Type of repair }\end{array}$ & Gender \\
\hline Vastamaki $^{60}$ & $110 \mathrm{UN}$ & $\begin{array}{l}\text { 2PD } \\
\text { Ridge sensitometer } \\
\text { BMRC }\end{array}$ & $\begin{array}{l}\text { Secondary } \\
\text { repairs }\end{array}$ & $\begin{array}{l}\text { Age (sensory) } \\
\text { Level of injury (motor) } \\
\text { Length of contusion } \\
\text { Sharp injuries } \\
\text { Delay (motor) } \\
\text { Length of graft (motor) }\end{array}$ & $\begin{array}{l}\text { Additional } \\
\text { injuries } \\
\text { Microscope vs } \\
\text { loupe } \\
\text { Graft } \\
\text { Nerve }\end{array}$ \\
\hline
\end{tabular}

* There was no clear relation between age and outcome in later decades.

** Industrial, suicide attempt, housework.

*** Sharp versus crush injury.

$\mathrm{MN}=$ median nerve, $\mathrm{UN}=$ ulnar nerve, $\mathrm{C}=$ combined median and ulnar nerve injury.

(Spearman correlation coefficient $0.62, \mathrm{P}=<0.001, \mathrm{n}=417$ ). Table 4 shows the crude association between the predictors and satisfactory motor and sensory recovery. Table 5 presents the multivariate logistic regression analysis and shows several independent predictors.

Patients under 16 years of age were four times more likely to have a satisfactory motor recovery (OR $4.395 \% \mathrm{Cl} 1.6-11.2, \mathrm{p}<0.05)$ than patients over 40 years of age. Intermediate or high lesions compared to low lesions (OR $0.4695 \% \mathrm{Cl} 0.20-1.1, \mathrm{p}<0.10$ ) and a longer delay between injury and repair were associated with a lower chance of motor recovery (per month OR $0.94,95 \% \mathrm{Cl} 0.90-0.98, \mathrm{p}<0.05$ ). Ulnar nerve injuries gave a $71 \%$ lower chance of motor recovery than median nerve injuries $(\mathrm{OR}=0.29,95 \% \mathrm{Cl} 0.15-0.55, \mathrm{p}<0.05)$. Since there were too many missing values on gap width, this predictor was not included in the final model, even though a gap of $\geq 50 \mathrm{~mm}$ was significantly and independently associated with a $17 \%$ lower chance of motor recovery compared to a gap of $<50 \mathrm{~mm}$.

For sensory recovery, younger age was predictive of satisfactory recovery, whereas longer delay between injury and repair was again associated with a lower chance of recovery, i.e. for each month of extra delay the chance of recovery was reduced by $8 \%$. After grouping the delay period into primary repair ( 0 days delay), delayed primary repair ( 1 day- 1 month), early secondary repair (1-3 months) and secondary repair (3-6 months, 6-12 months and more than 1 year delay), there seemed to be a tendency for the early secondary repair (1-3 months) to achieve slightly better results $(\mathrm{OR}=4.66,95 \% \mathrm{Cl} 0.81-26.83)$ compared to delayed 
Table 3. Description of study population

\begin{tabular}{|c|c|c|}
\hline Characteristic & Number & Percentage \\
\hline Nerves & 623 & \\
\hline Median & 322 & $51.7 \%$ \\
\hline Ulnar & 301 & $48.3 \%$ \\
\hline Of which combined & 138 & $23.7 \%$ \\
\hline Age group & 520 & \\
\hline Child (<16y) & 113 & $21.7 \%$ \\
\hline Adolescent (16-25y) & 151 & $29.0 \%$ \\
\hline Young adult (26-40y) & 145 & $27.9 \%$ \\
\hline Adult (>40y) & 111 & $21.3 \%$ \\
\hline Site & 538 & \\
\hline Low & 442 & $82.2 \%$ \\
\hline Intermediate \& high & 96 & $17.8 \%$ \\
\hline Graft used & 582 & \\
\hline Yes & 331 & $56.9 \%$ \\
\hline Gap & 268 & \\
\hline$<50 \mathrm{~mm}$ & 110 & $38.5 \%$ \\
\hline $50 \mathrm{~mm}$ and over & 176 & $61.5 \%$ \\
\hline Follow-up time & 500 & \\
\hline$<1$ year & 72 & $14.4 \%$ \\
\hline $1-2$ year & 124 & $24.8 \%$ \\
\hline 2-3 year & 200 & $40.0 \%$ \\
\hline$>3$ year & 104 & $20.8 \%$ \\
\hline BMRC Sensory & 608 & \\
\hline Satisfactory & 259 & $42.6 \%$ \\
\hline BMRC Motor & 432 & \\
\hline Satisfactory & 223 & $51.6 \%$ \\
\hline
\end{tabular}

primary repair ( 1 day 1 month, $\mathrm{OR}=2.38,95 \% \mathrm{Cl} 0.58$-9.82) and no delay ( 0 days, reference group), although this was not significant $(p=0.08)$. There was no significant difference between median and ulnar nerve injuries in relation to sensory recovery. For patients $>40$ years old and a delay of $>3$ months the predicted probability of a satisfactory sensory outcome was 0.14 compared to 0.43 in all other patients; for motor recovery these probabilities were 0.25 versus 0.55 . In the prediction of sensory recovery, the ROC area was $0.82(95 \% \mathrm{Cl}: 0.77-0.87)$, whereas for the prediction of motor recovery it was 0.87 ( $95 \% \mathrm{Cl}: 0.84-0.91$ ). Although the ROC area is not very informative for clinical purposes it is a measure of discriminative power and $>0.80$ can be considered as good. 
Table 4. Crude association of predictors with satisfactory outcome

\begin{tabular}{|c|c|c|c|}
\hline Predictor & Groups & $\begin{array}{l}\text { Satisfactory Sensory recovery } \\
\% \text { (n) }\end{array}$ & $\begin{array}{l}\text { Satisfactory Motor recovery } \\
\% \text { (n) }\end{array}$ \\
\hline \multirow[t]{5}{*}{ Age } & $<16$ years & $69(74 / 108)$ & $60(55 / 92)$ \\
\hline & $16-25$ years & $44(65 / 149)$ & $66(69 / 104)$ \\
\hline & $26-40$ years & $38(54 / 142)$ & $49(47 / 96)$ \\
\hline & $>40$ years & $20(21 / 106)$ & $34(26 / 77)$ \\
\hline & Total: & $n=505$ & $n=369$ \\
\hline \multirow[t]{3}{*}{ Gender } & Male & $39(57 / 148)$ & $53(73 / 137)$ \\
\hline & Female & $38(21 / 55)$ & $55(29 / 53)$ \\
\hline & Total: & $n=203$ & $\mathrm{n}=190$ \\
\hline \multirow[t]{3}{*}{ Nerve } & Median & $44(138 / 315)$ & $61(111 / 182)$ \\
\hline & Ulnar & $41(121 / 293)$ & $45(112 / 250)$ \\
\hline & Total: & $n=608$ & $n=432$ \\
\hline \multirow[t]{3}{*}{ Combined } & Yes & $41(56 / 138)$ & $54(53 / 98)$ \\
\hline & No & $43(183 / 430)$ & $51(170 / 334)$ \\
\hline & Total: & $n=568$ & $\mathrm{n}=432$ \\
\hline \multirow[t]{3}{*}{ Site } & Low & $43(185 / 433)$ & $54(136 / 253)$ \\
\hline & Intermed. \& high & $34(31 / 90)$ & $36(34 / 94)$ \\
\hline & Total: & $n=523$ & $n=347$ \\
\hline \multirow[t]{7}{*}{ Delay } & No delay & $47(96 / 206)$ & $67(46 / 69)$ \\
\hline & 1 day- 1 month & $39(19 / 49)$ & $60(18 / 30)$ \\
\hline & $1-3$ months & $66(38 / 58)$ & $79(46 / 58)$ \\
\hline & 3- 6 months & $47(51 / 109)$ & $56(62 / 111)$ \\
\hline & $6-12$ months & $25(15 / 59)$ & $26(15 / 58)$ \\
\hline & $>12$ months & $16(7 / 44)$ & $23(9 / 40)$ \\
\hline & Total: & $n=525$ & $n=366$ \\
\hline \multirow[t]{3}{*}{ Graft used } & No & $53(133 / 251)$ & $64(80 / 126)$ \\
\hline & Yes & $40(125 / 316)$ & $47(143 / 306)$ \\
\hline & Total: & $n=567$ & $n=432$ \\
\hline \multirow[t]{3}{*}{ Gap } & $<50 \mathrm{~mm}$ & $39(41 / 105)$ & $51(52 / 102)$ \\
\hline & $50 \mathrm{~mm}$ and over & $37(62 / 166)$ & $43(73 / 171)$ \\
\hline & Total: & $n=271$ & $n=273$ \\
\hline \multirow[t]{5}{*}{ Follow up } & $<1$ years & $24(17 / 72)$ & $40(19 / 47)$ \\
\hline & 1-2 years & $43(52 / 121)$ & $48(36 / 75)$ \\
\hline & 2-3 years & $48(92 / 193)$ & $51(90 / 177)$ \\
\hline & $>3$ years & $33(33 / 99)$ & $47(37 / 79)$ \\
\hline & Total: & $n=485$ & $\mathrm{n}=378$ \\
\hline
\end{tabular}


Table 5. Results of multivariate logistic regression analysis for satisfactory sensory and motor recovery and ROC area

\begin{tabular}{llll}
\hline Predictor & Categories & $\begin{array}{l}\text { Satisfactory Sensory Recovery } \\
\text { OR }(\mathbf{9 5 \%} \mathbf{C l}), \mathbf{n = 3 8 0}\end{array}$ & $\begin{array}{l}\text { Satisfactory Motor Recovery } \\
\text { OR }(\mathbf{9 5} \% \mathbf{C l}), \mathbf{n = 2 8 3}\end{array}$ \\
\hline Age & $<16$ yrs & $27.0(9.4-77.6)^{*}$ & $4.3(1.6-11.2)^{*}$ \\
& $16-25$ yrs & $6.6(2.8-15.3)^{*}$ & $2.8(1.2-6.9)^{*}$ \\
& $25-40$ yrs & $1.9(0.9-4.3)$ & $1.4(0.5-3.6)$ \\
& $>40$ yrs & Reference & Reference \\
Delay & per month & $0.92(0.87-0.98)^{*}$ & $0.94(0.90-0.98)^{*}$ \\
Follow-up & $<1 y$ & Reference & - \\
& $1-2$ yrs & $1.2(0 .-3.1)$ & \\
& $2-3$ yrs & $3.0(1.0-8.8)^{*}$ & \\
Site & $>3$ yrs & $1.2(0.4-3.9)$ & $0.46(0.20-1.1)^{* *}$ \\
Nerve & intermed/high vs low & - & $0.29(0.15-0.55)^{*}$ \\
ROC Area $(95 \% \mathrm{Cl})$ & - & \\
\hline
\end{tabular}

* Significant at the $p<0.05$ level, ${ }^{* *}$ Significant at the $p<0.10$ level.

$\mathrm{OR}=$ odds ratio, $95 \% \mathrm{Cl}=95 \%$ confidence interval.

ROC area $=$ Area under the Receiver Operating Characteristics curve.

\section{DISCUSSION}

Due to the considerable variety of factors influencing nerve regeneration and outcome, final recovery after peripheral nerve injury is a complex matter. In numerous studies in the past decades, several variables have been proposed to influence outcome. However, many of these publications were based on small patient numbers and due to the wide range of patient and injury characteristics, different parameters were found to be of prognostic importance. In this individual patient data meta-analysis we seek to find conclusive evidence for independent predictors of a satisfactory outcome.

Although several authors have proposed new assessment methods to evaluate functional recovery of the hand after nerve repair no conclusive test battery is available. Recently, Rosen published a rationale for the evaluation of functional recovery following nerve injuries. ${ }^{102} \mathrm{We}$ used the MRC scale for both motor and sensory function testing, as it is the most widely accepted classification to score the outcome of peripheral nerve injuries. ${ }^{103}$ Since the introduction of microsurgical techniques in the sixties, the repair of peripheral nerve injuries has not changed considerably. Therefore it seems not likely that the operation techniques have influenced our results. It is known that experience of the surgeon plays an important role, however it was not possible to take this into consideration. Not all variables were known for every patient, so it was not possible to include all patients in the data analysis. Furthermore, only studies that gave individual data could be included in our meta-analysis. This could have lead to selection bias if other predictors of recovery were present in the patients that were excluded from our analyses, 
especially for the larger studies. To reduce this, we evaluated the results of the studies that did not meet our inclusion criteria and had more than 100 nerve injuries. (Table 2) It showed that mainly the same predictors were found. To prevent further selection bias we also excluded case reports.

The significant prognostic factors influencing outcome found in this meta-analysis differed for motor and sensory recovery. For motor recovery age, delay, site and type of injured nerve were found to predict outcome, for sensory recovery age and delay were significant prognostic factors. Younger patients were more likely to have a satisfactory motor and sensory outcome, and the longer the delay between injury and repair the smaller the chance of a favorable outcome. Combined median and ulnar nerve injuries and the use of autologous nerve grafts did not significantly predict motor and sensory recovery.

From previous research, several factors have been pointed out to influence final recovery. In general age was found to be a main factor for recovery. $6-8,15,20,21,23,31,34,52,80,83,104$ This can be explained by factors like shorter regeneration distance and greater regeneration potential, but recent research in primates shows also that in children there is probably a higher potential for brain plasticity compared to adults. ${ }^{105,} 106$ Some authors mentioned that especially sensory recovery benefits from a younger age, which is in accordance with our findings. ${ }^{58}$ Barrios did not find a better outcome in children after nerve grafting.?

We found that delay is associated with outcome. This confirms the results of many earlier studies that found an unfavorable prognosis after more than six or twelve months delay. ${ }^{6-9,}{ }^{15,23,}$ $26,52,83,107,108$ Others advocated the use of an early secondary repair for all injuries. ${ }^{109}$ Merle found, in a small group of patients, a higher percentage of failures after nerve repair performed on an emergency basis than after secondary repair. ${ }^{54}$

In the past, several authors ${ }^{110-113}$ advocated the use of primary repair for clean-cut injuries and early secondary repair (4- 6 weeks) for blunt or extensive injuries. We found a similar tendency for sensory recovery, but this was not significant $(p=0.08)$. Our results favor a primary repair, although when contra-indicated an early secondary repair can be considered as a safe option. Unfortunately, we did not have individual information on the type of injury (blunt or cleancut).

It is important for both doctor and patient to know when the end point of recovery has been reached. This information can provide the patient a realistic prognosis especially regarding the possibility of returning to work. ${ }^{114}$ Furthermore this data can be used to predict at an earlier stage the need for other treatment options, such as tendon transfer. According to the literature, significant improvements can be found for up to 5 years after nerve repair. ${ }^{58}$ This meta-analysis indicated that there seems to be significant improvement for at least a follow-up period of 3 years.

Site has been mentioned ${ }^{80}$ as the most important determinant of outcome; our conclusion is that it is a significant predictor only for motor recovery. A muscle can become atrophic and irreversibly damaged in one and a half to two years. Nerve regeneration occurs with a speed of 
approximately $1 \mathrm{~mm}$ a day, and if in the meantime innervation is not restored, motor recovery will be poor. ${ }^{115}$

As in this meta-analysis, several authors found a better motor recovery in median nerve injuries compared to ulnar nerve injuries ${ }^{6,19,25,42,58,107}$, and no difference for sensory recovery. ${ }^{26}$ Combined ulnar and median nerve injury has been identified as a predictor for worse prognosis due to the associated extensive soft tissue damage. ${ }^{13,28,78}$ Although combined nerve injuries are usually accompanied by extensive tissue damage ${ }^{80}$, they do not necessarily imply a poor result. ${ }^{107}$ In this meta-analysis we did not find a significant effect on outcome either. Unfortunately, information

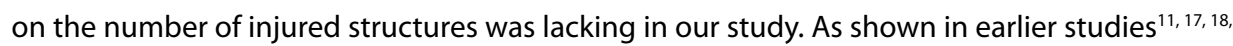
${ }^{27,104}$, we found no difference between direct repair and interfascicular grafting. However, it was not possible to measure the influence of the graft length with our data. It has been noticed that long grafts are more likely to give unfavorable results. ${ }^{6-8,42} \mathrm{~A}$ number of other factors were found in previous research to influence recovery but could not be investigated in this meta-analyses due to missing data. These factors are the effect of the type and severity of the initial injury ${ }^{116}$, good cooperation and motivation of the patient ${ }^{15,28}$, specialized hand therapy ${ }^{23,58,117}$, cognitive capacity ${ }^{33}$, early psychological stress experienced due to the trauma ${ }^{1}$ and comorbidity such as diabetes and alcoholism ${ }^{46}$, ${ }^{47}$. Since it is not possible to influence the factors regarding the injury, except sometimes for delay, effort should be made to intervene with the postoperative parameters such as optimized hand therapy and psychological intervention.

Improvement of the results may be sought in refinement of the surgical procedure, hand therapy in specialized centers and experimental techniques ${ }^{118}$, such as silicone tubes ${ }^{90,92,93}$ or biodegradable nerve guides ${ }^{119}$. It would be advisable to follow a large cohort of patients prospectively with detailed measuring of possible predictors. Also the use of a more extended test battery besides motor and sensory testing, such as $A D L$, quality of life, cold intolerance and psychosocial factors, could give a better insight in the outcome of peripheral nerve repair and regeneration.

\section{CONCLUSIONS}

In this individual patient data meta-analysis several predictors have been found influencing outcome after peripheral nerve repair. Age, site, injured nerve and delay significantly influenced prognosis after microsurgical repair of median and ulnar nerve injuries. In patients younger than 16 year with no delay, the chances of satisfactory sensory recovery are the highest, whereas for motor recovery a patient under 16 years, with a distal median nerve injury and no delay will give the best results. A follow-up time of at least 3 years is necessary to evaluate the final outcome. On the basis of the figures from this meta-analysis, it is possible to estimate which patients have a high or low chance of successful motor and sensory recovery after median or ulnar nerve injury. 


\section{REFERENCES}

1. Jaquet J, Kalmijn S, Kuypers P, Hofman A, Passchier J, Hovius S. Early psychological stress after forearm nerve injuries: a predictor for long term functional outcome and return to productivity. Ann Plast Surg.49: 82-90, 2002.

2. Mackinnon SE, Dellon AL. Results of nerve repair and grafting. Surgery of the peripheral nerve.: Thieme, 1988:115-29.

3. Vanderhooft E. Functional outcomes of nerve grafts for the upper and lower extremities. Hand Clin. 16: 93 - 104, 2000.

4. Frykman GK, Gramyk K. Results of nerve grafting. In: Gelberman RH, editor. Operative nerve repair and reconstruction. Philadelphia: JB Lippincott, 1991:553-567.

5. Clarke M, Stewart L, Pignon J-P, Bijnens L. Individual patient data meta-analyses in cancer. $\mathrm{Br} J$ Cancer.77: 2036-2044, 1998.

6. Amillo S, Mora G. Surgical management of neural injuries associated with elbow fractures in children. J Ped Orthop.19: 573-7, 1999.

7. Barrios C, Amillo S, de Pablos J, Canadell J. Secondary repair of ulnar nerve injury. 44 cases followed for 2 years. Acta Orthopaedica Scandinavica.61: 46-9, 1990.

8. Barrios $C$, de Pablos J. Surgical management of nerve injuries of the upper extremity in children: a 15-year survey. Journal of Pediatric Orthopedics. 11:641 - 5, 1991.

9. Daoutisn, Gerostathopoulos N, Efstathopoulos D, Misitizis D, Bouchlis G, Anagnostou S. Microsurgical reconstruction of large nerve defects using autologous nerve grafts. Microsurgery.15: 502 - 5, 1994.

10. Finseth F, Constable J, Cannon B. Interfascicular nerve grafting. Plast Reconstr Surg.56: 492 -5, 1975.

11. Frykman GK, Cally D. Interfascicular nerve grafting. Orthop Clin NA.19: 71 - 80, 1988.

12. Hakistan RW. Funicular orientation by direct stimulation. J Bone Joint Surg.50-A: 1178-86, 1968.

13. Ito $\mathrm{T}$, Hirotani $\mathrm{H}$, Yamamoto K. Peripheral nerve repairs by the funicular suture technique. Acta Orthop Scand.47: $283-9,1976$.

14. Jerosch-Herold C. Should sensory function after median nerve injury and repair be quantified using two-point discrimination as the critical measure? Scandinavian Journal of Plastic and Reconstructive Surgery and Hand Surgery.34: 339-43, 2000.

15. Jongen S, Van Twisk R. Results of primary repair of ulnar and median nerve injuries at the wrist: an evaluation of sensibility and motor recovery. Neth J Surg.40: 86-9, 1988.

16. Kato $\mathrm{H}$, Minami A, Kobayashi M, Takahara M, Ogino T. Functional results of low median and ulnar nerve repair with intraneural fascicular dissection and electrical fascicular orientation. 23: 471 -82, 1998.

17. Millesi H, Meissl G, Berger A. The interfascicular nerve-grafting of the median and ulnar nerves. $J$ bone Joint Surg.54A: 727-50, 1972.

18. Millesi H, Meissl G, Berger A. Further experience with interfascicular grafting of the median, ulnar, and radial nerves. J Bone Joint Surg.58-A: 209-18, 1976.

19. Moneim MS. Interfascicular nerve grafting. Clin Orthop Rel Res.163: 65-74, 1982.

20. Puckett $\mathrm{CL}$, Meyer VH. Results of treatment of extensive volar wrist lacerations: The Spaghetti Wrist. Plast Reconstr Surg.75: 714-9, 1985.

21. Rogers GD, Henshall AL, Sach RP, Wallis KA. Simultaneous laceration of the median and ulnar nerves with flexor tendons at the wrist. J Hand Surg.15A: 990-5, 1990.

22. Selma P, Emre O, Oguz P, Ersin N, Oya B. Evaluation of the improvement of sensibility after primary median nerve repair at the wrist. Microsurg.18: 192-6, 1998.

23. Stellini L. Interfascicular autologous grafts in the repair of peripheral nerves: eight years experience. Br J Plast Surg.35: 478-82, 1982.

24. Stevenson $\mathrm{JH}$, Zuker RM. Upper limb motor and sensory recovery after multiple proximal nerve injury in children: a long term review in five patients. Br J Plast Surg.39: 109-13, 1986.

25. Tackmann W, Brennwald J, Nigst H. Sensory electroneurographic parameters and clinical recovery of sensibility in sutured human nerves. J neurol.229: 195-206, 1983.

26. Trumble TE, Kahn U, Vanderhooft E, Bach AW. A technique to quantitate motor recovery following nerve grafting. J Hand Surg. American Volume.20: 367-72, 1995. 
27. Walton R, Finseth F. Nerve grafting in the repair of complicated peripheral nerve trauma. JTrauma.17: $793-6,1977$.

28. Widgerow AD. Full-house/spaghetti wrist injuries. Analysis of results. South African Journal of Surgery. Suid-Afrikaanse Tydskrif Vir Chirurgie.28: 6-10, 1990.

29. Deutinger M, Girsch W, Burggasser G, Windisch A, Joshi D, Mayr N, et al. Peripheral nerve repair in the hand with and without motor sensory differentation. J Hand Surg.18A: 426-32, 1993.

30. Imai H, Tajima T, Natsumi Y. Successful reeducation of functional sensibility after median nerve repair at the wrist. J Hand surg.16A: 60-5, 1991.

31. Jerosch-Herold C. Measuring outcome in median nerve injuries. J Hand Surg [Br]. 18: 624-8, 1993.

32. Novak CB, Kelly L, Mackinnon SE. Sensory recovery after median nerve grafting. J Hand Surg.17A: 59-68, 1992.

33. Rosen B, Lundborg G, Dahlin LB, Holmberg J, Karlson B. Nerve repair: correlation of restitution of functional sensibility with specific cognitive capacities. 19: 452-8, 1994.

34. Tajima T, Imai H. Results of median nerve repair in children. Microsurg.10: 145-6, 1989.

35. Trevett MC, Tuson C, de Jager LT, Juon JM. The functional results of ulnar nerve repair. Defining the indications for tendon transfer. J Hand Surg [Br].20: 444-6, 1995.

36. Berger A, Mailander P. Advances in peripheral nerve repair in emergency surgery of the hand. $W J$ Surg.15: 493 - 500, 1991.

37. Birch R, Raji AR. Repair of median and ulnar nerves. Primary suture is best. Journal of Bone and Joint Surgery. British Volume.73: 154-7, 1991.

38. Birch R, Achan P. Peripheral nerve repairs and their results in children. Hand Clinics.16: 579-95, 2000.

39. Bolitho DG, Boustred M, Hudson DA, Hodgetts K. Primary epineural repair of the ulnar nerve in children. 24: 16-20, 1999.

40. Chin G, Weinzweig N, Mead M, Gonzalez M. "Spaghetti wrist": management and results. Plast Reconstr Surg.102: $96-102,1998$.

41. Duteille F, Petry D, Poure L, Dautel G, Merle M. A comparative clinical and electromyographic study of median and ulnar nerve injuries at the wrist in children and aldults. J Hand Surg [Br].26: 58-60, 2001.

42. Haase J, Bjerre P, Simesen K. Median and ulnar nerve transections treated with microsurgical interfascicular cable grafting with autogenous sural nerve. J neurosurg.53: 73-84, 1980.

43. Hudson DA, de Jager LT. The spaghetti wrist. J Hand Surg.18B: 171 - 3, 1993.

44. Hudson DA, Bolitho DG, Hodgetts K. Primary epineural repair of the median nerve in children. $J$ Hand Surg.22B: 54-6, 1997.

45. Iconomou T, Zuker R, Michelow B. Management of major penetrating glass injuries to the upper extremities in children and adolescents. Microsurg.14: $91-6,1993$.

46. Kalomiri DE, Soucacos PN, Beris AE. Nerve grafting in peripheral nerve microsurgery of the upper extremity. Microsurgery.15: 506-11, 1994.

47. Kalomiri DE, Soucacos PN, Beriis AE. Management of ulnar nerve injuries. Acta Orthop Scand Suppl.264: 41 -4, 1995.

48. Kim DH, Kam AC, Chandika P, Tiel RL, Kline DG. Surgical management and outcomes in patients with median nerve lesions. J Neurosurg.95: 584-94, 2001.

49. Kim DH, Han K, Tiel RL, Murovic JA, Kline DG. Surgical outcomes of 654 ulnar nerve lesions. Journal of Neurosurgery.98: $993-1004,2003$.

50. Leclercq DC, Carlier AJ, Khuc T, Depierreux L, Lejeune GN. Improvement in the results in sixty-four ulnar nerve sections associated with arterial repair. J Hand Surg.10A: 997-9, 1985.

51. Lijftogt HJA, Dijkstra R, Storm van Leeuwen JB. Results of microsurgical treatment of nerve injuries of the wrist. Neth J Surg.39: 170-4, 1987.

52. Marsh D, Barton N. Does the use of the operating microscope improve the results of peripheral nerve suture? J Bone Joint Surg.69-B: 625-30, 1987.

53. Mailander P, Berger A, Schaller E, Ruhe K. Results of primary nerve repair in the upper extremity. Microsurgery.10: 147-50, 1989.

54. Merle M, Cour C, Foucher G, Michon J. Microsurgical repair of peripheral nerve lesions. A study of 150 injuries of the median and ulnar nerves. Peripheral Nerve Repair Reg.: 17-26, 1986. 
55. Pluchino F, Laccarelli G. Interfascicular suture with nerve autografts for median, ulnar and radial nerve lesions. Ital J Neurol Sci.2: 139-46, 1981.

56. Posch J, Dela Cruz-Saddul F. Nerve repair in trauma surgery. A ten-year study of 231 peripheral injuries. Orthop Rev.9: 35-45, 1980.

57. Rosen B, Dahlin LB, Lundborg G. Assessment of functional outcome after nerve repair in a longitudinal cohort. Scandinavian Journal of Plastic and Reconstructive Surgery and Hand Surgery.34: $71-8,2000$.

58. Rosen $B$, Lundborg $\mathrm{G}$. The long term recovery curve in adults after median or ulnar nerve repair: a reference interval. J Hand Surg.26B: 196-200, 2001.

59. Tallis R, Staniforth P, Fisher R. Neurophysiological studies of autogenous sural nerve grafts. J Neur Neurosurg Psych.41: 677-83, 1978.

60. Vastamaki M, Kallio K, Solonen KA. The results of secondary microsurgical repair of ulnar nerve injury. J Hand Surg.18B: 323-6, 1993.

61. Young VL, Wray RC, Weeks PM. The results of nerve grafting in the wrist and hand. Ann Plast Surg.5: 212-5, 1979.

62. Chakrabarti AJ, Kunzru KMN. Complete ulnar nerve division in a displaced supracondylar fracture: a case report. J Bone Joint Surg.77-B: 977-8, 1995.

63. Garg M, Kumar S. Entrapment and transection of the median nerve associated with minimally displaced fractures of the forearm: case report and review of the literature. Arch Orthop Trauma Surg.121: 544-5, 2001.

64. Huang K, Pun WK, Coleman S. Entrapment and transection of the median nerve associated with greenstick fractures of the forearm. J Trauma.44: $1101-2,1998$.

65. Matsunaga T, Saitoh S, Tanikawa H, Hayashi M, Ohira M, Kimura T. Deep cutting injury from the edges of a snowboard. Br J Sports Med.38: 80-3, 2004.

66. Sud V, Chang J, Lineaweaver W. Acute nerve grafting in traumatic injuries: two case studies. Ann Plast Surg.47: 555-61, 2001.

67. Trail I. Delayed repair of the ulnar nerve. Br J Hand Surg.10B: 345-5, 1985.

68. Yamano Y. Electrophysiological study of nerve grafting. J Hand Surg.7: 588-92, 1982.

69. del Pinal F, Cruz Camara A, Jado E. Total ulnar nerve transection during endoscopic carpal tunnel release. Arthroscopy: the Journal of Arthroscopic \& Related Surgery: Official Publication of the Arthroscopy Association of North America and the International Arthroscopy Association.13: 235-7, 1997.

70. Swenson JD, Bull DA. Postoperative ulnar neuropathy associated with prolonged ischemia in the upper extremity during coronary artery bypass surgery. Anesthesia and Analgesia.85: 1275-7, 1997.

71. Martens PR, Driessen JJ, Lanckriet W, Lust P. Bilateral ulnar nerve injury after high abdominal surgery. Acta Anaesthesiologica Belgica.39: 113-5, 1988.

72. Perreault L, Drolet P, Farny J. Ulnar nerve palsy at the elbow after general anaesthesia. Canadian Journal of Anaesthesia = Journal Canadien D'anesthesie.39: 499-503, 1992.

73. Scott TF, Yager JG, Gross JA. Handcuff neuropathy revisited. Muscle \& Nerve.12: 219-20, 1989.

74. Hurst LC, Dowd A, Sampson SP, Badalamente MA. Partial lacerations of median and ulnar nerves. $J$ Hand Surg.16A: 207 - 10, 1991.

75. Kallio P, Vastamaki M. An analysis of the results of late reconstruction of 132 median nerves. J Hand Surg [Br].18: $97-105,1993$.

76. Barisic N, Perovic D, Mitrovic Z, Jurenic D, Zagar M. Assessment of war and accidental nerve injuries in children. Pediatr Neurol.21: 450-5, 1999.

77. Omer GE. Injuries to nerves of the upper extremity. J Bone Joint Surg.56-A: 1615-24, 1974.

78. Taha A, Taha J. Results of suture of the radial, median, and ulnar nerves after missile injury below the axilla. Journal Of Trauma.45: 335-9, 1998.

79. Almquist $\mathrm{E}$, Eeg-Olofsson $\mathrm{O}$. Sensory-nerve-conduction velocity and two-point discrimination in sutured nerves. J Bone Joint Surg.52-A: 791-6, 1970.

80. Gaul JS. Intrinsic motor recovery - A long term study of ulnar nerve repair. J Hand Surg.7: 502-8, 1982.

81. Lindsay W, Walker F, Farmer A. Traumatic peripheral nerve injuries in children. Results of repair. Plast Reconstr Surg.30: 462-8, 1962. 
82. Nicholson O, Seddon H. Nerve repair in civil practice. BrMed J.2: 1065-71, 1957.

83. Sakellarides $\mathrm{H}$. A follow-up study of 172 peripheral nerve injuries in the upper extrenity in civilians. J Bone Joint Surg.44-A: 141-8, 1962.

84. Strzyzewski H. Multiple injuries to flexor tendons and nerves above the wrist. Hand.4: 178-83, 1972.

85. Kankaanpaa U, Bakalim G. Peripheral nerve injuries of the upper extremity. Acta Orthop Scand.47: $41-5,1976$.

86. McEwan L. Median and ulnar nerve injuries. Austr NZ J Surg.32: 89- 104, 1962.

87. Rana NA, Kenwright J, Taylor RG, Rushworth G. Complete lesion of the median nerve associated with dislocation of the elbow joint. Acta Orthop Scand.45: 365-9, 1974.

88. Match RM. Laceration of the median nerve from skiing. Am J Sports Med.6: 22-5, 1978.

89. Vahvanen V, Gripenberg L, Nuutinen P. Peripheral nerve injuries of the hand in children. A follow-up study of 38 patients. Scand J Plast Reconstr Surg.15: 49-51, 1979.

90. Braga-Silva J. The use of silicone tubing in the late repair of the median and ulnar nerves in the forearm. J Hand Surg.24B: 703-6, 1999.

91. Calder JS, Norris RW. Repair of mixed peripheral nerves using muscle autografts: a preliminary communication. British Journal of Plastic Surgery.46: 557-64, 1993.

92. Dahlin LB, Anagnostaki L, Lundborg G. Tissue response to silicone tubes used to repair human median and ulnar nerves. Scand J Plast Reconstr Hand Surg.35: 29-34, 2001.

93. Lundborg G, Rosen B, Dahlin L, Holmberg J, Rosen I. Tubular repair of the median or ulnar nerve in the human forearm: a 5-year follow-up. 29: 100-7, 2004.

94. Lundborg L, Rosen B, Dahlin L, Danielsen N, Holmberg J. Tubular versus conventional repair of median and ulnar nerves in the human forearm: early results from a prospective, randomized, clinical study. J Hand Surg.22A: 99-106, 1997.

95. Council MR. Nerve injuries committee: results of nerve suture. In: Seddon H, editor. Peripheral Nerve Injuries. London: Her Majesty's Stationary Office, 1954.

96. Dellon A, Kallman C. Evaluation of functional sensation in the hand. J Hand Surg.8: 865-70, 1983.

97. Dellon AL, Mackinnon SE, McDonald Crosby P. Reliability of two-point discrimination measurements. J Hand Surg.12A: 693-6, 1987.

98. Marx RG, Bombardier C, Wright JG. What do we know about the reliability and validity of physical examination tests used to examine the upper extremity? J Hand Surg.24A: 185-93, 1999.

99. Novak C, MacKinnon S, Williams J, Kelly L. Establishment of reliability in the evaluation of hand sensibility. Plast Reconstr Surg.92: $311-22,1993$.

100. Novak CB, Mackinnon SE, Kelly L. Correlation of two-point discrimination and hand function following median nerve injury. Ann Plast Surg.31: 495-8, 1993.

101. Brandsma J, Schreuders T, Birke J, Piefer A, Oostendorp R. Manual muscle testing: intraobserver and interobserver reliabilities for the intrinsic muscles of the hand. $J$ Hand Ther.8: 185-90, 1995.

102. Rosen B, Lundborg G. A model instrument for the documentation of outcome after nerve repair. $J$ Hand Surg. American Volume.25: 535-43, 2000.

103. Allan HA. Functional results of primary nerve repair. Hand Clin. 16: 67-72, 2000.

104. Simesen K, haase J, Bjerre P. Interfascicular transplantation in median nerve injuries. Acta Orthop Scand.51: $243-8,1980$.

105. Lundborg G. A 25-year perspective of peripheral nerve surgery: evolving neuroscientific concepts and clinical significance. J Hand Surg. American Volume.25: 391 -414, 2000.

106. Lundborg G. Brain plasticity and hand surgery: an overview. J Hand Surg [Br].25: 242 - 252, 2000.

107. Kabak S, Halici M, Baktir A, Turk C, Avsarogullari L. Results of treatment of the extensive volar wrist lacerations: 'the spaghetti wrist'. Eur J Em Med.9: 71-6, 2002.

108. Marsh D. The validation of measures of outcome following suture of divided peripheral nerves supplying the hand. J Hand Surg [Br].15: 25-34, 1990.

109. Dulken $\mathrm{vH}$, Thomeer RTWM. Recent developments in peripheral nerve surgery. Managemant of open traumatic peripheral nerve lesions. Arch Chir Neerl.30: 91 -9, 1978.

110. Merle M, Foucher G, Van Genechten F, Michon J. The repair of peripheral nerve injuries in emergency. Bull Hosp Joint Dis Orthop Inst.44: 338-46, 1984.

111. Millesi H. Microsurgery of peripheral nerves. W J Surg.3: 67-79, 1979.

112. Tupper JW, Crick JC, Matteck LR. Fascicular nerve repairs. Orthop Clin NA.19: 57-69, 1988.

113. Vuursteen PJ, Bloem JJ. Primary versus secondary nerve repair a review of the literature. Arch Chir Neerl.30: $21-28,1978$. 
114. Bruyns C, Jaquet J, Schreuders T, Kalmijn S, Kuypers P, Hovius S. Predictors for return to work in patients with median and ulnar nerve injuries. J Hand Surg [Am].28: 28-34, 2003.

115. Ehni BL. Treatment of traumatic peripheral nerve injury. American Family Physician.43: 897-905, 1991.

116. Beazley WC, Milek MA, Reiss BH. Results of nerve grafting in severe soft tissue injuries. Clin Orthop Rel Res.188: $208-12,1984$.

117. Jaquet JB, Luijsterburg JM, Kalmijn S, Kuypers PDL, Hofman A, Hovius SER. Median, ulnar and combined median-ulnar nerve injuries: functional outcome and return to productivity. J Trauma.51: 687-92, 2001.

118. Olson L. Regeneration in the adult central nervous system: experimental repair strategies. Nat Med.3: 1329-35, 1997.

119. den Dunnen WF, Meek MF, Grijpma DW, Robinson PH, Schakenraad JM. In vivo and in vitro degradation of poly $[(50) /(50)((85) /(15)(\mathrm{L}) /(\mathrm{D})) \mathrm{LA} / \mathrm{epsilon}-\mathrm{CL}]$, and the implications for the use in nerve reconstruction. Journal of Biomedical Materials Research.51: 575-85, 2000. 



\section{CHAPTER 9}

\section{GENERAL DISCUSSION AND CONCLUSIONS}

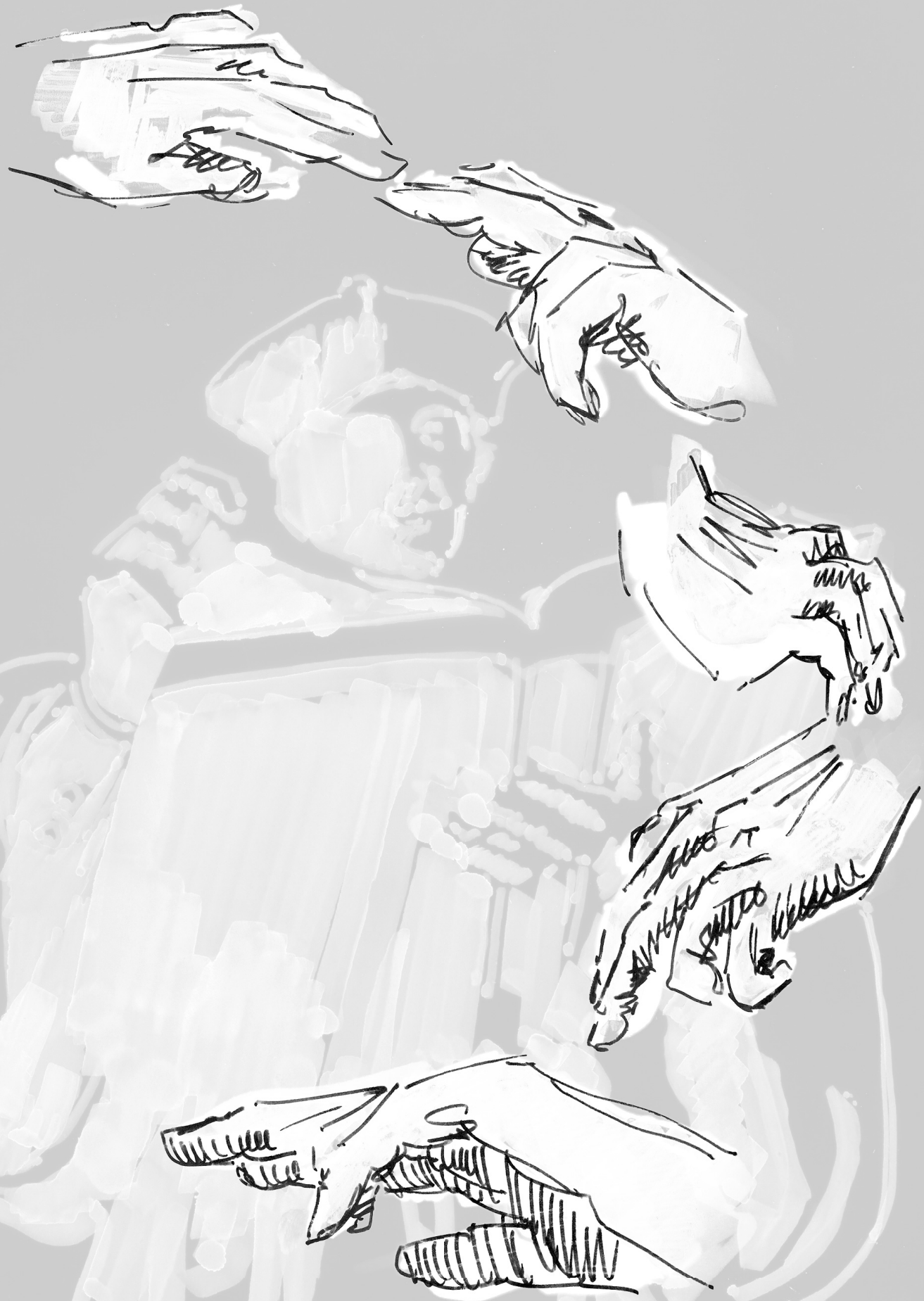





\section{GENERAL DISCUSSION}

The "Zenuwonderzoeksgroep Erasmus Rotterdam" - ZERO study

The following study design was used for this thesis. We retrospectively collected medical record data of all median and ulnar nerve injury patients who were operated on at the University Hospital Rotterdam "Dijkzigt" from January 1980 to December 1998. Based on the power analysis we needed 92 patients to perform statistical analysis concerning predicting variables. The following cohort was selected for a longitudinal follow-up study: all subjects with operative treatment of a median, ulnar or combined median-ulnar traumatic nerve injury during the period between January 1990 and December 1998. To participate in this study, the forearm nerve injuries were required to meet three entrance criteria: 1) A trauma of at least a single ulnar or median nerve located within the area between the wrist crease (distal border) and the flexor elbow crease (proximal border). 2) Patients had to be 12 years or older on the day of their injury and 3) Excluded from the study were subjects diagnosed with complete amputation of the hand followed by a replantation, patients with associated hand and or forearm fractures and also excluded were patients with amputation of hand or digits. On the basis of the entrance criteria, 136 patients were included. This study population was analyzed twice with a one year interval. In addition, a meta-analysis was performed and in 2001 a longitudinal prospective study was started.

\section{OUTCOME}

\section{Sensory and motor recovery}

Sensory and motor recovery are the classic outcome markers following peripheral nerve surgery. Rosen and Lundborg found that the combination of sensory/motor recovery and pain and discomfort was responsible for $73 \%$ of the final outcome. ${ }^{1}$ Grip strength was the reason for $36 \%$ of the variance of the activities of daily living (ADL) index. ${ }^{2}$

A large number of nerve injuries were analyzed during and after World Wars I and II..$^{3-6}$ In a 25 year perspective of peripheral nerve surgery, it was stated that clinical outcome is not much different from 25 years ago. ${ }^{7}$ After comparing previous outcome studies, we have to confirm the accuracy of this statement. ${ }^{8-36}$ Chapter 2 showed that for a median nerve injury 'good' sensory (grade S3+ or S4) and 'good' motor recovery (M4 and M5) was achieved in 25.7\% and 61.5\%, respectively. In cases where the ulnar nerve was injured, 'good' sensory and motor recovery was achieved in $21.7 \%$ and $39.4 \%$. These results do not much differ from the results of the metaanalyses in chapter 8. For median nerves: $44 \%$ S3+ or better and $61 \%$ M4 or better. For ulnar nerve repairs: $41 \%$ S3 or better and $45 \%$ M4 or better. Only the sensory results are significantly worse. One of the major reasons for this finding could be that in the meta-analysis a significant larger part of the study population (22\%) was below the age of 16 years. In our population 
only $5 \%$ of the population was below the age of 16 . A well-defined critical period has been described for sensory relearning following nerve repair. There is an optimum capacity below the 5 - 10 years age group followed by a rapid decline, which levels out after puberty. ${ }^{37}$

\section{Median versus ulnar nerve injuries}

It is generally accepted that median nerves have a better functional outcome than ulnar nerve injuries. ${ }^{1,38-41}$ In chapter $\mathbf{2}$ and $\mathbf{7}$ we found no difference for sensory recovery between the single median and ulnar nerve injuries. The meta-analysis confirmed this finding; there was no significant difference between median and ulnar nerve injuries in relation to sensory recovery (chapter 8). In contrast, motor recovery was statistically worse for the ulnar and combined median ulnar nerve injuries. Ulnar nerve injuries gave a $71 \%$ lower chance of motor recovery than median nerve injuries (chapter 8). Additionally, ulnar nerve injuries tended to have worse prospects concerning the ability to return to work within the first year (chapter $\mathbf{5}$ ). It may be concluded from this thesis that the ulnar nerve injuries only have worse prospects in relation to motor recovery. Based on the functional results of motor recovery in chapter $\mathbf{2}$ and $\mathbf{8}$, the differences in return to work ratio between ulnar and median nerve injuries will be more profound with longer follow-up (> 1 year).

\section{Sensory recovery versus motor recovery}

Recently, an association between sensory and motor recovery was hypothesized in a very small number of patients. ${ }^{42}$ The strength of association between these outcome parameters had never before been quantitated. Our meta-analysis (chapter 8) showed a significant correlation between motor and sensory recovery (Spearman correlation coefficient 0.62 ). Furthermore, motor recovery seemed to recover more successfully than sensory function (chapter $\mathbf{2}$ \& 8).

\section{Social consequences}

The social consequences and medical cost of nerve injuries have been particularly underexposed. Taking into account an average axon regeneration capacity of 1 millimeter a day, long term sensory and motor dysfunction will lead to long lasting work disability. Wound size is often small and functional consequences are therefore underestimated by social authorities and physicians. Patients recovering from a nerve trauma will not return to their previous level of functioning. ${ }^{43,44}$

In our study, 59\% were able to return to work within one year and the average time off work was 31 weeks (chapter 5). The cumulative proportion of patients returning to work at 3,6 and 9 months was $19 \%, 43 \%$ and $53 \%$. A hand trauma which results in a patient having on average 7 months off work, has a $50 \%$ chance of achieving protective sensation, has a $50 \%$ chance of achieving normal average motion, which in $60 \%$ of the patients requires more then two operations and the medical cost is $5-15$ times the operation, is classified as a severe hand trauma.(www.eatonhand.com) Based on the results of chapter $\mathbf{5}$ and the level of sensory and 
motor recovery of our study population, median and ulnar nerve injuries can be classified as severe hand traumas.

Grip strength loss, tip-pinch strength loss and sensory recovery were lower for the people who could return to work. Mean values are provided in chapter $\mathbf{5}$ and make it possible to evaluate whether a patient is functionally capable of returning to work. Single nerve injuries have a 7 times higher expectation of returning to work within one year compared to the combined nerve injuries. Other predicting variables were educational level and compliance to hand therapy. Furthermore a switch from blue to white collar employment will give a 4.3 times higher expectation of returning to work. The framework provided in chapter $\mathbf{5}$ can be used by physicians and social authorities during follow-up of a nerve injury patient to optimize treatment and limit absence from work.

Disability and activities of daily living

We used the Disabilities of Arm Shoulder and Hand (DASH) questionnaire to assess disability and the ability for activities of daily living to be restored. The DASH uses a self-reporting system. Patients attribute scores 1-5 (Likert scale) to thirty items relating to functional activities (such as preparing a meal and writing) and symptoms (such as pain and weakness). It does not matter which hand they are using to perform these tasks. The raw Functional Symptom Score (FSS) is transformed to a 0-100 scale, whereby 0 reflects minimum and 100 maximum disability (not able to perform any task). The FSS for upper extremity nerve injuries has never been described.

Our study population reported a mean FSS of 19 on average 5.5 years following surgery (chapter 4). A mean FSS of 19 on a scale ranging from 0-100 could be interpreted as "little" disability. Functional symptom scores of other studies varied between 2 for proximal phalanx fractures and 52 for distal biceps rupture. ${ }^{45,46}$ For example one of our patients with a FSS of 18, complained of mild difficulties preparing a meal, having mild difficulties with writing, having severe problems with recreational activities in which the arm is moved freely, having mild pain when performing any specific activity and having moderate stiffness, tingling and/or weakness in arm, shoulder or hand. Since the introduction of the DASH-questionnaire in 1996, an increasing amount of studies used the FSS to evaluate functional disability. Variation of the FSS is caused by difference in severity of injury and length of follow-up. Comparative FSS for other hand injuries are: a ray amputation: 29 (follow-up 32 months) ${ }^{47}$ and for a scaphoid fracture: 13 (follow-up 66 months). ${ }^{48}$

A trend was seen that the combined median and ulnar nerve injuries reported higher FSS values - 24 versus 16 - in cases of a median nerve injury and 19 in cases of an ulnar nerve injury. The differences can be expected to be even greater if assessment is performed at an earlier stage during follow-up. Compared to the literature, we concluded that the nerve injuries cause long lasting disabilities. Our prospective multicenter study will provide information about the FSS over time. This information can be used to optimize our vocational rehabilitation programs. 
Combined median-ulnar nerve injuries and 'spaghetti wrist' injuries

At the volar side of the wrist, 16 structures including 12 tendons, 2 nerves and 2 arteries are located just beneath the skin, and are therefore vulnerable to injury. The 'Spaghetti wrist' or'fullhouse' injury describes an extensive volar wrist laceration, in which several of these structures are injured. Various definitions have been used ranging from a relatively minor injury of three lacerated structures, to a major trauma with laceration of at least ten structures including the median and/or ulnar nerve. A select number of studies analysed spaghetti wrist injuries. 18,24,25,43,49 The study populations all consisted of small numbers of patients and most studies focused on sensory and motor recovery. We analyzed 50 spaghetti wrist patients for an average of 10 years following surgery in chapter $\mathbf{3}$. In comparison with the single nerve injuries, it is generally accepted that the combined nerve injuries and spaghetti wrist injuries have worse prospects. For the spaghetti wrist population we found: $55 \%$ return to work within one year, 35 weeks of sick leave, Functional Symptom Score of 15, Impact of Event Scale (IES) of 26 within the first month following surgery, grip strength loss of $24 \%$ compared to the uninjured hand, tip pinch strength loss of $34 \%$ and $32 \%$ had no protective sensation. Compared to the results of chapters $\mathbf{2}, \mathbf{4}, \mathbf{5}, \mathbf{6}$ and $\mathbf{7}$ (90-98 study population), the differences were small concerning all outcome parameters. Fifty-nine percent (59\%) return to work within one year, 31 weeks of sick leave, Functional Symptom Score of 19, IES of 26, grip strength loss of $22 \%$ compared to the uninjured hand, tip pinch strength loss of $32 \%$ and $32 \%$ had no protective sensation. After exclusion of 'spaghetti wrist' injuries $(n=20)$ within the 90 - 98 study population (chapters $\mathbf{2 , 4}, \mathbf{5}, \mathbf{6}$ and7) the single nerve injuries seemed to have better prospects concerning all outcome parameters. Seventy percent (70\%) return to work within one year, 29 weeks of sick leave, Functional Symptom Score of 17 , IES of 23 , grip strength loss of $20 \%$ compared to the uninjured hand, tip pinch strength loss of $30 \%$ and $24 \%$ had no protective sensation.

The "spaghetti wrist" injury population of chapter $\mathbf{3}$ had a longer mean follow-up time (10 and 5.5 years respectively) compared to the patients described in chapters $\mathbf{2 , 4 , 5 , 6}$ and $\mathbf{7}$. An additional data analysis of the 90-98 study population showed that the difference between the "spaghetti wrist" and single nerve injuries population, in relation to sensory recovery, return to work within one year, time of work and psychological morbidity within the first month, was statistically significant. Concerning motor recovery, the "spaghetti wrist" injuries had statistically less grip strength compared to the median nerve injuries. No difference was found compared to the ulnar nerve injuries. So, it may be concluded from this thesis that the prognosis of a "spaghetti wrist" trauma is significantly worse for all outcome parameters when compared to single nerve injuries.

\section{Psychological morbidity}

Knowing the direct post injury functional consequences, it was not surprising to discover the presence of posttraumatic psychological stress following median and ulnarnerve injuries. Ninetyfour percent (94\%) experienced psychological stress within the first month post-operatively. 
Thirty-six percent (36\%) of subjects and $43 \%$ of the "spaghetti wrist" patients (population '90-'98) reported sufficient symptoms at one month post-operatively to be classified as being in need of psychological treatment (IES $>30$ ). Daily confrontation with a disabled functional hand will cause considerable psychological stress. In addition to the awareness of a non-functional hand, non-medical factors such as return to work and social consequences were reported to be very stressful..$^{50}$ On the other hand, the cosmetic role of the hand should not be overlooked. ${ }^{51} \mathrm{~A}$ flat hand with clawed deformity is far from the esthetic ideal.

Based on the results of this thesis and what is already known from literature, collaboration with a psychologist is essential to identify those subjects who are likely to develop a posttraumatic stress disorder. This will increase the efficiency of our post operative rehabilitation program. An increasing number of hand units already have standardized cooperation with a psychologist. ${ }^{51,52}$ In addition, the plastic surgery nurse can be trained to identify the various responses that routinely occur with hand-injured patients. ${ }^{53}$ Based on our results, nerve injury patients need to be screened after two weeks following surgery. The predicting variables for the amount of post-traumatic psychological stress: number of severed structures, combined median ulnar nerve injuries, gender and education (chapter 6) can be used to facilitate the selection of patients who are in need of psychological assistance. In cases where psychological symptoms are diagnosed, a large number of psychological symptoms are treatable. In other diseases or traumatic injuries, standardized psychotherapy has already proven to be effective. ${ }^{54,55} \mathrm{~A}$ randomized trial in patients with a physical injury showed that a four-session cognitive-behavioural intervention following physical injury will significantly reduce the total Impact of Event Scale score. ${ }^{55}$ To reduce the number of visits to the outpatient clinic (hand surgeon, hand therapist and psychologist) and increase therapy fidelity, online therapy may be an option in the future..$^{56}$

The study described in chapter 6 discovered a high level of posttraumatic psychological stress within the first month post-operatively. The level of psychological stress had significantly diminished on average 5.5 years following surgery. In addition, only $4 \%$ of the patients reported psychological stress that was in need of psychological treatment. The course of decline is still unknown. In order to optimize post-operative psychological therapy, it is essential to establish the change in the IES score over time. Our prospective multi-center longitudinal study will provide this information. A first analysis showed a rapid decline of the amount of psychological stress after three months following injury.

\section{Cold intolerance}

Pain and discomfort from hyperesthesia and cold intolerance are underexposed aspects in the evaluation of nerve injuries. ${ }^{2,57}$ Pain sensation in the hand on exposure to cold is a common finding after upper extremity injuries, especially nerve injuries. Symptoms were present in at least $64 \%$ of hand injury patients, 24 months after injury. ${ }^{58}$ In nerve injury patients, incidences of up to $83 \%$ are reported. ${ }^{59-61}$ Furthermore, it seems that. ${ }^{62,63}$ No consensus exists on how the level 
of pain needs to be assessed and scored. Pain is often analysed with a visual analogue scale ${ }^{64}$ or the McGill pain questionnaire. ${ }^{65}$ Two subjective assessment methods were introduced in the 90 s to evaluate pain sensation on exposure to cold: the Cold Sensitivity Severity questionnaire ${ }^{66}$ and the Cold Intolerance Symptom Severity questionnaire. ${ }^{59}$ Unfortunately, no score was provided above which patients could be classified as experiencing cold intolerance. A large normative population study showed that patients with CISS scores of 36 or higher can be classified as experiencing pain from cold intolerance (in preparation). Based on this definition, on average 5.5 years following surgery, 36\% of the 1990-1998 study population reported sufficient symptoms to be classified as cold intolerance. Based on the results of our longitudinal cohort study we also concluded that symptoms of cold intolerance do not decrease over the years (in preparation).

We also initiated a study to create an objective method to quantify cold intolerance. An infrared thermocamera was used to visualize thermoregulation of the hand. A pilot study on nine nerve injury patients and several healthy volunteers showed that infrared thermography can be used to visualize thermoregulation of the hands. In nerve injury patients the thermoregulation differed markedly between the affected and contralateral hand. ${ }^{67}$ The capacity to warm the hand appears to correlate with the reported degree of cold intolerance. ${ }^{67}$

A very small number of studies tried to clarify the pathophysiology of cold intolerance. Unfortunately the pathogenesis of cold intolerance is still unclear. Previous studies defined various predictors for cold intolerance..$^{59,61,68-70}$ We found a very close relationship between the level of sensory recovery and the level of cold intolerance (in preparation).

Extended research is needed in this field in the near future. Maybe detailed investigation of the Cold Induced Vaso Dilatation (CIVD) and 'hunting reaction ${ }^{171}$ will provide more information about the etiology and pathophysiology of cold intolerance. Furthermore, different treatment options (for example conditioning therapy) need to be defined and investigated concerning their contribution by randomized clinical trials.

\section{PREDICTING VARIABLES AND QUANTIFICATION OF PREDICTORS}

Awareness of etiologic variables for functional recovery is of interest with regard to understanding the pathophysiologic process of nerve regeneration and may improve functional results. Surgery and post-operative rehabilitation services should be based on the profile drawn up by the risk factors. Identification of independent prognostic factors will open the way to the development of a valid prognostic model that can predict functional outcome postoperatively on an individual level. The use of the prognostic model will optimize post-operative treatment, by creating the ability to perform early secondary interventions. This will provide better functional outcome on an individual level. Furthermore patients can be informed about their functional and social prospects. 
Following World War II, every effort was paid to improving functional outcome following traumatic nerve injuries. Although microsurgery was a major breakthrough in the treatment of nerve injuries, Foucher and Marsh mentioned that microsurgery did not drastically changed the prognosis for nerve injuries. ${ }^{72}$ Techniques for clinical approximation of the severed nerve ends have reached a level of optimal technical refinement. ${ }^{7}$ The outcome is more influenced by other predicting variables such as mechanism of injury, delay in undertaking repair, level of section, age of the patient and functional integration. ${ }^{51}$ Most nerve injury outcome studies lack efficient sample size to define and quantify predicting variables.

\section{Suturing technique}

A select number of predicting variables for functional outcome are within the surgeon's control. The surgical technique used can genuinely influence the outcome. Tension-free suturing is essential to achieve successful repair of the peripheral nerve. Tension compromises both the integrity of the repair site and the blood supply. ${ }^{73,74}$ An association between tension, ischaemia and diminished nerve conduction velocity has been described. ${ }^{75}$ The results of elongation studies suggest a limited elongation of $8-10 \%$ to prevent ischaemia. ${ }^{76}$ Different techniques can be used to achieve a tension-free repair of the nerve deficit, in situ nerve mobilization, nerve rerouting and transposition, joint positioning and bone shortening.

Proper rotational alignment of the proximal and distal stump is another factor which can be influenced by the surgeon. Optimal alignment will reduce the amount of 'mismatch' of the regenerated axons ${ }^{77}$ and may therefore lead to better cortical mapping with less reorganization of the somatosensory cortex. Intra-operative electroneurographic tests and histochemical staining techniques have proven to optimize the coaptation of the nerve ends. ${ }^{78,79}$ The exact effect of intra-operative histological staining techniques on clinical outcome is still unclear. A randomized clinical trial is needed to determine the value on clinical outcome.

\section{Delay}

In 1975, Holst had a strong feeling that immediate repair of a transected nerve is superior to delaying the repair. ${ }^{80}$ Nowadays it is generally accepted that immediate, end to end primary nerve repair - when circumstances allow it - provide better results than secondary repairs. $32,36,72,81,82$ Our meta-analysis (chapter 8) confirmed that delay is a significant predictor for both sensory and motor recovery. For each month of extra delay the chance of successful sensory recovery was reduced by $8 \%$. Furthermore, if there is a delay for any reason, there seemed to be a tendency for an early secondary repair (1 - 3 months). Particularly in cases of a severe nerve defect, severe concomitant injuries or both, a planned early secondary ( $>3$ weeks) repair can be a good alternative. ${ }^{83}$ This may avoid adhesion between tendon and nerves. $A$ delay of more than six months will seriously diminish the quality of recovery. ${ }^{41}$ 
Age

The majority of the prime determinants cannot be influenced by the surgeon. ${ }^{84}$ One of the most well-known predictors for functional outcome following peripheral nerve surgery is the age of the patient. In 1962, Onne ${ }^{85}$ already described better functional sensibility in younger patients. Many others confirmed his findings..$^{29,36,40,72,80,81,86,87}$ There is a well-defined critical period for sensory relearning after nerve repair. ${ }^{37}$ The curve correlates with previously published data on critical periods for language acquisition among immigrants. ${ }^{37}$ Patients below the age of 13 recovered sensory function to normal levels even without a post-operative sensory re-education program. ${ }^{88}$ Younger patients have also better prospects concerning motor recovery. Patients below the age of 13 with an ulnar nerve injury at or above elbow level showed satisfactory function of the intrinsic hand..$^{86}$ In our study, patients below 16 years of age were four times more likely to have satisfactory motor recovery and 27 times more likely to have satisfactory sensory recovery than patients over 40 years of age (chapter $\mathbf{8}$ ). Based on the literature and the results of this study, age appears to be the most important determinant of outcome for injuries of the median and ulnar nerves. ${ }^{84}$

Level of injury

Based on the shorter regeneration distance and greater regeneration potential, distal nerve injuries have better prospects compared to proximal injuries. ${ }^{36,40,81,86}$ In our study, the level of injury significantly influenced final motor recovery (chapter 8). Patients with a distal (wrist and distal $2 / 3$ of forearm) nerve injury were 2.2 times more likely to have a better satisfactory motor outcome.

\section{Cognitive capacity}

For decades, most peripheral nerve research focused on the nerve lesion. The positive effect of sensory re-education was described in the mid 70s, despite the fact that the exact mechanism was not understood. ${ }^{89}$ It was Merzenich in 1983 who described cortical remapping in owl monkeys. After transection of the median nerve, somato-sensory fields were completely occupied by 'new' input from the ulnar and radial nerves ${ }^{90,91}$ Once the end organs have been reached, the reinnervated skin areas regain their cortical representation. Mismatch will alter the representation areas in the somato-sensory cortex. Reprogramming the 'brain computer' to adjust to the new sensory stimuli is necessary to regain functional sensory recovery. Lundborg was the first to report $(n=19)$ an association between cognitive capacity and sensory recovery, on average 3.3 years following surgery. ${ }^{92,93}$ They focused on tactile gnosis as functional sensory recovery. The exact contribution of cognitive capacity on the recovery of perception of touch and pressure (Semmes Weinstein monofilaments), which is the potential for sensory function, was not established.

We performed a large-scale study to determine the association between cognitive capacity and long-term recovery of perception of touch and pressure (chapter $\mathbf{7}$ ). Sensory recovery was 
assessed on average 5.5 years post-operatively, which can be seen as an end-point (chapter 8 and this thesis). We found an association between different tests to establish cognitive capacity and the long-term sensory recovery, in terms of perception of touch and pressure. Also level of intelligence appeared to affect the level of sensory recovery. A combined MSc project between the department of Epidemiology and the department of Plastic Surgery showed that the cognitive capacity did not influence sensory recovery at one year post-operatively. This can be explained by the fact that some of the regenerated axons have not reached their end-points. It seems that the reorganization of the somato-sensory cortex needs to be totally activated to establish the effect of this phenomenon. The combination of the results of our longitudinal follow-up study and the use of fMRI to visualize the somato-sensory cortex will help us to determine the exact time interval which is needed to activate reorganisational changes. This can be used to optimize the effect of our sensory re-education program.

\section{Psychological morbidity}

The association between psychological stress and outcome following nerve injuries has never been studied. Recently, work with animals has shown that nerve cell (re-)generation is affected by stress. Stress appears to decrease the capacity for (re-)generation of new nerve cells and stress seemed to affect the brain areas who play an important role in basic memory functions. ${ }^{94}$ This study provides evidence for an adverse effect of early psychological stress on functional recovery (FSS of the DASH, grip strength and tip-pinch strength) and capacity for work (chapter 6). Patients who suffered severe early posttraumatic psychological stress were six times more likely not to return to work within one year, compared to the group that reported a minor psychological response. As already mentioned in chapter $\mathbf{6}$, the results were based on retrospective data collection. In the near future we need a randomized clinical trial to establish the exact effect of psychological assistance post-operatively.

\section{Specialized hand therapy}

At the beginning of last century, it was already described that 'operation is only an incident in the treatment and that it must be preceded and followed by months of work'. Even massage, whirlpool baths and electricity were used to optimize outcome. ${ }^{95}$ Sensory reeducation improves functional sensibility and minimises the discomfort of paresthesias. ${ }^{89,96}$ We found that more than three months of specialized hand therapy, which focuses on early passive motion muscle strength and sensory reeducation, to be a predictor for functional recovery. Patients who followed this protocol had a 4 times higher chance of getting back to work (chapter 2). This finding was confirmed by our longitudinal cohort study that focused on return to work and time of work. Compliance with the hand therapy program gives patients a 3.5 higher chance of returning to work (chapter $\mathbf{5}$ ). As early as three months post-injury, interstitial muscle fibrosis occurs with proliferation of fibroblasts. ${ }^{97}$ Consequently, more than three months of hand 
therapy is essential to prevent this muscle fibrosis. Passive motion and splinting may prevent fibrosis during denervation. ${ }^{98}$

Speed of sensory recovery

Furthermore chapter $\mathbf{2}$ of this thesis showed that the time until the first sign of sensory reinnervation was noticed seemed to be a good predictor for final motor recovery. ${ }^{99}$ Patients at risk of poor motor recovery can therefore be distinguished by regular assessment of sensory reinnervation within the first five months.

\section{ASSESSMENT OF DISABILITY AND ACTIVITIES OF DAILY LIVING}

Conventional clinical research has focused primarily on morbidity and mortality as the outcomes of interest. The primary function was to provide the doctor with information concerning patient status and the effectiveness of treatment programs. ${ }^{100}$ Current outcome studies assess the results of interventions more from the patient's perspective, measuring the impact of medical care on physical functioning, well-being, and quality of life. ${ }^{101,102}$ The importance of an ADL reflection in the evaluation of nerve repair has already been emphasised. ${ }^{1,103}$ Not only in peripheral nerve surgery but also in general plastic surgery, there is a lack of assessment methods to evaluate outcome in a patient's perspective. ${ }^{101}$ Furthermore, the vast majority of patient-based measures in plastic surgery do not meet rigorous scientific standards. ${ }^{102}$ Assessment methods need the following qualities; reliability (the ability to assess consistently and predictably ${ }^{104}$ ), validity (to measure that which it purports to measure ${ }^{104}$ ), administrative instructions, equipment criteria, norms, instructions for interpretation and a bibliography. ${ }^{100}$

In 1996 the Disabilities of Arm, Shoulder and Hand questionnaire was introduced. ${ }^{105}$ They reported a good test retest reliability (ICC 0,92) and good internal consistency (crohnach's alpha 0.96). ${ }^{106}$ Unfortunately, the content validity has never been established. Only Semmes Weinstein monofilaments and the Jamar dynamometer fulfil all the requirements of standardization and have all specific clinical utility features considered important. ${ }^{2}$ So these tests were used to establish content validity. For the purpose of this study, the DASH was translated according to the criteria of the Institute for Work \& Health (IWH) and the American Academy of Orthopedic Surgeons (AAOS).

Multiple linear regression analysis (chapter 4) revealed associations between the functional symptom score (FSS) of the DASH and the level of sensory recovery (Semmes-Weinstein monofilamants) and motor recovery (grip and tip-pinch strength). So we concluded that the DASH had a 'good' content validity for all outcome parameters.

Quality of life and self reported measures of well-being are increasingly recognised as equally valid and important measures of a therapy's success. ${ }^{107}$ Interestingly, it has been shown that the reliability and responsiveness of clinical questionnaires can exceed that of many physical or 
mechanical tests. ${ }^{108}$ Following introduction, we have seen an increasing interest in the DASH. Based on the criteria for evaluating a good assessment method and our results, the DASH can be properly used to evaluate upper extremity physical (dys-) functioning. In my opinion, we need to ask all our patients visiting our hand outpatient clinic to complete the short version of the DASH, before entering the doctor's room.

\section{'END-POINT' OF FUNCTIONAL RECOVERY}

The regeneration capacity of the transected nerve has been described as between 1 millimeter and 4.5 millimeter a day. ${ }^{109}$ Tinel's 1 millimeter a day is the capacity that is mostly quoted. ${ }^{97,110}$ This means that reinnervation of the target end-points can take between 100 and 700 days. In most forearm nerve injuries, two years may not be sufficient for adequate motor recovery and sensory reinnervation. ${ }^{32,44}$ Improvement of function has been found after 1 to 6 years. ${ }^{57,97,111-113}$ Defining and assessing an end-point is critical to the success of outcome studies. ${ }^{114}$ Longitudinal studies following nerve repair are unfortunately scarce and have small sample sizes.

Motor recovery mainly depends on the interval between transection of the nerve and reinnervation of the muscle. From 1 week onwards, muscles begin to lose bulk and from three weeks the muscles become fibrotic. Muscle loses the ability to be reinnervated about one year after the injury. ${ }^{115,116}$ Muscle fiber degeneration and fibrosis are the limiting factors for motor recovery. ${ }^{41}$ Good to complete motor recovery has been seen for denervated periods of up to 12 to 18 months. ${ }^{83,97}$ While Barbier and co-authors found progression of all functional parameters in the first 9 to 12 months, no end-point was described. ${ }^{42}$ Recently, the first longterm longitudinal cohort study published the results of 19 patients followed over a four year period. ${ }^{57}$ They found significant improvement in motor recovery as late as between the third and fourth year. A longitudinal cohort study by our group, based on 88 patients, showed that a significant improvement in grip strength was seen 3.5 years following surgery and tip-pinch strength stabilized within three years post-operatively. ${ }^{112}$

The time between denervation and reinnervation of the sensory organs may be less essential for final functional sensory recovery. The moment when progress in sensibility stabilizes has not been investigated in detail. Dellon published that the sensory receptors in the skin can be reinnervated even years after the injury. ${ }^{115}$ Our meta-analysis (chapter 8) indicated a significant improvement in functional sensory recovery for at least a follow-up period of three years. Our longitudinal cohort study confirmed this finding and showed a significant improvement in sensory recovery up to 4 years following surgery.(in preparation) Based on a small number of repaired forearm nerve injuries with a maximum of $10 \mathrm{~cm}$ proximal to the wrist crease, the greatest change in sensory outcome was seen in the first post-operative year. ${ }^{57}$

After combining the results of our meta-analysis (chapter 8) and the results of our longitudinal follow-up study, it seems that both motor and sensory recovery stabilize between 
Table 1. Functional outcome for median, ulnar and combined nerve injuries

\begin{tabular}{|c|c|c|c|}
\hline & Median & Ulnar & Combined \\
\hline \multicolumn{4}{|l|}{ Motor recovery ${ }^{5}$} \\
\hline Grip strength" & $85 \%$ & $71 \%$ & $60 \%$ \\
\hline Tip-pinch strength" & $72 \%$ & $67 \%$ & $40 \%$ \\
\hline \multicolumn{4}{|l|}{ Sensory recovery $5^{5}$} \\
\hline Semmes-Weinstein (Imai)* & 2.9 & 3.1 & 3.7 \\
\hline \multicolumn{4}{|l|}{ Functional consequences ${ }^{5}$} \\
\hline FSS (DASH; range 1 - 100) & 16 & 19 & 24 \\
\hline \multicolumn{4}{|l|}{ Social consequences } \\
\hline Return to work $<1$ year & $80 \%$ & $59 \%$ & $24 \%$ \\
\hline Time off work < 1 year (weeks) & 24 & 31 & 45 \\
\hline \multicolumn{4}{|l|}{ Psychological morbidity } \\
\hline IES (range $0-75$ ) < 1 month & 24 & 23 & 35 \\
\hline \multicolumn{4}{|l|}{ Pain and discomfort ${ }^{\S}$} \\
\hline Cold intolerance (CISS; range 1 - 100) & 37 & 36 & 46 \\
\hline
\end{tabular}

${ }^{\S}$ On average 5.5 years following surgery

"Mean maximum achievable grip and tip-pinch strength of the injured hand, compared to the uninjured hand and adjusted for hand dominance.

* $1=$ normal, 2 = diminished light touch, $3=$ diminished protective sensation, $4=$ loss of protective sensation, $5=$ anesthetic

the third and fourth year following injury. A follow-up time of at least 4 years is necessary to evaluate final outcome. We need the data of our national longitudinal prospective multicenter study to confirm these findings. Furthermore, we also have to investigate improvement in pain, symptoms of cold intolerance and activities of daily living over time.

\section{CONCLUSIONS}

On one of the first pages of this thesis there were a number of questions raised by the patient with a forearm nerve injury and the surgeon who had to operate this patient. A number of questions could be answered by the results of this thesis. Some of them need further research.

What will the final outcome be and when will my 'end-point' of functional recovery be reached? In table 1 the long-term functional outcome for the three different type of nerve injuries is summarized. Both motor and sensory recovery stabilize between the third and fourth year following injury. A follow-up time of at least 4 years is necessary to evaluate final outcome.

What will be the functional consequences? Median, ulnar or combined median ulnar nerve injuries cause long lasting disabilities. Even 5.5 years following surgery a mean Functional 
Symptom Score of 19 on the DASH questionnaire was reported. Which can be interpreted as long-term disability of a number functional activities.

How long will it take before I can start work again? 59\% of our nerve injury patients were able to return to work within one year and the average time off work was 31 weeks. The cumulative proportion of patients returning to work at 3, 6 and 9 months was $19 \%, 43 \%$ and $53 \%$.

What are the prognostic factors?

Delay: For each month of extra delay the chance of successful sensory recovery was reduced by $8 \%$. Furthermore, if there is a delay for any reason, there seemed to be a tendency for an early secondary repair (1 - 3 months).

Age: Patients below 16 years of age were four times more likely to have satisfactory motor recovery and 27 times more likely to have satisfactory sensory recovery than patients over 40 years of age.

Level of injury influenced final motor recovery. Patients with a distal (wrist and distal $2 / 3$ of forearm) nerve injury were 2.2 times more likely to have a better satisfactory motor outcome.

Cognitive capacity: an association was found between different tests to establish cognitive capacity and the long-term sensory recovery, in terms of perception of touch and pressure.

Hand therapy: Patients who participated in our specialized hand therapy program had a 4 times higher chance of getting back to work.

Psychological morbidity: Evidence was found for an adverse effect of early psychological stress on functional recovery. Patients who suffered severe early posttraumatic psychological stress were six times more likely not to return to work within one year, compared to the group that reported a minor psychological response.

Speed of sensory recovery: Time until the first sign of sensory reinnervation was noticed seemed to be a good predictor for final motor recovery.

Does this man need psychological assistance? $94 \%$ of the median, ulnar or combined median ulnar nerve injuries experienced psychological stress within the first month post-operatively. $36 \%$ of subjects and $43 \%$ of the spaghetti wrist patients reported sufficient symptoms at one month post-operatively to be classified as being in need of psychological treatment.

How long do I need to participate in the post operative rehabilitation program? Patients who followed our hand therapy protocol, which focuses on early passive motion muscle strength and sensory reeducation had a 4 times higher chance of getting back to work. More than three months of hand therapy is essential to prevent muscle fibrosis and to optimize reorganization of new sensory inputs of somato-sensory cortex.

I experience pain during exposure to cold, will this diminish? On average 5.5 years following surgery, $36 \%$ of the study population reported sufficient symptoms to be classified as cold intolerance. It seems that symptoms of cold intolerance do not decrease over the years. A very close relationship between the level of sensory recovery and the level of cold intolerance was found. 


\section{FUTURE PERSPECTIVES}

'Techniques for clinical approximation of the severed nerve ends have reached an optimal technical refinement and new concepts are needed to further increase the results from nerve repair.'

\section{Prognostic model}

There is unfortunately still no good quantitative test that has a predictive value for final clinical functional outcome. ${ }^{17}$ As mentioned in the introduction, all test methods only give information about the actual status of reinnervation. In 1987 the question was raised as to whether it is possible to predict the outcome of peripheral nerve injuries. ${ }^{118}$ They hypothesized that considering the individual re-growth of the elementary components of a nerve, the neuritis rather than the global regeneration of the organ could lead to a better understanding of the mechanisms of nerve repair. This study provided a model that satisfactorily describes the events taking place in a healing nerve rather than a model to predict the outcome in individual situations. Based on a statistical and mathematical approach, Fahmy et al has tried to develop a computational measure to predict outcomes. ${ }^{119}$ In his model he included the axonplasmic volume of axons fibers distal to the lesion as one of the leading predictors. The axonplasmic volume is based on diameter, length of the distal segment and axon diameter. Age, duration and location of the lesion were incorporated into the model as additional predicting factors. Preliminary results showed an agreement coefficient of 0.9 , based on a small number of patients.

In order to design a clinical prognostic model for forearm nerve injuries, there is an important question which first needs to be answered. Do we need an overall functional outcome score which is based on the different outcome parameters, or do we need separate models which can predict the outcome of the different outcome variables? It is my opinion that we need separate models. Especially where the patient is concerned, we need separate predicting models that provide immediate post-operative information, for example about his changes to return to work and the ability to carry out his activities of daily living once again. Additionally, based on the type of job the patient had pre-injury, patients will be more interested in motor recovery than others. Furthermore, if we can predict the outcome of separate outcome variables, we will be able to optimize our post-operative treatment by early interventions. For example, if motor recovery is likely to be poor, we can perform early tendon transfers. A factor analysis showed that $73 \%$ of the variances were explained by the outcome variables: sensory recovery, motor recovery and pain and discomfort.' Additional elements for a model to quantify functional outcome will concern disabilities relating to the activities of daily living and the ability to return to work. I believe that if we would like to provide an overall outcome, we have to design predicting models for all these different outcome variables.

We performed a quantitative analysis of our prognostic variables. Different outcome variables (sensory recovery, motor recovery, recovery of activities of daily living, return to work and cold intolerance) were found to have different predicting variables. ROC (Receiver Operating 
Characteristic) area analysis showed that over $80 \%$ of the outcomes of our patients could be correctly predicted by the predicting variables: age, delay, level of injury and type of nerve injury (chapter 8). In order to build a prognostic model in the future the following predicting variables shoud be considered: age, delay, level of injury and type of injury. Cognitive capacity needs to be included in case sensory recovery needs to be predicted. Based on the results of our prospective study the inclusion of psychological stress in our models will be determined in the near future. Statistical analysis on our retrospective population (90-98) showed that our number of patients was too small to create valid prognostic models for the different outcome parameters.

Furthermore, we need information about the progression of the different outcome variables over time. Recently, a model instrument was introduced for documentation and quantification of the functional outcome after forearm nerve injury repair to evaluate functional recovery over time.' Unfortunately, the predictive capabilities of this kind of progression chart are only mediocre. On the other hand, these charts will create the ability to focus during our rehabilitation program on the outcome variables, which do not follow the normal functional progression curve. Our multicenter prospective study will provide this information.

\section{Future assessment}

After introduction of Von Frey hairs in 1896, there has being ongoing development of new assessment methods. In 1987, the MRI was introduced to visualize the median nerve in the hand and wrist. ${ }^{20}$ Although the quality of the images was not high, they could accurately depict anatomy and pathology of the carpal tunnel. ${ }^{121}$ Most of the MRI studies focused on the carpal tunnel syndrome. Different levels of sensitivity and specificity have been reported for diagnosing the carpal tunnel syndrome. MRI can also be used to diagnose and evaluate peripheral nerve injuries. ${ }^{122}$ The Wallerian degeneration of the distal segment in axonotmetic and neurotmetic injuries can be visualized as early as four days following the nerve injury. ${ }^{121}$ Furthermore, denervated muscles show increased signal changes. A study by West and coauthors showed that MRI provides a visual representation of denervated muscles that is useful in localizing and grading the severity of peripheral nerve injury secondary to either disease or trauma. ${ }^{123}$ Recently, a study has been started by our group to evaluate the association between the amount of MRI signal changes in the denervated muscles and the clinical outcome. ${ }^{124}$ Perhaps in the near future MRI will be able to help us to locate neuromas and extensive scar tissue, which inhibit the progress of regenerated nerve fibers, and to visualize the progress of the regenerating proximal nerve segment. Additionally, MRI diffusion-weighted imaging may revolutionize nerve imaging by transition from anatomic to physiologic imaging. ${ }^{121}$ MRI may then play an important role in the prediction of clinical outcome and the formulation of postoperative therapy.

New assessment methods to evaluate the different outcome markers of nerve regeneration are continually being developed. Some of them have an additional value. For example: 
quantitative evaluation of the intrinsic muscles. ${ }^{125}$ On the other hand, it is desirable to keep the number of outcome measures developed to a minimum to facilitate comparative studies and reduce confusion in literature. ${ }^{102}$ Recently a project group was set up comprising plastic surgeons representing the British association of plastic surgeons, experts in health measurements and health service researchers with the aim of trying to control the development of new patientbased outcome measures for hand/arm plastic surgery. ${ }^{102}$

\section{Central nervous system}

'The outcome from nerve repair depends mainly on central nervous system factors including functional cortical reorganisational processes caused by misdirection in axonal outgrowth..126

The size of the cerebral cortex area corresponding to the nervous center of the hand, in comparison with that of other parts of the body, gives a clear idea of the importance of the hand. ${ }^{127}$ An increasing number of studies suggest that cortical reorganisational changes are the major reasons for sensory dysfunction. ${ }^{126,128,129}$ In Chapter 7, we describe that patients with less capacity to reorganize the sensory inputs of the somatosensory cortex will have less long-term sensory outcome. ${ }^{130}$

The possibility of assessing, visualizing and influencing the reorganization process of the brain will be an important goal to improve sensory recovery and functional outcome of the hand. It was mentioned in the Richard P Bunge memorial lecture that since peripheral nerve repair techniques cannot be further refined, there is a need for new and improved strategies for sensory relearning following nerve repair. ${ }^{126}$ The process of reorganization of the somatosensory cortex can be visualized by the non-invasive functional MRI (fMRI). The different digits of the hand have already been visualised separately and quantified for their activation. ${ }^{131-134}$ The ability to visualize the somato-sensory cortex will help us to determine the exact time interval for the axons to reach their target organs. Furthermore the amount of mismatch can be visualized. Our sensory re-education program can be adjusted to the type and amount of mismatch which has been visualised by the fMRI. A first pilot study has shown better sensory recovery when sensory re-education was adjusted to the results of the fMRI (www.hand.mas.lu.se) A large randomized clinical trial is needed to confirm this finding.

\section{'End to side' nerve repair}

In cases where functional recovery is unsatisfactory or no proximal stump is available, an 'end to side' nerve repair can be performed. After the first description of the 'termino-lateral neurorrhaphy' by Balance and co-authors ${ }^{135}$, this method was reintroduced in the mid 1990 s. In animal experiments, collateral sprouting was found after connecting a distal segment to the donor nerve. ${ }^{136,137}$ Both sensory and motor axons were found in the donor nerve. ${ }^{138-140}$

The clinical application of the end to side repair is not totally defined and clinical studies are sparse. ${ }^{141,142}$ Most of these studies are case reports and functional results varied over a wide 
range. Some reported both motor and sensory reinnervation of the target organs. ${ }^{143-146}$ More negative results were published by others. ${ }^{147,148}$ Recently, in a prospective study of 10 patients with a mean follow-up of 14 months, no patient demonstrated objective evidence of motor recovery and three patients had modest recovery in their deep protective sensation. ${ }^{199,150}$ In some of the publications, the end to side repair is seen as an additional technique which may replace the use of nerve grafts in the future. ${ }^{143}$ In the near future we need controlled clinical trials to compare functional outcome of the end to side neurorrhaphy with the established nerve grafting techniques. In addition, the need for an epineural or perineural window at the connection site should be further investigated. If morbidity of an epineural or perineural window is better analyzed, maybe in the near future we will be able to offer patients with no or minimal sensory recovery an end to side neurorrhaphy.

Another application of end to side neurorrhaphy could be to diminish donor morbidity when using nerve grafts. To bridge nerve defects we have to sacrifice healthy nerves. Currently the sural nerve is mostly being used. There has been minimal analysis of the application of the end to side principle to minimize the sensory deficit following offering the sural nerve. ${ }^{151}$

Non-neural conduits

Donor morbidity and different diameter and fascicular architecture compared to the injured nerve are the most important disadvantages of the use of donor nerve grafts. Non-neural tissue and synthetic substances have been used as alternatives for nerve grafts for the last century, although with marginal success. ${ }^{122}$ Autologous muscle, arteries, veins, and silicon or bioabsorbable conduits have been developed to bridge nerve defects. Ultimately, conduit material does not as yet seem to have a profound effect on outcome. ${ }^{152}$ Recently, it was published that nerve repair by a silicon tube resulted in less cold intolerance. ${ }^{153}$ I have every confidence that progress in chemical engineering and molecular biology may provide superior nerve conduits, with all kind of additives like growthfactors etc., in the near future.

Nerve allografts and hand transplantation

To minimize donor site functional deficits and morbidity, nerve allografts can be used..$^{154}$ In 1885 , this method was introduced with disappointing results. ${ }^{155}$ In nearly all the following studies, animal models were used to analyze the outcome of nerve allografts. In the first clinical study, 6 out of 7 patients regained sensory and motor function, without rejection of the graft. ${ }^{156-158}$ To prevent rejection of nerve allografts, systemic immunosuppression is needed. Serious side effects of immunosuppressants have been reported. Since the use of azathioprine, in 1961, to prevent rejection of renal allografts, many new immunosuppressants have been introduced. Gold and co-authors were the first to describe the positive neuroenhancing effect of FK506 beside the immunosuppressive effects. ${ }^{159,160} \mathrm{FK} 506$ protects neural cells from ischemia and blocks neural apoptosis. ${ }^{161}$ Positive effects, without serious side effects, of low dose FK 506 in generalized myasthenia gravis have been reported. ${ }^{162}$ Maybe FK 506 can be used in a 
comparable dose to improve nerve regeneration and clinical results following nerve allografts. In my opinion, there may be an application of nerve allograft transplantation if the functional results of bio-artificial nerve grafts such as silicon tubes continue to be inferior to the autologous nerve grafts and if the toxicity of immunosuppressive therapy can be minimized or resolved.

In cases where a traumatically amputated hand cannot be replanted, hand transplantation may be an option. On September, 23 1998, the second human hand transplantation in human history was performed. ${ }^{51,163,164}$ In 1964 in Ecuador the first transplanted hand was rejected within two weeks. Extensive research into clinical and immunological aspects of partial hand transplantation was carried out by Hovius and Stevens. ${ }^{165}$ Until 2004, 18 patients had undergone 24 human hand transplantations. Functional results are promising with results superior to those obtained with protheses. ${ }^{16,167} \mathrm{~A}$ faster nerve regeneration rate than expected was found in the hand transplantation cases. It was proposed that this phenomenon could be related to neuroregenerative and neuroprotective effects of immunosuppression of FK 506 $154,168,169$ Despite a time range of 4 to 22 years following amputation, after 12 months patients recovered protective sensation and some discriminative sensation. Intrinsic muscle activity was documented with electromyography and the range of motion was satisfactory. ${ }^{167}$

Age is accepted as a restricted factor for microsurgery. Replantation of a hand in a very elderly patient is disputable. Even in nerve surgery, palliative surgery was proposed for elderly patients..$^{83} \mathrm{~A}$ non-functional hand with poor sensibility may be inferior to the highly sophisticated myoelectric hand prostheses. The most recent models provide a kind of local feedback, but still no sensory feedback can be provided..$^{170-172}$ It is well known from the literature that an amputated upper or lower limb will give disturbed body image with significant psychological morbidity. ${ }^{173}$ A recent study of a hand replantation in an 84 year old men showed after two years follow-up a hand with poor sensibility, absence of intrinsic muscle activity and weak extrinsic muscle activity. ${ }^{174}$ On the other hand the hand was warm and a good colour. Based on these results and what is known from the literature on hand prostheses, hand prostheses can still not be classified as an alternative for hand replantation or even homologous hand transplantations.

\section{Artificial sensibility}

In the case of absence of sensory recovery, creation of artificial sensibility may be an option. Osseoperception can be used to create a kind of tactile perception. Extensive research on osseoperception is done by dental researchers working with dental implants. Osseoimplanted prostheses restore jaw function more appropriately, with improved psychophysiological discriminatory ability and oral stereognosis. ${ }^{175-177}$ In hand surgery osseointegrated screws can be used to transmit pressure and vibration to bone giving a kind of sensation. ${ }^{170,177,178}$

Another option for artificial sensibility would be the use of hearing as an alternative sense. ${ }^{179,180}$ This principle was based on the fact that different textures create different acoustic stimuli. Microphones were mounted on the different fingertips of non-sensate hands. Different vibrotactile stimuli were magnified to generate different acoustic signals of the separate fingers 
as a substitute for lost of hand sensibility. Preliminary results showed that patients were able to perceive touch and differentiate between different textures. ${ }^{179}$

Lundborg, aimed to preserve the cortical hand representations by artificial sensibility, using a sensor glove and artificial neural network. ${ }^{181,182}$ This system was developed to minimize the process of cortical reorganisation. During the first months, when there is no sensibility in the hand, the somatosensory cortex kept activated. It seemed that the cortical acusto-tactile interaction provided a better recovery of tactile gnosis. ${ }^{26,182}$

\section{Cost-effective analysis}

Outcome research also aims to assess quality of care. ${ }^{183,184}$ In an era of research constraints, clinical practices must not only be effective, they must also provide benefit at the most reasonable cost. ${ }^{101,185}$ The cost effectiveness of upper extremity nerve injury repair has never been studied in detail. Nothing has been published on quality-adjusted life years. Gaul described a cost-benefit ratio of 1:16 for catastrophic hand injuries by dividing the net cost by the net benefits. ${ }^{186}$ It therefore seems that upper extremity nerve surgery may be very cost beneficial, but extensive surgery with secondary tendon transfers and long-term hand therapy with sensory re-education may become progressively less cost-effective with increasing age. Nowadays our health care system is increasingly influenced by market forces and doubts are being raised about the efficacy of some medical procedures. ${ }^{187}$ In response to increasing pressure from these social authorities and policy makers, more extensive research is needed in this field.

Multicenter prospective studies and randomized clinical trials

In 2000 the ZERO study group started a longitudinal prospective multicenter study in the Netherlands focused on median and ulnar nerve injuries. Data analysis has begun. ${ }^{188}$ With the results of the prospective part of the ZERO study, we hope to provide answers to questions that still exist and to confirm our conclusions.

Based on the European Community concept, it is necessary to set up effective collaboration between different hand surgery centers that specialize in peripheral nerve surgery. Progressive development and application of information technology in clinical medicine may facilitate such studies in the near future. ${ }^{189}$ In the field of hand surgery, a lack of randomized controlled clinical trials for many common therapies has already been mentioned. ${ }^{108}$ In the short term more clinical peripheral nerve surgery trials are therefore needed to provide statistically based information for clinical pre-, per- and post-operative decision making. 


\section{REFERENCES}

1. Rosen B, Lundborg G. A model instrument for the documentation of outcome after nerve repair. $J$ Hand Surg 2000;25A(3):535-43.

2. Rosen B. Recovery of sensory and motor function after nerve repair. A rationale for evaluation. $J$ Hand Ther 1996;9:315-27.

3. Brooks D. The place of nerve grafting in orthopaedic surgery. Journal of Bone and Joint Surgery 1955;37A:299-305.

4. Forrester-Brown M. The possibilities of suture after extensive nerve injury. Journal of Orthopaedic Surgery 1921;19:277.

5. Grantham E, Pollard C, Brabson J. Repair of nerve defects. Annals of Surgery 1948;127:696.

6. Bristow W. Injuries of peripheral nerves in two World Wars. British Journal of Surgery 1947;34: $333-348$.

7. Lundborg G. A 25-year perspective of peripheral nerve surgery: evolving neuroscientific concepts and clinical significance. J Hand Surg. American Volume 2000;25(3):391-414.

8. Kline D, Hudson A. Nerve Injuries: Operative Results from Major Nerve Injuries, Entrapments and Tumors. Philadelphia: WB Saunders Company, 1995.

9. Hakistan RW. Funicular orientation by direct stimulation. J Bone Joint Surg 1968;50-A(6):1178-86.

10. Millesi $H$, Meissl G, Berger A. The interfascicular nerve-grafting of the median and ulnar nerves. Journal of Bone and Joint Surgery 1972;54A(4):727-50.

11. Walton R, Finseth F. Nerve grafting in the repair of complicated peripheral nerve trauma. $J$ Trauma 1977;17(10):793-6.

12. Finseth F, Constable J, Cannon B. Interfascicular nerve grafting. Plast Reconstr Surg 1975;56(5): 492- 5.

13. Ito T, Hirotani H, Yamamoto K. Peripheral nerve repairs by the funicular suture technique. Acta Orthop Scand 1976;47(3):283-9.

14. Millesi $H$, Meissl G, Berger A. Further experience with interfascicular grafting of the median, ulnar, and radial nerves. J Bone Joint Surg 1976;58-A(2):209-18.

15. Moneim MS. Interfascicular nerve grafting. Clin Orthop Rel Res 1982;163:65-74.

16. Stellini L. Interfascicular autologous grafts in the repair of peripheral nerves: eight years experience. Br J Plast Surg 1982;35:478-82.

17. Tackmann W, Brennwald J, Nigst H. Sensory electroneurographic parameters and clinical recovery of sensibility in sutured human nerves. Journal of Neurology 1983;229(3):195-206.

18. Puckett $\mathrm{CL}$, Meyer VH. Results of treatment of extensive volar wrist lacerations: the spaghetti wrist. Plast Reconstr Surg 1985;75(5):714-21.

19. Stevenson $\mathrm{JH}$, Zuker RM. Upper limb motor and sensory recovery after multiple proximal nerve injury in children: a long term review in five patients. Br J Plast Surg 1986;39:109-13.

20. Jongen S, Van Twisk R. Results of primary repair of ulnar and median nerve injuries at the wrist: an evaluation of sensibility and motor recovery. Neth J Surg 1988;40(3):86-9.

21. Frykman GK, Cally D. Interfascicular nerve grafting. Orthop Clin NA 1988;19(1):71-80.

22. Barrios C, Amillo S, de Pablos J, Canadell J. Secondary repair of ulnar nerve injury. 44 cases followed for 2 years. Acta Orthopaedica Scandinavica 1990;61(1):46-9.

23. Barrios $C$, de Pablos J. Surgical management of nerve injuries of the upper extremity in children: a 15-year survey. J Pediatr Orthop 1991;11(5):641 - 5.

24. Rogers G, Henshall A, Sach R, Wallis K. Simultaneous laceration of the median and ulnar nerves with flexor tendons at the wrist. J Hand Surg [Am] 1990;15(6):990-5.

25. Widgerow A. Full-house/spaghetti wrist injuries. Analysis of results. S Afr J Surg 1990;28(1):6-10.

26. Daoutisn, Gerostathopoulos N, Efstathopoulos D, Misitizis D, Bouchlis G, Anagnostou S. Microsurgical reconstruction of large nerve defects using autologous nerve grafts. Microsurgery 1994;15:502 - 5 .

27. Trumble TE, Kahn U, Vanderhooft E, Bach AW. A technique to quantitate motor recovery following nerve grafting. J Hand Surg 1995;20A(3):367-72.

28. Kato $H$, Minami A, Kobayashi M, Takahara M, Ogino T. Functional results of low median and ulnar nerve repair with intraneural fascicular dissection and electrical fascicular orientation. 1998;23(3):471 - 82. 
29. Selma P, Emre O, Oguz P, Ersin N, Oya B. Evaluation of the improvement of sensibility after primary median nerve repair at the wrist. Microsurg 1998;18:192-6.

30. Amillo S, Mora G. Surgical management of neural injuries associated with elbow fractures in children. J Ped Orthop 1999;19(5):573-7.

31. Jerosch Herold C. Should sensory function after median nerve injury and repair be quantified using two-point discrimination as the critical measure? Scandinavian Journal of Plastic and Reconstructive Surgery and Hand Surgery 2000;34(4):339-43.

32. Birch R, Raji A. Repair of median and ulnar nerves. Primary suture is best. J Bone Joint Surg [Br] 1991;73(1):154- 7.

33. Kalomiri DE, Soucacos PN, Beris AE. Nerve grafting in peripheral nerve microsurgery of the upper extremity. Microsurgery 1994;15(7):506-11.

34. Kalomiri DE, Soucacos PN, Beriis AE. Management of ulnar nerve injuries. Acta Orthop Scand Suppl 1995;264:41-4.

35. Merle M, Amend P, Cour C, Foucher G, Michon J. Microsurgical repair of peripheral nerve lesions: A study of 150 injuries of the median and ulnar nerves. Peripheral Nerve Repair 1986;2:17-26.

36. Vastamaki $\mathrm{M}$, Kallio $\mathrm{P}$, Solonen $\mathrm{K}$. The results of secondary microsurgical repair of ulnar nerve injury. J Hand Surg [Br] 1993;18(3):323-6.

37. Lundborg G, Rosen B. Sensory relearning after nerve repair. Lancet 2001;358(9284):809-10.

38. Hudson $D$, de Jager $L$. The spaghetti wrist. Simultaneous laceration of the median and ulnar nerves with flexor tendons at the wrist. J Hand Surg [Br] 1993;18(2):171 - 3.

39. Mailander P, Berger A, Schaller E, Ruhe K. Results of primary nerve repair in the upper extremity. Microsurgery 1989;10(2):147-50.

40. Posch J, Cruz-Saddul Fdl. Nerve repair in trauma surgery: A ten-year study of 231 peripheral injuries. Orthopaedic Review 1980;9(3):35-45.

41. Sunderland SS. Nerve injuries and their repair: acritical appraisal. Third ed. Singapore: Churchill Livingstone, 1991.

42. Barbier O, Thonnard JL. Prospective functional analysis of the median nerve recovery. 9th IFSSH 2004, Budapest, Hungary: 185 - 186.

43. Chin G, Weinzweig N, Mead M, Gonzalez M. "Spaghetti wrist": management and results. Plast Reconstr Surg 1998;102(1):96-102.

44. Trevett MC, Tuson C, de Jager LT, Juon JM. The functional results of ulnar nerve repair. Defining the indications for tendon transfer. J Hand Surg [Br] 1995;20(4):444-6.

45. Kuhn KM, Dao KD, Shin AY. Volar A1 pulley approach for fixation of avulsion fractures of the base of the proximal phalanx. 2001;26(4):762-71.

46. Karunakar MA, Cha P, Stern PJ. Distal biceps ruptures. A followup of Boyd and Anderson repair. Clinical Orthopaedics and Related Research 1999(363):100-7.

47. Melikyan EY, Beg MS, Woodbridge S, Burke FD. The functional results of ray amputation. Hand Surg 2003;8(1): 47-51.

48. Sauerbier M, Gunther C, Bickert B, Pelzer M, Germann G. [Long-term outcome of reconstruction of proximal scaphoid pseudarthroses with Matti-Russe-plasty]. Handchirurgie, Mikrochirurgie, Plastische Chirurgie 1999;31(3):182-6.

49. Hudson DA, de Jager LT. The spaghetti wrist. J Hand Surg 1993;18B(2):171 - 3 .

50. Landsman IS, Baum CG, Arnkoff DB, et al. The psychosocial consequences of traumatic injury. Journal Of Behavioral Medicine 1990;13(6):561-81.

51. Foucher G. Prospects for hand transplantation. Lancet 1999;353(9161):1286- 7.

52. Grunert BK, Hargarten SW, Matloub HS, Sanger JR, Hanel DP, Yousif NJ. Predictive value of psychological screening in acute hand injuries. J Hand Surg [Am] 1992;17(2):196-9.

53. Grunert BK, Maksud DP. Psychological adjustment to hand injuries: nursing management. Plast Surg Nurs 1993;13(2):72-6.

54. Koszycki D, Lafontaine S, Frasure-Smith N, Swenson R, Lesperance F. An open-label trial of interpersonal psychotherapy in depressed patients with coronary disease. Psychosomatics 2004;45(4):319-324.

55. Bisson J, Shepherd J, Joy D, Probert R, Newcombe R. Early cognitive-behavioural therapy for post-traumatic stress symptoms after physical injury. Randomised controlled trial. Br J Psychiatry 2004; 184:63-69. 
56. Lange A, van de Ven J, Schrieken B, Emmelkamp P. Interapy, treatment of posttraumatic stress through the Internet: a controlled trial. J Behav Ther Exp Psychiatry 2001;32(2): 73-90.

57. Rosen B, Dahlin LB, Lundborg G. Assessment of functional outcome after nerve repair in a longitudinal cohort. Scandinavian Journal of Plastic and Reconstructive Surgery and Hand Surgery 2000;34(1):71 - 8 .

58. Campbell DA, Kay SP. What is cold intolerance? J Hand Surg 1998;23B(1):3-5.

59. Irwin M, Gilbert S, Terenghi G, Smith R, Green C. Cold intolerance following peripheral nerve injury. Natural history and factors predicting severity of symptoms. J Hand Surg 1997;22B(3):308-16.

60. Landis JR, Koch GG. The measurement of observer agreement for categorical data. Biometrics 1977;33:159- 74.

61. Lenoble E, Dumontier C, Meriaux J, Mitz V, Sokolow C, Lemerle J. Cold sensitivity after median or ulnar nerve injury based on a series of 82 cases. Ann Chir Main Memb Super 1990;9(1):9-14.

62. Povlsen B, Nylander G, Nylander E. Cold-induced vasospasm after digital replantation does not improve with time. A 12-year prospective study. 1995;20(2):237-9.

63. Povlsen B, Nylander G, Nylander E. Natural history of digital replantation: a 12-year prospective study. Microsurgery 1995;16(3):138-140.

64. Gift AG. Visual analog scale: measurement of subjective phenomena. Nursing Research 1989;38: 286-288.

65. Melzack R. The McGill Pain Questionnaire: major properties and scoring methods. Pain 1975;1(3): 277-299.

66. McCabe S, Mizgala C, Glickman L. The measurement of cold sensitivity of the hand. J Hand Surg 1991;16A:1037-1040.

67. Posch N, Ganghi A, Jaquet J, Daanen H, Hovius S. Diminished thermoregulation in nerve injury patients: A reason for cold intolerance? J Hand Surg 2003;28B(Supplement):19.

68. Koman LA, Nunley JA. Thermoregulatory control after upper extremity replantation. $J$ Hand Surg 1986;11A(4): 548- 52.

69. de Medinaceli L, Hurpeau J, Merle M, Begorre H. Cold and post-traumatic pain: modeling of the peripheral nerve message. Biosystems 1997;43(3):145-67.

70. Gelberman RH, Urbaniak JR, Bright DS, Levin LS. Digital sensibility following replantation. J Hand Surg. American Volume 1978;3(4):313-9.

71. Lewis T. Observations upon the reactions of the vessels of the human skin to cold. Heart 1930;15: 177-208.

72. Marsh D, Barton N. Does the use of the operating microscope improve the results of peripheral nerve suture? J Bone Joint Surg [Br] 1987;69(4):625-30.

73. Trumble TE, McCalisster WV. Repair of peripheral nerve defects in the upper extremity. Hand Clinics 2000;16(1):37-52.

74. Tanoue M, Yamaga M, Ide J, Takagi K. Acute stretching of peripheral nerves inhibits retrograde axonal transport. J Hand Surg [Br] 1996;21:358-63.

75. McLaren A. Peripheral nerve response to tension. Transactions of the 35th Annual Meeting of the Orthopaedic Research Society 1989, Las Vegas, Nevada: 24.

76. Lundborg G, Rydevik B. Effects of stretching the tibial nerve of the rabbit. A priliminary study of the intraneural circulation and the barrier function of the perineurium. Journal of Bone and Joint Surgery 1973;55B:390-401.

77. de Medinaceli L, Merle M. How exact should nerve stump coaptation be? A new answer given by cell surgery. J Hand Surg [Br] 1991;16(5):495-8.

78. Deutinger M, Girsch W, Burggasser G, et al. Clinical application of motorsensory differentiated nerve repair. Microsurgery 1993;14(5):297-303.

79. Deutinger $M$, Girsch W, Burggasser G, et al. Peripheral nerve repair in the hand with and without motor sensory differentiation. J Hand Surg [Am] 1993;18(3):426-32.

80. Holst H. Primary peripheral nerve repair in the hand and upper extremity. J Trauma 1975;15(10): 909-11.

81. Kallio $P$, Vastamaki M. An analysis of the results of late reconstruction of 132 median nerves. J Hand Surg [Br] 1993;18(1):97-105.

82. Merle $M$, de Medinaceli L. Primary nerve repair in the upper limb. Our preferred methods: theory and practical applications. Hand Clin 1992;8(3):575-86. 
83. Millesi H. Reappraisal of nerve repair. Surg Clin North Am 1981;61(2):321 - 40 .

84. Allan C. Functional results of primary nerve repair. Hand Clinics 2000;16(1):67-71.

85. Onne L. Recovery of sensibility and sudomotor activity after nerve suture. Acta Chir Scand 1962;300: 1-70.

86. Bolitho DG, Boustred M, Hudson DA, Hodgetts K. Primary epineural repair of the ulnar nerve in children. 1999;24(1):16-20.

87. Hudson DA, Bolitho DG, Hodgetts K. Primary epineural repair of the median nerve in children. J Hand Surg 1997;22B(1):54-6.

88. Tajima T, Imai H. Results of median nerve repair in children. Microsurgery 1989;10(2):145-6.

89. Dellon AL, Curtis RM, Edgerton MT. Re-education of the sensation in the hand after nerve injury and repair. Plastic and Reconstructive Surgery 1974;53:297-305.

90. Merzenich MM, Kaas JH, Wall JT, Sur M, Nelson RJ, Felleman DJ. Progression of change following median nerve section in the cortical representation of the hand in areas $3 \mathrm{~b}$ and 1 in adult owl and squirrel monkeys. Neuroscience 1983;10(3):639-65.

91. Merzenich MM, Kaas JH, Wall J, Nelson RJ, Sur M, Felleman D. Topographic reorganization of somatosensory cortical areas $3 \mathrm{~b}$ and 1 in adult monkeys following restricted deafferentation. Neuroscience 1983;8(1):33-55.

92. Lundborg G, Rosen B, Dahlin LB, Holmberg J, Karlson B. Functional sensibility of the hand after nerve repair. Lancet 1993;342(8882):1300.

93. Rosen B, Lundborg G, Dahlin L, Holmberg J, Karlson B. Nerve repair: correlation of restitution of functional sensibility with specific cognitive capacities. J Hand Surg [Br] 1994;19(4):452 - 8.

94. (NIMH) NloMH. Coginitive research. Cognition. www.nimh.nih.gov., 2000: 1 - 4.

95. Souttar S, Onon MC. Some points arising in nerve injuries. British Medical Journal 1917;8:817-820.

96. Imai H, Tajima T, Natsumi Y. Successful reeducation of functional sensibility after median nerve repair at the wrist. J Hand Surg 1991;16A:60-5.

97. Diao E, Vannuyen T. Techniques for primary nerve repair. Hand Clinics 2000;16(1):53-66.

98. Dagum A. Peripheral nerve regeneration, repair, and grafting. J Hand Ther 1998;11(2):111- 7.

99. Jaquet JB, Luijsterburg AJ, Kalmijn S, Kuypers PD, Hofman A, Hovius SE. Median, ulnar, and combined median-ulnar nerve injuries: functional outcome and return to productivity. The Journal of Trauma 2001;51(4):687-92.

100. Fess EE. Rehabilitation of the patient with peripheral nerve injury. Hand Clin 1986;2:207-15.

101. Wilkins E, Lowery J, Smith DJ J. Outcomes research: a primer for plastic surgeons. Ann Plast Surg 1996;37(1):1 - 11 .

102. Cano SJ, Browne JP, Lamping DL. Patient-based measures of outcome in plastic surgery: current approaches and future directions. British Journal Of Plastic Surgery 2004;57(1):1 - 11.

103. Marsh D. The validation of measures of outcome following suture of divided peripheral nerves supplying the hand. J Hand Surg [Br] 1990;15(1):25-34.

104. Downie N. Fundementals of measurement: techniques and practices. 2nd ed. New York: Oxford University Press, 1967.

105. Hudak P, Amadio P, Bombardier C. Development of an upper extremity outcome measure: the DASH (disabilities of the arm, shoulder and hand [correction of head]). The Upper Extremity Collaborative Group (UECG). Am J Ind Med 1996;29(6):602-8.

106. McConnell S, Beaton D, Bombardier C. The DASH outcome measure user's manual. 1 ed. Toronto: Institute for Work \& Health, 1999.

107. Berg AT, Vickrey BG. Outcomes research. Science 1994;264:757-8.

108. Amadio P. Outcomes assessment in hand surgery. What's new? Clin Plast Surg 1997;24(1):191 -4.

109. Holmquist B, Kanje M, Kerns J, Danielsen N. A mathematical model for regeneration rate and initial delay following surgical repair of peripheral nerves. J Neurosci Methods 1993;48(1 - 2):27-33.

110. Hoffmann P, Buck-Gramcko D, Lubahn JD. The Hoffmann-Tinel sign. 1915 [classical article]. J Hand Surg $[B r]$ 1993;18(6):800-5.

111. Rosen $B$, Lundborg $G$. The long term recovery curve in adults after median or ulnar nerve repair: a reference interval. J Hand Surg 2001;26B(3):196-200.

112. Ghandi A, Jaquet JB, Kalmijn S, Hovius S. Motor recovery following median and ulnar nerve injuries. 2003;28 Suppl 1:16. 
113. Gaul JS J. Intrinsic motor recovery - a long-term study of ulnar nerve repair. J Hand Surg [Am] 1982;7(5):502-8.

114. Macey A, Burke F, Abbott K, et al. Outcomes of hand surgery. British Society for Surgery of the Hand. $J$ Hand Surg [Br] 1995;20(6):841 - 55.

115. Dellon AL. Nerve Injury, Nerve Reconstruction and Recovery of Nerve Function. Baltimore: Sensory Management Services, LLC, 2003.

116. Frykman GK, Gramyk K. Results of nerve grafting. In: Gelberman RH, ed. Operative nerve repair and reconstruction. Philadelphia: JB Lippincott, 1991: 553-567.

117. Shen N, Zhu J. Functional assessment of peripheral nerve injury and repair. J Reconstr Microsurg 1996;12(3):153-7.

118. de Medinaceli L, Rawlings R. Is it possible to predict the outcome of peripheral nerve injuries? A probability model based on prospects for regenerating neurites. Biosystems 1987;20(3):243-58.

119. Fahmy W, Fahmy M. Prediction of early outcome of nerve reconstruction: a statistic and mathematic approach. 6th IFFSH 1995, Helsinki, Finland: 457-461.

120. Weiss KL, Beltran J, Sharmam OM. High-field MR surface-coil imaging of the hand and wrist. Radiology 1986;160:143.

121. Jarvik JG, Kliot M, Maravilla KR. MR Nerve imaging of the wrist and hand. Hand Clinics 2000;16(1): $13-23$.

122. Gupta S, Littman T. Nerve injury repair. In: Sudekum A, Talavera F, Chang D, Slenkovich N, Downey S, eds. Hand: eMedicine, 2003.

123. West GA, Haynor DR, Goodkin R, et al. Magnetic resonance imaging signal changes in denervated muscles after peripheral nerve injury. Neurosurgery 1994;35(6):1077-85.

124. Viddeleer A, Kuypers P, Ginai A, Hovius S. Magnetic resonance imaging as a method for monitoring nerve regeneration after median and ulnar nerve repair. J Hand Surg 2002;27B:10.

125. Schreuders TA, Roebroeck ME, Jaquet JB, Hovius SE, Stam HJ. Measuring the strength of the intrinsic muscles of the hand in patients with ulnar and median nerve injuries: reliability of the Rotterdam Intrinsic Hand Myometer (RIHM). 2004;29(2):318-24.

126. Lundborg G. Richard P. Bunge memorial lecture. Nerve injury and repair - a challenge to the plastic brain. Journal of the Peripheral Nervous System 2003;8(4):209-26.

127. Penfield, Ramussen. The cerebral cortex in man. In: Peele T, ed. The neuroanatomical basis for critical neurology. New York: McGraw-Hill, 1954: 350.

128. Anders B, Rosen B, Lundborg G. Acute improvement of contralateral after deafferentation. 9th IFSSH 2004, Budapest, Hungary: 303 - 304.

129. Jaquet J, Koning I, Kalmijn S, Kuypers P, Hofman A, Hovius S. Central nervous system plays a major role in sensory outcome following nerve injuries. J Hand Surg 2002;27B:11 - 12.

130. Jaquet J, Koning I, Kalmijn S, Kuypers P, Hofman A, Hovius S. Cognitive capacity is associated with longterm sensory outcome following nerve injuries. 9th IFSSH 2004, Budapest, Hungary: 280.

131. Maldjian JA, Gottschalk A, Patel RS, Pincus D, Detre JA, Alsop DC. Mapping of secondary somatosensory cortex activation induced by vibrational stimulation: an fMRI study. Brain Research 1999;824(2):291 - 5.

132. Nakamura A, Yamada T, Goto A, et al. Somatosensory homunculus as drawn by MEG. Neuroimage 1998;7:377-86.

133. Gelnar PA, Krauss BR, Szeverenyi NM, Apkarian AV. Fingertip representation in the human somatosensory cortex: an fMRI study. Neuroimage 1998;7:261-83.

134. Baumgartner C, Doppelbauer A, Deecke L, et al. Neuromagnetic investigation of somatotopy of human hand somatosensory cortex. Experimental Brain Research 1991;87(3):641-8.

135. Balance CA, Balance HA, Stewart P. Remarks on the operative treatment of chronic palsy of the peripheral origin. British Medical Journal 1903;1:1009-1013.

136. Viterbo F, Trindade JC, Hoshino K, Mazzoni Neto A. Latero-terminal neurorrhaphy without removal of the epineural sheath. Experimental study in rats. Revista Paulista de Medicina 1992;110(6): 267-75.

137. Viterbo F, Trindade JC, Hoshino K, Mazzoni Neto A. End-to-side neurorrhaphy with removal of the epineurial sheath: an experimental study in rats. Plastic and Reconstructive Surgery 1994;94(7): $1038-47$. 
138. Lundborg G, Zhao Q, Kanje M, Danielsen N, Kerns JM. Can sensory and motor collateral sprouting be induced from intact peripheral nerve by end-to-side anastomosis? J Hand Surg. British Volume 1994;19(3):277-82.

139. Kanje M, Arai T, Lundborg G. Collateral sprouting from sensory and motor axons into an end to side attached nerve segment. Neuroreport 2000;11(11):2455-9.

140. Xiong G, Ling L, Nakamura R, Sugiura Y. Retrograde tracing and electrophysiological findings of collateral sprouting after end-to-side neurorrhaphy. J Hand Surg 2003;8(2):145 - 50.

141. Rowan PR, Chen LE, Urbaniak JR. End-to-side nerve repair. A review. Hand Clinics 2000;16(1): $151-9$.

142. Zhang F, Fischer KA. End-to-side neurorrhaphy. Microsurgery 2002;22(3):122 - 7.

143. Mennen U. End-to-side nerve suture in clinical practice. J Hand Surg 2003;8(1):33-42.

144. Rapp E, Lallemand S, Ehrler S, Buch N, Foucher G. Restoration of sensation over the contact surfaces of the thumb-index pinch grip using the terminal branches of the superficial branch of the radial nerve. Chir Main 1999;18(3):179-83.

145. Franciosi LF, Modestti C, Mueller SF. Neurotization of the biceps muscle by end-to-side neurorraphy between ulnar and musculocutaneous nerves. A series of five cases. Chir Main 1998;17(4):362-7.

146. Boutros S, Nath RK, Yuksel E, Weinfeld AB, Mackinnon SE. Transfer of flexor carpi ulnaris branch of the ulnar nerve to the pronator teres nerve: histomorphometric analysis. Journal of Reconstructive Microsurgery 1999;15(2):119-22.

147. Bertelli JA, Ghizoni MF. Nerve repair by end-to-side coaptation or fascicular transfer: a clinical study. Journal of Reconstructive Microsurgery 2003;19(5):313-8.

148. Kayikcio Ÿlu A, Karamursel S, AŸao Ÿlu G, Kecik A, Celiker R, Cetin A. End-to-side neurorrhaphies of the ulnar and median nerves at the wrist: report of two cases without sensory or motor improvement. Annals of Plastic Surgery 2000;45(6):641-3.

149. Solomons M, Swan M, Pienaar C, De Jager W. Clinical experience with end to side nerve anastomosis. 9th IFSSH 2004, Budapest, Hungary: 39-40.

150. Pienaar C, Swan M, de Jager W, Solomons M. Clinical experience with end-to-side nerve transfer. J Hand Surg 2004;29B:438-443.

151. Viterbo F, Palhares A, Franciosi LF. Restoration of sensitivity after removal of the sural nerve. A new application of latero-terminal neurorraphy. Revista Paulista de Medicina 1994;112(4):658 -60.

152. Strauch B. Use of nerve conduits in peripheral nerve repair. Hand clinics 2000;16(1):123-133.

153. Lundborg G, Rosen B, Dahlin L, Holmberg J, Rosen I. Tubular repair of the median or ulnar nerve in the human forearm: a 5-year follow-up. J Hand Surg 2004;29B(2):100-7.

154. Myckatyn TM, Mackinnon SE. A review of research endeavors to optimize peripheral nerve reconstruction. Neurological Research 2004;26(2):124-38.

155. Albert E. Operationen an nerven. Wied Med Presse 1885;26:1285-1288.

156. Mackinnon SE, Doolabh VB, Novak CB, Trulock EP. Clinical outcome following nerve allograft transplantation. Plastic and Reconstructive Surgery 2001;107(6):1419-29.

157. Mackinnon SE. Nerve allotransplantation following severe tibial nerve injury. Case report. Journal of Neurosurgery 1996;84(4):671-6.

158. Mackinnon SE, Hudson AR. Clinical application of peripheral nerve transplantation. Plastic and Reconstructive Surgery 1992;90(4):695-9.

159. Gold BG, Storm-Dickenson T, Austin DR. The immunosuppressant FK506 increases functional recovery and nerve regeneration following peripheral nerve injury. Restor Neurol Neuroscience 1994;6:287-296.

160. Gold BG, Katoh K, Storm Dickerson T. The immunosuppressant FK506 increases the rate of axonal regeneration in rat sciatic nerve. The Journal of Neuroscience 1995;15(11):7509-16.

161. Owen ER, Dubernard JM, Lanzetta $M$, et al. Peripheral nerve regeneration in human hand transplantation. Transplantation Proceedings 2001;33(1 - 2):1720-1.

162. Konishi T, Yoshiyama Y, Takamori M, et al. Clinical study of FK506 in patients with myasthenia gravis. Muscle \& Nerve 2003;28(5):570-4.

163. Dubernard JM, Owen E, Herzberg G, et al. Human hand allograft: report on first 6 months. Lancet 1999;353(9161):1315-20.

164. Dubernard JM, Owen E, Herzberg G, et al. [The first transplantation of a hand in humans. Early results]. Chirurgie; Memoires de L'academie de Chirurgie 1999;124(4):358-65. 
165. Hovius SER, Stevens HJPD. Thesis. The allogenic transplantation of the radial side of the hand in the rhesus monkey: Erasmus University Rotterdam, 1991.

166. Lanzetta M. Functional results of the Italian hand transplantation program. 2003;28:74.

167. Lanzetta M, Nolli R, Vitale G, Pioltelli P, Lucchina S, Carta I. Functional results of hand transplantation. The italian experience. 9th IFSSK 2004, Budapest, Hungary: 381.

168. Schuind FA, Abramowicz D, Van Holder C, Mouraux D, Robert C, Meyer A. Nerve regeneration in hand transplantation. 9th IFSSH 2004, Budapest, Hungary: 395-396.

169. Doolabh VB, Mackinnon SE. FK506 accelerates functional recovery following nerve grafting in a rat model. Plastic and Reconstructive Surgery 1999;103(7):1928-36.

170. Lundborg G. Tomorrow's artificial hand. Scandinavian Journal of Plastic Reconstructive and Hand Surgery 2000;34:97-100.

171. Jones L. Dextrous hands: human, prosthetic, and robotic. Presence Teleoper Virtual Environ 1997;6(1):29-56.

172. Yun $\mathrm{MH}$, Cannon D, Freivalds $\mathrm{A}$, Thomas $\mathrm{G}$. An instrumented glove for grasp specification in virtualreality-based point-and-direct telerobotics. 1997;27(5):835-46.

173. Heijden van der M. Psychosocial aspect in traumatic hand injuries and congenital hand deformaties. J Hand Surg 2002;27B:68.

174. Liverneaux P. Hand replantation in a 88 year old man: replanted's senior? 9th IFSSH 2004, Budapest, Hungary: $15-16$.

175. Klineberg I, Murray G. Osseoperception: sensory function and proprioception. Adv Dent Res 1999;13:120-129.

176. van Steenberghe D. From osseointegration to osseoperception. J Dent Res 2000;79(11):1833 - 1837.

177. Eriksson E, Branemark P. Osseointegration from the perspective of the plastic surgeon. Plast Reconstr Surg 1994;93(3):626-637.

178. Lundborg G, Branemark P, Rosen B. Osseointegrated thumb prostheses: a concept for fixation of digit prosthetic devices. J Hand Surg [Am] 1996;21(2):216-221.

179. Lundborg G, Rosen B, Lindberg S. Hearing as substitution for sensation: a new principle for artificial sensibility. J Hand Surg 1999;24A:219-224.

180. Lundborg G, Rosen B, Lindstrom K, Lindberg S. Artificial sensibility based on the use of piezoresistive sensors-priliminary observations. J Hand Surg 1998;23B:620-626.

181. Rosen B, Lundborg G. Sensory re-education after nerve repair: aspects of timing. Handchirurgie, Mikrochirurgie, Plastische Chirurgie 2004;36(1):8-12.

182. Lundborg G, Rosen B. "Sensory by-pass after median nerve repair: effect of early post operative artificial sensibility using the sensor glove. 9th IFSSH 2004, Budapest, Hungary: 243 - 244.

183. Guadagnoli E, McNeil BJ. Outcomes research: hope for the future or the latest rage? Inquiry 1994;31(1):14-24.

184. Sage WM. Outcomes research. NEngl J Med 1994;330:434-5.

185. Birkmeyer JD. Outcomes research and surgeons. Surgery 1998;124:477-83.

186. Gaul JS J. Identifiable costs and tangible benefits resulting from the treatment of acute injuries of the hand. J Hand Surg [Am] 1987;12:966-70.

187. Ellwood PM. Shattuck lecture - outcomes management. A technology of patient experience. New England Journal Of Medicine 1988;318(23):1549-56.

188. Ultee J, van Neck JW, Jaquet JB, Hovius SE. Difficulties in conducting a prospective outcome study. Hand Clinics 2003;19(3):457-62.

189. McAllister R, Gilbert S, Calder J, Smith P. The epidemiology and management of upper limb peripheral nerve injuries in modern practice. J Hand Surg 1996;21B(1):4-13. 


\section{CHAPTER 10}

SUMMARY

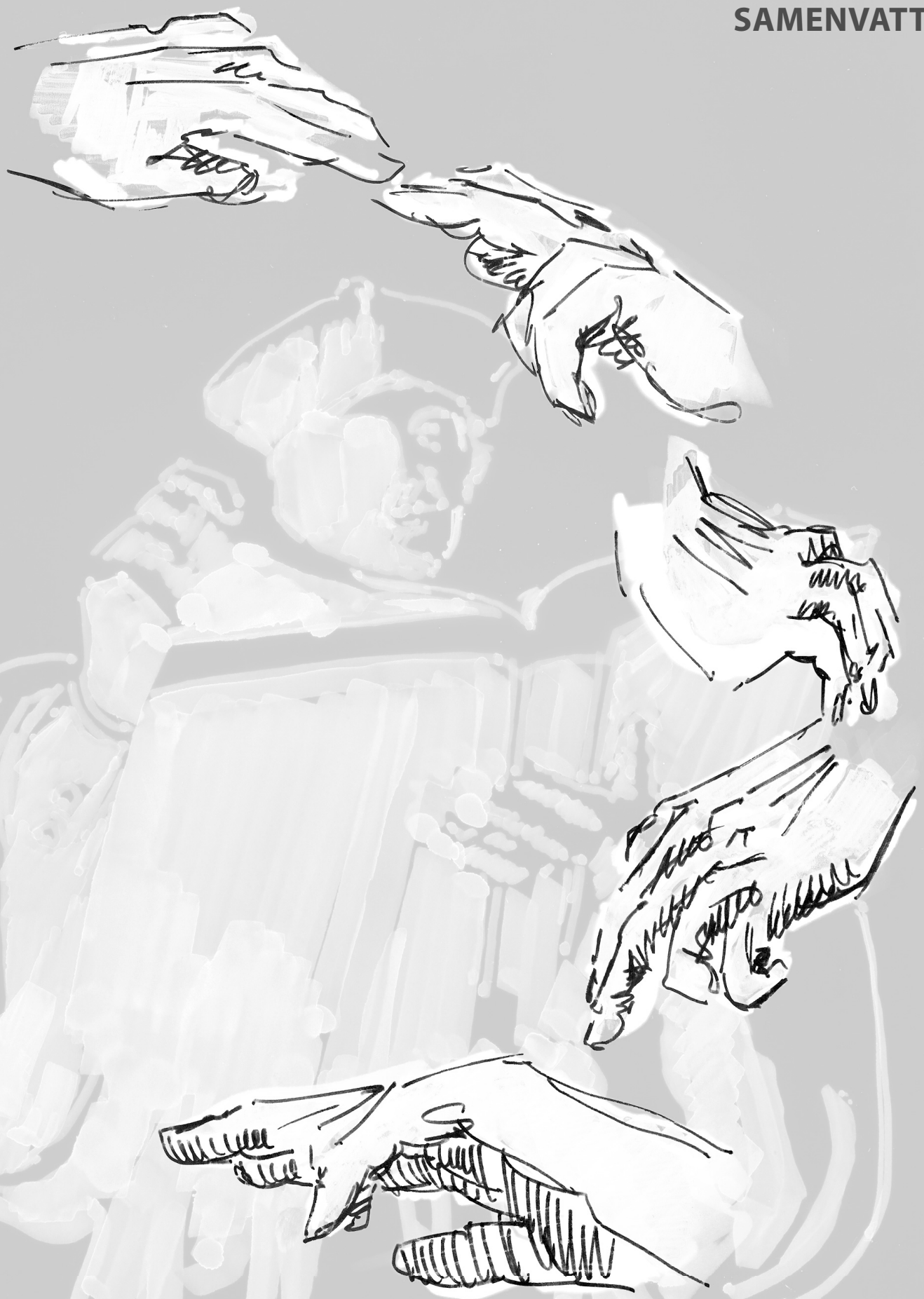





\section{SUMMARY}

In chapter 1 the author provide a general introduction on median and ulnar nerve injuries. Furthermore the aims for this thesis, entitled median and ulnar nerve injuries: prognosis and predictors for clinical outcome, are defined.

Chapter 2 comprises an investigation into the overall functional outcome of median and ulnar nerve injuries. 313 wrist and forearm nerve injuries operated upon between 1980 and 1997 were reviewed in relation to complications, return to work, sensor and motor recovery. Twentyone percent $(21 \%)$ of the study-population achieved 'good' sensory recovery. 'Good' motor recovery occurred in forty-nine percent. Motor recovery, progress of sensory reinnervation and number of severed structures were related to the type of injury. Time between laceration of the nerve and the first sign of sensory reinnervation seemed to be a good predictor for final motor recovery. A probability of a $24 \%$ of work loss, after a mean follow-up of 17.7 months, was found. Poor sensory and motor recovery were associated with work disability. Level of injury, type of work, number of complications and hand-therapy were found to influence return to work. This study was used to define further aims for the thesis.

Despite the devastating nature of 'spaghetti wrist' injury, little attention has been paid to this extensive wrist trauma. The main objective of chapter $\mathbf{3}$ was to assess long-term outcome following 'spaghetti wrist' injury in terms of functional recovery, return to work potential and psychological distress for a large group $(n=67)$ of 'spaghetti wrist' patients. This study demonstrated that, despite a mean follow-up of 10 years, spaghetti wrist patients were still functionally impaired. Grip strength loss of $24 \%$ compared to the uninjured hand, tip pinch strength loss of $34 \%$ and $32 \%$ had no protective sensation. Almost half of the study-population, employed at the day of injury, could not return to work within one year following the accident. Mean time off work (TOW) was 35 weeks. Moderate to severe psychological symptoms (Impact of Event Scale >17) during the first month following the injury, were present in $64 \%$ of the patients. Based on a statistical analysis the definition 'a minimum of ten completely injured structures, including at least one major nerve' is the most appropriate definition to describe 'spaghetti wrist' trauma.

In chapter 4 content validity of the DASH (Disabilities of Arm Shoulder and Hand) questionnaire was examined. This study was additionally designed to investigate the ability to resume various everyday tasks and provide long-term DASH scores for forearm nerve injury patients. Multiple linear regression analyses adjusted for age, sex, hand dominance and severity of the trauma revealed associations between the functional symptom score (FSS) of the DASH and the level of sensory recovery (Semmes-Weinstein monofilamants) and motor recovery (grip and tip-pinch strength). Patients capable of returning to productivity showed lower DASH scores (adjusted mean $=12.5$ ) compared to the non-return to work population (adjusted mean=26.6). We concluded that the DASH had a 'good' content validity for all outcome parameters. Mean DASH score was 18.7 after a mean follow-up of 5.5 years. 
Chapter $\mathbf{5}$ analyses absence from work and the ability to return to work (RTW) after surgical repair of median, ulnar and combined median-ulnar nerve injuries. Furthermore was aimed to define risk factors for delayed RTW. Within 1 year after injury, 59\% returned to work. The cumulative proportion of return to work at 3, 6 and 9 months post-injury was 19\%, 43\% and $53 \%$, respectively. Mean TOW was 31.3 weeks. RTW after combined nerve injuries was $24 \%$ versus $80 \%$ after isolated median and $59 \%$ after ulnar nerve injuries. Level of education, type of job and compliance to hand therapy were found predictors for RTW. Grip strength loss, tip pinch strength loss and sensory recovery differed strongly between the RTW and No RTW population.

Psychological stress following median and ulnar nerve injuries has never been investigated in detail. Chapter 6 discusses the psychological impact of forearm nerve injuries. Another objective was to examine to what extent psychological stress has an effect on outcome. Ninetyfour (94\%) percent of our study population experienced psychological stress, within the first month post-operatively. Thirty-six (36\%) percent of subjects reported sufficient symptoms at one month post-operatively to be classified as, in need for psychological treatment (IES > 30). Combined median-ulnar nerve injuries (mean IES 35.0) were accompanied with a higher psychological stress compared to the single nerve injuries (median: mean IES 24.2 and ulnar: mean IES 22.6). Multiple linear regression analyses adjusting for age, sex and severity of the trauma revealed an association between the IES-score and functional symptom score (FSS), mean TOW and motor recovery (grip strength and tip-pinch strength). High education was found to be a protecting variable for post traumatic psychopathology.

The denervated hand loses cortical representations in the central nervous system. To establish pre-injury representations remodelling of the somatosensory cortex is needed. The level of cognitive may play a role in this process and therefore may have a substantial effect on the prognosis. The study described in chapter $\mathbf{7}$ was designed to quantify the association between cognitive capacity and long-term sensory recovery, in terms of perception of touch and pressure. The Stroop Colour Word Test (SCWT), the Dutch version of the National Adult Reading Test (NART) and the California Verbal Learning Test (CVLT) were used to assess the different components of cognition. Multiple linear regression analyses adjusting for age, sex and education revealed an association between long-term sensory recovery and SCWT, NART and a number of scores of the CVLT. We concluded that beside cognitive capacity level of intelligence appeared to affect the level of sensory recovery. Furthermore, this study showed that combined median-ulnar nerve injuries were accompanied with less sensory recovery compared to the single nerve injuries.

In chapter 8 the results of a meta-analysis based on individual patient data on motor and sensory recovery after microsurgical nerve (median, ulnar and combined) repair are reported. Motor and sensory recovery were significantly associated. Multivariate logistic regression analysis showed that age, site and delay were significant predictors of successful motor 
recovery. In ulnar nerve injuries the chance of motor recovery was $71 \%$ lower than in median nerve injuries. For sensory recovery age, and delay were found to be significant predictors.

Chapter 9 includes the general discussion and conclusions. The results of the different chapters will be compared. Directions for further research in the future are being given. 



\section{SAMENVATTING}

Hoofdstuk 1 is de introductie voor dit proefschrift naar medianus en ulnaris zenuwletsels. Verder worden de doelstellingen voor dit proefschrift met de titel: 'median and ulnar nerve injuries: prognosis and predictors for clinical outcome' beschreven.

Hoofdstuk 2 is een onderzoek naar de totale uitkomst van medianus en ulnaris zenuwletsels. 313 zenuwletsels van pols en onderarm, die geopereerd waren tussen 1980 en 1997 werden geanalyseerd met betrekking tot complicaties, terugkeer naar werk, sensibel herstel en motorisch herstel. Eenentwintig procent (21\%), van de onderzoekspopulatie behaalde een'goed' sensibel herstel. 'Goed' motorisch herstel werd bereikt in negenenveertig procent (49\%). Het motorische herstel, de progressie van het sensibele herstel en het aantal bij het letsel betrokken structuren bleken af te hangen van het type letsel (medianus, ulnaris of gecombineerd). De tijd die zat tussen de doorsnijding van de zenuw en het eerste teken van sensibele reïnnervatie bleek een voorspellende maat voor het uiteindelijke motorisch herstel. Vierentwintig procent (24\%) van de studie populatie bleek nog niet te zijn teruggekeerd naar het werk, na een gemiddelde van 17.7 maanden. Slecht sensibel en motorisch herstel waren geassocieerd met een verminderde kans om terug te keren naar het werk. De mogelijkheid tot terugkeer naar het werk werd bepaald door de volgende voorspellende waarden: niveau van de zenuwdoorsnijding, soort werk, aantal complicaties en het volgen van handtherapie. Deze studie werd verder gebruikt voor het definiëren van verdere doelstellingen voor dit proefschrift.

Ondanks het slechte karakter van het 'spaghetti pols' trauma is er weinig aandacht, in de internationale literatuur, geweest voor dit uitgebreide trauma van de pols. Het doel van hoofdstuk 3 was dan ook onderzoek te doen naar de lange termijn resultaten van het'spaghetti pols' trauma. Er is gekeken naar de functionele uitkomst, de mogelijkheid terug te keren naar het werk en psychologische stress bij 67 'spaghetti pols' patiënten. Deze studie liet zien dat, zelfs na een gemiddelde follow-up van 10 jaar, 'spaghetti pols' patiënten duidelijk functioneel beperkt zijn. Grijpkracht was $24 \%$ minder ten opzichte van de niet aangedane hand, een 'tippinch' kracht verlies van 34\% en 32\% van de studiepopulatie bleek geen beschermend gevoel van de hand verkregen te hebben. Bijna de helft van de patiënten die aan het werk waren toen het trauma optrad, kon het werk niet hervatten binnen een jaar, wat resulteerde in de 'WAO'. Gemiddeld aantal ziektewetweken was 35 weken. Matig tot ernstige psychologische stress symptomen (Impact of Event Scale > 17), waren in de eerste maand na het trauma aanwezig in $64 \%$ van de patiënten populatie. Gebaseerd op statistische analyse van onze resultaten bleek dat de definitie van 'minimaal 10 anatomische structuren met daarbij op z'n minst betrokkenheid van een van de grote zenuwen van de onderarm' de meest toepasselijke definitie was om het 'spaghetti pols' trauma te definiëren.

In hoofdstuk 4 is onderzoek gedaan naar de 'content validity' van de DASH (Disabilities of Arm Shoulder and Hand). Verder is de mogelijkheid tot het verrichten van de activiteiten van het dagelijkse leven (ADL) bestudeerd. Tot slot zijn de DASH scores voor zenuwletsels van de 
onderarm bepaald. Multipele lineaire regressie analyse gecorrigeerd voor leeftijd, geslacht, dominante hand en ernst van het trauma liet een verband zien tussen de 'functional symptom score (FSS)'van de DASH en de mate van sensibel herstel (Semmes-Weinstein monofilamenten) en motorisch herstel (grijp en 'tip-pinch' kracht). Patienten die konden terugkeren naar het werk hadden een lagere DASH score (gecorrigeerd gemiddelde 12.5) dan de patienten die niet konden terugkeren naar het werk (gecorrigeerd gemiddelde 26.6). Wij concludeerden dan ook een 'goede"content validity' van de DASH voor alle uitkomst parameters. De gemiddelde DASH score was 18,7 bij een gemiddelde follow-up van 5.5 jaar.

In hoofdstuk 5 worden sociale consequenties van medianus, ulnaris en gecombineerde medianus-ulnaris zenuwletsels geanalyseerd. Gekeken is naar het aantal weken in de ziektewet en de mogelijkheid terug te keren binnen een jaar naar het werk. Verder is getracht voorspellende waarden te definiëren voor de mogelijkheid terug te keren naar het werk. Binnen het eerste jaar na het zenuwletsel, was 59\% van de studiepopulatie in staat terug te keren naar het werk. Het cumulatieve percentage van terugkeer naar werk was respectievelijk na 3, 6 en 9 maanden, 19\%, 43\% and 53\%. Gemiddeld aantal ziektewet weken was 31.3 weken. Terugkeer naar werk, binnen 1 jaar bij een gecombineerd medianus-ulnaris zenuwletsel was $24 \%$, versus $80 \%$ voor een medianus letsel en $59 \%$ voor een ulnaris letsel. Mate van educatie, soort werk en therapietrouw aan de handtherapie bleken voorspellende waarden voor de terugkeer naar het werk. Verlies van grijpkracht, verlies van 'tip-pinch' kracht en sensibel herstel verschilde aanzienlijk tussen de mensen die konden terugkeren naar het werk en de mensen die niet in staat waren terug te keren naar het werk.

Psychologische stress na letsel van de nervus medianus en ulnaris is nooit in detail onderzocht. Binnen hoofdstuk 6 is onderzoek gedaan naar de psychologische stress na zenuwletsels van de onderarm en het effect van deze stress op de uitkomst. Vierennegentig procent (94\%) van de studiepopulatie ervoer enige mate van psychologische stress, binnen de eerste maand postoperatief. Zesendertig procent (36\%) van de studiepopulatie liet genoeg symptomen van psychologische stress zien (IES > 30) om daarvoor behandeld te worden. De gecombineerde medianus-ulnaris zenuwletsels (gemiddelde IES 35.0) gingen gepaard met een aanzienlijk hogere mate van psychologische stress dan de geïsoleerde medianus (gemiddelde IES 24.2) en ulnaris (gemiddelde IES 22.6) zenuwletsels. Multipele lineaire regressie analyse gecorrigeerd voor leeftijd, geslacht en ernst van het trauma liet een associatie zien tussen de hoogte van de IES score en de 'functional symptom score' (FSS), gemiddeld aantal ziektewet weken en motorisch herstel (grijpkracht en 'tip-pinch' kracht). Hoge mate van educatie bleek een beschermende factor voor het ontwikkelen van post traumatische psychopathologie.

De gedenerveerde hand verliest zijn corticale representaties in het centrale zenuwstelsel. Om de corticale representaties van voor het trauma te herstellen is een proces van remodulatie van somatosensorische cortex nodig. De cognitieve capaciteit van de patiënt zou hierop van invloed kunnen zijn. De studie beschreven in hoofdstuk $\mathbf{7}$ onderzoekt het effect van cognitieve capaciteit op het sensibele herstel (perceptie van aanraking en druk) op de lange termijn. De 
Stroop Colour Word Test (SCWT), de Nederlandse versie van de National Adult Reading Test (NART) en de California Verbal Learning Test (CVLT) werden gebruikt om de verschillende componenten van cognitie te onderzoeken. Multipele lineaire regressie analyse gecorrigeerd voor leeftijd, geslacht en educatie liet een verband zien tussen sensibel herstel op de lange termijn en SCWT, NART en een aantal van de scores op de CVLT. Verder concludeerden wij dat naast cognitieve capaciteit de mate van intelligentie van invloed lijkt te zijn op het sensibele herstel. Deze studie liet tot slot zien dat de gecombineerde medianus-ulnaris zenuwletsels gepaard gaan met een lager niveau van sensibel herstel dan de geïsoleerde zenuwletsels.

In hoofdstuk 8 zijn de resultaten beschreven van een meta-analyse, gebaseerd op individuele patiëntendata, naar motorisch en sensibel herstel van medianus en ulnaris zenuwletsels. Motorisch en sensibel herstel bleken statistisch met elkaar te zijn geassocieerd. Multivariabele logistische regressie analyse liet zien dat leeftijd, 'delay' en niveau van de laesie voorspellende waarden waren voor 'succesvol' motorisch herstel. Verder bleek dat de ulnaris zenuwletsels een $71 \%$ lagere kans hebben op 'succesvol' motorisch herstel. Voor sensibel herstel waren leeftijd en 'delay' significante voorspellers.

Hoofdstuk 9 bevat de discussie en de conclusies van dit onderzoek. De resultaten van de verschillen hoofdstukken worden met elkaar vergeleken. Verder worden richtingen gegeven voor verder onderzoek in de toekomst. 

CHAPTER 11

\section{ACKNOWLEDGEMENTS}

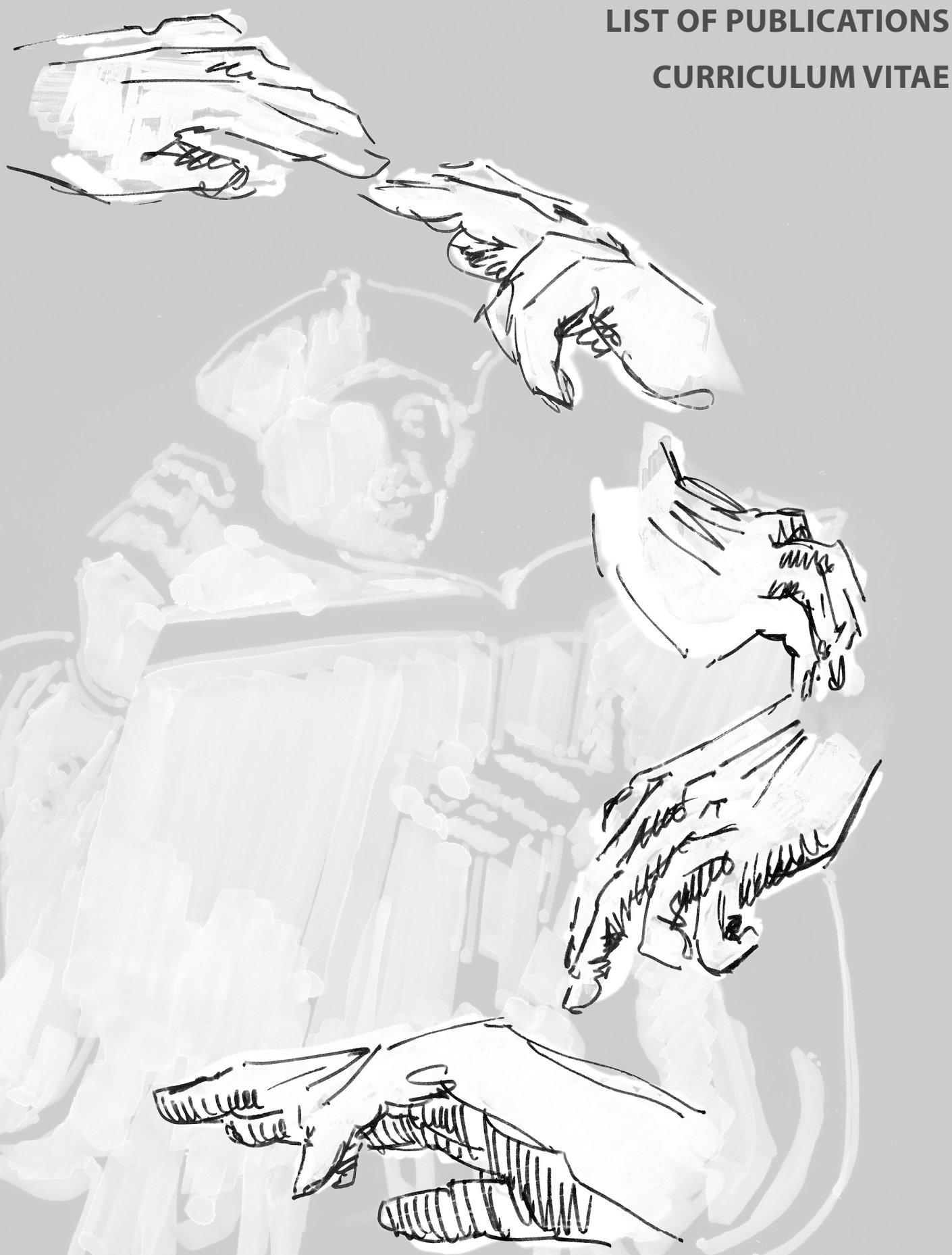





\section{ACKNOWLEDGEMENTS}

Professor S.E. R. Hovius, beste prof. Dit is de tweede mijlpaal waarvoor wij samen hebben moeten afzien. Met de eerste fysieke krachtmeting nog vers in het geheugen bleek deze 'marathon' niet binnen een geprotocoliseerd trainingsschema te passen. $U$ heeft mij alle vrijheid gegeven om dit onderzoek op te zetten. Ik heb het als zeer prettig ervaren dat naast al het zakelijke er altijd genoeg ruimte was voor ludieke uitstapjes en ideeën.

Professor H.J. Stam, beste tweede promotor. Geregeld hebben we met 'z'n vieren' rond de tafel gezeten om het onderzoek van Ton en mij vorm te geven. De bijeenkomsten waren meestal erg gezellig en daarbij ook constructief. De laatste vergadering, waarbij wij een datum hebben geprikt en besloten hebben tot een 'dubbel' promotie, zal ik nooit vergeten. Verder denk ik dat naast de intensieve klinische samenwerking tussen de plastische chirurgie en de revalidatie geneeskunde, verdere uitbreiding van de wetenschappelijke samenwerking essentieel is.

Professor Hofman, zonder $\mathrm{u}$ had de inhoud van dit boekje er heel anders uitgezien. Toen bleek dat een promotieonderzoek gericht op de magnetoneurografie geen optie was en er op dat moment al enige tijd verloren was gegaan, wist u met een zeer heldere kijk op de zaak het onderwerp een meer epidemiologisch karakter te geven en het onderzoek daarmee tot een hoger niveau te brengen. Ik ben u daar zeer dankbaar voor.

Professor Passchier, u bent nauw betrokken geweest bij het onderzoek naar de psychologische stress bij zenuwletsels. Voor een (hand-) chirurg is psychologische stress niet een fenomeen dat iedere dag wordt meegenomen in de dagelijkse zorg voor patiënten. Ik ben dan ook blij dat met uw ideeën meer duidelijkheid is gekomen met betrekking tot de psychologische stress die onze patiëntenpopulatie ervaart. Ik denk dat een verdere uitbreiding van dit onderzoek essentieel is.

Professor de Zeeuw, beste Chris. Jij hebt mij gezegd dat Overschie de bakermat is voor neuroanatomen. Nou ben ik niet van mening dat het terecht is dat ik me als jongste telg aansluit in die rij, ondanks het onderzoek naar de invloed van het brein op het herstel na perifere zenuwletsels. Ik ben je zeer dankbaar dat je mijn manuscript op wetenschappelijke kwaliteit hebt willen toetsen.

Professor McGrouther, dear prof. It is an honour, you will be one of the members of the'promotie commissie.' You and Erik have made me enthusiastic for research in the field of hand surgery. It was a wonderful experience to stay at your department for nearly one year. Now the thesis is finished, our paper on tendons can and will be finished. 
Professor Spauwen en dr. Houpt, dank dat jullie willen plaatsnemen in de commissie. Jullie waren als eerste bereid te participeren binnen het multicenter gedeelte van dit onderzoek. Met name jullie enthousiasme voor het onderzoek en het grote aantal patiënten dat jullie hebben geïncludeerd voor het prospectieve onderzoek, heb ik zeer gewaardeerd.

Sandra Kalmijn, beste Sandra. Wie had verwacht dat na onze eerste afspraak toen ik voor wat statistische hulp bij jou kwam, jij een van mijn copromotoren zou worden. Door jouw analyses begon ik steeds enthousiaster te worden voor het onderzoek. Dat jij doorgegaan bent met de begeleiding van het ZERO project ondanks dat je uit Rotterdam vertrok, heb ik heel speciaal gevonden. Onze afspraken door het gehele land waren altijd erg gezellig. Dank voor alles.

Paul Kuypers, beste Paul. Jij hebt je ontzettend ingespannen om het onderzoek op te zetten. Onze gesprekken waren altijd zeer motiverend.

Ton Schreuders, beste Ton. Zonder enige vorm van concurrentie hebben wij samen onderzoek gedaan naar dezelfde patiëntenpopulatie. Jij was altijd in voor een praatje om verdere lijnen uit te zetten. Nooit gedacht dat wij hier op dezelfde dag zouden staan. Wel een mooie afsluiting van dit hoofdstuk in ons leven. Hoop in de toekomst nog veel met je samen te werken.

ErikWalbeehm, beste Erik. Toch op dezelfde dag promoveren. Jij was diegene die mij enthousiast heeft gemaakt voor onderzoek en het leven dat daarbij hoort. In Londen in het lab werken, bij Wagamama's eten en daarna met de onderzoekers in een willekeurige pub verder vergaderen. Dank.

Michiel Dudok van Heel, beste Michiel. Helaas heeft jouw ziekte de oneerlijke strijd gewonnen. We hadden nog veel plannen

Irene Mathijssen en Nicole Posch, natuurlijk ook voor jullie een apart stukje. Irene, jij was de persoonlijke begeleider en 'mental coach' van Smitje en mij. Wij hebben dat gewaardeerd. Hopend op nog vele persoonlijke adviezen. Nicole, samen een publicatie en presentatie in Lissabon. Leuk om samen onderzoek gedaan te hebben.

Teun Luystenburg, de kopjes cappuccino smaakten altijd beter met jou. Veel dank ben ik je verschuldigd voor alle hulp bij de aanhoudende computer-aangelegenheden.

Carin Oostdijk, jij bent de contactpersoon tussen Hovius en de buitenwereld. Jij wist altijd wel een gaatje te vinden in de overvolle agenda. Ook jij blijft maar gaan. Ik heb daar respect voor.

Mevrouw Meijlink, ook u moet ik ontzettend bedanken om mijn geschreven tekst op engels te corrigeren. 
Ingrid en Krijn, bedankt dat ik deze zomer zonder enig probleem de LE 21 mocht gebruiken als studiecentrum. Er is daar veel werk verricht. Hopend op een mooi vaarseizoen volgend jaar.

Collega's en bazen Reinier de Graaf Gasthuis, dank voor de goede tijd die ik reeds gehad heb in Delft. Veel geleerd en ook gestimuleerd tot het afschrijven van dit boekje. Hoop nog lang contact met jullie te houden.

Patiënten van het 'ZERO' onderzoek. Zonder patiënten geen klinisch onderzoek. Ik stond versteld van de hoge 'response rate' en de bereidheid om mee te doen aan al die onderzoeken. Ik heb in ieder geval veel van jullie geleerd. Jullie probleem wordt geregeld onderschat en verdient meer aandacht.

Coen, Ingeborg, Ali, Aleid en Mathijs, de onderzoeksstudenten van het ZERO team. Allereerst veel dank voor jullie hulp op alle fronten. Ik heb met een ieder van jullie fijn samen gewerkt. Ondanks al het plezier is er ook resultaat geboekt. Drie van jullie hebben zelf een artikel gepubliceerd. Knap werk.

Paranymfen, Smitje en Tinus, daar staan we weer. Vandaag hebben we de jacquet ingeruild voor het rokkostuum. Voor de rest zal de deze dag niet veel van de elfde januari 2003 verschillen. Calvados, Brakman, officiële plechtigheid, borrel, diner, feestje en kater. Dank voor alle mooie herinneringen. Ik hoop dat er in de toekomst nog velen mogen volgen.

Erik, Christine en Emile. Ook jullie stonden altijd voor ons klaar. Emile, jij hebt er voor gezorgd dat ondanks alle drukte ik altijd op de hoogte was van alle sportuitslagen.

Pa en ma, jullie onvoorwaardelijke steun voor al mijn 'activiteiten' is zeer bijzonder. Niks is voor jullie te veel. De manier hoe jullie ons hebben opgevoed is een voorbeeld voor mij. Dank voor alles.

Mon, broer. Met veel plezier kijk ik altijd terug op onze jeugd. In het bijzonder die jaren samen op het hoogste niveau zeilen, blijven mij bij. Zoals dat in de boot al was, zo is het nu nog steeds; een half woord is meestal genoeg om elkaar te begrijpen. Fijn om zo iemand als broer te hebben.

Bine, schat, jij bent toch wel het mooiste wat ik in mijn leven ben tegengekomen. ledere dag geniet ik van het enthousiasme waarmee jij met ons jonge gezin bezig bent. Rest mij nog een vraag aan jou en Olivier: "hoe heten de volgende 'hoofdstukken' in ons leven?" 



\section{LIST OF PUBLICATIONS}

Related to this thesis

Bruyns CNP, Jaquet JB, Schreuders TAR, Kuypers PDL, and Hovius SER. Return to work following traumatic nerve injuries: An underestimated problem? In abstractbook "key to the future", ISBN 90-802347-3-7.

Jagt vd I, Jaquet JB, Passchier J, Kuypers PDL, and Hovius SER. The psychological impact of spaghetti wrist trauma. In abstractbook "key to the future", ISBN 90-802347-3-7.

Jaquet JB, Mink van der Molen AB, Hovius SER. BASH: Beperkingen van Arm Schouder en Hand. Volume 1, ISBN 90-76580-04-9.

Jaquet JB, Luijstenburg AJM, Kalmijn S, Kuypers PDL, Hofman A, Hovius SER. Median, ulnar and combined median-ulnar nerve injuries: functional outcome and return to productivity. Journal of Trauma: $51 ; 4: 687-692$.

Jaquet JB, Kalmijn S, Kuypers PDL, Passchier J, Hovius SER. Psychological impact of median and ulnar nerve injuries. $8^{\text {th }}$ congress of the International Federation of Societies for Surgery of the Hand. Abstractbook. ISBN 975-7508-41-1.

Jaquet JB, Kalmijn S, Kuypers PDL, Hofman A, Passchier J, Hovius SER Early psychological stress following forearm nerve injuries: a predictor for long-term functional outcome and return to productivity. Annals of Plastic Surgery: 49; 1: 82-90.

van de Kar, ThHJ, Jaquet JB, Meulstee J, Molenaar CBH, Schimsheimer RJ, Hovius SER. Clinical value of electrodiagnostic testing following repair of peripheral nerve lesions: a prospective study. J Hand Surg: 27B; 4: 345-349.

Jaquet JB, Ghandi A, Schreuders TAR, Kalmijn S, Kuypers PDL, Hovius SER. The DASH and outcome following median or ulnar nerve injuries. European Journal of Plastic Surgery: 25; 1 : 50-64.

Jaquet JB, de Koning I, Kalmijn S, Kuypers PDL, Hofman A, Hovius SER. Central nervous system plays a major role in sensory outcome following nerve injuries. J Hand Surg: 27B; 2 Supplement: 11-12.

Bruyns CNP, Jaquet JB, Schreuders TAR, Kalmijn S, Kuypers PDL, Hovius SER. Traumatic median and ulnar nerve injuries: the impact on employment. J Hand Surg: 27B; 2 Supplement: 11 - 12. 
Ghandi A, Jaquet JB, Hovius SER. Motor recovery following median and/or ulnar nerve injuries: setting an end-point. J Hand Surg: 27B; 2 Supplement: 11 - 12.

Jaquet JB, Kuypers PDL, Kalmijn S, Hovius SER. The DASH: A useful assessment method to evaluate functional recovery following median and ulnar nerve injuries. J Hand Surg: 28B; Supplement 1: 16.

Bruyns CNP, Jaquet JB, Schreuders TAR, Kalmijn S, Kuypers PDL, Hovius SER. Predictors for return to work in patients with median and ulnar nerve injuries. $J$ Hand Surg: 28A; 1: 28-34.

Ghandi A, Jaquet JB, Kalmijn S, Hovius SER. Motor recovery following median and ulnar nerve injuries. J Hand Surg: 28B; Supplment 1: 16.

Ruijs A, Jaquet JB, Giele $H$, Hovius SER. Meta-analysis: repair of median and ulnar nerve transaction injuries. J Hand Surg: 28B; Supplment 1: 16.

Posch N, Ghandi A, Jaquet JB, Daanen H, Hovius SER. Dimished thermoregulation in nerve injury patients: a reason for cold intolerance?. J Hand Surg: 28B; Supplment 1: 19.

van de Kar ThHJ, Jaquet JB, Meulstee J, Molenaar CBH, Schimsheimer RJ, Hovius SER. Letters to the editor: Clinical value of electrodiagnostic testing following repair of peripheral nerve lesions: a prospective study. J Hand Surg: 28B; 3: 283.

Schreuders TAR, Roebroeck ME, Jaquet JB, Hovius SER, Stam HJ. Measuring the strength of the intrinsic muscles of the hand in patients with ulnar and median nerve injury; reliability of the Rotterdam Intrinsic Hand Myometer (RIHM). J Hand Surg: 29A; 2: 318-324.

Jaquet JB, de Koning I, Kalmijn S, Kuypers PDL, Hofman A, Hovius SER. Cognitive capacity is associated with longterm sensory outcome following nerve injuries. Magyar Traumatologia Ortopedia, Kezsebeszet, Plasztilai Sebeszet. Abstarctbook ISBN 1217-32-31. 280.

Jaquet JB, van der Jagt I, Schreuders TAR, Kalmijn S, Kuypers PDL, Hovius SER. Spaghetti wrist trauma: Functional recovery, return to work and psychological impact.

Accepted Plastic and Reconstructive Surgery.

Jaquet JB, Schreuders TAR, Ghandi A, Kalmijn S, Stam HJ, Hovius SER. Content validity of the DASH and a long-term functional outcome of median and ulnar nerve injuries. Accepted $J$ Hand Surg, American Volume. 
Schreuders TAR, Roebroeck ME, Jaquet JB, Hovius SER, Stam HJ. Longterm outcome of muscle strength in patients with ulnar and media nerve injury: Comparing manual muscle strength, grip and pinch strength dynamometers and a new intrinsic muscle strength dynamometer. Accepted Journal of Rehabilitation Medicine.

Ruijs ACJ, Jaquet JB, Kalmijn S, Giele H, Hovius SER. Median and ulnar nerve injuries: A Metaanalysis of predictors of motor and sensory recovery after modern microsurgical nerve repair. Accepted Plastic and Reconstructive Surgery.

Other publications

Jaquet JB, Walbeehm ET, Brown RA, Hovius SER, McGrouther DA. Flexor digitorum superficialis tendon compression mechanism induces compression differentiated areas in flexor digitorum profundus of the rat. Journal of Anatomy, 1998: 193; 303.

Jaquet JB, Walbeehm ET, Brown RA, Hovius SER, McGrouther DA. FDP has areas differentiated for tension and compression. VIt ${ }^{\text {th }}$ Congress of the International Federation of Societies for Surgery of the Hand. Abstract Volume.

Jaquet JB, Walbeehm ET, Brown RA, Hovius SER, McGrouther DA. Compressiekrachten van de FDS veroorzaken fibrocartilagineuze specialsatie van de FDP. Congresboek $11^{\text {e }}$ SEOHS, ISBN 90-75823-18-5, 1998; 21.

Ultee J, van Neck JW, Jaquet JB, Hovius SER. Difficulties in conducting a prospective study. Hand Clinics: 19; 3: 457-462.

van den Haak A, Jaquet J. B. Oei I. H. Eenvoudige kostenbesparende techniek voor ballondissectie bij endoscopische totaal extraperitoneale procedure (TEP) bij liesbreukoperaties. Accepted Nederlands Tijdschrift voor Heelkunde.

Smit PC, Jaquet JB, Oei IH, Marcoen CMGJA, Koning, J. Varices in focussed factory concept; patient vriendelijk en efficient. Abstractbook Chirurgendagen 2004. ISBN 90-805633-7-4. 182. 



\section{CURRICULUM VITAE}

Theauthor of this thesis was born on May $21^{\text {st }}, 1971$ in Rotterdam, the Netherlands. On completion of his secondary school education at the Caland Lyceum, Rotterdam, he was accepted in 1991 by the Erasmus University Rotterdam medical school, from which he graduated in 1997. As part of his study, he spent almost a year at the Department of Plastic and Reconstructive Surgery, University College of London (Prof. D. A. McGrouther), investigating the effect of compression forces of Flexor Digitorum Superficialis on the Flexor Digitorum Profundus in the hand. During his period at medical school, he worked in the first aid department of Ikazia Hospital Rotterdam ('Les Forgerons'). In 1997 he began working as a PhD student at the Department of Plastic and Reconstructive Surgery (Prof. dr. S.E.R. Hovius), where this research project "Median and ulnar nerve injuries: prognosis and predictors for clinical outcome" was carried out. In 2000 he began his medical training and in 2001 he qualified as a doctor at the Erasmus University Rotterdam. In 2001 he spent six months as a resident in plastic and reconstructive surgery at the Department of Plastic and Reconstructive Surgery (Prof dr. S.E.R. Hovius). He is currently nearing completion of his basic surgical training at Reinier de Graaf Hospital in Delft (Dr. L.P.S. Stassen). In March 2005 he will start his training in plastic and reconstructive surgery at the Department of Plastic and Reconstructive Surgery, University Hospital, Erasmus Medical Center in Rotterdam (Prof. dr. S.E.R. Hovius). 


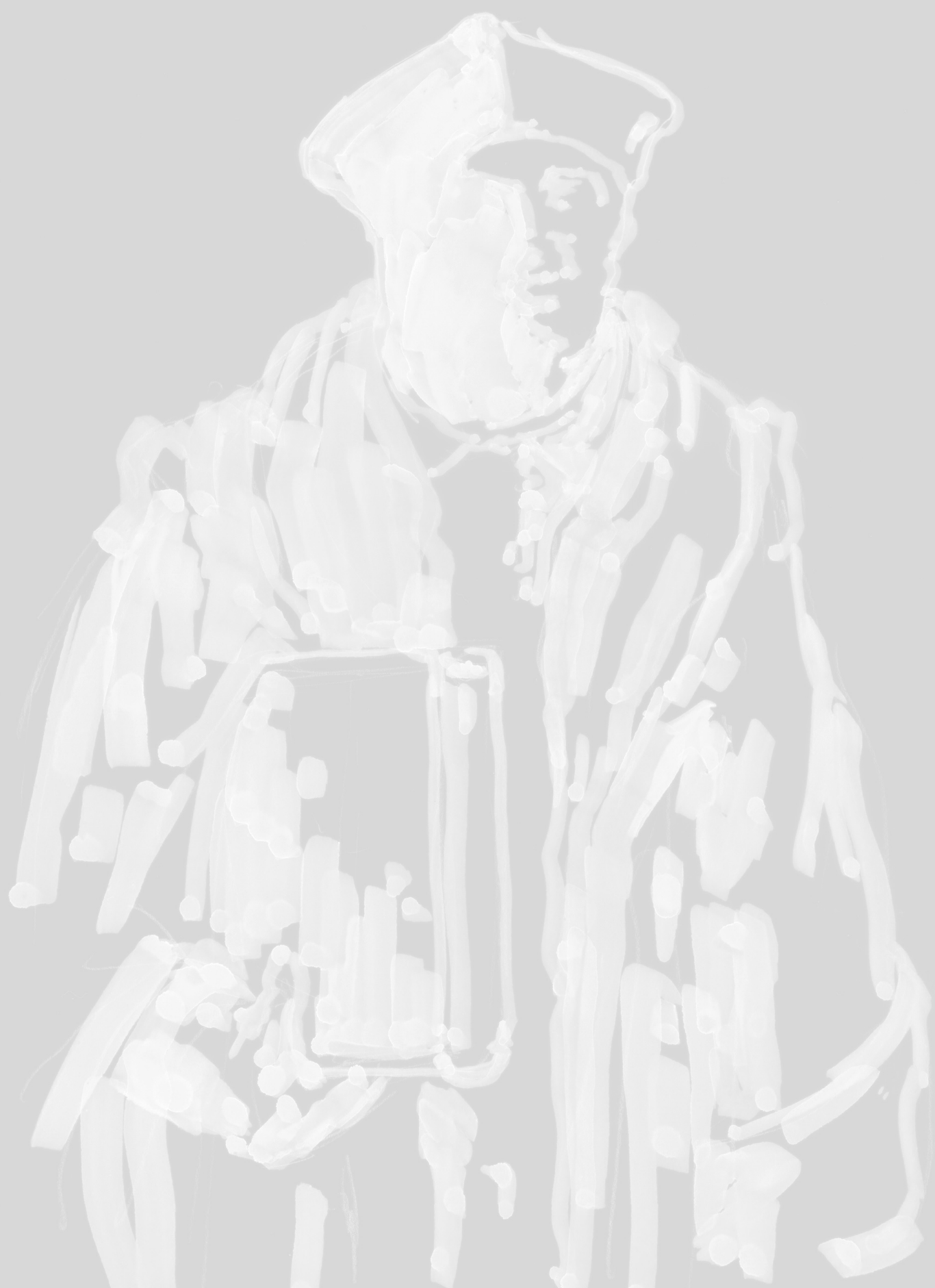

